UC-NRLF

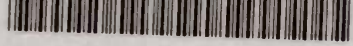

В 3105 ㄹㄹ 

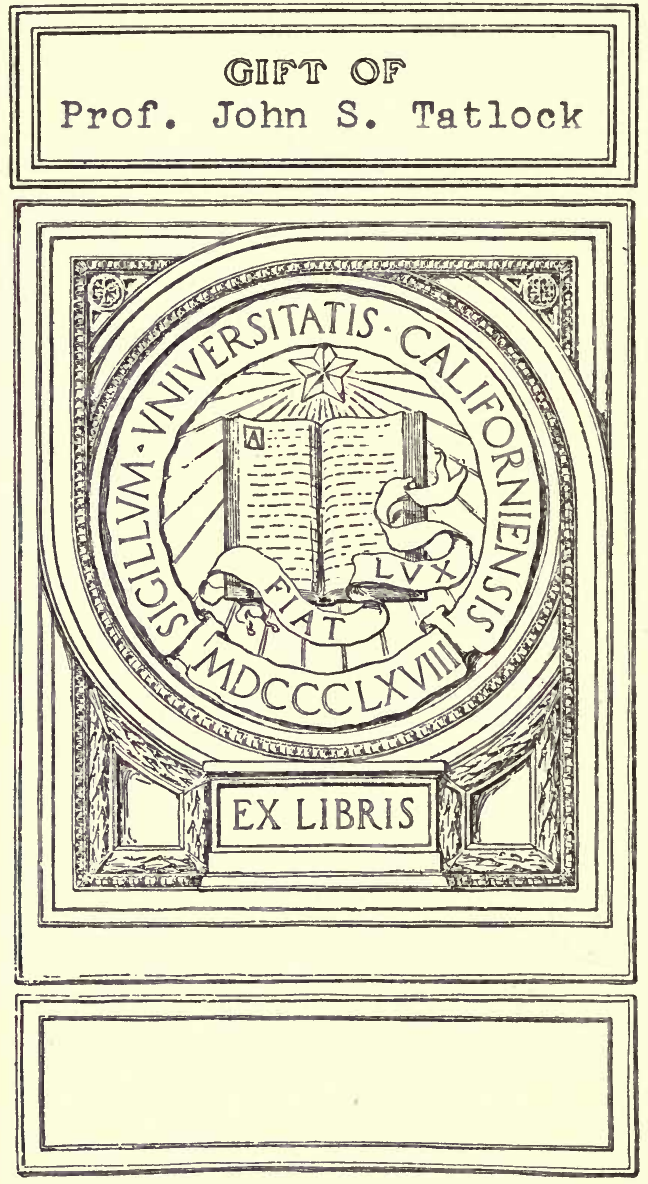






\section{SELEC'T WOR.K S}

OF

\section{JOHN}

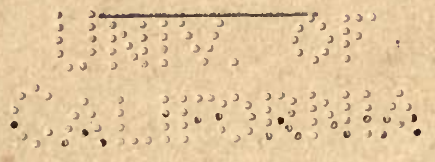

FORMS OF WATER.

LESSONS IN ELECTRICITY.

SIX LECTURES ON LIGHT.

NEW YORK:

JOHN B. ALDEN, PUBLISHER, 1886 . 
Q171
T94

-

Irrs

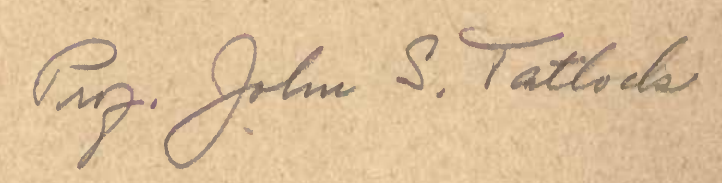




\section{FORMS OF WATER. \\ I3Y}

JOHN TYNDALL. 



\section{OONTERNIS.}

CECTION.

$\therefore$ 'ino $W$ aves or light. .......... 81

1. The Waves of Heit which produce the Vapir of our Atmosphere and ineit our Glaciers.................... 86

J. Experiments to prove the foregoing

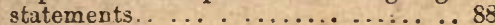

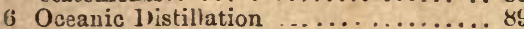

7. Tropical Raius .................90

8. Mountain Condonsers.............. 91

4. Architecture of snow............. . .

11). Atomic Poles....................

i1. Architecture of Lake $\mathbf{i c e . . . . . . . . . . . 9 1 ~}$

i:. The Source of the Arveiron. Ice $\ddot{Y i n-}$ nacles, Towers, and Chasms of tho Glacier des Bois. Passage to the

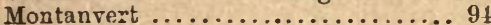

13. The Mer de Glace and its Sources. Our First Climb to the Cleft Station... 95

11. Ice-cascade and Snows of the Col du

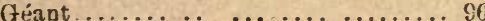

1.j. Questioning tue Glaciers........... 97

16. I3ranches and Medial Moraines of the Mer de Glace from the Cleft Station... ci

17. The Talèfre and the Jardin. Work among the Crevasses............... 9S

13. First Questions regarding Glacier Motion. Drifting of Bodies Buried in

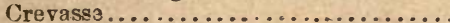

19. The Motion of Glaciers. Measurements bv Hugi and Agaseiz. Drifting of Huts on the Ico ... ............. 100

ㅇ. Precise Measurements of Agassiz and Forbes. Motion of a Glacier proved to resemble the Motion of a River ....100

11. The Theodoiite and its Use. Our own

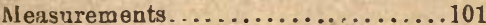

22. Motion of the Mer de Glace..........101

23. Unequal Motion of tho two sides of the Mer de Glace.... . . . . . . . . . . 103

24. Suggestion of a new Lakeness of $\mathrm{Gia}$ cier Motion to River Motion. Conjecturs tested ....................104

25. New Law of Hlacier Motion..........105

26. Motion of $\Lambda x$ is of Mer do Glace .......100

27. Motion of Tributary Glaciens...........10

28. Motion of Top and Bortom of Clacicr...115

29. Latoral Compression of a Chacrer......105
SECTION.

FAGT.

3"). Longitudinal Compression of a Glacier lut 31. Sliding and Flowing. Hard Ice and

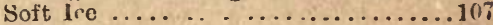

32. Winter ou tho Merdo Glace...............

33. Winter Motion of the Mer de Glace.....1Us

84. Niotior of the Grindelwald and Aletsch

(rlacier.... ................ 1c8

35. Mntion of Morteratsch Giacier...........

ษ6. Birth of a Crevisse: Reflections .......1119

37. Icicles ....................110

38. The Bergschrund ................

¿y. 'Transvers9 Crevasso $\ldots \ldots \ldots \ldots \ldots . .111$

40. Marginal Crevasses................111

41. Longitudinal Crevasses................

42. Crevasses in relation to Curvature of Glacier .....................

43. Moraine-ridges, Glacier 'Tablas, and Fiand Cone ${ }^{2} \ldots \ldots \ldots \ldots \ldots \ldots \ldots \ldots \ldots \ldots$

4t The Glacier Mills or Moulins..........114

4.) The Changes of Volume of Water ly Heat and Co'd .................. 115

43. Consequences fowing from the foregoing Properties of W ater. Correction of Errors.................... 116

47. The Molecular Mechanism of WatcrCongelation ..................116

4x. The Dirt llands of the Mer de Giace...117

49 Ser-ice and Icebergs ...............119

50. The Aggischhorn, the Märgelix Sec and its icebergs................... 119

51. The Bel $\Lambda 1$..................... 121

52. The Riffelherg and Gürner Glacier....121

53. Ancient Glaciers of switzerland....... 122

54. Erratic Block ...................123

55. Ancient Glaciers of England, Ireland, Scotlaud, and Wales..............123 56. The Glacier Epoch............... . 24

57. Glacial 'Theories.................. 125

58. Dilation and Sliding Theories......... 125

59. Plastic Theory ................. 12.)

60. Viscous Theory ................... . .

61. Regelation Therry....................

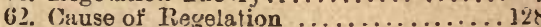

63. Faraday's View of Regelation.... . . . 129

64. The lBlue Veins of Glaciers ..........180

0.) Relation of itructurs to Pressure......132

c6. Slate Clesrago and Glacier Lamination $13:$

67. Guclusicn ...................... 



\title{
THE FORMS OF WATER
}

IN

\section{CLOUDS AND RIVERS, ICE AND GLACIERS,}

BY

\author{
JOHN TYNDALL, LL.D., F.R.S.,
}

PROFKSSOR OF NATURAL PHILOSCFHY IN THE ROYAT, INSTITUTION, LONDON.

\section{WITH NINETEEN ILLUSTRATIONS DRAWN UNDER THE DIRECTION OF THE AUTHOR.}

\section{PREFACE TO THE FOURTH EDITION.}

AT a meeting of the Managers of the Royal Institution held on December 12th, 1825, "the Committee appointed to consider what lectures should be delivered in the Institution in the next session," reported " that they had consulted Mr. Furaday on the subject of engaging him to take a part in the juvenile lectures proposed to be given during the Christmas and Easter recesses, and they found his avocations were such that it would be exceedingly inconvenient for him to engage in such lectures."

At a general monthly meeting of the members of the Royal Institution, held on December $4 \mathrm{th}, 1826$, the Managers reported " that they had engaged Mr. Wallis to delivel a course of lectures on Astronomy, adapted to a juvenile auditory, fluring the Christmus vacation.'

In a report dated April 16th, 1827, the Doard of Visitors express " their satisfaction at finding that the plan of juvenile courses of lectures has been resorted to. 'They feel sure that the influence of the. Institution cannot be extended too far, and the system of nstructing the younger portion of the com. munity is one of the most effective means which the Institution possesses for the diffuson of science."

Faraday's holding aloof was but tempo.

Iy, for at Christmas: 1827, we find lim giving a "Course of Six Elementary Lectures on Chemistry, adapted $t r$ a Juvenile Auditory."*

The Easter lectures were soon abaniloned ; but from the date here referred to to the present time the Christmas lectures have been a marked feature of the Roval Institution.

In 1871 it fell to my lot to give one of these courses. I had been frequently invited to write on Glaciers in encyclopædias, jouruals, and magazines, but lad always declined to do so. I lad also abstained from making them the subject of a course of lectures, wishing to take no advantage of my position here, and indeed to avoid writing a line or uttering a sentence on the subject for which I coula not be held personally responsible. In view of the discussions which the subject had provoked, I thought this the fairest course.

But, in 18\%1, the time (I imagined) had come, when, without risk of offence, I might tell our young people something about the labors of those who had unravelled for their instruction the various problems of the iceworld. My lamented friend and ever-helpful counselior, Dr. Bence Jones, thought the subject a good one, and accordingly it was chosen. Strong in my sympathy with youth, and remembering the damage done by defective exposition to my own young mind, I sought, to the best of my ability, to confer upon these lectures clearness, thoroughness. 
and life.

Wishing, moreover, to render them of permanent value, I wrote out copious Notes of the course, and had them distributed among the boys and girls. In preparing these Notes I aimed at nothing less thar, presenting to my youtliful audience, in a concentrated but perfectly digestible form, every essential poirt embraced in the Jiterature of the giaciers, and some things in addition, which, derived as they were from my own recent rescarches, no book previously published on the sibject contained.

P:nt my theory of education agrees with

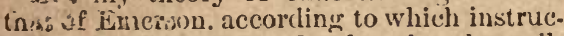
tiun is orly half the battle, what he cails prrocation being the other half. By this he means that power of the teacher, through the force of his character and the vitality of his thought, to loring out all the latent stiength of his pupil, and to invest with interest even the driest matters of detail. In the present instance I was determined to shirk nothing essential, however dry ; and, to keep my mind alive to the requirements of my pupil, I proposed a series of ideal rambies, in which he should be always at my side. Oddly enough, though I was here dealing with what might be called the ab. stract idea of a boy, I realized his prescnce so fully as to entertain for hin, before our excursions cnded, an affection cousciously warm and real.

The Notes here referred to were at first intended for the use of my audience alone. $\Lambda$ the urgent request of a friend I slightly expanded thein, and converted them into the little book here presented to the reader.

The amount of attention bestored upon the volume induces me to give this brief listory of its origin.

A German critic, whom I have no reason to regard as specially favorable to me or it, makes the following remark on the style of the book : "This paission [for the mountains] tempts him to reveal more of his Alpine wanderings than is necessary for his demonstrations. The reader, however, will not find this a disugrecable interruption of the course of thought; for the book thercby gains wonderfully in vividness." This, I would say, was the express aim of the breaks referred to. I desired to keep my companion fresh, as well as instructed, and these intersuptions were so many breathing-places where the intellectual tension was purposely relaxed and the mind of the pupil braced to fresh action.

of other criticisms, flattering and other wise, I forbear to speak. As regards some of them, indeed, it wonld be a reproach to that manliness which I have sought to encourage in my pupil to returu blow for blow. If the reater be acruainted with them, this will let him know how I regard them; and if he be not acquainted with them, I would recommend him to ignore them, anil to form his own judgment of this bonk. No fairminded person who reads it will drearn that

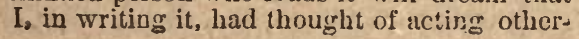

wise than justly and generously toward $m$ y predecessors, the last of whom, to the grief of all who knew him, has recently passed away. APRiL, $18 \pi 4$.

JOIN TYNDALL.

\section{§1. Clouds, Rains, and Rivers.}

1. Every occurrence in Nature is precede by otuer occurrences which are its causes, and succeeded by others which are its effects. The human mind is not satisfied with observ. ing and studying any natural occurrence alone, but takes pleasure in connecting every natural fact with what has gone before it and with what is to come after it.

2. Thus, when we enter upon the study of rivers and glaciers, our interest will be greatly augmented by taking into account not only their actual appearances, but also their causes and effects.

3. Let us tance a river to its source. Legiuning where it cmpties itself into the sea, and following it backwar!, we tind it from time to tims joined by tributaries which swell its waters. The river of course becomes smaller as these tributaries tre passed. It shrinks tirst to a brook, then to a strearn this again divides itself into a number of smaller streamlets, ending in mere threads of water. These constitute the source of the river, and are usually found anong hills.

4. Thus the Severn blas its sounce in the Welsh Mountains ; the Thames in the (C)tswold Hills; the Danube in the hills of the Black Forest ; the Rhine and the lihone in the Alps; the Ganges in llie II Imalaya Mountains; the Euplirates near Momint Ara rat; the Garoune in tine Pyremees; 11 s Elbo in the Giant Mountains of Bohemia; the Missouri in the Rocky Mountains, and the Amazon in the Audes of Peru.

5. But it is quite plain that we hatve not yet reached the real beginning of the tivers. Whence do the earliest streans derive their water? A brief residence amoug the moun. tains would prove to you that they are feel by rains. In dry weather you would find the streams feeble, sometimes indeed quite dried up. In wet weather yos would see them foaming torrents. In general these streams lose themselves as little threads of water upon the hill-sides ; lut sr metimes you may trace a river to a definite spring. The river Albula in Switzerland, for instance, rushes at its origin in considerable voluno. from a mountain-side. But you very so:n assure yourself that such springs tre also feil by rain, which has percolated throum the rocks or 80 il, and which, through some orifice that it his found or formed, comes to the light of day.

6. But we cannot end here. Whence comes the rain which forms the mountain streams? Observation enables you to answer the question. Rain does not come from a clear sky. It comes from clouds. But what are clouds? Is there nothing you are acquainted with which they resemble? Yorr discover at once a likeness between them and the condensed steam of a locomotire. At 
every puff of the engine a cloul is projected into the uir. Watch the clond sharply: you notice that it first forms at a little distance from the top of the funnel. Give close attention and you will sometimes see a perfeetly clear space between the funnel and the cloud. Through that clear space the thing which makes the cloud must pass. What, then, is this thing which at one moment is transparent and invisible, and at the next moment visible as a dense opaque cloud?

7. It is the steam or vapor of water from the boiler. Within the boiler this steam is transparent and invisible; but to keep it in this invisible state a lieat would be required as great as that within the boiler. When the vapor mingles with the cold air above the hot funnel it ceases to be vapor. Every bit of steam shrinks, when ehilled, to a much more minute particlc of water. The liquid particles thus produced form a kind of watcr-dust of exceerling fineness, which floats in the air, and is called a cloud.

8. Watch the eloud-banner from the funne? of a running locomotive; you see it srowing gradually less dense. It finally melts away altogether, and if you coztinue your observations you will not fail to notice ilat the speed of its disappearauce depends upon the charaeter of the day. In liumid weather the eloud hangs long and lazily in the air; in dry weather it is rapidly licked up. What has become of it? It lias been reeonverted into true invisible vapor.

9. The drier the air, aud the hutter the air, the greater is the amount of cloud which can be thus dissolverl in it. When the cloud first forms, its quantity is far greater than the air is able to maintain in an invisible state. But as the cloud mixes gradually with a larger mass of air it is more an.l more dissolved, and finally passes altogether from the condition of a finely-divided liquid into that of transparent vapor or gas.

10. Make the lid of a kettle air-tight, and permit the steam to issue from the pipe; a cloud is precipitated in all respects similar to that issuing from the funnel of the locomotive.

11. Permit the steam as it issues from the pipe to pass through the flame of a spiritl:mp, the cloud is instantly dissolved by the 3ieut, and is not again precipitated. With a special boiler and a special nozzle the experiment may be made more striking, but not more inst ructive, than with the kettie.

12. Look to your bedroom windows when the weather is very cold outside ; they sometimes stream with water derived from the condensation of the aqueous vapor from your own lungs. The windows of railway carriages in winter show this condensation in $\approx$ striking manner. Pour cold water into a dry Irinking-glass on a summer's day : the outsille sufface of the glass becones instantly linned by the precipitation of moisture. On a warm day you notice no rapor in front of your mouth, but on a colit day you form there a jittle cloud derived from ihe rondensation of the aqueous vapar from the linger.
13. You may notice in a ball-room that as long as the door and windows are kept closed, and the room remains hot, the air remains clear ; but when the doors or windows are opened a dimness is visible, eaused by the precipitation to for of the aqueous vapor of the ball-room. If the weather be intenseiy cold the entrance of fiesh air may even cantse snowo to fall. This has been observerl in Russian ball-rooms ; and also in the subterranean stables at Erzeroom, when the doors are opened and the cold morning air is pernitted to enter.

14. Even on the driest day this vapor is never absent from our atmosphere. Thie vapor diffused ihrough the air of this room may be congealed to hoar frost in your presence. This is done by filling a vessel with a mixture of pounded ire and salt, which is colder than the ice itself, and which, therefore, conteuses and freezes the arjueous vapor. The surface of the vessel is finally coated with a frozen fur, so thick that it may he scraped away and formed into "s snowbill.

15. To produce the cloud, in the ease of the locnmotive and the ketlle, heat is necessary. By heating the water we first convert it in:n steam, and theu, lyy chilling the steam we convert it into colnul. Is there any fire in nature which produces the clonds of our atmosphere? There is : the fire of the sun.

16. Thus, by traeing backward, without any lreak in the chin of necurrenees, our river from its end 1 it its rial leginnings, we come at length to the suu.

\section{§.}

17. There are, hotwever, rivers which have sources somewhiat dliferent from those just mentinned. They do not begiu by driblets on a lill-side, nur can they be traced to a spring. Go, for exampie, is the mouth of the river Rhone, and trace it hackward to Lyons, where it :urus to the cast. Bending round by Cliamivery, you come at length to the Lake of Geneva, from which the liver rushes, and which you might be disposed to regard as the source of the Rlione. But go to the head of the lake, and you find that the Rhone there enters it, thit the lake is in fact a kind of expansion of the tiver. Follow this upward; you find it joined by smaller rivers from the mountains right and left. Pass these, and push your journey higher still. You come at length to a linge mass of ice-the corl of a glacier-which fills the Rhone valley, and from the bollum of tinc glacier the river rushes In the rrlacier of the Rhone you thus find the sulice of the river Rhone.

18. But again we have not reached the real beginning of the river. You soon convince yourself that this earliest water of the Rhone is produced by the melting of the ice. You get upon the glacier and walk upward along it. After a time the ice disappears and you come upon snow. If yon are a competent mountaineer you may go to the very top of this great snow-field, and if you cross the top 
and descend at the other side you finally auit the snow, anil get upon another glacier called the Trift. from the end of which rushes a river smaller than the Rhone.

1). Ynu soou learn that the mountain snow feeds the glacier. By some means or nther the snow is converted into ice. But whence comes the snow? Like the rain, it comes from the clouds, which, as before, ean be traced to vapor raised hy the sun. Without solar fire we could have no atmospheric vapor, withont vapor no clouds, without clouds no snow, and without snow no gla. ciers. Curious then as the conclusion may be, the cold ice of the Alps leas its origin in the heat of the sun.

\section{§3. Tue Waves of Lrant.}

20. But what is the sun? We know its size and its weight. We also know that it is a globe of fire far hotter than any fire upon earth. But we now enter upon another inquiry. IVe have to learn definitely what is the meaning of sclar light and solar heat; in what way they make themselves known to our senses; by what means they get from the sun to the earth, and how, when there, they produce the clouds of our atmosphere, and thus originate our rivers and our glaciers.

21. If in a dark room you close your eyes and press the eyelid with your finger-nail, a circle of light will be seen opposite to the point presserl, while a sharp blow upon the eye produces the impression of a flash of - light. There is a nerve specially devoted to the purposes of vision which comes from the brain to the back of the eye, and there divides into fine filaments, which are woven together to a kind of screen called the retina. The retina can be excited in various ways so as to produce the consciousness of light; it may, as we have seen, be excited by the rude incchanical action of a blow imparted to the cye.

22. There is no sposianeous creation of light by the healthy eye. To excite vision the retiua must be affected by something coming from without. What is that something? In some way or olber, luminous hodies have the power of affecting the retina -but how?

23. It was long supposed that from such bodies issued, with inconceivable rapidity, an inconcervably fine matter, which flew through space, passed through the pores supposed to exist in the humors of the eye, reached the retina behind, and by their shock igainst the retina, aroused the sensation of light.

21. This theory, which was supported by the greatest men, among others by Sir Isaac ivewton, was found competent to explain a great number of the phenomena of iight, but it was not found competent to explain all the phenomena. As the skill and knowledge of cxperimerters increased, large classes of facts were revealed which could only be explained by assuming that light was produced, not by a fine matter flying through space and hitting the retina, but by the shock of minute waves against the retina.

25. Dip your finger into a basin of water, and cause it to quiver rapidly to and fro. From the point of disturbance issue smali ripples which are carried forward by the water, and which finaliy strike the basin. Here, in the vibrating tinger, you have a source of agitation; in the water you have a vehicle through which the finger's motion is transmitted, and you have finally the side of the basin which receives the shock of the little waves.

26. In like manner, according to the voave theory of light, you have a source of agitation in the vibrating atoms, or smallest particles, of the liminous body; jou have a vehicle of transmission in a substance which is sup. posed to fill all space, and to be diffused through the humors of the eye ; and finally, you have the retina, which receives the sucecessive shocks of the waves. These shocks are supposed to produce the sensation of light.

27. We are here dealing, for the most part, with suppositions and assumptions merely. We have never seen the atoms of a luminous body, nor their motions. We have never seen the medium which transinits therr motions, nor the waves of that merlium. How, then, do we come to assume their existence?

28. Before such an idea could have taken any real root in the limman mind, it must liave been well disciplined and prepared by obser. vations and calculations of ordinary wavemotion. It was necessary to know how both water-waves and sound-waves are formed and propagated. It was above all thingy necessary to know how waves, passing through the same medium, act upon each other. Thus disciplined, the mind was pre. pared to detect any resemblance presentiny itself between the action of light and that of waves. Great classes of optical phenomena accordingly appeared which could be ac. counted for in the most complete and satisfactory manner by assuming them to he produced by waves, and which could not be otherwise accounted for. It is because of its competence to explain all the phenomena of light that the wave theory now receives universal acceptance on tho part of scicntific men.

Let me use an illustration. We infer from the flint implements recently found in such profusion all over England and in other countries, that they were produced by men, and also that the Pyramids of Egypt were built by men, because, as far as our experience goes, nothing but men could form such implements or build such Pyramids. In like manner, we infer from the phenomena of light the agency of waves, because, as far as our experience goes, no other agency could produce the phenomena.

§ 4. The Waves of Heat Wiricil prodece tile VAPOR of oUR ATMOSPHERE AND MELT OUR GLACIERS.

29. Thus, in a general way, I have given you the conception and the grounds of tho 


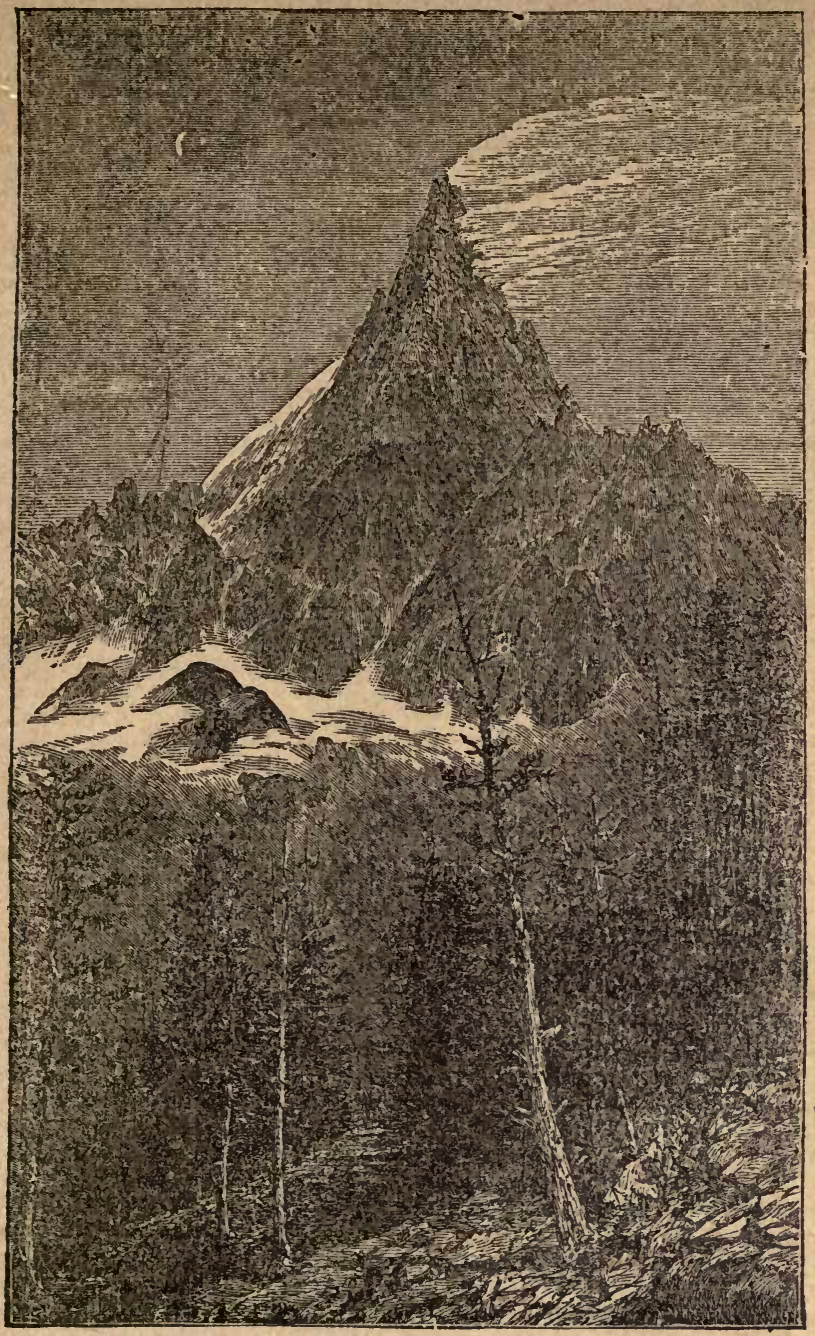

Fia. 1.-Cloud-banner of the Aiguille du Dru (par. 81 and 227 ).

conception, which regards light ats the pioduct of wave-motion ; but we must go farther than this, and follow the conception into sonie of its details. We have all seen the wayes of water, and we know they are of different sizes-different in length and different in height. When, therefore, you are tolil that the atoms of the sun, and of almest all other luminous bodies, vibrate at difiercr: rates, and produce waves of different size, your experience of water-waves will cnable you to form a tolerably clear notion of what is meant.

30. As observed ahove, we have never seen the light-waves, but we judge of their presence, their position, and their magnitude, by their effects. Their lengths have been thus determined, and found to vary from about 30000 th to $\frac{1}{6000}$ th of an inch.
31. But besides those which produce light, the sun sends forth incessantly a multitude of waves which produce no light. Th: largest waves which the sun sencis forth ar: of this non-luminous character, thougle they pussess the highest heating power.

32. A cnmmon sunbeam contains waves of all kinds, but it is possibie to sift or filter the beam so as to intercept all its light, and to allow its obscure heat to pass unimpeded. For substances have been discovered which. while intensely opaque to the light-waves, are almost perfectly trausparent to the others. On the other hand, it is possible, by the choice of proper substances, to intercept in a great degree the pure heat-waves, and to allow the pure light-waves free transmission. This last separation is, however, not so per. fect as the first. 
33. We shall learn presently how to detach the one class of waves from the other class, and to prove that waves competent to light a fire, fuse metal, or burn the hand like a hot solid, may exist in a perfectly dark place.

34. Supposing, then, that we willidraw, in the first instance, the large heat-waves, and allow the light-waves alone to pass. These miy be concentrated by suitable lenses and sent into water without sensibly warming it. Let the light-waves now be withdrawn, and the larger heat-waves concentrated in the same nanner, they may be caused to boil the water almost instantaneously.

35. This is the point to which I wished to ead you, and which without due preparation could not be understood. You now perceive the important part played by these large darkness-waves, if I may use the term, in the work of evaporation. When they plunge into seas, lakes, and rivers, they are intercepted close to the surface, and they heat the water at the surface, chus cinusing it to evaporate; the light-waves at the same time entering to great depths without sensibly lieating the water through which they pass. Not only, therefore, is it the sun's fire which roduces evaporation, but a particular constituent of that fire, the existence of which you probably were not aware of.

36. Further, it is these self-same lightless waves which, falling upon the E'aciers of the Alps, melt the ice and produce all the rivers llowing from the glaciers; fi: I shall prove to you presently that the light-waves, even when concentrated to the uttermost, ate unable to melt the most delicate hoar-frost; much less would they be able to produce thi copious liquefaction observed upon the glia ciers.

37. These large lightless waves of the sun, as well as the heat-waves issuing 1 um nor. luminous hot bodies, are frequently cülled obscure or invisible heat.

We have here an example of the minner in which phenomena, apparently remnte, are connected together in this wouderfu! system of things that we call Nature. You cannot study a snow-flake profoundly without heing. led back by it step loy step to the const itution of the sun. It is thus throughout. Nature. All its parts are interdependent, and tho study of any one part completely would really involve the study of all

\section{§ 5. Experiments to prove '. He fore- gorng Statements.}

38 Heat issuing from any source not visibly red cannot be concentrated so as to produce the intense effects just referred to. To produce these it is necessary to employ the obscure heat of a body raised to the highest possible state of incandescence. The sun is such a lody, and its dark heat is therefore suitable for experiments of this nature.

39. But in the atmosphere of London, and for experinients such as ours, the heat-wavis emitted by coke raised to intense whiteness by a current of electricity are much more manageable than the sun's waves. The elec.
UF WATER

tric light has also the advautage that its dark radiation embraces a larger proportion of the total radiation than tlee dark heat of the sun. In fact, the force of energy, if I may use the term, of the daik waves of the electric light is fully seven times that of its light waves. The electric light, therefore, shall he employed in our experimental demonstralions.

40. From this souree a powerful beam is sent through the room, revealing its track by the mutes flonting in the air of the room ; for were the motes entirely absent the beam. would be unscen. It falls unon a concave mirror (a glass one silvered behind will answer) and is gathered up by the mirror into a cone of reflected rays; the laminous apex of the cone, which is the focus of the mirror, being about fifteen inches distant from its reflecting sinface. Let us mark the focus accurately by a pointer.

41. And now let us place in the path of the beim a substance perfectly opacyue to light. This substance is iodine dissolved in a liquid calleil bisulphide of carbon. The light at the focus instautly vanishes when the dark solution is introchuced. But the so lution is intensely trausparent to the dark waves, and a focus of such waves remains in the air of the room after the light has been abolished. You may feel the heat of these waves with your hand; you may let them fall upon a t'jermometer, and thus prove their presence; or, liest of all, you may cause them to prodice a current of electricity, which ceflects a large magnetic needle. The maguir ce of the deflection is a measure of the hea:

42. OnI is ject now is, by the use of a more power.il lamp, and a better mirror (one silvered in frout and with a shorter focal dis. tance), to intensify the action here rendered so sensible. As before, the focus is rendered strikingly visible by the intense illumination of the clust particles. We will first filter the beam so as 10 intercept its dark waves, and then permit the purely lummous waves to exert their utmost power on a small bundle of gun-cotton placed at the focus.

43. No effect whitever is produced. The gun-colton might remulu there for a week without ignition Let us now permit the anfiltered beam to act upon the cotton. It is instantly dissipatel in an explosive flash. This experiment proves that the light-waves are incompetent to explode the cotton, while the waves of the full beam are competent to do so: hence we may conclude that the dark waves are the real agents in the explosion.

44. But this conclusion would be ouly probuble; for it might be urged that the mixture of the clark waves anil the light waves is necessary to produce the result. Let us then, by means of our opuque solution, isolate our lark waves and converge them on the cotton. It expluiles as before.

45. IIence it is the dark waves. and they only, that are concerned in the ignition of the cotton.

46. At the same dark focus sheets or platinum are russed to vivid relness; zunc is 
burned up; paper iustantly blazes, magne. sium wire is ignited; cliarcoal witinn a ra. ceiver containing (1xygen) is set burning : a diamnnd similariy placed is caused to glow like a star, being afterward gradually dissipated. And all this while the air at the foous remains as cool as in any other part of the roon.

47. To obtain the light-waves we employ a clear solution of alum in water; to obtain the dark waves we employ the solution of iodine above referreal 10. But as before stated (32), the alnini is not so perfect a filter is the iodine; ;or it. clansmits a portion of the obscure her t.

48. Though the light-waves here prove their incompetence to ignite gun-cotton, they are able to burn up black paper; or, indeed, to explode the cotton when it is blackened. The white cotton does not ausorb the light and without absorption we have no heating: The blackened cotton absorbs, is heated, and explories.

49. Instead of a solution of alum, we will employ for our next experiment a cell of pure water, through which the light passes without sensible absorption. At the focus is placed a test-tube also containing water, the full force of the light being concentrated upon it. The water is not sensibly warmed by the concentrated waves. We now remove the cell of water ; no change is visible in the seam, but the water contained in the test-tube now boils.

50. The light-waves being thus proved ineffectual, and the full beam effectuai, we may infer that it is the dark waves that do the work of lieating. But we clinch our inference by employing our opaque jodine filter. Placing it on the path of the beam, the light is en. irely stopped, but the water boils exactly as it did when the full bean fell upon it.

51. The truth of the statement made in paragraph 34 is thus demonstrated.

52. And now with regard to the mclliug of ice. On the surface of a flask containing a freczing mix ture we obtain a thick fur of hoarfrost (Par. 14). Sending the beam 1 t.rougi a water-cell, its luminous wares $\mathrm{sr}$; concen. trated upon the surface of t,n3 fias: Not a spicula of the frost is dissclven. "re now remove the water-coll, and in a mument a patch of the frozen fur as lerge as half-a-crown is melted. Hence, inasmuch as the full beam produces this cffect, and the luminous part of the beam does not produce it, we fix upon the dark portion the melting of the frost.

53. As before, we clinch this inference by concentrating the dark waves alone upon the flask. The frost is dissipated exactly as it was by the full beam.

54. 'These effects are rendered strikingly visible by darkening with ink the freezing mixt'rre within the flask. When the hoar. frost is removed, the blackness of the surface from which it had been melted comes out in strong col. - st with the adjucent snlwy whiteness. When the flask itself, insterd of the ireezing nixturo, is blackened, the putrely luminous waves being $a^{\prime}$ ssorbed by the glass: warm it ; the glass reacts upon the frost and melts it. Hence the wisdon of datkening, instead of the flask itself, the mixtlie within the flask.

5j. This experiment proves to demonstra. tion the statement in paragraph 36 : that it is the dark waves of the sun that melt the mountain snow and ice, and originute all the rivers derived from glaciers.

There ate writers who seem to regard science as an aggregate of facts, and hence doubt its efficacy as an exercise of the reasoning powers. But all lhat I have here taught you is the result of reason, taking its stand, however, upon the sure basis of observation and experiment. And this is the spirit in which oul further studies are to be pursued.

\section{§o. OCEanic Distillation.}

56. The sun, you know, is never exactly overhead in England. But at the cquator, and within certain limits north and south of it, the sun at certain periods of the year is directly overhead at nuon. These limits are called the Tropics of Cancer and of Capricorn. Upon the belt comprised between these two circles tlic sun's rays fall with their mightiest power; for here they shoot directly downward, and heat hoth earth and sea moro than when tliey strike slantingly.

57. When the vertical sunbeams strike tho land they heat it, and the air in contact with the hot soil becomes heated in turn. But. when heated the air expands, and when it expands it becomes lighter. This lighter air rises, like wood plunged into water, through the heavier air overhead.

58. When the sunbeams fall upon the sea the water is warmed, though not so much as the land. The warmed water expands, becomes thereby lighter, and therefore continues to float upon the top. This upper layer of water warms to some extent the air in contact with it, but it also sends up a quantity of aqueous vapor which, being far lighter than. air, heips the latter to rise. Thus both from the land and from the sea we have ascending. currents established by the action of the sun.

59. When they reach a certain elevation in. the atmosphere, these currents divide and flow, part toward the north and part toward. the south; while from the porth and the south. a flow of heavier and colder air sets in to. supply the place of the ascending warm air.

60. Incessant circulation is thus estabhisheil in the atmosphere. The equatorial air and vapor flow above toward the north aud south poles, while the polar air flows beluw toward the equator. The two currents of air thus established are called the upper and the lower trade-ivinds.

61. But before the air returns from the poles great changes hive occurred. For the air as it quitted the equatorial regions was larlen with aqueous vapor, which could not subsist in the cold polal regions. It is there precipitated, falling sometimes as rain, or more commonly as snow. The land near the pole is covered with this snow, which gives 
birth to vast glaciers in a manner hereafter to he explained.

62. It is necessary that you should liave a perfectly clear view of this process, for great mistakes have been made regarding the manner in which glaciers are related to the heat of the sun.

63. It was supposed tinat if the sun's heat were climinished, greater glaciers than those now existing would be produced. But the lessening of the sun's lieat would infallibly diminish the quantity of aqueous vapor, and thus cut off the glaciers at their source. A brief illustration will complete your knowledge here.

64. In the process of orlinary distillation, the liquid to be distilled is heated and converted into vapor in one vessel, and chilled and reconverted in to liquid in another. What has just been stated renders it plain that the earth an 1 its atmosphere constitute a vast distilling apparatus in which the-equatorial ocean plays the part of the boiler, and the chill regions of the poles the part of the condenser. In this process of distillation heat plays quite as necessary a part as cold, and before Bishop Heber could speak of " Greenland's icy mountains," the equatorial ocean had to be warmed by the sun. We shall have more to say upon this question afterward.

\section{ILLUSTRATIVE EXPERIMENTS.}

3.5. I have said that when heated, air expands. If you wish to verify this for yourself, proceed thus. Take an empty tlask, stop it by a cork; pass through the cork a narrow glass tube. By heating the tube in a spirit-lamp you can bend it downward, so that when the flask is standing upright the open end of the narrow tube may dip into water. Now cause the flame of your spiritlamp to play against the flask. The flam? heats the glass, the glass heats the air; the air expands, is driven through the narrow tube, and issues in a storm of bubbles from the water.

66. Were the heated air unconfined, it would rise in the heavier cold air. Allow a sunbeam or any other intense light to fall upon a white wall or screen in a dark room. Bring a heated poker, a candle, or a gas-flame underreath the beam. An ascending current rises from the heated body through the beam, and the action of the air upon the light is such as to render the wreathing and waving of the current strikingly visible upon the screen. When the air is hot enough, an! therefore light enough, if entrapped in a paper bag it carries the bag upward, and you have the fire halloon.

67. Fold two sheets of paper into two cones, and suspend them with their closed points upward from the end of a delicate balance. See that the cones balance each other. Then place for a moment the flame of a spirit-lamp beneath the open base of one of them ; the liot air ascends from the lamp and instantly tosses upward the cone above it. a lit:'e smoke. Let the air come to rest. an 1 then simply place your hand at the open mouth of the shade. Mimic hurricanes are produced by the air warmed by the haucl, which are strikingly visible when the smukis is illuminated by a strong light.

69. The heating of the tropical air by the sun is indirect. The solar beams have scarcely any power to heat the air through which they jass; but they heat the land and ocean. and these communicate their lieat to the air in contact with them. The air ard vapor start upward charged with the heat thus communicuted.

\section{§7. Tropical RaIns.}

70. But long before the air and vapor from the equator reach the poles, precipitation occurs. Wherever a humid warm wind mixes with a cold dry one, rain falls. Indeed the heaviest rains occur at those places where the sun is vertically overhead. We must inquire a little more closely into their origin.

71. Fill a bladder about two thirds full of air at the sea-level, and take it to the summit of Mont Blanc. As you ascend, the bladder becomes more and more distended; at the top of the mountain it is fully distended, and has evidently to bear a pressure from within. Returning to the sea-level you find that the tightness disappears, the bladder finally appearing as flaccid as at first.

72. The reason is plain. At the sea-level the air within the bladder has to bear the pressure of the wholc atmosphere, being thereby squeezed into a comparatively smali volume. In ascending the mountain, you leave more and more of the atmosphere behind; the pressure becomes less and less, and by its expansive force the air within the bladder swells as the outside pressure is diminished. At the top of the mountain the expansion is quite sufficient to render the bladder tight, the pressure within being then actually greater than the pressure without. By means of an air-pump we can show the expansion of $u$ balloon partly filled with air, when the external pressure has been in part removed.

73. But why do I dwell upon this? Simply to make piain to you that the unconfined air, heated at the earth's surface, and ascending by its lightness, must expand more and more the ligher it rises in the atmosphere.

74. And now I lave to introduce to you a new fact, toward the statement of which I lave been working for some time. It is this : The uscending air is chilled by its expansion. Indeed this chilling is one source of the coldness of the higher atciospheric regions. And now fix your eye upon those mixed currents of air and aqueous vapor which rise from the warm tropical ocean. They start with plenty of heat to preserve the vapor as vapor; but as they rise they come into regions already chilled, and they are still further chilled by their own expansion. . The cunsequence might be foreseen. The 
load of vapor is in great part precipitaterl, dense clouds are formed, their particles co:llesce to rain-drops, which descend daily in gishes so profuse that the word "torrenial " is used to express the copiousness ot the rainfall. I could shors you this chilling by expansion, and also the consequent precipitation of clouds.

75. Thus long before the air from the equator reaches the poles, its vapor is in great part removed from it, having rede scended to the earth as rain. Still a good quantity of the vapor is carried forward, which yields hail, rain, and snow in nothern and southern lands.

\section{ILLUSTRATIVE EXPERIIENTS.}

76. I have said that the air is chilled during its expansion. Prove this, if you like, thus. With a condensing syringe, you can force air into an iron box furnished with a stopcock. to which the syringe is serewed. Do so till the density of the air within the hox is doubled or trebled. Immediately after this condensation, both the box and the air within it are varm, and can be proved to be so by a proper thermometer. Simply turn the cock and allow the compressed air to stream into the atmosphere. The current, if allowed to strike a thermometer, visibly chills it ; and with other instruments the chill may to made more evident still. Even the hand feels the chill of the expandling air.

77. Throw a strong light, a cencentrated sunbeam for example, across the issuing cur. rent; if the compressed air be ordinary humid air, you see the precipitation of a litlle cloud by the chill accompanying the expansion. This cloud-formation mav, linwever, be better illustrated in the following way:

78. In a darkened room send in strong beam of light through a glass tube three feet long and three inches wide, stopperd at its ends by g'ass plates. Connect the tube by means of a stopcock with a vessel of abnut one fourth its capacity, from which the air lits been removed by an air-pump. The exhansted cylinder of the pump itself will answer capitally. Fill the glass tube with lummid air ; then simply turn on the stopeock which eonnects it with the exliausted vessel. Having more ronm the air expands, cold accompauies the expansion, and, as a consequence, a dense and brilliant cloud immecliately fills the tuhe. If the experiment be made for yourself aione, you may see the cloud in ordinary daylight ; indeerl, the brisk exhaustion of any receiver filled with liumid air is known to produce this condensation.

79. Other vapors than that of water may be thus precipitated, some of them yielding clouds of intense brilliancy, and displaying iridescences, such as are sometimes, but not frequently, seen in the clouds floating over the Alps.

8\%. In science, what is true for the small is true for the large. Thus by combining the conditions observed on a large scale in nature we obtain on a small scule the phenomena of atmospheric clouds.

\section{§ 8. Mountain Condensers.}

81. To complete our view of the process of atmospheric precipitation we must take into account the action of mountains. Imagine il sonth-west wind blowing across the Atlantic toward Ireland. In its passage it charges itself with aqueous vapor. In the south of Ireland it encounters the mountains of Kerry: the lighest of these is Magillicuddy's Reeks, ncar Killarney. Now the lowest stratum of this Atlantic wind is that which is most fully charged with vapor. When it encounturs the base of the Kerry mountains it is tilied up and flows bodily over $1 \mathrm{hem}$. Its load of rajor is therefore carried to a height, it expands on reaching the height, it is chlllea in consequence of the expansion, and comes down in copious showers of rain. From this, in fact, arises the luxuriant vegetation of Killanney ; to this, indeed, the lakes owe their water supply. The cold crests of the mountains also aid in the work of condensation.

82. Finte the consequence. There is a town called Cahirciveen, to the south-west of Magillicuddy's Reeks, at which observations of the suinfall have been made, and a goorl distance farther to the north-east, riglit in the course of the south-west wind, there is another town, called Pottarlington, at which observations of rainfall have also been made. But before the wind reaches the latter station it lias passed over the mountains of kerry andl left a great portion of its moisture belimil it. What is the result? At Cahirciveren, as sliown by Dr. Lloyd, the rainfall amounts to 59 inches in a year, while at Portarlington it is only 21 inches.

83. Again, you may sometimes descend from the Alps, when the fall of rain and snow is heavy and incessant, into Italy, and find the sky over the plains of Lombardy blue and cloudless, the wind at the sam: cime blowing over the plain towoard the Alps. Below the wind is hot enough to keep its vapor in a perfectly transparent state; but it meets the mountains, is tilted up, expanded and chilled. The cold of the higher summits also helps the chill. The consequence is that the vapor is precipitated as rain or snow, thus producing bad weather upon the heights, while the plains below, flooded with the same air, enjoy the aspect of the unclouded summer sun. Clouds blowing from the Alps are also sometimes dissolved over the plains of Iombardy.

84. In connection with the formation of clouds by mountains, one particularly instructive effect may be here noticed. You frequently see a streamer of eloud many hundred yards in length drawn out from an Alpine peak. Its steadiness appears perfect, though a strong wind may be biowing at the same time over th 3 mountain-head. Why is the cloud not blown away? It is blown away ; its permanence is only apparent. At one end it is incessuntly dissolved, at the other end it is incessantly renewed : supply and consumption being thus equalized, the 
cloud appears as changeless as the mountain duced in ealm air, the iry particles build to which it seems to eling. When the red themselves into beautiful stcllar shapes, ench sun of the evening sinines upon these cloud-star possessing six rays. There is no deviastrcamers they iesemble vast torches with tion from this type, though in other respects their flames blown through the air.

\section{\$9. A RCHITECTURE OF SNow.}

the appearances of the snow stars are jutinitely various. In the polar regions these exquisite forms were observed ly Dr. Scores-

85. We now resemble jersons who have liy, who gave numerous drawings of them. climbed a difficult peak, and therehy carned Ihave observed them in midwinter filling the the enjoyment of a wide prospect. Having air, and loading the slopes of the Alps. But made ourselves masters of the conditions in England they are alsu to be seen, and no necessary 10 the production of mountain words of mine could convey so vivid an imsuow, wa are able to take a comprehensive pression of their beauty as the aninexed frawand intelligent view of the phenomena of ings of a few of them, execuled at Greengiaciers.

86. A few worls are still necessary as to 90 . It is worth pausing to think what won-
the formation of snow. The molecules and derful work is gomg on in the atmospicere wich by Mr. Gliasher. the forme atmospinere the of all substances, when allowed free during the formation and descent of every play, build themselves into definite and, for snow-shower: what building power is the most pat, beautiful forms called cres- brought into play! and how imperfect seem tals. Ir:on, copper, golil, silver, lead, sulphur, the productions of human minds and hands when melted and permittel to conl gradually, when compared with those formed by the all show this crystallizing power. The metal blind forces of nature!

hisinuth shows it in a particularly striking minner, and when properly fused and solicii. fiel, self-built crystals of great size and beauty are formed of this metal.

87. If you dissolve saltpetre in water, and fillew the solution to evaporate slowly, you may oblain large crystals, for no portion of the salt is converted into vapor. The vater of our atmosphere is fresh, though it is desivel frum the salt sea. Sugar cissolved in water, and permittel to evaporate, yieids crystais of sugar candy. Alum 1 cadily erystallizes in the same way. Flints dissolved, as they sometimes are in nature, and perinitted to crystallize, yield the prisms and pyramids of rock crystal. Chalk dissolved and crystallized yields Iccland spar. The diamond is crystallized carbon. All our pre. cious stones, the ruby, sapphire, beryl, topaz emerald, are all examples of this crystallizing power.

88. You have heard of the force of gravitation, and you know that it cousists of an aitraction of every particle of matter for every other particle. You know that plan. ets and moons are held in their crbits by this attraction. But gravitation is a very simple affair compared to the force, or ratber forces, of crystallization. For licre the ultimat: particles of matter, inronceivably small as they are, show themselres possessed of attractive and repelten poies, by the mutual action of which the shape and structule of tie crystal are tetermined. In the soiid conthiton the attracting ioles are rigidly lncked teggether; but if sufficient heat be applied the livind of union is dissolved, and in the state of fusion the poles are pushed so far asunder as to be practically out of each other's range. The natural tendency of the molecules to brith themselves tougether is thus neutralized.

89. This is the case with water, which as a liquid is to all appearance formless. When sufliciently cooled the molecules are brought within the play of the crystallizing force, aud they then -rrange the mselves in $101 \mathrm{~ms}$ of in iescribavie wow When snow is pro.

91. But who ventures to call the forces of nature blind? In reality, when we spials thus we are deseribing our own condition. The blindness is ours; and what we really ought to say, and to confess, is that our powers are absolutely unable to comprehenel either the origin or the end of the operations of nature.

92. But while we thus acknowletge on limits, there is also reason for wonder at the extent to which science has mastered the system of nature. From age to age, aul from generation to generation, fact his hec(11 added to fact, and law to law, the true moth. od and order of the Universe being therebs more and more revealed. In doing this sei(nce has encountered and overthrown vaisius forms of superstition and deceit, of credulity and imposture. But the world continually produces weak persons and wicked persons: and as long as they continue to exist sille liy side, as they do in this our day, very delrising beliefs will also continue to infest the world.

\section{§ 10. Atomic Poles.}

93. "What did I mean when, a few mo. inents ago (88), I spoke of attracting and re. pellent poles?" Let me try to answer this question. You know that astronomers ant geographers speak of the earth's poles, an. you have also heard of magnetic poles, the poies of a magnet being the points at whith the attraction and repulsion of the magnit are as it were concentrater.

94. Every magnet passesses two such poles; and if iron filings be scaltercd over magnet, each particle becomes atro endoweil with two poles. Suppose such particles de. void of weight and floating in our atmos phere, what must occur when they come near each other? Manifestly the repellent poles will retreat from each other, while the attractive poles will approach and finally lock themselves together. And supposing the particles, instead of a single pair, to possess several pairs of poles arranged at definits 

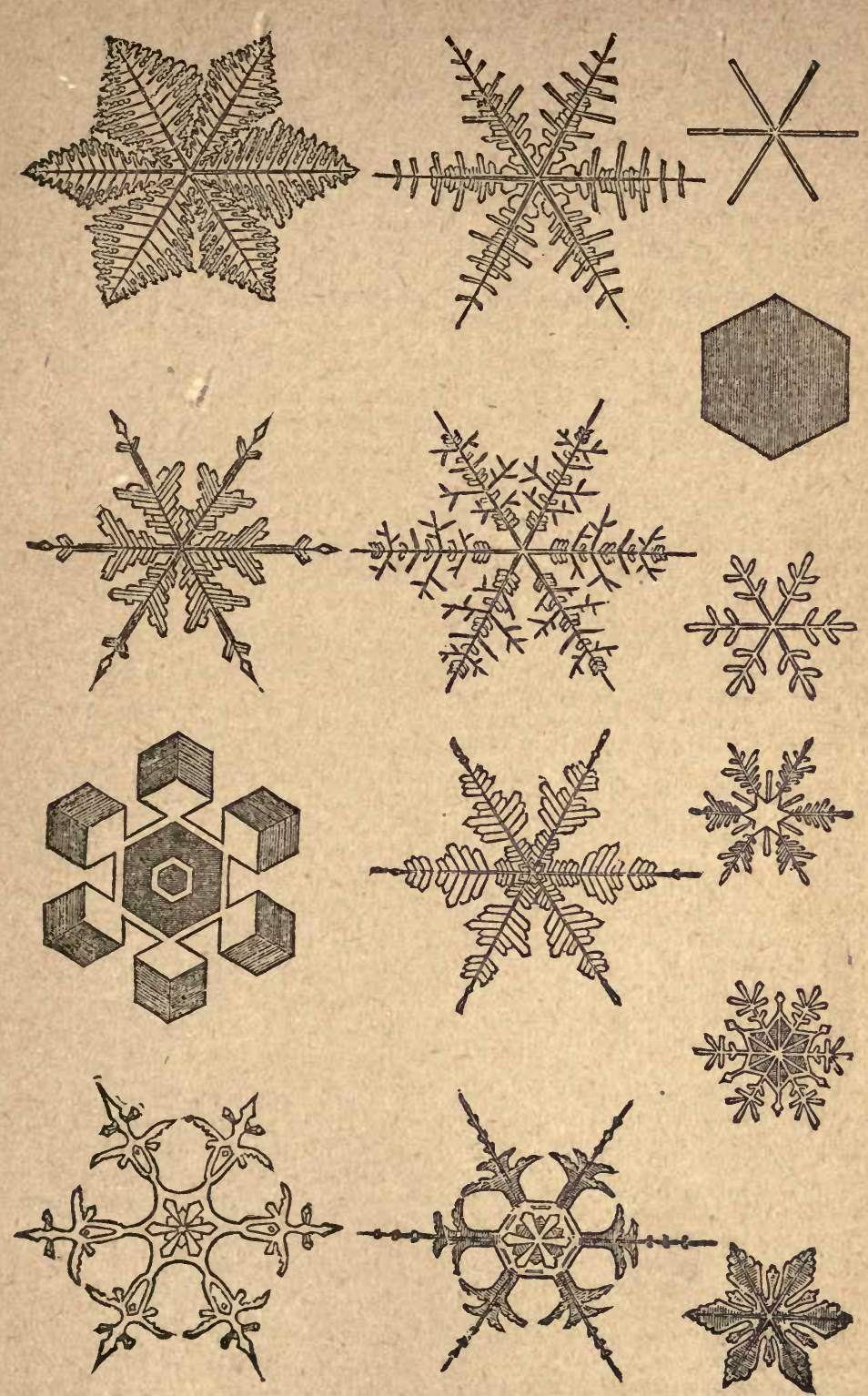

Fig. 2.-Snow Crystals.

points over their surfaces; you can then pic- ble and beautiful crystals of the ritow. ture them, in obedience to their mutual at- Thus our first notions and concep,rivis of tr:ictions and repulsions, building themselves logether to form masses of definite shape and siructure. poles are obtained from the sight of vur eyes in looking at the effects of magnetism; and we then transfer these notions and concep-

95. Imagine the molecules of water in tions to particles which no eye has ever calm cold air to be gifted with poles of this seen. The power by which we thus picture description, which compel the particles to lay to ourselves effects beyond the range of the themselves together in a definite order, and seuses is what philosophers call the Imaginayou have before your mind's eye the unseen tion, and in the effort of the nind to seize architecture which finally produces the visi-: upon the unseen architecture of crystals, we 
arve an example of the "scientiflc use" of this faculty. Without inagination we might have critical power, but not creative ?ower, in science.

\section{\$11. Arcittecture nF Lase Ice.}

DC. We have thus made ourselves acquaintd with the beautiful snow-1lowers self-constructel by the molecules of water in calm cold air. Do the molecules show this archirecturial power when ordinuly water is frozen? What, for example, is the structure of the ice over which we skate in winter? Quito as wonderful as the flowers of the snow. The observation is rare, if not new, but I have seen in water slowly freezing sixrayed ice-stars formed, and fluating free on the surface. A six-rayed star, moleover, i typical of the construction of all our lalse ice. It is built up of such forms wonderfully in. terlaced.

97. Take a slab of lake ice and place it in the path of a concentrated sunbern. Watch the track of the beam through the ice. Part of the beam is stopped, part of it groes through ; the former produces inteinal liquefaction, the latter has no (ffect whatever upon the ice. But the licutufaction is not uniformly diffused. From separate spots of the ice little shining points the seen to sprarkle forth. Every one of those points is sitrrounded by a beantiful liquid flower with six petals.

99. Ice and water are so optically alike that unless the light fall properly upon these Howers you cannot see them. But what is the central spot? A vacuum. Ice swims on water because, bulk for bulk, it is lighter than water ; so that when ice is melted it shrinks in size. Can the liquid flowers then occupy the whole space of the ice melted! Plainly no. A little empty space is fim $m: 1$ with the flowers, and this space, or rather its surface, shines in the sun with the lustre of burnished silver.

99. In all cases the flowers are formed parallel to the surface of freczing. They ure formed when the sun shines upin the ice of every lake; sometimes in myrials. and so small as to require a magnif ying-glass to see them. They are always attrimable, but theit beauty is ofien marted by internal defects of the ice. Even one portion of the same piece of ice may show them exquisitely, while a seeond portion shows them imperfectly.

100. Annexed is a very imperfect sketch of these beautiful figures.

101. Here we have a reversal of the pro cess of crystallization. The searching solar beam is delicate enough to take the molecules down without deranging the order of their archibocture. Try the experiment for vourrelf with a pocket-lens on a sunny day. You will not find the flowers confused ; they all lie parallel to the surface of freezing. In this exquisite way every lit of the ice over which our skaters glide in wiuter is put together.

102. I said, in 97 , that a portion of the sunbeam was stopped by tlue ice and lique- fied it. What is this portion? Tise dark heat of the sur. The great lody of the light waves and even a portion of the dark onces pass though the ice without losing any of their heating power. When propelly concentrated on combustible bojics, even after having passed througl the ice, their burning power becromes manifest.

103. Ant the ice itself may be emplozed to concentiate them. With au icc-lens in the polar regions Dr. Scoresby has often con. centrated the sun's rays so as to make them hurn woml, fire gunpowder, and melt lea' ; thus prosing that the hating power is retained by the rays, even after they have passed through so cold a substance.

104. By rendering the rays of the electri, lamp parallel, and then sending them through a lens of ice, we obtain all the effects which 1)r. Scoresby obtained with the rays of the sun.

5 12. The Source of tire Arvemon.-Ick Prinacles, Towers. and Chasms of thl

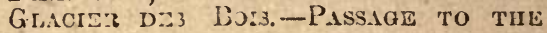
Moxtazivert.

10i. Our preparatory studies a:e fur the present calcd, and thus informed, let us ap. proach the Aips. Through the village of Chamouni, in S.roy, a river rus'ies which is called the Arve. Let us trace this rivin hackwaril from Chamouni. At a littlo distance from the village the river forks; one of its brancles still continues to ke called the Arve, the other is the Arveiron. Following this latter we come to what is called the "source of the Arveiron"-a short hour's walk from Chamouni. Here, as in the case of the Rhone already referied to, you are fronted by a liuge mass of ice, the end of a glacier, and from an arch in the ice tho Arveiron issues. Do not trust the arch $i_{i}$ summer. Its roof falls at intervals with is startling crash, and would infallibly crusis auy person on wliom it might fall.

106. We must now be observant. Iooking about us liere, we find in front of the ice curions heaps and ridges of débris, which are more or less concentric. These are the terminal moraines of the glacier. We shall examine them subsequently.

107. We now turn to the left, and ascend the slope beside the glacier. As we ascend we get a better view, and find that the ice here fills a narrow valley. We come upon another singular ridge, not of fresh débris. like those lower down, but ccvered in part with trees, and appearing to be literally as "old as the hills." It tells a wonderful tale. We soon satisfy ourselves that the ridge is an ancient moraine, and at once conclude that the glacier, at some former period of its existence, was vastly larger than it is now: This old moraine stretches right across the main velley, and abuts against the mountrins at the opposite side.

108. Having passed the terminal portion of the glacier, which is covered with stones and rubbish, we find ourselves beside a very wonderful exhibition of ice. The glacier de 
scends a stcep gorge, and in doing so is riven and broken in the inost extraordinary manner. Here ate towers, and pinnacles, ancl fautastic shapes wrought out liy the action of the weather, which put one in mind of rude sculpture. From cleep chasms in the glacier issues a delicate sli:mmer of blue light. At times we liear a souml like thunder, which arises either from the falling of a tower of ice or from lie tumble of a ligge stone into a chasm. The glacier maintains this wild and chactic chancter for some time: and the best iceman would find himself defeated in any attempt to gret along it.

109. We reach a plice called ine Cliapean, where, if we wish, we can have sefresliment in a little mountain lut. We then pass the Maurais Pas, a precipitous rnck, ou the face of which steps are hewu, and the uupractised traveller is assisted by a Iope. We pursue our journey, partly along the mountainside, and partly along a ridge of singularly artificial aspect-a luteral moraine. We at length face a house perched upon an eminence at the opposite sille of the glacier. This is the auberge of the Montanveit, well knnwn to all visitors to this portion of the Aips.

110. Here we closs the glacier. I should have told you that its lower part, including t'ic broken portion we lave passed, is called the Glacier des Bcis; while the place that we are now about to cross is the lueginning of the Nicr de Giace. Yon feel that this term is not quite appropriate, for the glacie: here is much more like a ricer of ice than a sta. The valley which it fills it about half a suile wirle.

111. The ice may be riven where we enfer upon it, but with the necessary care there is ni) difficulty in crossing this portion of the Mer cle Glace. The clefts and chasms in the i.e ate ralled crecusses; we shall make their acquaintance on a grander scale by and by.

112. Look up and down this side of the glacier. It is considerably riven, but as we advance the crevasses will diminish, and we shali find very few of them at the other side. Note this for future use. The ice is at first clity : but the dirt soon divappears, and you come upon the clean crisp sut face of the glacier. You have already noticed that the clean ice is white, and that finm a distance it resembles snow rather than ice. This is caused hy the breaking up of the surface by the solar heat. When you pound transparent rock-salt into powiler it is as white as table-salt, and it is the minute fissuring of the surface of the glacier by the sun's rays that causes it to appear white. Within the glacier the ice is transparent. After an exhilarating passage we get upon the opposite lateral moraine. and ascend the steep slope from it to the Montanvert Inn.

$\S$ 13. Tre Mer DE Glace AND ITS Sources.-Our First Cimm to the Cleft Statiox.

113. ITere the view before us is very grand. We look across the glacier at the heautiful pyramid of the Aiguille di Dru (shown in our frontispiece); and to the right at the Aiguille des Charmoz, with its sharp pinnacles bent as if they wero ductile. Look. ing straight up the glacier the view is bound cit by the great crests called La Grarica Jorasse, nearly 14,000 feet high. Our object now is to met into the very heart of the mountains, and to pursue to its origir the wonderful flozen river which we have just crossed.

114. Starting from the Montanvert with the glacier below us is our left, we soon reach some rocks resembling the Mauvais Pas ; they are calle!l les Ponts. We cross t'icm and reach l'Angle, where we quit tine land for the ice. We walk up the glacier, hat before reaching the promontory called Trelaporte, we take once more to the mountairi-side; for though the path here has been forsaken on account of its danger, for the sake of knowledge we are prepared to incur danger to a reasonable extent. A lit:le glacier reposes on the slope to our right. IWe may sce a luge boulder or two poised on the cnd of the glacier. and, if fortunate, alsa see the boulder liberatei and plunging violently down the slope. Presence of mind is all that is necessary to render our safety certain ; but travellers do not always show prisence of mind, and hence the path which formerly led over this slope has been forsaken. The whole slope is cumbered by masses of rock which this little glacier has sent down. These I wished you to see; by and by they shall be fully accounted for.

115. Above Trélapiorte to the right you sce a most singular cleft in the rocks, in the middle of which stands an isolated pillar, hewn out by the weather. Our next object is to get to the tower of rock to the left of that cleft, for from that position we shall gain a must commanding and instructive view of the Mer cle Glace and its sources.

116. The cleft referred to, with its pillar, may be seen to the right of the above engraving of the Mer de Glace. Below the cleft is also seen the little glacier just referred to.

117. We may reach this cleft by a steep gully, visible from our juresent position, and leading directly up to the cleft. But these gullies, or couloirs, are very dangerous, being the patliways of stones falling from the heights. TVe will therefore take the rocks to the left of the gully, by close inspcction ascertain their assailabls points, and there attack them. In the Alps as elsewhere wonderful things may be dias liy looking stead. fastly at ditficulties, and testine them whercrer they appear assuilable. WTe thus reach our station, where the glory of t'se prospect, and the insight that we gain als to the formation of the Mer cle Gl ice. fir more than re. pay us for the labor of out ascent.

118. For we see, the glacier below us, stretching its frozen tongue downward past the Montanvert. And we now find this sin. gle glacier branshing out into three others, some of them wider than itsult. Regard the 


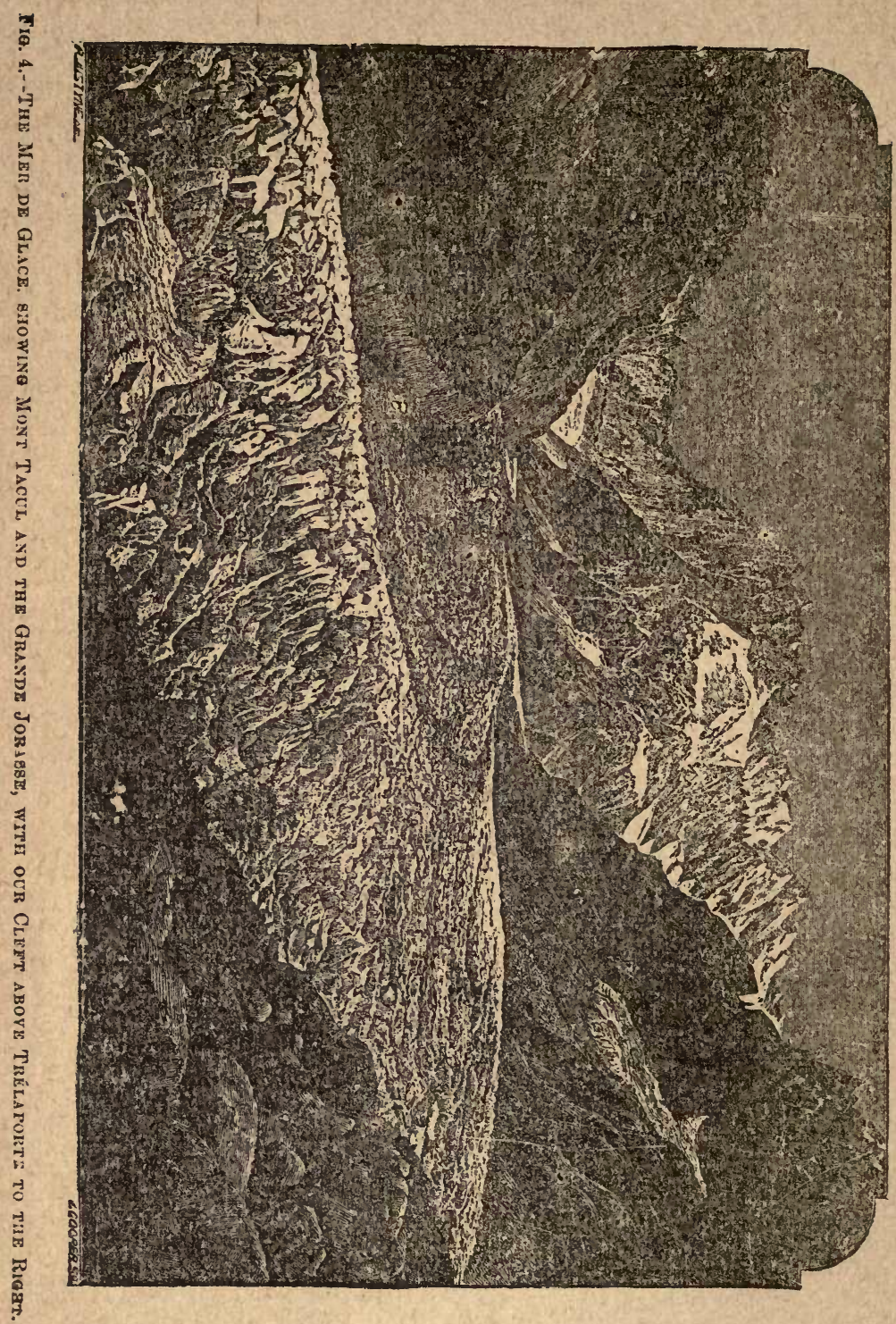

1. Im h to the right, the G'ucier du Géant. the promontory of Téllaporte, and walked It stretches smonthly up for a long distance, right up the Glacier du Géant. We should licen becomes disturbed, and then changes to have found ice under our feet up to the bottom a great frozen cascade, down which the ice of the cascade. It is not so compact as the uppears to thmble in wild confusion. A bove ice lower down, but you would not thin of the cascade you see an expanse of shinug lefusing to call it ice.

snow, occupying an area of some square mikes.

120. A we approach the fall, the smonth and unbroken character of the glacier changes more and more. We encounter \$ 14. ICE-CASCADE AND SNows OF THE transverse ridges succeeding each other with Col DU GE.ANT. augmenting steepness. The ice becomes 119. Iustead of climbing to the height where mure and more fissured and confused. We we now stand, we might have continued our wind through tortuous ravines, climb huge wal's upon the Mer de Gilice turned round ice-mounds, and creep cautiously along 
crumbling crests, with crevasses right and left. The confusion increases until further advance along the centre of the glacier is impossible.

121. But with the aid of an axe to cut steps in the steeper ice-walls and slopes we might, by swerving to either side of the glacier, work our way to the top of the cascade. If we ascended to the right, we should have to take care of the ice uvalanclies which sometimes thunder down the slopes; if to the left, we should have to taise care of the stones let loose from the Aiguille Noire. After we had cleared the cascade, we should have to beware for a time of the crevasses, which for some distance above the fall yatwn terribly. But by ciution we could get round them, and sometimes cross them by bridges of snow. Here the skill and knowledge to be acquired only by long practice conie into play ; and here also the use of the Alpine rope sugrgests itself. For not cn:y are the snow-bridges often frail, but whole crevasses are sometimes covered, the unhappy traveller being first made aware of their existence by the snow breaking under his feet. Many lives have thus been lost, and some quite recently.

122. Once upon the plateau above the icefall we find the surface totally changed. Below the fall we walkec upon ice; here we are upon snow. After a gentlc but long ascent we reach a depression of the ridge which hounds the snow-firld at the tep, and now look over Italy. We stand unon the famous Col du Géant.

123. They were no idle scimperers on the mountains that made these wild recesses first known; it was not the desire for health which now brings some, or the desire for trandeur and beanty which brings others, or the wish to be able to say that they have climbed a mountain or crossed a col, which I fear brings a good many more; it was a desire for knovdedge that brought the first explorers here, and on this col the celebrated De Sanssure lived for seventeen days, mak. jugr scientific observations.

\section{\$ 15. Qcestroning ture Glaciens.}

124. I would now ask you to consider for a moment the facts which such an excur. sion places in our posression. The snow through which we have in idea trudged is the strow of last winter and spring. Had we placed last August a pioper mark upon the surface of the suow, we should find it this August at a certain depth beneath the surfrce. A yood deal has been melted by the summer sin, but a good deal of it remains. and it will eontinue until the snows of the coming winter fall and cover it. This again will be in part preserved till next August, a good deal of it remaining until it is covered hy the snow of the subsequent winter. We thus arrive at the certain conclusion that on the plateau of the Col du Géant the ouantity of snow that falls annually exceeds the quantity melted.

125. Had we come in the montl of $I$ pril or May, we should have found the glacier below the iee fall also covered with snow, which is now entirely cleared away by the heat of summer. Nay, more, the ice there is obviously melting, forming running brooks which cut channels in the ice, and expand here and there into small blue-green lakes. Hence you conclude with certainty that below the ice-fall the quantity of frozen material faiting upon the gilacier is less than the quantity melted.

126. And this forces upon us another conclusion ; between the glacier below the icefall and the plateau above it there must exist a line where the quantity of snow which falls is exacily equal to the quantity annually melted. Tlis is the snow-line. Un some glaciers it is quite distinct, and it would be distinct here were the ice less broken and confused than it actually is.

127. The French term néré is applied to the glacial region above the snow-line, while the word glacier is restricted to the ice below it. Thus the snows of the Col du Géant constitute the névé of the Glacier du Geant, and in part, the névé of the Mer de Glace.

12S. But if every year thus leaves a residue of snow upon the platean of the $\mathrm{Col}$ din Géant, it necessarily follows that the plateau must get annually higher, provided the snorn remain upon it. Equally certain is the conclusion that the whole length of the glacier below the cascade m:1st sink gradua!ly lower, if the uaste of annull melting be not made good. Supposing two feet of snow a year to remain upon the $\mathrm{Col}$, this would raise it to $s$ height far surpassing that of MIont Blane in five thousand years. Such accumulatinn must take place if the snow remain upon the Col; but the accumulation does not take place, hence the snow does not remain on the Col. The question then is, Whither does it go ?

§ 16. Brancies and Medial Moraines of thl Meir de Glace frow the Cleft Station.

129. We shall grapple with this question inmediately. MLeanwhile look at that icevalley in finnt of us, stretching up between Mont Tacul and the Aiguille de Léchaud, to the base of the great ridge called the Grande Jorasse. This is called the Glacier de Léchaud. It receives at its head the snows of the Jorasse and of MIont Mallet. and joins the Glacier du Gétınt at the promontory of the Tacul. The glaciers seens welded together where they join, but they continue distinct. Between them you clearly trace a stripe of débris (c on the annexed sketch-plan): you trace a similar though smaller stripe ( $a$ on the sketch) froin the junction of the Glacier du Gánt with the Glacier de; Perriades at the font of the $\mathbf{A i}$. guille Noire, which you also follow along the Mer de Glace.

130. We also see another glacier,or a portion of it, to the left, falling apparently in broken fragments through in narrow gorge (Cascado du Talefre on the sketch) aud joining the 


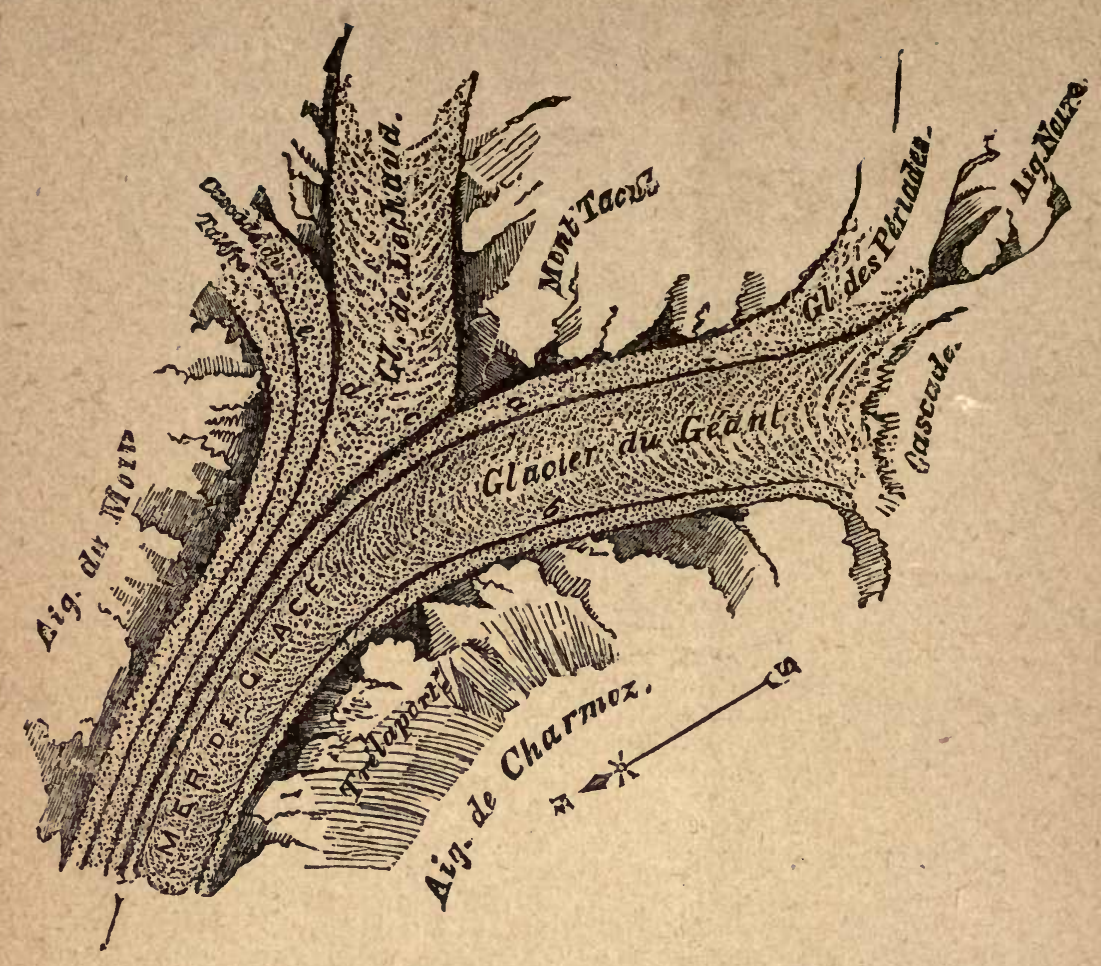

Fro. 5.-Sketch-Plan, showing tine Moraines a, b, c, d, c, of the Mer de Gr.ace.

Léchaud. and from their point of junction which we have not yet seen. We aim at the also a stripe of débris (d) runs downward farther side of the glacier, and to reach it we along the Iler de Glace. Beyond this again must cross those dark stripes of débris which we notice another stripe (e), which seems to we observed from the heights. Looked at begin at the bittom of the ice-fall, rising as from above, these moraines seemed flat, but it were from the bodv of the glacier. Beyond all of these we can notice the literal moraine of the Mer de Glace.

131. These stripes are the medinl moraines of the Mer de Glace. We shall learn more about them immediately.

1:32. And now, liaving informed our minds by these olservations, let our eyes wimler over the who!e glorious scene, the splintered peaks and the hacked and jagged crests, the far-stretching snow-fields, the smaller glaciers which nestle on the heights, tive deep blue lieaven and the sailing clouds. $\mathrm{I}$ : it nut worth some labor to gain command of sur'h a scene? But the delight it imparts is heightened by the fact that we did not (n)me expressly to see it ; we came to instruct inrselves about the glacier, and this high enjivnent is an incident of our labor. You will find it thus through life; without hon. eat liber there can be no deep joy.

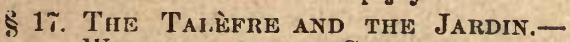
Work among the Crevasses.

133. And now let us descend to the Mer de (ilace, for I want to take you across the slacier to that broken ire-fall, the origin of now we find them to be ridges of stones and rubbish, from twenty to thirty feet liigh.

134. We quit the ice at a place called the Couvercle, and wind round this promontory, ascending all the time. We squeeze ourselves through the Égralets, a kind of natural staircase in the rock, and soon afterward obtain a full view of the ice-fall, the origin of which we wish to find. The ice upon the fall is much broken; we have pinnacles and towers, some erect, some leaning, and some, if we are fortunate, falling like those upon the Glacier des Bois; nd we have chasms from which issues a delicate blue light. With the ice-fall to our right we continue to ascend. until at length we command a view of a huge glacier basin, almost level, and on the middle of which stands a solitary island, entirely surrounded by ice. We stand at the edge of the Glacier du Talefre, and connect it with the ice-full we have passed. The glacier is bounded by rocky ridges, hacked ind torn at the top into teeth and edges, and buttressed by snow fluted by the descending stones.

135. We cross the basin to the central island, and find grass and flowers at the 
place where we enter upon it. This is the celehrated Jardin, of which you have often beurl. The upper part of the Jardin is hare rock. Close at hand is one of the noblest renks in this portion of the Alps, the Aiguille Verte. It is letween thirteen and fourteen thousased feet high, and down its sides, ufter freshly-fallen snow, avalanches incessantly thunder. From one of its projections a streak of moraine starts down the Talef re; from the Jardin also a similar streak of moraine issues. Both continue side by side to the top of the ice-fall, where they are engulfer in the chasms. But at the bottom of the fall they reappear, as if newly emerging from the body of the glacier, and afterward they continue along the Mer de Glice.

136. Walk with me now alongside the moraine from the Jardin down foward the icefall. For a time our work is easy, such fissures as appear offesing no impediment to our march. But the crevasses become gradually wider and wilder, following each other at length so rapidly as to leave merely walls of ice between them. Here perfect stearliness of foot is necessary-a slip would be death. We look toward the fall, and observe the confusion of walls and blocks and chasms below us increasing. At length prudence and reason. ery "Halt!" We may swerve to the iight or to the left, and making our way along crests of ice, with chasms on both hands, reach either the right lateral moraine or the left lateral moruine of the placier.

§ 18. Finst Questions nhgarding Glacier Muton. - Driftivg of Bodies buried in a Crevasse.

137. But what are these lateral moraines? As you and I go from day to day along the giaciers, their origin is gradually made plain. We see at intervils the stones and rubbish descending from the mountain-sides and arrested by the ice. All thlong the fringe of the glacier the stones and rubbish fall, and it soon becomes evident that we have here the source of the lateral moraines.

138. But how are the medial moraines to be accounted for? How does the déliris range itself upon the glacier in stripes some hundreds of yards from its edge, leaving the space between them and the edge clear of rubbish? Some have supposed the stones to have rolled over the glacier from the sides, but the supposition will not bear examination. Call to mind now our reasoning regarding the excess of snow which falls above the snow-line, and our subsequent question, How is the snow disposed of ? Can it be that the entire mass is moving slowly downward ? If so, the lateral moraines would be carried along by the ice on which they rest, and when two branch glaciers unite they would lay their adjacent lateral moraines together to form a medial moraine upon the trunk glacier.

139. There is, in fact, no way that we c:in see of disposiag of the excess of snow above the snow-line; there is no way of making good the constant waste of the ice below the snow-line; there is no way of accounting for the medial moraines of the glacier, but by supposing that from the highest snow-tields of the Col lu Geant, the Lechaud, and the Talef re, to the extreme end of the Glacier des Bois, the whols nass of frozen matter is moving down ward.

140. If you were oller, it would grive me fi zasure to take you un Mont Blanc. Startny from Chamouni, we should first pass through woods an 1 pastures, then up the steep hill-face with the Glacier des Bossons to our right, to a rock known as tho Pierre Pointue ; lience to a higher rock called the Pierre l'Echelle, baciuse here a la.tuer is usually placed to assist in crossing the chasmis of the glasier. At the Pierre I'Echelle we should strike the ice, and passing under the Aiguille du MIili, which towers to the left, and which someimes stveeps a portiun of the track witls stone avalanches, we should cross the Glacier des Boss'uns ; amid heapedup mounds and broken torvers of ice; up steep slapes ; orer chasins so deep that their bottoms are hid in darkness.

141. We reach the rocks of the Grands Mulets, which form a kind of barren islet in the icy sea ; thence to the higher-snow-fields, crossing the Petit Plateau, which we should find cumbered by blocks of ice. Looking to the right, we should see whence they came, for rising here with threatening aspect high above us are the broken ice-crags of the Dôme du Goûté. The guides wish to pass this place in silence, and it is just as well to humor them, however much you may doubt the competence of the liuman voice to bring the ice-crags down. From the Petit Plateau a steep snow-slope would carry us to the Grand Plateal, and at day-dawn I know nothing in the whole Alps more grand and solemn than this place.

142. Une object of our ascent mould be now attained : for liere at the heal of the Grand Plateau, and at the foot of the fiual slope of Mont Blanc, I should show you a great crevasse, into which three guides wore poured by an avalanclie in the year 18:0.

143. Is this language correct? $\mathbf{A}$ crevasse hardly to be distinguished from the present one undoubtedly existed here in 1820. But was it the identical crevasse now existing? Is the ice riven here to-day the same as that riven fifty-one years ago? By no means. How is this proved? By the fact that more than forty years after their interment, the rernains of those three guides were found near the end of the Glacier des Bossons, many miles below the existing crevasse.

144. The same observation proves to dem onstration that it is the ice near the bottom of the higher neve that becomes the surface-ice of the glacier near its end. The waste of the surface below the snow-line lorings the deeper portions of the ice more and more to the light of lay.

145. There are numerous otvious indicatiuns of the existence of glacier motion, though it is too slew to catch the eye at. 
once. The crevasses change within certain limits from year to year, and sometimes from month to month; and this could not be if the ice did not move. Rocks and stones also are observed, which have been plainly torn from the mountain-sides. Blocks seen to fall from particular points are afterward observed lower down. On the moraines rocks are found of a totally different mineralogical character from those composing the mountains right and left; and in all such cases strata of the same character are found bordering the glacier higher up. Hence the conclusion that the foreisn boulders have been floated down by the ice. Further, the cnds or " snouts" of many glaciers act like ploughshares on the land in front of them, overturning with slow but merciless energy huts and châlets that stand in their way. Facts like these have been long known to the Inhabitants of the High Alps, who were thus made acquainted in a vague and general way with the motion of the glaciers.

§ 19. The MIotion or Glaciers. -Measurements by IIUgi aNd Agassiz.-Dirifting OF Huts oN THE ICE.

146. But the growth of knowledge is from vagueness toward precision, and exact determinations of the rate of glacier motion were soon desired. With reference to such ineasurements, one glacier in the Bernese Oberland will remain forever memorable. From the little town of Meyringen in Switzerland you proceed up the valley of Hasli, fast the celebrated waterfall of IIandeck, where the river Aar plunges into a chasm more than 200 feet deep. You approach the Grimsel Pass, but instead of crossing it you turn to the right and follow the course of the Aar upward. Like the Rhone and the Arveiron, you find the Aar issuing from a glacier.

147. Get upnn the ice, or rather upon the deep m.raine shingle which covers the ice, and walk upward. It is hard walking, but af:er some time you get clear of the rubbish, and on to a wide glacier with a great medial moraine running along its back. This moraine is formed by the junction of two branch glaciers, the Lauteraar and the Finsteraar, which unite at a promontory calleil the $\mathrm{Ab}$ schwung to form the trunk glacier of the Unteraar.

148. On this great medial moraine in 1827 an intrepid and enthusiastic Swiss professur, Hurgi, of Solothurm (French Solcure), built a hut with a view to observations upon the glacier. His hut moved, and he measured its motion. In the three years-from 1827 to 1830-it had moved 330 feet dnwnward. In 1830 it has moved 2354 feet ; and in 1841 M. Agassiz found it 4712 feet below its first posilion.

149. In $1840, \mathbf{M}$. $\Lambda$ gassiz himself and somo bold companions tock shelter under a great overhanging slab of rock on the same moraine, to which they added side-wills and other means of protection. And because he and his comrades came from Neufchatel, the hut was called long afterward the "Hoted des Neuchâtelois." Two years subsequent to its crection M. Agassiz found that the "hotel" had inovea 486 feet downward.

§ 20. Precise Measuremgnts of Agagsiz and Foribs.- IIotion of a Glacier PROVED to MeseMble tue Motion of A RIVER.

150. We now approach an epoeh in the scientific history of glaciers. Had the first observers been practically acquainted with the instruments of precision used in surveying. accurate measurements of the motion of glaciers would prrbably have been carlier executed. We are now on the point of seeing such instruments introduced almost simultaneously by II. Agassiz on the glacier of the Unteraar, and by Professor Forbes on the Mer de Glace. Attempts had been made by M. Escher de la Linth to determine the mntion of a series of wouden stakes driven into the Aletsch glacier, but the melting was so rapid that the stakes soon fell. To remedy this, MI. Agassiz in 1841 undertook the great labor of carrying boring tools to his "lotel," and piercing the Unteraar glacier at six different places to a diepth of ten feet, in a straight line across the glacier. Into the holes six piles were so firmly driven that they remained in the glacier for a year, and in 1842 the displacemen!s of all six were determined. Thev were found to be 160 feet, 225 feet, $269^{\circ}$ feet, 245 feet, 210 fect, and 125 fect, respectively.

151. A great step is here gained You notice that the middle numbers arr: the largest. They correspond to the central portion of the giacier. Hence, these measurements conclusively establish, not only the fact of glacier untion. but that the centre of the glacier. like that of a river, moves more rapialy than the sides.

152. With the aid of trained enginecrs M. A gassiz followed up these measurements in subsequent years. His researches are recorded in a work entitled "Système glaciaire," which is accompanied by a very noble atlas of the Glacier of the Unteraar, published in 1847.

153. These determinations were made by means of a theodolite, of which I will give you some notion fomediately. The same instrument was employed the same year by the late Principal Forbes upon the Mer de Glace. He established independently the greater central motion. He showed, more. over, that it is not necessary to wait a year, or even a week to determine the motion of a glacier; with a correctly-adjusted theodolite he was able to determine the motion of vari. ous points of the Mer de Glace from day to day. He affirmed, and with truth, that the motion of the glacier might be determined from hour (') four. We shall prove this farther on (162). Professor Fortues also triangulated the Ner de Glace, and laid down an excellent map of it. His first observations and his survey are recorded in a celebrated book published in 1843, and entitled 
"Travels in the Alps."

154. These observations were also follurred up in subsequent years, the results being recorded in a seties of detached letters and essilys of great interest. These were subsequently collected in a volume entitled " Occasional Papers on the Theory of Glaciers," published in 1859. The labors of $\mathbf{A g a s s i z}$ and Forbes are the two chief sources of out knowledge of glacier phenomena.

\section{\$21. The TIEedolite ANo its Use.-Oura oWr MEasurements.}

155. My object thus far is attained, i hare given you prosfs of glacier motiou, and a historic account of its measurement. And now we must try to add a little to the knowledge of glaciers by our own lahors on the ice. Resolution must not be warting at the commencement of our work, ror steadfast. patience during its prosecutior. Look then at this theodolite; it consists mainly of a telescope and a graduater circle, the telescope capable of motion us and down, and the circle, carrying the teiescope along with it, capable of motion right and lett. When desired to make the motion exceedingly fine an' minute, suitable screws, called tangent screws, are employed. The instrument is supported by tirce lege, movab!e, but firm when properly plarted.

156. Two spirit-levels are fixed at right angles to each other on the circle just referred to. Practice enahles one to take liold of the lears of the instrunent, and so to fix them that the circle sliall be nearly horizontal. By means of four levelling screws we render it accurately horizontal. Exactly under the centre of the instrument is a small hook from which a plummet is suspended: the point of the bob just touches a rock on which we make a mark : or if the earth be soft underneath, we drive a stake into it exactly under the plummet. By re-sispending the plummet at any future time we can find to a hall:breadth the position occupied by the instrument to-day.

15\%. Look through the teleser,pe; you see it crosced hy two tibres of the finest spider's thread. In actual work we first direct the telescope across the glacier, until the intersection of the two fibres accurately covers some well-detined pcint of rock or tree at the other side of the valley. This, our fixed standard, we sketch with its surroundings in a note-book, so as to be able immediately to recognize it on our return to this place. Imagine a straight line drawn from the centre of the telescope to this point, and that this line is permitted to drop straight down upon the glacier, every point of it falling as a stone wonld fall; along such a line we have now to fix a series of stakes.

158. A trainell assistant is already upon the glacier. He erects his staff and stands belind it ; the telescope is lowered without 3 werving to the right or to the left; in mathematical language it remains in the same rertial plane. The crossed fibres of the telescope probably strike the ice a little away from the staff of the assistant; by a wave of the arm he moves right or left ; lie may move too much, so we wave him back again. After a trial or two lie knows whether lie is near the proper point, and if so makes lis motions small. He soon exactly strikes the point covered by the intersection of the tibres. A signal is made which tells him that he is right; he pierces the ice with an auger and drives in a stake. He then goes forwarl, and in precisely the same manner takes up another point. After one or two stakes have been driven in, the assistant is able to take up the other points very rapidly. Any requisite number of stakes may thus be fixed in a straight line across theglacier.

159. Next morning we measure the motion of all the stakes. The theodolite is mountal in its former position and carefully levelled The telescope is directed first upon tho standard point at the opposite side of the valley, being moved by a tangent screw until the intersection of the spider's threads accu. ritely covers the point. The telescone is then lowered to the first stake, beside which our trained assistant is already standing. $\mathrm{He}$ is provided with a staff with feet and inches marked on it. A glance shows us that the stake has moved down. By our sig. nals the assistant recovers the point from which we started yesterday, and then determines the distance from this point to the stake. It is, say, 6 inches; through this distance, therefore, the stake has moved.

160. We are careful to note the hour and minute at which each stake is driven in, and the lour and the minute when its distance from its first position is measured ; this enables us to calculate the accurate daily motion of the point in question. The distances throngh which all the other points have moved are determined in precisely the same way.

161. Thus we shall proceed tn work, first making clear w) our ninds what is to be done, and then making sure that it shall be iccurately done. To give our work reality, I will here record the actual measurements executed, and the actual thought suggested, on the Mer de Glace in 1857. T'he only unreality that I would ask you to allow, is that you and I are supposed to be making the observations together. The labor of measuring was undertaken for the most part by Mr. Hirst.

\section{§ 22. Motion of the Mer de Glace.}

162. On July 14, then, we find ourselves st the end of the Glacier des Bois, not far from the source of the Arveiron. We direct our telescope across the glacier, and fix the intersection of its spider's threads accurately upon the edge of a pinnacle of ice. We leave the instrument untouched, looking through it from hour to hour. The edge of ice moves slowly, but plainly, past the fibres, and at the end of three hours we assure our. selves that the motion has amounted to several inches. While standing near the vault 


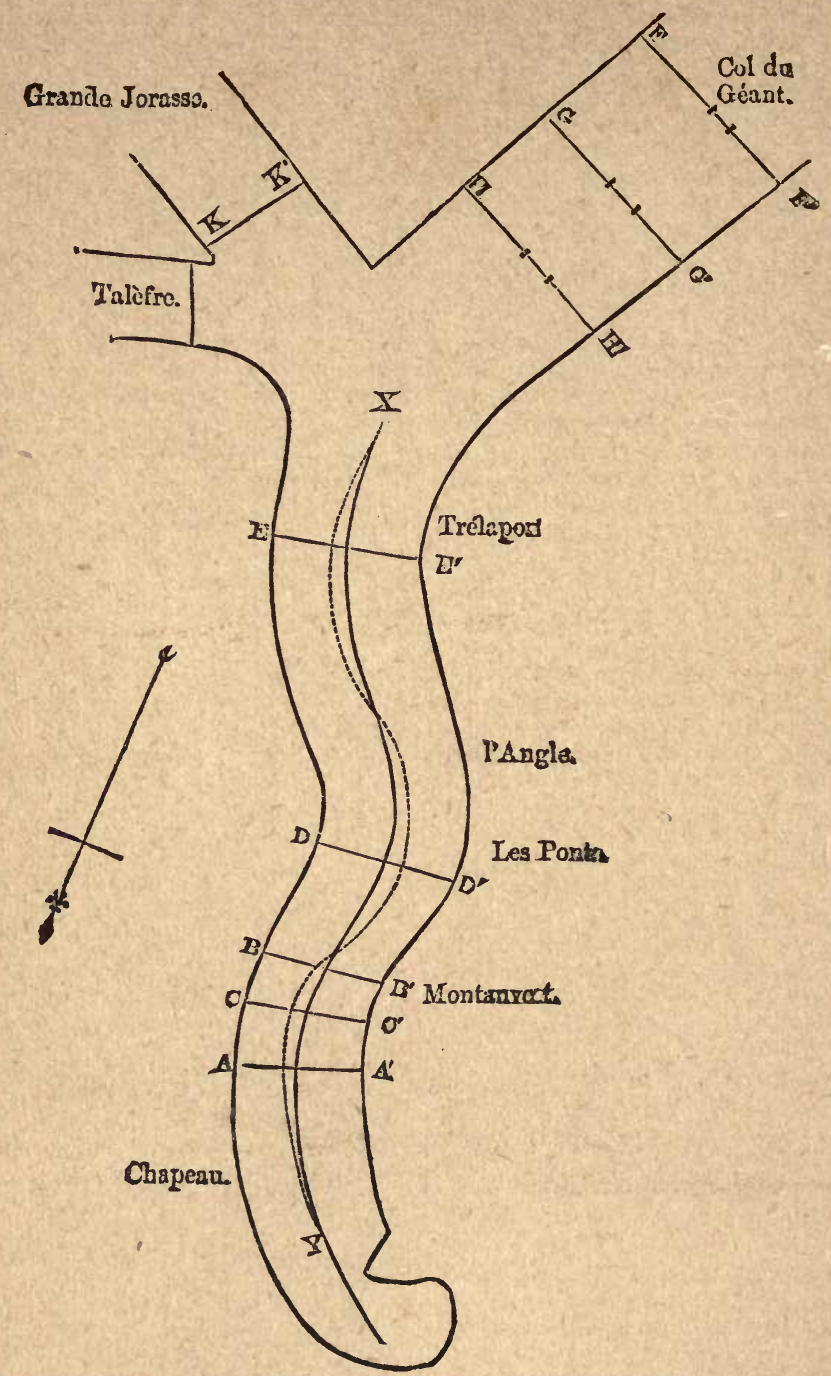

Fig. 6. Outline-Pran, ghowing the Measured lines of tue Mun de ficace and its Tributarimo

of the Arveiron, and talking about going into it, its roof gives way and falls with the sound of thunder. It is not, therefore. withwat reason that I warned you against enterfing these vaults in summer.

163. We ascend to the Montanvert Inn, fix on it as a residence, and then descend to the lateral moraine of the glacier a little below the iun. Here we erect our theodolite, and mark its exact position by a plummet. We must first make sure that our line is perpendicular, or nearly so, to the axis or mid. dle line of the glacier. Our instructed assistant lays down a long staff in the direction of the axis, assuring himself, by lonking up and down, that it is the true direction. Wich another staff in his hand, pointed toward our theodolite, he shifts his position until the seeond staff is perpendicular to the first. Here be gives us a signa!. We direct our telescope upon him, and then gradually raising its end in a vertical plane we find. and note by sketching, a standard point at the other side of the glacier. This point known, and our plummet mark known, we can on any future day find our line. (To render the measurements more intelligible, I append an outline diagram of the Mer de Glace, and of its tributaries.)

164. Along the line just described ten stakes were set on July 1; th, 1857 . Their displacements were mensured on the followiag day. Two of them had fallen, but here ure the distances passed over by the eight re. 
mainlng ones in twenty-four hours.

DAILY MOTION OF THE MER DE GLACE. First Line : A A' upon tue SKetch.

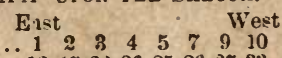

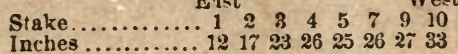

165. You have already assured yourself by actual contact that the body of the glacier is real ice, and you may have read that glaciers move : but the actual observation of the motion of a body apparently so rigid is strangely interesting. And not only does the ice move bodily, but one part of it moves past another; the rate of motion angmenting gradua!ly from 12 inches a clay at the side to 33 inches a day at a distance from the side. This quicker movement of the central ice of ylacier's had been already olserved liv Agas. siz and Forbes; we verify their restilts, and now prnceed to something new. Crossing the Glacier du Geant, which occupies more than half the valley, we find that our line of stakes is not yet at an end. The 10th stake stands on the part of the ice which comes from the Talif:e.

166. Now the motion of the siles is slow, hecause of the friction of the ice arainst its houndaries; but then one would think that midway between the boundaries, where the friction of the sides is least, the motion ought to be greatest This is clearly not the case ; for though the 10 th stake is nearer than the 9 th to the eastern or Ciripeau side of the val. ley, the 10 h stake surpasses the 9 th by 6 inches a day.

167. Here we have something to think of ; but before a natural plilosopher can think with comfort he must be perfectly sure of his facts. The foregoing line ran across the glacier a little below the Montanvert. We will run another line across a little wry ahove the hotel. On July 18 th we set out this line, and to multiply our chances of discovery we place along it 31 stakes. On the subsequent day five of these were found unfit for use ; but here are the distances passed over by the remaining six-and-twenty in 24 hours.

Second Line : $B B^{\prime}$ vpon tre SKetch.

\section{West}

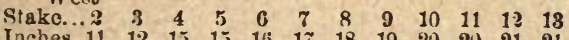
$\begin{array}{llllllllllll}\text { Inches..11 } & 12 & 15 & 15 & 15 & 17 & 13 & 19 & 20 & 20 & 21 & 21\end{array}$ $\begin{array}{llllllllllll}\text { Stake...15 } & 16 & 17 & 18 & 1: 1 & 2.1 & 21 & 22 & 23 & 24 & 25 & 26\end{array}$

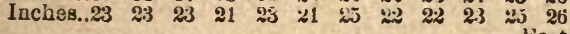

168. Look at these numbers. The first broad fact thev reveal is the advance in the rate of motion from first tis last. There are, however, small irregularities : from 23 inches at the 17 th stake we fall to 21 inches at the 18 th ; from 23 inclies at the 19 th we fall to 21 inches at the 20 h ; from 25 inches at the 21 st we fall to 22 inches at the $22 d$ and 231; but notwithstanding these small ups and downs, the general advance of the rate of motion is manifest. Now there may have been some slight displacement of the stakes by melting, sufficient to account for these small deviations from uniformity in the increase of the motion. But another solution is also possible. We sluall afterward learn that the glacier is retarded not only by its sides but by its bed; that the upper portions of the ice slide over the lower ones. Now if the bed of the Mer de Glace should have eminences here and there rising sufficiently near to the surface to retard the motion of the surface, they might produce the small irregularities noticed above.

169. We note purticularly, while upon the ice, that the 26 th stake, like the 10 th stake in our last line, stands much nearer to the eastern than to the western side of the glacier; the me isuremenis, therefore, offer a further proof that the centre of this portion of the glacier is not the place of swiltest mo. tion.

\section{UNEQUAL MOTION OF THE TWO SIDES OF THE MER DE GLACE.}

170. But in neither the first line nor the second were we able to push our measurements quite across the glacier. Why? In attempting to do one thing we are often taught another, and thus in science, if ve are only steadfist in our wurk, our very de. feats are converted into meaus of instruction. We at first planted pur theodolite on the lateral moraine of the Mer de Glace, expecting to bu able to command the glacier from side to side. Bat we are now undeceived; the centre of the glacier proves to be higher than its silles, and from our last two positions the view of the ice near the oppogite side of the glacier was intercepted by the elevation at the centre. The mountainslopes, in fact, are warm in summer, anil they melt the ice nearest to them, thus causing a fall from the centre to the sides.

171. But yonder ou the heights at the other side of the glacier we see a likely place for our theodolite. We cross the glacier and plant our instrument in a posilion from which we sweep the glacier from side to side. Our first line was below the Montan. vert, our second line above it : this third line is exactly opposite the Montanvert ; in fact, the mark on which we have fixed the fibrecross of the theodolite is a corner of one of the windows of the little inn. Along this line we fix twelve stakes on July 20th. On the 21st one of them had fallen: but the veloei ties of the remaining eleven in 24 hour's were found to be as follows:

THInd LINE: C C' CPON THR SkzTCH.

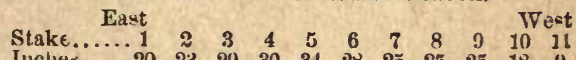
$\begin{array}{lllllllllll}\text { Iuchee......20 } & 23 & 29 & 30 & 34 & 25 & 25 & 25 & 25 & 18 & 9\end{array}$

172. Both the first stake and the eleventh in this series stond near the sides of the glacier. On the eastern side the motion is 20 inches, while on the western side it is only 0 . It rises on the eastern side from 20 to 34 inches at the 5th stake, which we, standing upon the glacier, can see to be much nearer to the eastern than to the western side. The united evidence of these three lines places the fact beyond doubt, that opposite the Montanvert, and for some distance above it and below it, tho whole eastern side of the glacier is moving more 
quickly than the vostern side.

§ 24. Suagestion OF A NEW LIKENESS OF gracier motion to riveir Motion.CONJECTURE TESTED.

173. Here we have cause for reflection, and facts are comparatively worthless if they do not provoke this exercise of the mind. It is because facts of nature are not isolited but connected, thit science, to follow them, must also form a connected whole. The mind of the nutural philosopher must, as it were, be as web of thougit corresponding in all its Abres with the well of fact in nature.

174. Let us, then ascend to a priut which commands a good view of this portion of the Mer de Glace. The ice-river we ste is not straight hut curved, and its curvature is from the IIontanvert; that is to say, its convex side is east, and its concave side is west (look to the sketch). You have already pondeied the fact that a glacier, in some respects, moves like a river. How would a river move througl a curved channel? This is known. Were the ice of the Mer de Glace displaced by water, the point of swiftest motion at the Montanvert would not be the centre, but a point east of the centre. Can it be then that this "water rock," as ice is sometimes called, acts in this respect also like water ?

175. This is a thouglit suggested on the spot; it may or it may not be true, luut tlie means of testing it are at hilnd. Looking up the glacier, we see that at les Ponts it also bends, but that there its convex curvature is toward the western sille of the valley (look again to the sketch). If our surmise be tue, the point of swiftest motion opposite les Ponts ought to lie west of the axis of the glacier.

176. Lut us test this conjecture. On July 25 th we fix in a line across this portion of the ylacier seventeen stakes ; every one of them has remained firm, and on the $26 \mathrm{th}$ we tind the motion for 24 hours to be follows :

Focrtu LiNe : D D' upoN tue SKEtch. Eust

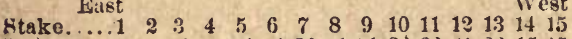

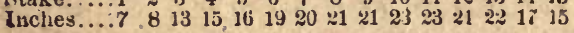

17\%. Inspected by the anked eye alone, the stakes 10 and 11, where the glacier reaclies its greatest motion, are seen to be consilerilbly to the west of the axis of the glacier. Thus far we have a perfect verification of We guess which prompted us to make these measurenients. You will here observe that the "guesses" of science are not the work of chance, but of thoughtful pondering over antecordent fauts. Tho guess is the " indue. tion" from the facts, to be ratitied or exploded by the test of subsequent experiment.

178. And though even now we have ex. ceorlingly strong reasun for holding that the point of miximum velocity obeys the law of liquid motion, the strength of our eonclusinn will be doubled if we can show that the point shifts back to the eastern sile of the uxis at another place of flexure. Forturiateds such a place exists opposite Trélaporte.
Here the convex curvature of tue vallsy turns again to the east. Across this puttiva of the glacier a line was set out on July 2sth. and from measurements on the : $1 \mathrm{~s}$, the rato of motion per 24 hours was delermined.

FifTh LiNe: E E' UPON THE SKetch.-J West

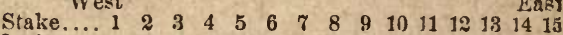
$\begin{array}{lllllllllllllll}\text { Inches....11 } & 14 & 13 & 15 & 15 & 16 & 17 & 19 & 20 & 19 & 20 & 18 & 10 & 15 & 18\end{array}$

179. Here, ayain, the mere estimate of distarces by the eye would show us that the threc takes which moved fastest, viz. the 9 th, 10 th, and 11 th, were all to the east of the middle line of the glacier. The demonstration that the point of swiftest motion wanders to and fro across the axis, as the flexure of the valley chinges, is, therefore -shall I say complete?

180. Not yet. For if surer menns are open to us we must not rest content witl estimates by the eye. We have with us a surveying chain : let us shake it out and measure these lines, noting the distance of erery stake from the side of the glacier. This is no easy work among the crevasses, but I contide it confidently to Mr. Hirst and you. We can ufterward compare a number of stakes on the enstern side with the same number of stakes taken at the same distances $1 \mathbf{r} m$ the western side. For example, a pair of slakes, one ten yards from the eastern side and the other ten yards fiom the western side; annther pair, one fifiy yards from the eastein sirle and the other fifty yarls from the western sile, and so on, can be compared together. For the sake of ensy reference, let us rall the points thus compared in pairs, equirulent points.

181. The re were fire puirs of such points upon onr fourth line, D D', and liere are their relocities :

Eastern points: molion in inches..13 $15 \quad 16 \quad 18 \quad 20$

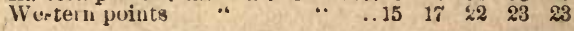
In every case here the stake ut the western side moved in'sie rapidly than the equivalent stane at the eastern side.

182 Applying the same analysis to our ficth ine, $\mathrm{E} \mathrm{E}$, we have the following series of velocities of thrce pairs of equivalent prints :

Easlern points ; motion in inches .......15 $18 \quad 19$ Westrern poiuts ".

183. Here the three points on the eastern side move more rapidly than the equivalent points on the western side.

1S4. It is thus porved:

1. That (1)posite the Montanvert the eastern half of the Mer de Glace moves more rapidly lhan the western half.

2. 'That opposite les I'onts the restern half of the glacier moves mure rapidly than the castern lialf.

3. That opposite Tielaporte t: e eastern haif of the gracier again moves more rapidly than the western haif.

4. That these changes in the place of greatest motiun are determined by the flexures of the valley through which the Mer de Glaco moves. 


\section{§ 25. New Law of Glacier Motion.}

155. Let us express these facts in another vay. Suiposing the points of swiftest motion or a very great number of lines crossing the fler de Glace to be determined; the line oining all those points together is what nathematicians woull call the locus of the joiut of swiftest motion.

186. At Trélaporte this line would lie cast ff the centre; at the Punts it would lie west of the centre; hence in passing from Tiélaporte to the Punts it would cross the centre. But at the Montanvert it would again lie zust of the centre; lience between the Ponts and the Montanvert the centre must be crossed a second time. If there were further sinuosities upon the Mer de Glace there would be further elossings of the axis of the glacier.

18\%. The points on the axis which mark the transition from eastern to western bend. ing, and the reverse, m:ly be called points of contrary flezure.

188. Now what is true of the lier de Glace is true of ail other glaciers moving through sinuous valley3; so that the facts establisthed in the Ner ac Glace may be expanded into the following general law of grl teier mution :

When a glacier moves through a sinuous valley, the locus of the point of maximun motion does not coincite with the centre of the glacier, but, on the contrary, always lies on tue convex side of the central line. The locus is therefure a curved line more deeply sinums than the valley itself, and crosses the uxis of the glacier at each point of contrary flexure.

189. The dotted line on the Uutline Pian (Fig. 6) represents the locus of the point of maximum inotion, the firm line marking the centre of the glacier.

190. Substituting the word river for glacier, this law is also true. The motion of the water is ruled hy precisely the same conditions as the motion of the ice.

191. Let us now apply our law to the explanation of a diffeculty. Turning to the careful measurements excented by i. Agas. siz on the glacier of the Unteratr, we notice in the discussion of these measurements a section of the "Systeme glaciaire" devoted to the "Migrations of the Centre." It is here shown that the middle of the Unteraar glacier is not always the point of swiftest motion. This fact has hitherto remained wishout explantion; but a glance at the Unteraar valley, or at the map of the valley, shows the enigma to be an illustration of the litw which we have just established on the Mer de Glace.

\section{\$23. Motroy or Axis of Mer de Glace.}

192. We have now measured the rate of motion of five different lines across the trunk of the Mier de Glace. Do they all move alike? No. Like a river, a glacier at different places moves at different rates. Com- paring together the points of naximum mo. tion of all five lines, we have this resuit:

MOTION OF MER DE GLACE.

At Trélaporte...........20 inches a day

At les Punts..............23

Above the Moutaivert......20

At the Montanvert............. 31

Jelow the Montanvert...... 33

$\begin{array}{cc}\because 6 & \because \\ \because 6 & 16 \\ 6 & 16\end{array}$

193. There is thus an increase of rapility as we descend the glacier from Trélaporie to the Montanvert ; the maximum motion at the Montanvert being fourteen inches a day greater than at Tiélaporte.

\section{§ 27. Motion of Tributary Glaciers.}

194. So much for the trunk glacier; le us now investigate the branches, permitting, as we have hitherto dune, reflection on known facts to precede cur attempts to dis. cover unknown ones.

195. As we stood upon our " cleft statiou," whence we had so capital a vicw of the Mer de Glace, we were struck by the fuct that some of the tributaries of the glacier were wider than the glacier itself. Supposing water to be substituted for the ice, how do you suppose it would behave? You would doubtless conclude that the motion down the broad and slimhtly inclined valleys of the Géant and the Leechats would be compara. tively slow, bnt that the water would forcu itself with increased rapidity through the "narrows" of Trélaporte. Let us test this notion as applied to ihe ice.

196. Planting our thendolite in the shadow of Mont 'Tacul, and clroosing a suitab!e point at the opposite side of the Glacier du GEant, we fix on July 29th a series of tes stakes across the glacier. The motion of thi line in twenty-four hours was as follows :

\section{MOTION OF C:LACIER DU GEANT.}

SIXTU LINE: II Il' LPON SKETCH.

$\begin{array}{llllllllllllll}\text { Stake....... } & \ldots & 1 & 2 & 3 & 4 & 5 & 6 & 5 & 8 & 9 & 16\end{array}$ Inclies........ 11 10 :2 1 ; 12 13 13 is 11 is 9

197. Our conjecture is fully verified. The maximum inotion liere is seven incles a day less than that of the Mer de Glace at Tréla. porte (192).

198. And now for the Léchaud branch. On August 1st we fix ten stakes across this glacier above the point where it is joined hy the Talèfre. Measured on August 3d, and reducerl to twenty-four hours, the motion was found to he :

\section{MOTION OF GLACIER DE LECHAUD.}

SEVENTH LINE: KK' UPON SKITCH.

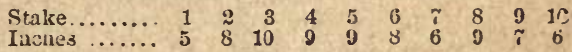

139. ITere our conjecture is still further verified, the rate of motion being even less than that of the Glacier du Géant.

\section{§ 2 . MIOtIoN of Top AND Bottox of GLACIEL.}

200. We have here the most ample and varied evidence that the sides of a glacier, like those of a river, are retarded by iriction against its boundaries. But the likeness does 


\section{ह 31. Sliding and Flowing.-Hard Ice AND SOFT ICE.}

218. We have thus far confined ourselves to the measurement and discussion of glacier motion; but in our excursions we have no. ticed many things besides. Here and there, where the ice has retreated fiom the mountain side, we bave seen the rocks fluted, seored and polished; thus proving that the ice had slidden over them and ground them down. At the source of the Arveiron we noticed the water rushing from beneath the glacier charged with fine matter. All glacier rivers are similarly cliarged. The Rhone carrics its load of matter into the Lake of Geneva; the rush of the river is here arrested, the matter subsides, and the Rhone quits the lake clear and blue. The Lake of Geneva, and many other Swiss lakes, are in part filled up with this matter, and will, in all probability, finally be obliterated by it.

219. One portion of the motion of a glacier is due to this bodily sliding of the mass over its bed.

220. We have seen in our journeys over the glacier streams formed by the melting of the ice, and escaping thrusgh cracks and crobasses to the bed of the glacier. The inc matter ground lown is thus washed away; the bed is kept lubricated, and the sliding of the ice rendered more casy than it would otherwise be.

221. As a skater also you know how much ice is weakened by a thaw. Before it actually melts it becomes roiten and unsafe Test such ice with your penknife : you cils dig the blate readily ints it, or cut the ice with ease. Try good sound ice in the same way: you find it much more resistant. The one, indeed, resem'les sult chalk ; the other hard stone.

222. Now the Mer d? Crace in summer is in this thawing condlition. Its iee is rendered soft and yieldiur by the sun; its motion is thereby facilitated. We have seen that not only does the glacier slide over its bed, but that the upper layers slide over the under ones, and thit the centre slides past the sides. The softer and more yielding the ice is, the more free will be this motion, and the more readily also will it be forced throurh a defile like Trélaporte.

223. But in winter the thaw ceases; the quantity of water reaching the bed of the glacier is diminished or entirely cut off. The ice also, to a certain depth at least, is frozen hard. These considerntions would justify the opinion that in winter the glacier, if it moves at all, must move more slowly than in summer. At all events, the summer measurements give no clue to the winter motion.

224. This point merits examination. I will not, however, ask you to visit the Alps in midwinter; but, if you allow me. I will be your deputy to the mountains, and report to you faitafully the aspect of the region and the behavior of the ice.
§ 32. Winter oN the Mer de Glack.

225. The winter chosen is an inclement one. There is snow in London, snow in Paris, snow in Geneva ; snow near Chamouni so deep that the road fences are entirely effaced. Un Christmas night-nearly at mid. night-1859, your deputy reaches Chamouni.

226. The snow fell heavily on December 26 th ; but on the 23th, during a lull in the storm, we turn ont. There are with ne four good guides and a porter. They tie planks to their feet to prevent them from sinking iu the snow ; I neglect this precaution and sink often to the waist. Fuur or five times during our ascent the slope cracks with an explosive sound, and the snow threatens to come down in avalanches.

The freshly-fallen snow was in that partic. ular condition which causes its granules to adhere, and hence every flake falling on the trees had been retained there. The laden pines prescnted beautiful au:l of ten fantastic forms.

227. After five hours and a half of arduous work the Montanvert was attained. We unlocked the forsiken auberge. round which the snow was reared in buttresses. I have already spoken of the ccmplex play of crystallizing forces. The frust-figures on the window-panes of the auberge were wonderful : mimic shrubs and ferns wrought by the building power while liampered by the anlhesion between the glass and the film in which it workel. The appearance of the glacier was very inpressive; all sounds were stilled. The cascades which in summer fill the air with their music were silent, hanging from the ledges of the rocks in fluted columns of ice. The surface of the glacier was obviously higher than it had been in summer; suggesting tho thought that while the winter cold maintained the lower end of the glacier jammed hetween its boundaries, the upper portions still moved downward aud thickened the ice. The peak of the Aiguille du Dru shook out a cloud banner, the origin and nature of which have been alrealy explained (84).

228. On the morning of the 28th this banner was strikingly large and grand, and reddened by the light of the rising sun it glowed like a flame. Roses of cloud also clustered round the crests of the Grande Jorasse and hung upon the pinnacles of Charmoz. Four mon, well roped together, descended to the glacier. I had trained one of them in $185 \%$, and he was now to fix the stakes. The storm had so distributed the snow as to leive alternate lengths of the glacier bare and thickly covered. Where much snow lay, great caution was required, for hidden crevasses were underneath. The men sounded with their staffs at every step. Once while looking at the party through my telescope the lealer suddenly disappeared: the roof of a crevasse had given way beneath him: but the cther three men promptly gathered round and lifted him out of the fissure. The true line was soon picked up by the thoodo 
lite : one by one the stakes were fixed until a series of eleven of them stood across the glacier.

229. To get higher up the ralley was impracticable; the snow was too deep, and the aspect of tho weather too threatening ; so the theodolite was planted amid the pines a little way below the Montanvert, whence through a vista I could see across the glacier. The men were wrapped at intervals by whirling snow-wreaths, which quite hid them, and we had to take advantage of the lulls in the winel. Fitfully it came up the valley, darkening the air, catching the snow upon the glacier, and tossing it throughout its entire length into high and violently agitated clouds, separated from each other by cloudless spaces corresponding to the naked portions of the ice. In the midst of this turmoil the men continued to work. Bravely anil steadfastly stake after stake was set, until at length a series of ten of them was fixed across tha glacier.

230. Many of the stakes were fixed in the snow. They were four feet in length, and were driven in to a cepth of about three feet. But that night, wlile listening to the wild onset of the storm, I thought it possible that the stakes and the snow which held them might be carried bodily away before the morning. The wind, however, lulled. We rose with the dawn, but the air was thick with descending snow. It was all composed of those exquisite six-petalled flowers, or sixrayed stars, which have been already figured and deseribed (\$9). The weather brighten. ing, the theodolite was planted at the end of the first line. The men descended, and, trained by their previous experience, rapidly executed the measurements. The first line was completed before 11 A.M. $A$ gain the snow began to fall, filling all the air. Spangles innumerable were showered upon the heights. Contrary to expectation, the men could be seen and directed through the shower.

231. To reach the position occupied $\mathrm{b}_{7}$ the theodolite at the end of our second line, 1 had to wade breast-deep through snow which seemed as dry and soft as flour. The toil of the men upon the glacier in breaking through the snow was prodigious. But they did not flinch, and after a tinie the leader stood bebind the farther stake, and cried, Nous avons fini. I was surprised to licur him so disiinctly, for falling snow had been thought very deadening to sound. The work was linished, and I struck my theodolite with the feeling of a general who had won a small battle.

232. We put the house in order, packed up, and shot by glissade down the steep slopes of Ia Filia to the vault of the Arveiron. We found the river feeble, but not dried up. Many weeks must have elapscd since any water had been sent down from the suriace of the glacier. But at the setting in of winter the fissures were in a great measure charged with water; and the Arveiron of to-day was probahly due to the gradual drainage of the glacier. There was now no danger of entering the vault, for the lce seemed as firm as marble. In the cavern we were bathed by blue light. The strange beauty of the place suggested magic, and put me in mind of stories about faily caves which I had read when it boy. At the source of the Arveiron our winter visit to the Mer de Glace ends ; next morning your deputy was on his way to London.

\section{\$33. Winter MIOTION OH THE MEK DE GI.ACE.}

233 Hore are the measurements executed in the winter of 1859 :

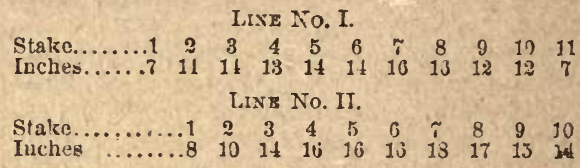

234. Thus the winter motion of the Mer de Ghace near the Montanvert is, in round numbers, half the summer motion.

235. As in summer, the eastern side of the glacier at this place mored quicker than the western.

\section{§ 31. Motion of the Gindelwhild and Aletscin Graciens.}

236. As regards the question of motion, to no other glacier lave we clevoted ourselves with such thoroughness as to the Mer de Glace; we are, however, abie to add a few measurements of other celebrated glaciers. Near the village of Grindelwald in the Bernese Oberland, there are two great icestreams called i espectively the Upper and the Lower Grindelwald glaciers, the second of which is frequently visited by travellers in the Alps. Auross it on August 6th, 1860, a series of twelve stakes was fixed by MIr. Vaughan Hawkins and myself. Mcusured on the 8 th and reduced to its daily rate, the motion of these stakes was as fullows :

MOTION OF LOWER GRINDELWALD GLACIER.

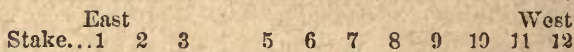
$\begin{array}{llllllllllll}\text { Inches..18 } & 19 & 20 & 21 & 21 & 21 & 22 & 20 & 19 & 18 & 17 & 14\end{array}$ 237. The theodoiite was here planted a little below the footway leading tis the higher glacier region, and at about a mile above the end of the glacier. The measurement พ£ళ rendered difficult by crevasses.

238. The ligrgest glacier in Switzerland is the Great Aletsch, to which further reference shall subsequently be made. Across it on August 14th, 1860, a series of thirty-four stakes was planted by Mr. Hawkins and me. Measured on the 16th and reduced to their daily rate, the velocities were found to be as follows :

MOTION OF GREAT ALETSCH GLACIEI. East

$\begin{array}{lllllllllllll}\text { Stake...... } & 1 & 2 & 3 & 4 & 5 & 6 & 7 & 8 & 9 & 10 & 11 & 12\end{array}$ $\begin{array}{lllllllllllll}\text { Inches...... } 2 & 3 & 4 & 6 & 8 & 11 & 13 & 14 & 16 & 17 & 17 & 1.1\end{array}$ $\begin{array}{lllllllllll}\text { Stak } \theta \ldots \ldots .13 & 14 & 15 & 16 & 17 & 13 & 19 & 20 & 21 & 23 & 23\end{array}$ $\begin{array}{lllllllllll}\text { Inches } \ldots . . .19 & 18 & 18 & 17 & 19 & 19 & 19 & 19 & 17 & 17 & 15\end{array}$ $\begin{array}{llllllllllll}\text { Stake.....21 } & 25 & 25 & 27 & 28 & 29 & 30 & 31 & 39 & 33 & 31\end{array}$

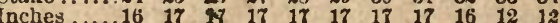

. 
251. It is difficult to believe that the for. midable fissures, among twhich you and I have so often trodiden with awe, could com. mence in this small way. Such, however, is the case. The great and gaping chasms on rnat above the ice-fail's of the Géant and the Talefre begin as narrow eracks, which open gradually to crevasses. We are thus taught in an instructive and impressive way that ap pearances suggestive of very violent action miay really be produced by processes so slow is to require refined observations to detect them. In the production of natural pheunmena two things always come into play, the intensity of the acting force, and the time during which it acts. Nake the intensity great and the time small, an I you have suctden convulsion; but precisely the same apparent effect may be produced by making the intensity small and the time great. This truth is strikingly illustrated hy the Alpine jev-falls and crevasses; and many genlogical phenomena, which at first sight suggrest violent convulsion, may be really profueed in the self-same almost imperceptibls way.

\section{\$ 37. ICICLES.}

252. The crevasses are granilest on the higher névés, where they sometimes nppear as long yawning fissures, and sometimes as chusms of irregular outline. A delicate blue light shimmers from them, but this is gra:lually lost in the darkness of their profounder portions. Over the edges of the chasms, and mostly over the southern edges, hangs a eoping ef snow, and from this depend like stalactites rows of transparent icicles, 10,20 , 80 feet long. These pendent spears constitute one of the most beantiful features of the higher crevasses.

253. How are they produced? Evidently by the thawing of the snow. But why, when once thawed, should the water freeze again to solid spears? You have seen icicles pendent from a house-eave, which have been manifestly produced by the thawing of the snow upon the roof. If we understand these we shall also understand the vaster stalactites of the Alpine crevasses.

254. Gathering up such knowlerge as we possess, and reflecting upun it paticnlly, let us found on it, if we can, a thenry of icicles

$25 \%$. First, then, you aie to know that the air of our atmosphere is lardly heated at all by the rays of the sun, whether visible or invisible. The air is highly transparent to all kinils of rays, and it is only the scanty fraction to which it is not transparent that expend their force in warming it.

256. Not so, however, with the snow on which the sunbeams fall. It absorbs the solar heat, and on a sunny day you miay see the summits of the high Alps glistening with the water of liquefaction. The air above and around the mountains may at the same time be many degrees beluw the freezing point in temperature.

257. You have only to pass from sunshine into shade to prove this. A single step suffices to carry you from a place where the thermometer stands high to one where it stands low ; the clange being due, not to any difference in the temperature of the ciir, but simply to the withdrawal of the thermometer from the direct action of the solar rays. Nay, without shifting the thermometer at all, by interposing a suitable screen, which cuts off the sun's rays, the coldness of the air may be demonstrated.

258. Look now to the snow upon your house-roof. The sun plays upon it and melts it; the wuter trickles to the eave and then drops down. If the eave face the sun the water remains water; but if the eave do not face the sun, the drop, before it quits its parent snow, is already in shadow. Now the shaded space, as we have learned, may be below the freezing temperature. If so, the drop, instead of faling, congeals, and the rudiment of an icicle is formed. Other drops and driblets succeed, which trickle over the rudiment, congeal upon it in part and thicken it at the root. But a portion of the water reaches the free end of the icicle, hangs from it, and is there congealed before it escapes. The icicle is thus lengthened. In the Alps, where the liquefaction is copious and the cold of the shaded crevasse intense, the icicles, though produced in the same wily, naturally grow to a greater size. The drainage of the snow after the sun's power is withdrawn also produces icicles.

259. It is interesting and important that you should be able to explain the formation of an icicle; but it is far more important that you should realize the way in which the various threads of what we call Nature are woven together. You cannot fully understand an icicle without first knowing that solar beams powerful enough to fuse the snows and blister the human skin, nay, it might be added, powerful enough, when concentrated, to burn up the human body itself, may pass through the air and still leave it at an icy temperature.

\section{§ 38. The Bergaschrund.}

260. Having cleared away this difficulty, let us turn once more to the crevasses, taking them in the order of their formation. First then above the névé we have the final Alpine peaks and erests, against which the snow is often reared as a steep buttress. We have alrearly learned that both névés and glaciers are moving slowly downward; but it usually happens that the attachment of the highest portion of the luuttress to the rocks is great enough to enable it to hold on while the lower portion breaks away. A very characteristic crevasse is thus formed, called in the German-speaking portion of the Alps a Bergschrund. It often suriounds a peak like a fosse, as if to defend it against the assaults of climbers.

261. Look more closely into its formation. Imagine the snow as yet unbroken. Its higher portions cling to the rocks and move downward with extreme siowness. But its lower portions, whether from their greatel depih and weight or their less perfect at 
tacnment, are compeiled to move more quickty. A pull is therefore exerted, tending to separate the lower from the upper suow. For a time this pull is resisted $b_{y}^{-}$the cohesion of the névé; but this at length gives way, and a crack is formed exactly across the line in which the pull is exerted. In other words, a crevesse is formed at right angles to the line of tension.

\section{\$ 39. Transverse Crevasses.}

262. Both on the névé and on the glacier the origin of the crevasses is the same. Through some eause or other, the ice is thrown into as state of strain, and as it can. not stretch it breaks across the line of tension. Take, for example, the ice-fall of the Geant, or of the Talefre, above which you lnow the crevasses yawn terribly. Imagine the névé and the glacier entirely peele!! away, s) as to expose the surface over which they move. From the Col du Géant we should see this surface falling gently to the place now nccupierl by the brow of the cascade. Ilere the surface would fall steeply down to the bed of the present rilacier du Geant, whera the slope would become gentle once mure.

263. Think of the névé moving over such a surface. It descends from the Col till it reaches the brow just referred to. It crosses the brow, and must bend down to keep upon its beci. Realize clearly what must occur. The surface of the nere is evidently thrown - ato a state of strain : it breaks and forms a revisse. Each fresi portion of the névé as it passes the brow is similarly broken, and this a succession of crevasses is sent down the fall. Between every two chasnis is a great transverse ridge. Through local strains ipon the fall those ridges are also frequently broken across, towers of ice-seracs-being the result. Down the fall both ridges and séracs are borne, the dislocation being augmented during the descent.

261. What must occur at the foot of the fall? Here the slope suddenly lessens in steepness. It is plain that the crepasses must not only cease to open here, but that they must in whole or in part close up. At the summit of the fall. the bending was such as to make the surface convex ; at the hot tom of the fall, the bending renders the surface concave. In the one cise we hatve strain, in the other pressure. In the one case, therefore, we have the opening, and in the other the closing of crevasses. This reasuning corresponds exactly with the facts of observation.

265. Lay hare your arm end stretch it straight. Make two ink dots half an inch or an inch apart, exactly opposite the elbow. Bend your arm, the dots approach each other, and are finally brought together. Let the two dots represant the two sides of a crevasse at the bottom of an ice-fall; the bending of the arm rescmbles the bendling of the ice, and the closing up of the dots resembles the closing of the fissures.

266. The same remarks apply to various dortions of the Mer de Glace. At certain places the inclination changes from a gentler to a stceper slope, and on crossing the brow between both the gracier breaks its back. Transver:se crevasses are thus formed. There fis such a change of inclination opposite to the Angle, and a still greater but similar change at the head of the Glacier des Bois. The consequence is that the Mer de Glace at the former point is impassable, and at the latter the rending and dislosation are such as we have seen and descritued. Below the Angle, and at the bottom of the Glarier des Bois, tric steepuess relaxes, the crevasses heal up, anil the glacier vecomes once more contiuu. ous and compact.

\section{\$ 40. Marginal Crevasses.}

267. Supposing, then, that we had ro changes of inclination, should we have no crevasses? We should certainly have less of them, but they would not wholly disappear. For other circumstances exist to throw the ice into a state of strain. and to determine its fracture. The principal of these is the more rapid movement of the centre of the glacier.

268. Helped by the labors of an eminent man, now dead, the late Mr. W $\mathrm{m}$. Hopkins, of Cambridge, let us master the explanation of this point together. But the pleasure of mastering it would be enhanced if we could see beforehand the perplexing and delusive appearances accounted for by the explanation. Courd my wishes be followed out, I would at this point of our researches carry you uff with me to Basel, thence to Thun, thence to Interlaken, thence to Grindelwald, where you would find yourself in the actua? presence of the Wetteihorn and the Eiger, with all the greatest peaks of the Bernese Oberland, the Finsteraal horn, the Schreck, horn, the Monch, the Jungfrau, at hand. At Grindelwald, as we have already learned, there are two well-known glaciers-the Ober Grindelwald and the Unter Grindel walc glaciers-on th. latter of which our observa. tions should coinmence.

269. Dropping down from the village to the bottom of the valley, we should breast the opposite nountain, and with the great limestone precipices of the Wetterhorn to our left, we should get upon a path which commands a view of the glacier. Here wc should see beautiful examples of the opening of crevasses at the summit of a brow, and their closing at the bottom. But the chief point of interest wouid be the crevasses formed at the side of this glacier-the marginal crevasses, as they may be called.

270. We should find the sude copiously fissured, even at those places where the centre is compact ; and we should particularly notice that the fissures wonld neither run in the cirrection of the glacier nor straight across it, but that they would be oblique to it, inclosing an angle of about 45 degrees with the sides. Starting from the side of the glacier the crevasses would be seen to point upwoard; that is to say, the ends of the fissures abutting against the bounding mountain would apiear to be dregged dowon. Were 


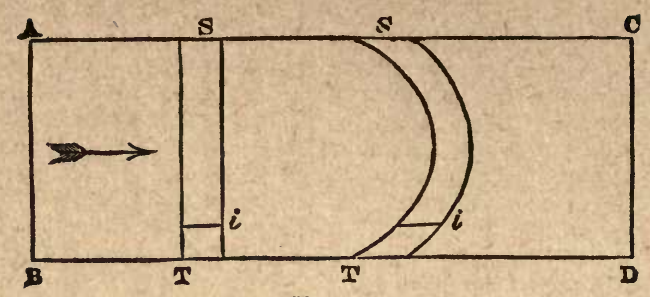

Fig. 7 .

'you less instructed than you now are, I might lay $n$ wager that the aspect of these fissures would cause you to conclude that the centre of the glacier is left behind by the quicker motion of the sides.

271. This indeed was the conclusion drawn by M. Agassiz from this very appearance, before he had measured the motion of the sides and centre of the glacier of the Unteraar. Intimately versed with the treatment of mechanical problems, Mr. Hopkins immediately deduced the obiiquity of the lateral crevasses from the quicker tlow of the centre. Standing beside the glacier with pencil and note-book in hand, I would at once make the matter clear to you thus.

272. Let $\mathrm{A} \mathrm{C}$, in the annexed figure, he one side of the glacier, and $13 \mathrm{D}$ the other; and let the direction of motion be that indicated by the arrow. Let s $\mathrm{T}$ be a transverse slice of the glacier, taken straight atross it, say today. I few days or weeks hence llis slice will have heen carried down, and bec'ause the centre moves more quickly than the sides it will not remain straight, but will bend into the form $\mathrm{s}^{\prime} \mathrm{T}^{\prime}$.

2\%3. Supposing $\mathrm{T} i$ to be a small square of the original slice near the side of the glacier. In its new position the square will be distorted to the lozenge-shaped figure $T^{\prime} i^{\prime}$. Fix your attention upon the diagonal $\mathrm{T} i$ of the Equare : in the lower position this diagonal, if the ice could stretch, would be lengthened to $T^{\prime} i^{\prime}$. But the ice does not stretch; it loreaks, and we have a crevasse formed at right angles to $T^{\prime} i$. The mere inspection of the diagram will assure you that the crevasse will point obliquely uproard.

274. Along the whole side of the glacier the quicizer movement of the centre produces a simiar state of strain; and the consequence is that the sides are copiously cut by those oblique crevasses, even at places where the centre is free from them.

275 . It is curious to see at other places the transverse fissures of the centre uniting with those at the sides, so as to form great curved crevasses which stretch across the glacier irom side to side. The convexity of the curve is lurned umoard, as mechanical principles declare it ought to be. But if you were ignorant of those principles, you would never infer from the aspect of these curves the quicker motion of the centre. In !andslips, and in the motion of partialy ludurated mud, you may sometimes notice appear. ances similar to those exhibited by the ice.

\section{$\S$ 41. Longrtedinal C'revasses}

276. We inave thus unravelled the origin of both transverse and marginai creva-ses. But where a glacier issues fiom a steep and narrow defile upon a comparatively level plain which allows it room to expand laterally, its motion is in part arrested, and the level portion has to bear the thrust of the steeper portions behind. Here the line of thrust is in the direction of the glacier, while the direction at right angles to this is one of tension. Across this latter the glacier breaks, and lengitudinal crevasses are formeri.

27. Examples of this kind of erevisse are furnished by the lower patt of the Glacier of the Rhone, when looked down upon from the Giimsel Pass, or from any cornmanding point on the flanking mountains.

\section{§ 42. Crevasses in relation to Curva- TURE OF GLACIER.}

278. One point in addition remains to bo discussed, and your present knowledge will enable you to master it in a moment. You remember at an early period of our researches that we crossed the Mer de Glace from the Chapeau side to the Montanvert side. I then desired you to notice that the Chapeau sido of the glacier was more fissured than either the centre or the Montanvert side (75). Why should this be so? Knowing as we now do that the Chapeau side of the glacier moves more quickly than the other, that the point of maximum motion does not lie on the centre but far east of it, we are prepared to auswer this question in a pelfectly satisfictory manner.

279. Let $\mathrm{A} B$ and $\mathrm{C} D$, in the following diagram, represent the two curred sides of the Mer de Glace at the Montanvert, and let $m e n$ be a straight line across the glacier. Let $o$ be the point of maximum motion. The mechanical state of the two sides of the glacier may be thus made plain. Supposing the line $m n$ to be a straight elastic string with its ends fixed; let it be grasped firmly at the point $o$ by the finger and thumb, and drawn to $o^{\prime}$, keeping the distance between $o^{\prime}$ and the side $\mathrm{C} D$ constant. Here the length, $n o$ of the string wonld have stretched to $n v^{\prime}$, and the length $m o$ to $m o^{\prime}$, and you see plainiy that the stretching of the sloort line, in comparison with its length, is greater than that of the long line in comparison with its length. 


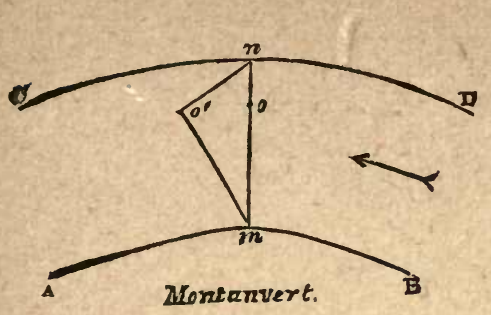

Fig. 8.

In other words, the strain upon $n o^{\prime}$ is greater than that upon in $o^{\prime}$; so that if one of them were to break under the strain, it would be the short one.

280 . These two lines represent the conditions of strain upon the two sides of the glacier. The sides are held back, and the centre tries to move on, a strain being thus set up between the centre and sides. But the rlisplacement of the point of naximum motion through the curvature of the valley makes the strain upon the eastern ice greater than that upon the western. The eastern s.ice of the glacier is therefore more crevassed than the western.

281. Here indeed resides the difficulty of getting along the rastern side of the Mer de Glace : a diffienity which was one reason for our crossing the glacier opposite to the Montanvert. There are two convex sweeps on the eastern side to one on the western side, hence on the whole the eastern side of the Ier de Glace is most riven.

\section{$\S$ 43. Moraine-ridges, Glacier Tables, AND SAND Cones.}

282. When you and I first crossed the Mer de Glace from Trelaporte to the Couvercle, we found that the stripes of rocks and rubbish which constituted the medial moraines were ridges raised above the general level of the glacier to a height at sume places of twenty or thirty feet. On examining these ridges we found the rubbish to be superficial, and that it rested upon a great spine of ice which ran alung the back of the glacier. By what means has this ridge of ice been raised? 283. Most boys have read the story of Dr. Franklin's placing lits of cloth of various colors unon snow on a sunny day. The bits of cloth sank in the snow, the dark one irost.

284. Consider this exporiment. The sun's rays first of all fall upon the upper surface of the cloth and warm it. Tine neat is then conducted through the cloth to the under surface, and the under surface passes it on to the snow, which is fina!ly liquetied by the heat. It is quite manifest that the quantity of snow melted will altogether depend upon the amount of heat sent from the upper to the under surface of the cloth.

235. Now cloth is what is called a bad conductor. It does not permit heat to travel f:eely through it. $\quad$ b... where it has merely to pass through the thickness of a single bit of cloth, a good quantity of the heat gets through. But if you double or treble or quintuple the thickness of the cloth; or, what is easier, if you put several pieces one upon the other, you come at length to a point where no sensible amount of heat could get through from the upper to the under surface.

286. What must occur if such a thick piece, or such a series of pieces of cloth, were placed upon snow on which a strung sun is falling? The snow round the cloth is melted, but that underneath the cloth is protected. If the action continue long enough the inevitable result will be that the level of the snow all round the cloth will sink, and the cloth will be left behind perched upon an eminence of snow.

287. If you understand this, you have already mastered the cause of the moraineridges. They are not produced by any swelling of the ice upward. But the ice underneath the rocks aud rubbish being protected from the sun, the glacier right and left melts away and leaves a ridge behind.

288. Various other appearances upon the glacier are accuunter for in the same way. Here upon the Mer de Glace we have flat slabs of rock sometimes lifted up on pillars of ice. These are the so-called Glacier Ticbles. They are produced, not by the growth of a stalk of ice out of the glacier, but by the melting of the glacier all round the ice protected by the stone. Here is a sketch of one of the Tables of the Mer de G'ace.

289. Notice moreover that a glacier table is hardly ever set square upon its pillar. It generally leans to one side, and repeated chservation teaches you that it so leans as to enable you always to draw the north and south line upon the glacier. For the sun being soutl of the zenith at noon pours its rays against the southern end of the table, while the northern end remains in shadow. The southern end, therefore, being most warmerl does not protect the ice underneath it so ef fectually as the northern end. The tahle becomes inclined, and ends by s'iding bodi!y off its pedestal.

290. In the figure opposite we have what may be called an ideal table. The oblique lines represent the direction of the sunbeams, and the consequent tilting of the table here shown resembles that observed upon tha glaciers.

291. A pebble will not rise thus: like Franklin's single bit of cloth, a dark-colored pebble sinks in the ice. A spot of bluck inould will not rest upon the surface, but will sink; and various parts of the Glacier du Géant are honcycombed by the sirking of such spots of dirt into the ice.

292. But when the dirt is of a thickness sufficient to protect the ice the case is different. Sand is often washed a way by a stream from the mountains, or from the moraines, and strewn over certain spaces of the glacier. A most curious action tollows the sanded surface rises, the part on which the sand lies thickest rising highest. Little peaks and eminences jut forth, and when the distribu 


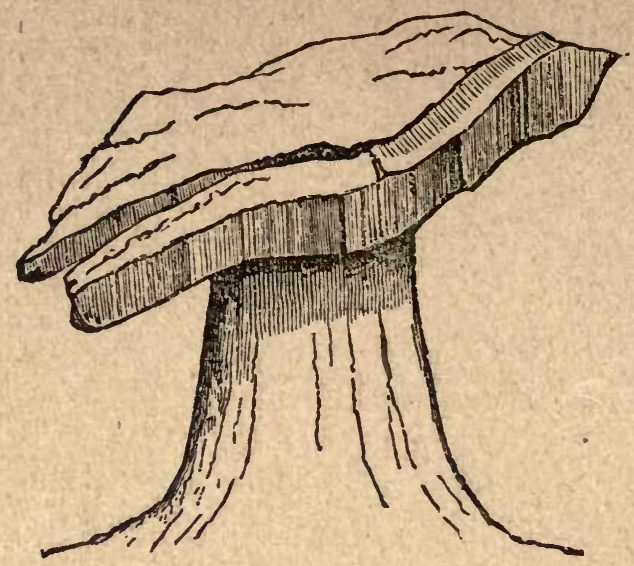

FIG. 9.

tion of the sand is faverable, and the acticn sufticiently prolonged, you have little moun. tains formed, sometimes singly, and sometimes grouped so as to mimic the Alps themselves. The Sand Cones of the Mer de Glace are not striking; but on the Görner, the Aletsch, the Norteratsch, and other glaciets, they form singly and in groups, reaching sometimes a height of ten or twenty feet.

\section{\$44. The Glacier Mills or Moulins.}

29:3 You and I have learned by long ex perience the chatracter of the Mer de Glace. We have marched over it daily, with a definite object in view, but we have not closed our eyes to r.ther objerts. It is from side giimpses of things which are uot at the mo inent occupving our attention that fresh subjects of inquiry arise in scientific investiga. iion.

294. Thus in marching over the ice near Trelaporte we were often struck by a sound resembling low rumbling thunder. Wo subsequenily sought out the origin of this sound, and found it.

29). A large area of this portion of the glacier is unbroken. Driblets of water have room to form rills, rills to unite and form streams, streams to combine to form rush. ing lirooks, which sometimes cut deep channels in the ice. Sooner or later these streams reach a strained portion of the glacier, where a crack is formed across the stream. A way is thus opened for the water to the bottom of the glacier. By long action the stream lobllows out a shaft, the crack thus becoming the starting-point of a funnel of unseen nepth, into which the water leaps with the so: $n$ nd of thunder.

296. This funnel and its cataract form \& giacier Mill or Moulin.

297. Let me grasp your hand firmly while you stand upon the edge of this shaft and look into it. The hole, with its pure blue himmer, is beautiful, but it is terrible. In-

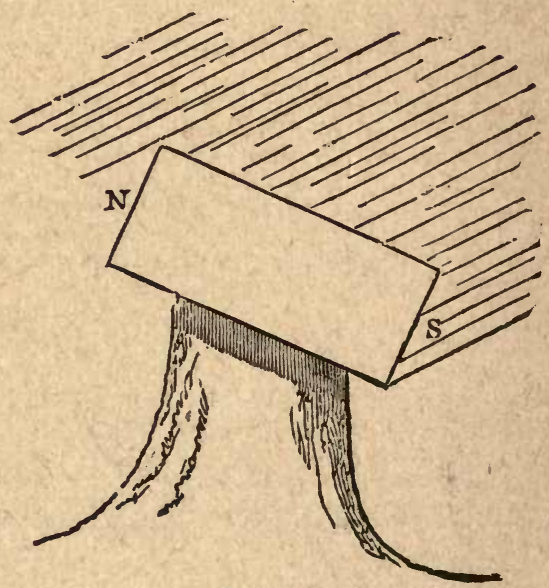

Fita. 10.

cautious persons lave fallen into these shafis, a second or two of bewilderment being followed ly suciden death. But caution upon the glaciers and inountains ought, hy habit, to be made a second nature to explor. ers iike you and me.

298. The crack into which the stream frst descended to form the moulin, moves down with the glacier. A succeeding portion of the ice reaches the place where the breaking strain is exerted. A new crack is theu formed above the moulin, which is thence. forth forsaken by the stream, and moves downward as an empty shaft. Here upon the Mer de Glace, in advance of the Grand Moulin we see no less than six of these forsaken holes. Some of them we sound to a depth of 90 feet.

299. But you and I both wish to determine, if possible, the entire depth of the Her de Glace. The Grand Moulin offers a chance of doing this which we must not neglect. 
Our trrst effort to sound the moulin fails Grough the breaking of our cord by the impetuous plinge of the water. A lump of grease in the hollow of a weight enables a mariner to judge of a sea bottom. We employ such a weig!ht, but canuot reach the bed of the giac er. A depth of 163 feet is the utmost riahed by our plummet.

300. From July 28th to August 8th we have watched the progress of the Grand Moulin. On the former date the pusition of the moulin was fixed. On the 31 st it had moved down 50 inches; a little more than a day afterward it had moved 74 inches. On August 8 th it had moved 193 inches, which gives an average of about 18 inches in iwenty-four hours. No doubt next summer upon the Mer de Glace a Grand Moulin wilt be found thuudering near. Trélaporte; but like the crevasse of the Grand Plateau, already referred to $(s 16)$, it will not be our moulin. This, or rather the ice which it penetrated, is now probably more than a mile lower down than it was in 1857 .

\section{$\$ 45$. The Crranges of Volume of Waten BY Heat aNd Cold.}

301. We have noticed upon the glacier shafts and pits filled with water of the most delicite blue. In some cases these have been the shafts of extinct moulins clused at the bottom. A theory has been advanced to ac. count for them, which, though it may be untenable, opens out considerations regarding the properties of water that ought to be faniliar to inquirers like you and me.

302. In our dissection of lake ice by a beam of heat (\$11) we noticed little vacuous spots at the centres of the liquid flowers formed by the beam. These spots we referred to the fact that when ice is melted the water produced is less in volume than the ice, and that hence the water of the flower was nut able to occupy the whole space covered by the flower.

303. Let us more fully illustrate this subject. Stop a small flask water-tight with a cork, and through the cork introduce a narrow glass tube also water-tight. It is easy to fill the flask with water so that the liquid shall stand at a certain height in the glass tube.

304. Let us now warm the flask with the flame of a spirit-lamp. On first applying the tlame you notice a momentary sinking of the liquid in the glass tube. This is due to the mumentary expansion of the flask by heat; it becomes suddenly larger when the tlame is tirst applied.

305. But the expansion of the water soon overtakes that of the flask and surpasses it. We immediately seo the rise of the liquid column in the glass tube, exactly as mercury rises in the tube of a waimed thermometer.

306. Our glass tube is ten inches long, and at starting the water stood in it at a height of five inches. We will apply the spirit-lamp flame until the water rises quite to the top of the tube and trickles over. This experiment suftices to show the expansion of the water y heat.

307. We now take a common finger-glass and put into it a little pounded ice und salt. On this we place the tlask, and then lovild round it the freezing mixture. The liquid column retrents down the tube, proving the contraction of the liquid by cold. We allow the shrinking to contınue for some minutes, noticing that the downward retreat of the liquid becomes gradually slower, and that it finally censes altogether.

308. Keep your eye upon the liquid col. umn ; it remains quiescent for a fraction of a minute, and then moves once more. But its motion is now uprcard instead of downward. The freceing mixture now acts exactly ine the flanne.

309. It would not be difficult to pass a thermometer through the cork into the flask, and it would tell us the exact temperinture at which the liquid ceased 10 coutract and began to expand. At that momeat we should tind the temperatuic of the liquid a shade over $39^{\circ}$ Fahr.

310. At this temperature, then, water attains its maximum clensity.

311. Seven degrees below this temperature, or at $32^{\circ}$ Falir., the liquid begins to turn into solid crystals of ice, which you know swims upon water because it is bulkier for a given weight. In fact, this halt of the appr $2 \mathrm{sh}$ ing inolecules at the temperature of $39^{\circ}$, is but the preparation for the subsequent act of crystallization, in which the expansion by cold culminates. Up to the point of solidifi. cation the increase of volume is slow and gradual ; while in the act of solidification it is sudden, and of overwhelming strength.

312. By this force of expansiun the Florentine Academicians long ago burst a sphero of copper nearly three quaiters of an inch in thickness. By the same force the celebrated astronomer Huyghens burst in 1667 iron can. nons a finger breadth thick. Such expen. ments have been frequently made since. Major Williams during a severe Quebec winter filled a mortar with water, and closed it by driving into its muzzle a plug of wooul. Exposed to a temperature $50^{\circ}$ Fahr. below the freezing point of water, the inetal resist. ed the strain, but the plug gave way, boing projected to a distance of 400 feet. At Warsaw howitzer shells bave been thus ex. ploded ; and you and I have shivered thick bomb-shells to fragments by placing them for half an hour in a freezing m:xture.

313. The theory of the shafts and pits re. ferred to at the beginning of this section is this : The water at the surface of the shaft is warmesl by the sun, say to a temperature of $39^{\circ}$ Fahr. The water at the lottom, in contact with the ice, must be at $32^{\circ}$ or near it. The heavier water is therefore at the top; it wiil descend to the bottom, melt the ice there, and thus deepen the shaft.

314. The circulation here referred to undoubtedly goes on, and some curious effects are clue to it; but not, I think, the one here ascribed to it. 'The deepening of a shaft implies a quicker melting of its bottom than of 
the surtace of the glacier. It is not easy to see how the fact of the solar heat being first absorbed by water, and then conreyed by it to the bottum of the shaft, should make the melting of the bottom more rapid than that of the ice which receives the direct impact of the solar rays. The surface of the glacier nust sink at least as rapidly as the botiom of the pit, so that the circulation, though actually cxisting, cannot produce the effect ascribed to it.

\section{\$46. Consequences flowing from ture} Folzegoina Propeirties OF Watkr. Colrection of Errons.

315. I was not much above your age when the property of water ceasing to contract by cold at a temperature of $29^{\circ}$ Falir. was made known to me, and I still remeniber the impression it made upon me. For I was asked to consider what would occur in case this solitary exception to an otherwise universal law ceased to exist.

316. I was asked to reflect upon the condition of a lake stured with fish and offering its surface to very cold air. It was made clear to me that the water on being first chilled would shrink in volume and become heavit:, that it would therefore sink and have its p'ace supplied hy the warmer and lighter water fiom the deeper portions of the lake.

317. It was pointed out to me that without the law referred to this process of circulation would go on until the whole water of lie lake had been lowered to the freezing temperanile. Congelation would then begin, and would continue as long as any waller remained to be stilidified. One consequence of this would be to destioy every living thing contained in the lake. Other calamities were added, all of which were said to be prevented by the perfectly exceptional arrangement. that after a certain time the coider water becomes the lighter, floats on the surface of the lake, is there congealed, thus throwing a protecting roof over the life below.

318. Count Rumford, one of the most solid of scientitic men, writes in the following strain ahout this question: "Il does uot appear to me that there is anything which human sagacity can fathom, withm the wide-extenderl bounds of the visible creation, which uffords a more striking or more palpable proof of the wisclom of the Creator, and of the special care He has taken, in the general arrangement of the uvivelse, to preserve animal hife, than this wonderful contrivance.

319. "Let me beg the attention of my readers while $I$ endearor to investigate this most interesting subject : and let me at the fume time bespeak his candor and indulgence. I feel the danger to which a mostal cxposer himself who has the temerity to ex. plitin the designs of Infinite Wistum. The enterprise is adventusous, vat it surcly cannot lie improper.

:20. "Had not Providence interfered ca bhis occasion in a manner which may well be considered as miaculous, all the fresh water within the polar circle must inevitably lave been frozen to a very great depth in winter, and every plant and tree tlestroyed."

321. Through many pages of his book Count Rumford continues in this strain to expound the rays and intentions of the Al. mighty, and he does not hesitate to apply very harsh words 10 those who canuot share his noticns. He calls them lardened and degraded. We are here warned of the fact, which is too often forgotten, that the pieasure or comfort of a belief, or the warmth or exaltation of feeling which it produces, is no guarantee of its truth. For the whole of Count Rumford's delight and enthusiasm in connection with this subject, and the whole of his ire against those who dia not share his opinions, were founded upon an erroneous notion.

622. Water is not a solitary exception to an otherwise general law. There are other moleculc's than those of this licquid which require more room in tlie solicl ciystalline condition than in the adjacent mollen condition. Iron is a case in ponut. Solid iron thuts upon molten iron exactly as ice tloats upou water. Bismuth is a still more impressive case, and we could shiver a bomb as certainly by the solidification of bismuth as by that of water. There is no fish to lie taken care of here, still the "contrivance" is the same.

32:3. I am reluctant to mention them in the same breath with Count liumlotd, but I am told that in our own rlay these are people who prof 'ss to find the conforts of a religion in a superstition lower than any that, has hitherto legraded the civilized human mind. So that the happiness of a fiath and the truth of a failh are two tolaily different things.

324 . Life and the conditions of life are in necessary liamony. This is a truism, for without the sumable conditions life could not exist. But both life and its conditions set forth the operutions of inscrutsible Power. We know not its origin; we know not its eud. And the presumption, if not the derradation, rests with those who place upon the throne of the universe a magnitied image of themselves, and make its doings a mere colossal imitation of their own.

\section{§47. The Moleculan Mechanism of WATER-CONGELATION.}

325. But let us return to our science. IIow are we to picture this act of expansion on the part of freezing water? By what operation do the mulecules demand with such irresistible emphasis more room in the solit than in the adjacent liquid condition? In all cases of this kind we must dlerive our con. ceptinns from the world of the senses, and transfer them afterward to a world transcending the range of the senses.

326. You have not forgotten our conversation regarding "atomic poles" (\$10), and how the not:on of polar force came to be apflied to crys:als. With this fresh in your memory, you will have no great difficulty 
In understanding how expansion of volume may accompany the act of crystallization.

327. I place a number of magnets before you. They, as matter, are affected by gravity, and, if perfectly free, they would move toward each other in obedience to the attraction of gravity.

328. But they are not only matter, but maynetic matter. They not only act upon each other by the simpie force of gravity, but by the polar force of magnetism. Im. agine them piaced at a distance from each other, and perfectly free to move. Gravity first makes itsclf felt and draws them togrether. For a time the magnetic force issuing from the poles is insensible; but when a certain nearness is attainerl, the polar force comes into play. The mutually attracting points close un, the mutually repellent points retreat, and it is easy to see that this action may produce an arrangement of the magnets which requires more room. Suppose them surrounded by a box which exactly incloses them at the moment the polar force first comes into play. It is easy to see that in arranging themselves subsequently the repelled corners anil ends of the magnets may bo caused to nress against the ciles of the box, and even to burst it, if the forces be suffciently strong.

329. Here then we have a conception which may be applied to the molecules of water. They, like the maguets, ars acted upnn hy two clistinct forces. For a time, while this

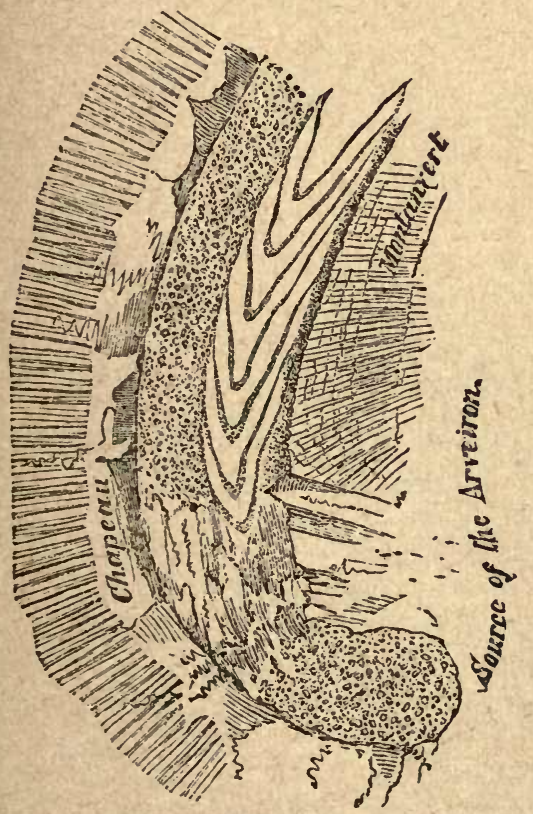

Fia. 11.

Itquid is being cooleil they approach earb other, in obedience to their general attraction for each other. But at a certai i point new iarces, some attractive, some repuisive, ena. nating from seccial points of t'le mrlecules, come into plav. The attracted points close up, the repelled points retreat. Thus the molecules turn and rearrange themselves. demanding, as they do so, more space, and overcoming all ordinary resistance by the energy of their demand. This, in general terms, is an explanation of the expansinn of water in soliaifying: it would be easy to construct an apparatus for its illustration.

\section{§ 48. The Dirt Bands of tme Mer DE GLACE.}

330. Pass from bright sunshine into a moderately lighted room; for a time all appcars so dark that the objects in the room aro not to be clearly distinguisbed. Hit violently by the waves of light (\$3) the uptic nerve is numbed, and requires time to recover its sensitiveuess.

331. It is for this reason that I choose the present hour for a special observation on the Mer de Glace. The sun has sunk behind the ridge of Charmoz, and the surface of the glacier is in sober shade. The main portion of our day's work is finished, but we have still sufficient energy to climb the slopes adjacent to the Montanvert to a height of a thousand feet or thereabout above the icc.

232. We now look fairly down upon the placier, and see it less foreshortened than from the Montanvert. We notice the dirt overspreading its eastern side, due to the crowling together of its medial moraines. iTe see the comparatively clean surface of the Glacier du Géunt ; but we notice upon this surface an apjearance which we have not hitherto seen. It is crossed by a series of gray bent bands, which follow each other in succession, from Tréiaporte downward. IVe count eighteen of these from our present position. (See sketch, Fig. 12.)

2ir3. These are the Dirt Bunds of the Mircr ie Glace; they were first obsarved by Professor Forlocs in 1812.

334. They cxtend down the glacior further than we can sec: and if we cross the vallcy of Chamouni, anil climb the mountains at the opposite side, to a point near the little auberge, called La Flégère, we shall command a view of the end of the glacicr and observe the completion of the series of kands. We notice that they are confined throughout to the portion of the glacier dirived from the Col du Géant. (See sketeh, Fig. 11.)

335. We must trace them to their source. You know how noble anil camplete a viow is ohtained of the glacier and Col de Grist from the Cleft Stalion alove Tréliporte. Thither we must once more clinh : and thence we can see the suceession of hanlis stretching downward to the MIonlanvert, and upward to the base of the ice-cusciule upon the Glacier du Géant. The cascaude is evidently concerned in their formation. (See sketch, Fig. 13.)

336. And how ? Simply enough. The glacier, as we know, is broken trunsversely it the summit of the ice-fall, and duscends the de- 

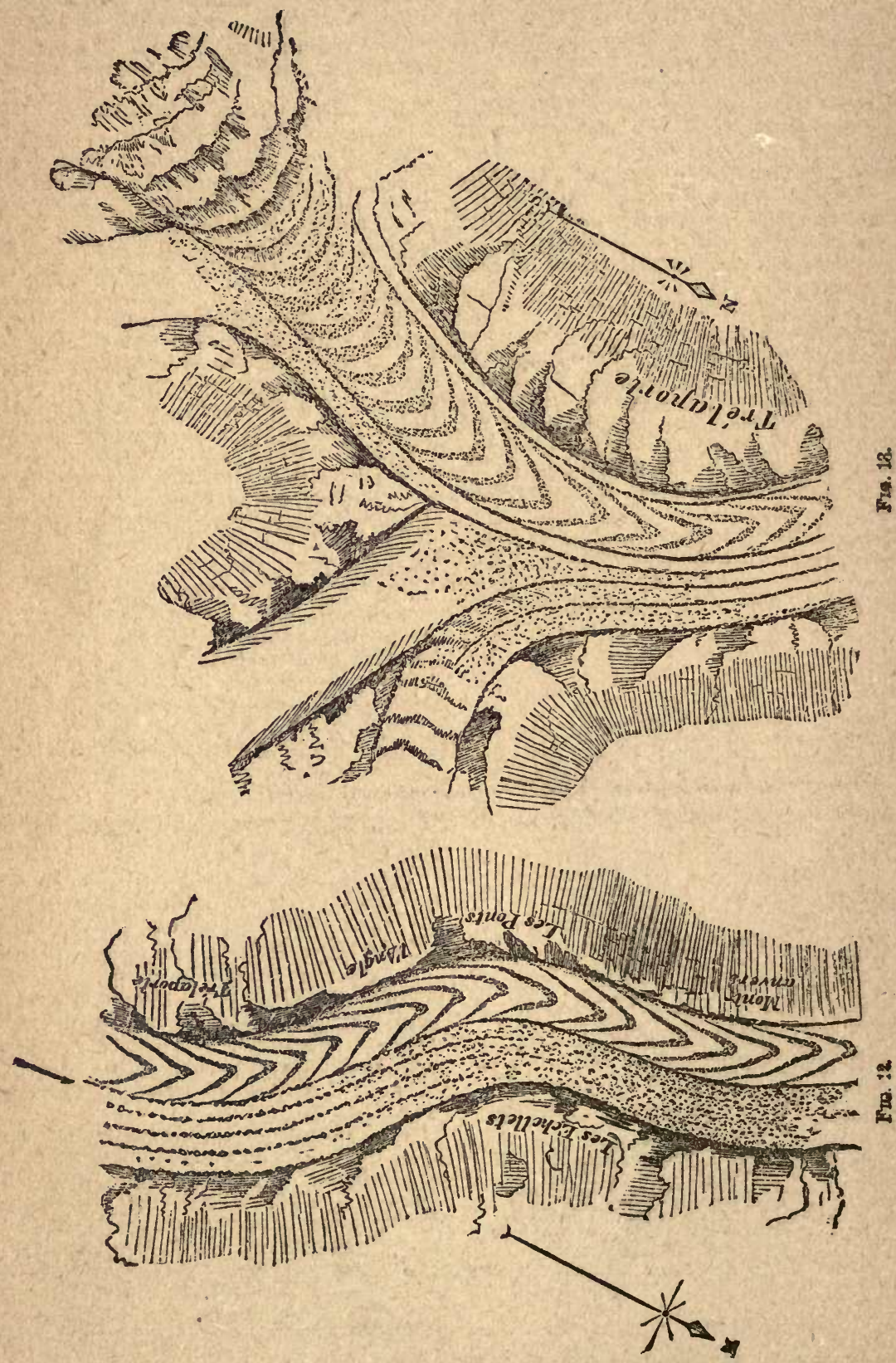
clivity in a series of great transverse ridges. At the base of the fall, the chasms are closed, but the ridges in part remain, forming nrotuherances, which run like vast wrinkles across the glacier. These protuberances are more and more bent because of the quicker motion of the centre, and the depressions be. tween them form receptacles for the fine mud anci débris washed by the little rills from the adjacent slopes.

337. The protuberances sink gradually through the wasting action of the sun. so that long before Trelaporte is reached they have wholly disappeared. Not so the dirt of which they were the collectors : it continues to occupy, in transverse bands, the flat surface of the glacier. At Trélaporte, moreover, where the valley becomes narrow, the bands are much sharpened, obtaining there the character which they afterwaid preserve throughout the Mer de Glace. Other glaciers with cascades also exhibit similar banuls.

\section{§49. SeA ICE ANd ICEdergs.}

338. We are now equipped intellectually for a campaign into another territory. Water becomes heavier and more difficult to freeze when salt is dissolved in it. Sea water is therefore heavier than fresh, and the Greenland Ocean requires to freeze it a temperature $3 \frac{1}{2}$ degrees lower than fresh water. When concentrated till its specific gravity reaches 1.1045 , sea water requires for its congelation a temperature $18 \frac{1}{8}$ degrees lower than the ordinary freezing-point.

339. But even when the water is saturated with salt, the crystallizing force studiously rejects the salt, and devotes itself to the congelation of the water alone. Hence the ice of sea water, when multed, produces fresh water. The only saline particles existing in such ice are those entangled mechanically in its pores. They have no part or lot in the structure of the crystal.

340. This exclusiveness, if I may us? the term, of the water molecules; this entire rejection of all foreign elements from the edifices which they build, is enforced to a surprising degree. Sulphuric acid has so strong an affinity for water that it is nne of the most powerful agents known to the chemist for the removal of luumidity from air. Still, as shown by Faraday, when a mixture of sulphuric acid and water is frozen, the crystal formed is perfectly sweet and free from acidity. The water alone has lent itself to the crystallizing force.

341. Etery winter in the Arctic regions the sea freezes, roofing itself with ice of enormous thickness and vast cxtent. By the summer lieat, and the tossing of the waves, this is broken up; the fragments are drifted by winds and borne by currents. They clash, they crush each other, they pile themselves into heaps, thus constituting the chief danger encountered by mariners in the polar seas.

342. But among the drifting masses of flat sea-ice, vaster masses sail, which spring from wotalls different source These are the Ico- bergs of the Arctic seas. They rise some. times to an elevation of hundreds of feet above the water, while the weight of ice sub. merged is ahout seven times that seen above.

343. The first observers of striking natural phenomena generally allow wonder and im. agination more than their due place. But tn exclude all error arising from this cause, I will refer to the journal of a conl and intrepid Arctic navigator, Sir Leopolr MeClintock. He describes an iceberg $2 ; 0$ feet high, which was aground in 500 fect of water. This would make the entire height of the berg 750 feet, not an unusual altitude for the greater icebergs.

344. From Baffin's Bay these mighty masses come sailiug down through Davis' Straits into the broad Atlantic. A vast amount of heat is demanded for the simple liquefaction of ice $(\$ 48)$; and the melting of icebergs is on this account so slow, that when large they sometimes maintain themselves till they have been drifted 2000 miles from their place of birth.

345. What is their origin? The Arctic. glaciers. From the mountains in the interior the indurater snows slide into the valleys and fill them with ice. The glaciers thus formed move like the Swiss ones, incessantly downward. But the Arctic glaciers reach the sea, enter it, often ploughing up its bottom into submarine moraines. Undermined by the lapping of the waves, and unable to resist the strain imposed by their own weight, they break across, and discharge vast masses into the ocean. Some of these run aground on the adjacent shores, and often maintain themselves for years. Others escape southward, to be finally dissolved in the warm waters of the Atlantic. The first engraving on this page is copied from a photograph taken by Mr. Bradford during a recent ex. pedition to the Northern seas. The second represents a mass of ice upon the Glacier des Bossons. Their likeness suggests their common origin.

\section{§50. The Aiggrschironn, the Margeliy SEe AND ITS ICEBERgs. \\ 346. I am. however, unwilling that you} should quit Switzerland without seeing such icebergs as it can show, and indeed there are other still nobler glaciers tian the Mer de Glace with which you ought to be acquainted. In tracing the Rhone to its source, you have already ascended the valley of the Rhone. Let us visit it again together; halt at the little town of Viesch, and go from it straight up to the excellent hostelry on the slope of the Eggischliorn. This we shall make our headquarters while we exploro that monarch of European ice-streams-the great Aletsch glacier.

347. Including the longest of its branches, this noble ice-river is ahout twenty miles long, while at the middle of its trunk it measures nearly a mile and a quarter from sido to side. The grandest mountains of the Bernese Oberland, the Jungfrau, the Monch, the Trugberg, the Aletschhorn, the Breithorn, the Gletscherhorn, and many another noble 
peak and ridge, are the collectors of its neves. horn and the Weisshorn. The scene indeed From threc great valleys formed in the heart is one of impressive grandeur, a multitude of of the mountains thiese névés are poured, penks and crests here unnamed contributing uniting together to form the trunk of the to its glory.

Aletsch at a place narued by a witty moun- 349. But low down to our right, and surtaineer, the "Place de la Concorde of $\mathrm{Na}$ - rounded by the sheltering mountains, is an ture." If the phrase be meant to convey object the beauty of which startles those who the ileas of tranquil grandeur, beauty, of are unpreparcd for it. Yunder we see the furm. and purity of hue, it is well bestowed. naked side of the glacier, exposing glistening

34. Our hotel is not upon the peak of the ice-cliffs sixty or seventy feet high. It Aiggischhorn, but a brisk morning walk would seem as if the Aletsch here were cnsoon piaces us upon the top. 'Thence we see gaged in the vain attempt to thrust an arm the grlacier like a broad river stretehing up- through a lateral valley. It once did so ; but ward to the rnots of the Jungfrau, and the arm is now incessantly broken off close downward past the Bel Alp toward its end: to the body of the glacier, a great space forProlinging the vision downward, we strike merly covered by the ice being orcupied by the niblest mountain group in all the Alps - its water of liquefaction. A lake of the lovethe Dom and its attendant peaks, the Matter- liest, blue is thus formed, which reucines quite

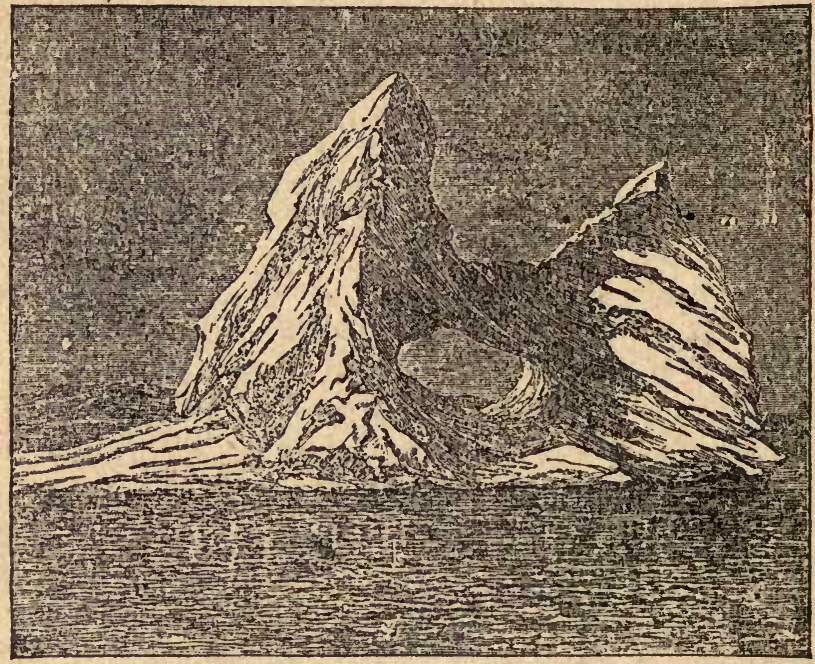

Fia. 14.

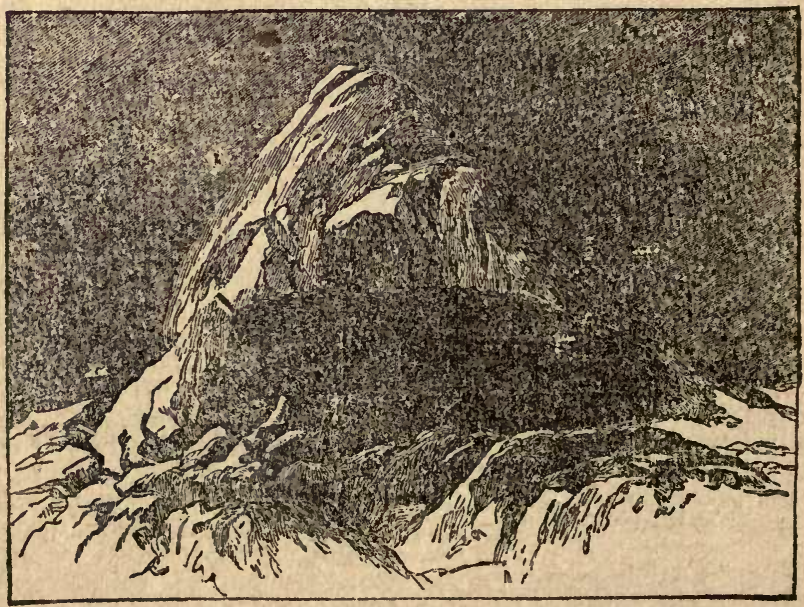

Fre. 15 
to the base of the ice-cliffs, saps them, as the Arctic waves sap the Greenland glaciers, and receives from them the broken masses which it has undermined. As we look down upon the lake, small icebergis sail over the tranquil surface, each resembling a snowy swan accompanied by its shadow.

$3 \tilde{0} 0$. This is the beautiful little lake of Marrgelin, or, as the Swiss here call it, the Märgelin Sce. You see that splash, and immediately afterward hear the sound of the plunging ice. The glacier has broken before our eyes, and dropped an icebery into the lake. All over the lake the water is set in commotinn, thus illustrating on a small scale the swamping waves produced by the descent of vast islands of ice frum the Arctic gliciers. Look to the end of the lake. It is cumbered with the remnauts of iccbergs now aground, which have been in part wafted thither by the wind, but in part slowiy borne by the water which moves gently in this direction.

351. Imagine us below upon the margin of the lake, as I huppened to be on one occusion. There is one large and lonely iceborg about the middle. Suddenly a sound like that of a cataract is heard; we lnok toward the iceberg and see water teeming from its sides. Whence cumes the water? the berg has become top-heavy through the melting under. neath ; it is in the act of performing a somersilult, and in rolling over carries with it a vast quantity of water, which rushes like a waterfall down its sides. And notice that the iceberg, which a moment ago was snowywhite, now exhibits the delicate blue color characteristic of compact ice. It will soon, however, be rendered white again by the action of the sun. The vaster iceberys of the Northern seas sometimes roll over in the
same fashion. A week may be spent with delight and profit at the $\mathbb{E}$ grgischhorn.

\section{\$51. The Ber, AlP.}

35.2. From the Agrischhorn I might lead you aloug the mountain ridge by the Belten See, the fish of which we have already tasted, to the Pieder Alp, and thence across the Aletseh to the Bel Alp. This is a fine mountain ramble, but you and I prefer making the glacier our highway downward. Eidsy at some places, it is hy no means chilid's play at others to unravel its erevasses. But the steady constancy and cluse olsservation which we have bitherto found availing in dificult places do not forsake us here. We cleal the fissures; and, after four hours of exhilarating work, we find ourselves upon the slope leading up to the Bel Alp hotel.

353. This is one of the finest halting-places in the Alps. Stretching before us up to the Argrgischhorn and Märgelin See is the long last reach of the Aletsch, with its great medial moraire running along its back. At hand is the wild gorge of the Missa, in which the snout of the glacier lies couched like the head of a serpent. The beautiful system of the Oberaletsch glaciers is within easy reach. Above us is a peak called the Sparrenhorn, accessib!e to the most moderate climber, and on the summit of which little more than an hour's exertion will place you and me. Below us now is the Oberaletsch glacier, exhibiting the most pertect of medial muraines. Near us is the great mass of the Aletschhorn, clasped by its névés, an l culminating in brown rock. It is supported by other peaks almost as noble as itself. The Nesthorn is at hand; while sweeping round to the west we strike the glotious triad already referred to, the Weiss. horn, the Matterhorn, and the Dom. Take one glance at the crevasses of the giacier immediately below us. It tumbles at its end down a steep incline, and is greatly riven. But the crevasses open before the stiep part is reached, and you notice the coalescence of marginal and transverse crevasses, prodicing a system of curved fissures with the convexities of the curves pointing upward. The mechanical reason of this is now known to you. The glacier-tables are also numerous and tine. I should like to linger with you here for a weck, exploring the existing grla. ciers, and tracing out the evidences of others that have passed away.

\section{§ 52. The Riffelderg and GönNer Gracreli.}

354. And though our masurements and observations on the Mer de Glace are more or less representative of all that can be mado or solved elsewhere, I am unwilling to leavo you unacquainter with the great system of glaciers which strean from the northern slopes of Minnte Rnsa and the adjacent mountains. From the Bel Alp we cau descend to Brieg, and thence drive to Visp; but you and I.prefer the breezy heights, so we sweep round the promontory of the Nessel, until we stand over the Rhone valley, in front of Visp. From this village an hour's walking carrits us to Stalden, where the valley divides into two branches: the one leading through Saas over the Monte Moro, and the other througin St. Nicholas to Zermatt. The latter is our route.

35̃. We rearh Zermatt, but do not halt there. On the mountain ridge, 4000 feet above the valley, we discern the Riffelberg hutel. 'This we reach. Right in front of us is the pinnacle of the Matterhorn, upon the top of which it must appear incredible to yo:1 that a human foot could ever tread. Constancy and skill, however, accomplished this, hut in the first instance at a terrible price. In the little churchyard of Zermatt we lave seen the graves of two of the greatest muuntaineers that Savoy and England have produced; and who, with two gallant young companions, fell from the Matterhorn in 1865.

356. At the Rififelberg we are within an hour's walk of the famous Görner Grat, which commands so grand a view of the glaciers of Monte Rosa. But yonder huge knob of perfectly bare rock, which is called the Riffelhorn, must be our station. What the Cleft Station is to the MIer de Glace, the Riffelhorn is to the Gorner glacier and its tributaries. From its lower side the rock, easy as it may seem, is inaccessible. Hera 
indeed, in 1865, a fifth good man met his ena, snd he also lies beside his fellow-countrymen in the churchyard of Zermatt. Passing a little tarn, or lake, called the Riffel See, we assail the Riffelhorn on its upper side. It is capital rock-practice 10 reach the summit; and from it we command a most extraordinary scene.

357. The liuge and many-peaked mass of Monte Rosa faces us, and we scan its snows frum bottom to top. To the right is the mrghty ridge of the Lyskamm, also laden with snow; and between both lies the Westerk Glacier of Monte Rosa. This glacier meets another from the vast snow-fields of the Cima di Jazzi ; they juin to form the Gorner glacier, and from their place of junction stretches the customary medial moraine. ()n this side of the Lyskamm rise two beautiful snowy eminences, the Trins Castor and Pullux; then come the brown crags of the Breithorn, then the Little viatterhorn, and then the broad snow-field of the Théudule, out of which springs the Great Matterhorn, and which you and I will cross subsequentiy into Italy.

353. The valleys and depressions between these mountains are filled with glaciers. D wn the flinks or the Twin Castor comes the Glacier des Jumeaux, from Pollux comes the Schivartze glacier, from the Breithorn the Trifti glacier, then come the Little Matterhorn glacier and the Théndule glacier, each, as it welds itself to the trunk, carrying with it its medial moraine. We can count nine such moraines from our present position. And to a still more surprising degree than on the Mer de Glace, we notice the power of the ice to yield to pressure; the broad névés being squeezed on the trunk of the Görner into white stripes, which become ever narrower netween their bounding moraines, and finally disappear under their own shingle.

359. On the two main tributaries we als? notice moraines which seem in each case to rise from the body of the glacier, appearing in the middle of the ice without any apparent origin himber up. These at their sources are sub-glacial moraines, which have bren rubbed away from rocky promontories entirely covered with ice. They lie hidden for a time in the body of the glacier, and appear at the surface where the ice above them has been melted away by the sun.

360. This is the place to mention a notion long entertained by the inhabiants of the ligh Alps, that glaciers possess the power of thrusting out all impurities from them. On the Mer de Glace you and I have noticed large patches of clay and black mud which evidently came from the body of the glacier, and we can therefore understand how natural was this notion of extrusion to people unaccustomed to close observation. But the power of the glacier in this respert is in reality the power of the sun, which fuses the ice above concealed impurities, and, hke the bodies of the guides on the Glacier iles 13ossons (143) brings them to the light of day
361. On no other glacier will you tind more objects of interest than on the Görner. Sand cones, glacier-tables, deep ice-gorges cut by streams and bridged fantastically by bould. er's, moulins, sometimes arched ice-caverns of extraordinary size and besnty. On the lower part of the glacier we notice the partial disappearance of the medial moraine in the crevassts, anil its reappearance at the foot of the incline. For many years this glacier was steadily alvancing on the meadow in front of it, ploughing up the soil and overturning the châlets in its way. It now shares in the generul reticat exhibited during the last fifteen years among the glaciers of the Alps. As usual, a river, the Visp, rushes from a vault at the extrelaity of the Görner glacier.

§53. Ancient Glaciens of Switzerladt,

362. You have not lost the memory of the old moraine, which interested us so much in our tirst ascent fiom the source of the Arveiron : for it opt ned our minds to the fact that at one periorl of its listory the lier de Glace attained far greater dimensions than it now exhibits. Our experience since llat time has enabled us to pursue these evidences of ice action to an extent of which we had then no notion.

363. Close to the existing glacier, for example, we have repeatedly seen the monutainside laid bare by the retreat of the ice. This is especially conspicuous just now, because for the last fifteen or sixteen years the glaciers of the Alps have been steadily shrinking; so that it is no uncommon thing to see the marginal rocks laid bare for a licight of fifty, sixty, eighty, or even one hundred feet above the present glacier. On the rocks thus exposed we see the evident marks of the sliding; and our eyes and minỏs have been so educated in the observation of these appearances that we are now able to detect, with certainty, icemarks, or moranes, ancient or morlern, wherever they appear.

364. But the elevations at which we have found such evidence might well shake belief in the conclusions 10 which they point. Beside the Massa Gorge, at 1000 fect above the present Aletseh, we found a great old moraine. Descending the meadows between the Bel Aip and Platten, we found another, now clothed with grass, and bearing a village on its back. But I wish to carry you to a region which exhibits these evidences on a still grander and more impressive scale. We have alrealy taken a brief fllght to the valley of Hasli and the Glacisir of the Aar. Let us make that glacier our starting-point. Walking from it downward toward the Grimsel, we pass everywhere over rocks singularly rounded, and fluted, and scarred. These appearances are manifestly the work of the glacier in recent times. But we approach the Grimsel, and at the turning of the valley stand before the precipitous yranite flank of the mountain. The traces of the ancient ice are here as plain as they are amazing. The rocks are so hard that not only the fluting 
and polishing, but even the fine scratches r. years are as evident as if they had been made yesterday. We may trace these evidences to a height of two thnisand feet above the present valley bed. It is indubitable that an lce-river of this astounding depth once flowed through the vale of Hasli.

365. Yonder is the summit of the Siedel$\mathrm{h} \mathrm{rn}$; and if we gain it the Unteraar glacier w:I lie iike a map below us. From this cuinmauding point we piainly see marked upon the mountain-sides the height to which the ancient ice extended. The ice ground part of the mountains is clearly distinguished from the splintered crests which in those distant diys rose above the surface of the glacier, and which must have then appeared as island peaks and crests in the midst of an ocean of ice.

366. We now scamper down the Siedelhorn, get once more into the valley of Hasli, along which we follow for more than twenty miles the traces of the ice. Fluted precipices, polished slabs, and beautifully-rounded granite domes. Right and left upon the mountain flanks, at great elevations, the evidences appear. We follow the footsteps of the glacier to the Lake of Brientz; and if we prolonged our inquiries, we should learn that all the lake beds of this region, at the time now referred to, bore the burden of inmense masses of ice.

367. Instead of the vale of Hasli, we might take the villey of the Rhone. The traces of a mighty glacier, which formerly filled it, may be followed all the way to Martiguy, which is 60 miles distant from the present ice. At Martigny the Rhone glacier was reinforced by another from Mont Blanc, and the welded masses moved onward, planing the mountains right and left, to the lake of Aeneva, the basin of which they entirely illed. Oilier evidences prove that the glacier did not end here, but pushed across the low country until it encountered the limestone barrier of the Jura Mountains.

\section{§ 54. Erratic Blocks.}

368. What are these other evidences ? We have seen mighty rocks poised on the mo. raines of the Mer de Glace, and we now know that, unless they are split and shattered by the frost, these rocks will, at some distant day, be linded borlily by the Glacier des Bois in the valley of Chamouni. You have already learned that these boulders often reveal the mineralogical nature of the mountains among which the glacier has passed; that specimens are thus brought down of a character totally different from the rocks among which they are finally landed; this is strik. ingly the case with the erratic blocks strande.l alony the Juria.

369 . For the Jura itself, as already stated, is limestone; there is no trace of native granite to be found among these hills. Still along the breast of the mountain above the town of Neufchâtel, and at about 800 feet above the lake of Neufchâtel, we find stranded a belt of granite boulders from Mont Blanc. And when we clear the soil away from the adjacent mountain-side, we find upon the limestone rocks the scarrings of the ancient glacier which brought the boulders here.

370. The most famous of these rocks, called the Pierre a Bôt, measures 50 feet in length, 40 in height, and 20 in width. Multiplying these three numbers together, we obtain 40,000 cubic feet as the volume of the boulder.

371. But this is small compared to some of the rocks which constitute the freight of even recent glaciers. Let us visit annther of them. We have already been to Stalden, where the valley divides into two branches, the right branch running to St. Nicholas and Zermatt, and the left one to Saas and the Monte Moro. Three hours ahove bias we crme upon the end of the Allelein glacier, not filling the inain valley, but thrown atiw wart it so as to ston its drainage ike a dam. Above this ice-dam we have the Mattmark Lake, and at the head of the lake a small inn well known to travellers over the MIonte Moro. 372. Close to this inn is the greutest bould. er that we have ever seen. It measures 240,000 cubic feet. Looking across the valley we notice a glacier with its present end half a mile from the boulder. The stone, I believe, is serpentine, and were you and I to explore the Scliwartzberg glacier to its upper fastnesses, we should find among them the birthplace of this gigantic stone. Fuur-andforty years ago, when the glacier reached the place now occupied by the houlder, it landed there its mighty freight, and then retreated. There is a second ice-borne rock at hand, which wonld be considered vast were it not dwarfer by the aspect of its huger neighbor.

373. Evidence of this kind might be multi. plied to any extent. In fact, at this moment, distinguished men, like Professor Favre of Geneva, are determining from the distribution of the erratic blocks the extent of the ancient glaciers of Switzerland. It was, however, an engineer named Venctz that first brought these evidences to light, and announced to an incredilous world the vast extension of the ancient ice. M. Agassiz afterward developed and wonderfully expanded the discovery. Pehaps the most interesting observation regarding ancient glaciers is that of Dr. Hooker, who, during a recent visit to Palestine, found the celebrated Cedars of Lebunon growing upon ancient moraines.

\section{\$ 55. Ancient Glaciers of Englanj,} Ireland, Scotland, aNd Wales.

374. At the time the ice attained this extraordinary development in the Alps, many uther portions of Europe, where no glaciers now exist, were covered with them. In the Highlands of Scotland, among the mountsins of England, Ireland, and Wales, the ancient glaciers have written their story as plainly uS in the Alps themselves I skould like te wander with you through Borrodule in Cum. 
berland, or through the valleys near Bethgellert in Wales. Under all the leauty of the present scenery we should discover the me. morials of a time when the whole region was locked in the embrace of ice. Professor Rausay is especially distinguished by his writings on the ancient glaciers of Wules.

375. We have made the acquaintance of the Reeks of Magillicuddy as the great condensers of Atlantic vapor. At the time now referred to, this moisture did not fall as soft and fructifying rain, but as snow, which formed the nutriment of great glaciers. A chain of lakes now constitutes the chief attraction of Killarney, the Lower, the Midule, and the Upper Luke. Let us suppose our. selves rowing toward the head of the Upper Lake with the Purple Misuntain to our left. Feinembering our travels in the Alps, you would infallibly call my attention to the planing of the rocks, and declare the action to be unuistakably that of glaciers With our uttention thus sharpened, we land at the heal of the lake, and walk up the Black Valley to the busu of Marrillicuddy's Rerks. Your conclusion would be, that this valley tells a tale as wonderful as that of Hasli.

376 . We reach our boat and row homeward along the Upper Lake. Its islauds now posstsis a new interest for us. Some of them are bare, others are covered wholly or in purt with luxuriant vegetation ; but both the naked and clothed islunds are glaciated. The weathering of ages has not altered their forms; there aie the Cannon IRock, the Giant's Collin, the Man-of-War, all sculptured as if ilie chisel had passed over them in our own lifetine. T'liese lakes, now fringed with tender woodland beauty, were all occu. pied by the ancient ice. It has disappeared, and seeds from other regions have been wafted thither to sow the trees, the shrubs, the ferns, and the grasses which now benutify Killurney. Mau himself, lhey say, has made his appearance in the world since that time of ice; but of the real period and manner of man's introduction little is professed to be known since, to make them square with science, new meanings liave been found for the beautiful myths aud stories of the Bible.

377. It is the nature and tendency of the human mind to look backward and torward; to endeavor to restore the past and predict the future. Thus endowed, from data patiently and painfuliy won, we recover in idea a state of things which existed thousands, it may be millions, of years before the history of the human race began.

\section{\$ 56. THE Graciar, Eroch.}

378. This period of ice-extensiou has been named the Glucial Epoch. In accounting for it great minds have fallen into grave er. rors, as we glall presently see.

379. The substance on which we have thus far been working exists in three different states: as a solid in ice; as a liquid in water; as a gas in vapor. 'To cause it to pass from one of these states to the next following one, heat is necessary.
380. Dig a liole in the ice of the Mer de Glace in summer, und pace a thermometer in the hole; it will staud nt $33^{\circ}$ Falir. Dip your thermometer into one of the glacier streams; it will still mark $32^{\circ}$. The wouter is therefore as cold as ice.

381 . Hence the whole of tha heat poured by the sun upon the glacier, and which has I cen absorbed by the glacier, is expended in simply liquefying the ice, and not in render. ing either ice or water a siugle digree warmer.

382. Expose water to a lire; it becomies hotter for a time. It loils, and from that moment it cerses to $g \cdot t$ hitter. After it hus begun to boil, all the lixat communicated by the fire is carrind away liy the steam, tirough the steam itself is not the least fraction if a de. gree liotter than the water.

¿83. In fuct, simply to liquefy ice a large quantity of heat is necessary, and to vaporizo water a still larger quantity is necessary. And inasmuch as this lieat does not render the water warmer than the ice, nor the steam warmer than the water, it was at one time supposed to be lidden in the water and in the steam. And it was therefore called latent lieat.

384. Let us ask how much heat must the sun expend in order to convert a pound weiglit of the tropical ocenu into iapor? This problem has leen rccurately solved by experiment. It would requise in ronnd numbers 1000 times the amount of lieat necessary to raise one pound of water one degree in temperature.

385. But the quantity of heat which wou:d raise the tempirature of a pound of water one degree would raise the temperature of a pound of irou ten degreıs. 'This lias been also proved by experiment. Hence to convert one pouid of the trupical ncean into vapor the sun unst expend 10,000 times as much heat as would raise one pound of iron one degree in temperature.

386. 'This quantity of heat wrould raise the temperature of 5 liss. of iron 2000 degrees, which is the fusing point of cast iron; at this temperature che metal would not only be white hot, but would be passing into the molten condition.

387. Consider the conclusions at which we have now arrived. For every pound of tropical vapor, or for every pouid of Alpine ice produced by the congelation of that vapor, au amount of heat has bren expended by the sun sufficient to raise 5 lbs. of cast iron to its melting.point.

388. It would not be difficult to calculate approximately the weight of the Mer do Glace and its tributaries-to say, for example, that they contained so many willions of millions of tons of ice and snow. Let the plase of the ice be taken by a mass of whitehot iron of quintuple the weight; with such a picture before your mind you get some notion of the enormous amount of heat paid out by the sun to produce the present glacier.

389. You must think over this, until it is as clear as sunshine. For you must never henceforth fall into the error already referrod 
to, and which has entangled so many. So natural was the association of ico and cold, that even celebrated men assumed that all that is needed to produce a great extension of our glaciers is a diminution of the sun's temperature. Had they gone through the foregoing reflections and calculations, they would probably have demanded more heat instead of less for the production of a "glacial epoch." What they really needed were condensers sufficiently powerful to "congeal the rapor generated by the heat of the sun.

\section{$\$ 57$. Glacier Theories.}

390. You have not forgotten, and hardly ever can forget, our climbs to the Cleft Station. Thoughts were then suggested which we have not yet discussed. We saw the branch glaciers coming down from their névés, welding themselves together, pushing throuıh Trélaporte, and afterward moving through the sinuous valley of the Mer de (ilace. These appearances alone, without taking into account subsequent observations, were sufficient to suggest the idea that glacier ice, however hard and brittle it may appear, is really a viscous substance, resembling treacle, or honey, or tar, or lava.

\section{§58. Dilatation amd Suiding Theories.}

391. Still this was not the notion expressed by the majority of writers upon glaciers. Scheuchzer of Zurich, a great naturalist, visited the glaciers in 1705 , and propounded a theory of their motion. Water, he knew, expands in freezing, and the force of expansion is so great that thick bomb-shells filled with water, and peruitted $t$ ) freeze, are, as we know (312), shiattered to pieces by the ico within. Scheuchzer supposed that the water in the fissures of the ylaciers, freezing there and expanding with resistless force, was the power which urged the glacier downward. Ile added to this theory other notions of a less scientifie kind.

392. Many years subsequently. De Cliar. pentier of Bex renewed and developerl this theory with such ability and completeness that it was long known as Charpenier's Theory of Dilatation. M. Agassiz for a tine espoused this theory, and it was aiso more or less distinctly held by other writess. 'The glacier, in fact. was considered to be a mag. azine of cold, capable of freezing all water percolating through it. The theory was abandoned when this notion of glacier cold was proved by M. Agassiz to be untenable.

393. In 1760 , Altmann and Grüner propounded the view that glaciers mored by sliding over their beds. Nearly wrty years subsequently, this notion was revived by $\mathrm{De}$ Saussure, and it has therefore been called "De Srussure's 'Theory," or the "Sliding Theory," of glacier motion.

394. There was, however, but little reason to connect the name of De Saussure with this or any other theory of glaciers. Incessantly occupied in observations of another kind, this celebrated man devoted very little time or thought to the question of glacier motion.
What he has written upon the subject reads less like the elaboration of a theory than the expression of an opinion.

\section{$\S 59$. Plastic Theory.}

395. By none of these writers is the property of viscosity or plasticity ascribed to gla. cier ice; the appearances of many glaciers are, however, so sugrestire of this idea that we may be sure it would have iound wore frequent expression, were it not in such apparent contradiction with our every day ex. perience of ice.

396. Still the idea found its adrocates. In a little book, publislied in 1773 , and entitled "Picturesque Journey to the Glaciers of Savoy," Burdier of Geneva wrote thus: "It is now time to look at all these objects with the eyes of reason; to study, in the first place, the position and the progression of glaciers, and to seek the solution $r f$ their principal phenomena. At the first aspect of the ice-mountains an observation presents itself, which appears sufficient to explain all. It is that the entire mass of ice is connected together, and presses from above downward after the manner of fluids. Let us then regard the ice, not as a niass entirely rigid and immobile, but as a heap of coagulated matter, or as softened wax, flexible and ductile to a certain point." Here probably for the first time the quality of plasticity is ascribed to the ice of glaciers.

397. To us, familiar with the aspect of tho glaciers, it must seem strange that this idea once expressed did not at once receive recognition and development. But in those early dass explorers were few, and the "Picturesque Journey" probably but little known. so that the notion of plasticity lay dormant for more than half a century. But Bordier was at length succeeded by a man of far greater scientific grasp and insiglit than himself. This was Rendu, a Catholic priest and canon when he wrote, and afterward Bishop. of Annecy. In 1841 Rendu laid before the Royal Academy of Sciences of Savoy his "Theory of the Glaciers of Savoy," a contribution forever memorable in relation to: this subject.

398. Kendu seized the idea of glacier plasticity with great power and clearness, and followed it resolutely to its consequences. It is not known that he had ever seen the work of Bordier; probably not, as he never. mentions it. Let me quote for you some of Rendu's expressions, which, however, fail to gire an adequate idea of his insight and precision of thought: "Between the Mer do. Glace and a river there is a resemblance so complete that it is impossible to find in the glacier a circumstance which does not exist in the river. In currents of water the motion is not uniform eitlier throughout their width or throughout their depth. The friction of the bottom and of the sides, with the action of local hindrances, canses the motion to vary, and only toward the middle of the surface do we obtain the full motion."

399. This reads like a predicti'n of what 
has since been established by measurement. Looking at the glacier of Mont Dolent, which resembles a sheaf in form, wide at both ends and narrow in the middle, and refecting that the upper wide part had become narrow, and the narrow middle part again wide, Rcndu observes, "There is a multitude of facts which seem to necessitate the belief that glacier ice enjoys a kind of ductility which enables it to mould itself to its lochlity, to thin out, to swell, and to contract as if it were a soft paste."

400. To fully test his conclusions, Rendu required the accurate measurement of glacier motion. Had he added to his other endowments the practical skill of a land-surveyor, he would now be regarded as the prince of glacialists. As it was he was obliged to be content with imperfect measurements. In one of his excursions he examined the guides regarciing the successive positions of a vast rock wilich he found upon the ice close to the side of the glacier. The mean of five years gave him a motion for this block of 40 leet a year.

401. Another block, the transport of which he subsequently measured more accurately, gave him a velocity of 400 feet a year. Note his explanation of this discrepancy : "The enormous difference of these two olnervations arises from the fact that one block stood near the centre of the glacier, which moves most rapidly, while the other stood near the side, whe:e tlie ice is held back by to friction." So clear and definite were Rendu's ideas of the plastic motion of glaciers, that had the question of curvature occurred to him, I entertain no doubt that he would have enunciated beforehand the shifting of the point of maximum motion from side to side across the axis of the glacier (\$25).

40\%. It is rirnt that you sho'sld know that scientific men do not always agree in their (stimates of the comparative value of facts and ideas; and it is especially right that you should know that your present tutor attaches is very high value to ideas when they spring from the profound and persistent ponilering of superior minds, and are not, as is too often the case, thrown out without the warrant of cither deep thought or natural cayacity. It is because I belicve Rendu's labors fulfil this condition that I ascribe to tinem so high a value. But when you become older unil better informed, you may differ from rec; and I write these words lest you should too readily accept my opinion of Rendu. Jiudge me, if you care to do so, when your knowledge is matured. I certainly shall not iear your verdict.

403. But, much as I prize the prompting itlea, and thoroughly as I beliere that often in it the force of genius mainly lies, it would, in my opinion, be an error of omission of the uravest kind, and which, if habitual, would insure the ultimate decay of natural know:i. Ige, to neglect verifying our ideas, and giving them outward reality and substance when the means of doing so are at hand. In sciunce, thought, as far as possible, ought to to wedded to fact. This was attempted by rendu, and in great part a:complished by Agassiz and Forbes.

\section{$\S 60$. Viscols Theorr.}

404. Trere indeed the merits of the distin. guished glacialist last named rise conspicu. ously to view. From the able and earnest adrocacy of Professor Forbes, the public knowledge of this doctrine of glacial plasticity is almost wholly derived. He gave the doctrine a more distinctive form; he first applie: the term viscous to glacier ice, and sought to found upon precise measurements a "Viscous Theory" of glacier motion.

405. I am here obliged to state facts in their historic seruence. Professor Forbes when lie began his investigations was acquainted with the labors of Rendu. In his earliest work upon the Alps be refers to those labors in ierms of flattering recogni. tion. But though as a ma te: of fact Kendu's ideas were there to pron pî him, it would be too mucla to say that lie needed their inspiration. Had Rendu not preceded him, he might none the less have grasped the idea of viscosity, exccuting his measurements and applying his knowledge to maintain it. Be that as it may, the appearance of Professor Forbes on the Unteraar glacier in 1841, and on the Mer de Glace in 1542, and his labors then and subsequently, have given lim a name not to be forgotien in the scientific history of glaciers.

406. The theory advocated by Professor Forbes was enunciated by bimself in these words : "A glacier is an imperfect fluid, or viscous body, which is urged down slopes of certain inciination bv the natural pressure of its rarts." In 1773 Bordier wrote thus : "As the giaciers always advance upon the plair, and never disilppear, it is alssolutely essential that new ice shall perpetually take the place of that which is melted: it must therefore be pressed forward frem above. One can hardly refuse then to accept the astonishing truth, that this vast extent of hard and solid ice moves as a single piece downward." In the passage alreary quoted he speaks of the ice being pressed as a fluid from abore. These constitute, I believe, Bordier's contributions to this subject. The quotations show his sagacity at an early date; but, in point of completeness, his views are not to be compared with those of Rendu and Forbes.

407. I must not omit to state here that though the idea of viscosity has not been espoused by M. Agassiz, liis measurements, and maps of measurements, on the Unteraar glacier have been recently cited as the most clear and conclusive illustrations of a quality which, at all events, closely resembles viscosity.

408. But why, with proofs before him more copious and characteristic than those of any other observer, loes MI. A gassiz hesitate to accept the idea of viscosity as applied to ice? Doubtless because he believes the notion to be contradicted by our cvery-day ex- 
perience of the substance.

409. Take a mass of ice ten or even fifteen cubic feet in volume; drew a saw across it to a depth of half an inch or an inch; and strike a pointed pricker, not thicker than a very small round file, into the groove; the substance will split from top to bottom with a clean crystalline fracture. How is this brittleness to be reconciled with the notion of viscosity?

410. We have, moreover, been upon the glacier and have witnessed the birth of crevasses. We have seen them weginning as narrow cracks suddenler formed, days being leyuired to open them a single inch. In many glaciers fissures may be traced narrow and profound for liundreds of yards through the ice. What does this prove? Did the ire possess even a very simall modicum of that power of stretching, which is characteristic of a viscous substance, such crevasses couli not be formed.

411. Still it is undoubted that the glacier moves like a viscous body. The centre flows past the sides, the top flows over the bottom, and the motion through a curved valley corresponds to fluid motion. Mr. Mathews, Mr. Froude, and above all Signor Bianconi, hatve, moreover, recently made experiments on iee which strikingly illustıate the llexibility of the substance. These experiments merit, and will doubtless receive, full atten. ticn at a future time.

\section{§ 61. Regela tioN THeORY.}

412. I will now describe to you an attempt that has been made of late years to reconcile the brittleness of ice with its motion in glaciers. It is founded on the observation, made by Mr. Faraday in 1850 , that when two pieces of thawing ice are placed together they freeze together at the place of contact.

413. This fact may not surprise yud ; still it : a urised Mr. Faraday and others, and in $u$ of very great distinction in science have differed in their interpretation of the fact. The ditficulty is to explain where, or how, in ice already thawing the cold is to be found requisite to freeze the film of water between the two touching surtaces.

414. The word Regelation was proposed by Dr. Hooker to express the freezing together of two pieces of thawing ice ohserved by Faraday; and the memoir in which the term was first used was published by Mr. Huxley and Mr. Tyndall in the Philosophical Transactions for 18.7 .

415. The fuct of regelation, and its application irrespective of the cause of regelation, may be tinus illustrated: Saw two slabs from a block of ice, and bring their flat surfrees into contact, ; they immediately freeze rogether. Two plates of ice, laid one upon the other, with finnel round them over night, ate sometimcs so firmly frozen in the morning that they will ratluer break elsewhere than along theit surface of junction. If you enter one of the dripping ice-caves of Switzerland. you have on!y, to press for a moment a slab of ice agairst the roof of tho cave to cause it to freeze there and stick to the roof.

416. Place a number of fragments of ice in a basin of water, and cause them to touch each other; they freeze together where they touch. You cen form a chain of such frag. ments ; and then, by taking hold of one end of the chain, you can draw the whole series after it. Chains of icebergs are sometimes formed in this way in the Aretic seas.

417. Consider what follows from these observations. Snow consists of small particles of ice. Now if by pressure we squeeze out the air entangled in thawing snow, and bring the little ice-granules into close contact, they may be expecied to freeze together; and if the expulsion of the air be complete, the squeezed snow may be expected to assume the appearance of compact ice.

418. We arrive at this conclusion by rea. soning ; let us now test it by experiment, employing a suitable hydraulic press, and a mould to hold the snow. In exact accordance with our expectation, we convert by pressure the snow into ice.

419. Place a compact mass of ice in a proper mould, and subject it to pressure. It breaks in pieces; squeeze the pieces forcibly together; they reunite by regelation, aud a compact piece of ice; totaliy different in shape from the first one, is taken from the r ress. To produce this effect the ice must bo in a thawing condition. When its temperature is much below the melting-point it is crushed by pressure, not into a pellucid mass of another shape, but into a white powder.

420 . By means of suitanle moulds you may in this way change the sirape of ice to any cxtent, turning out spheres, and cups: and rings, and twisted ropes of the sub. stance; the change of form in these cases being effected through rude fracture and regelation.

421. By applying the pressure carefully, rude fracture inay be avoided, and the ice compelled slowly to change its form as if it were a plastic body.

422. Now our first experiment illustrates the consolidation of the snows of the higher Alpine regions. The deeper layers of the neve have to bear the weight of all above them, and are thereby converted into more or less perfect ice. And our last experiment illustrates the changes of form observed upou the glacier, where, by the slow and constant application of pressure, the ice gradually moulds itself to the valley which it tills.

$4: 3$. In glaciers, however, we Lave also ample illustrations of rude fracture and rege lation. The opening and closing of crevassea illustrate this. The glacier is broken on the cascades and mended at their bases. When two branch glaciers lay their sides together, the regelation is so firm that they begin iminediately to flow in the trunk glicier as a single stream. The medial moraine gives ne indieation by its slowness of motion that it is derived from the sluggish ice of the sides of 
the lirarich glacicrs.

424. The gist of the Regelation Theory is that the ice of glaciers changes its form and preaerves its continuity under pressure which keeps its particles together. But when subjected to tension, soower than stretch it breaks, and behaves no longer as a viscous body.

\section{§ 62. Cause of Regelation.}

435. Here the fact of regelation is applicd to explain the plasticity of glacicr ice, no attempt being made to assign the cause of regelation itself. They are two entirely dis. ,tinct questions. But a little time will be well spent in looking more closely into the cause of regelation. You may feel some surprise that eminent men should devote their attention to so smali a point, lout we must not forget that in nature nothing is small. Laws and principles interest the scientific student most, and these may be as well illus. irated by small things as by large ones.

426. The question of regelation immediately connects itself with that of "latent heat," already referred to (383), but which we must now subject to further examination. To melt ice, as already stated, a large amount of heat is necessary, and in the case of the glaciers this heat is furnished by the sun. Neither the ice so melted nor the water which results from its liquefaction can fall below $32^{\circ}$ Fahrenheit. The freezing-point of water and the melting-point of ice touch each other, as it were, at this temperature. A hair's-breadth lower water ireczes ; a hair'sbreadth higher ice melts.

427. But if the ice could be caused to melt without this supply of solar heat, a temperature lower than that cf ordinary thawing ice would result. When snow and salt, or pounded ice and salt, are mixed together, the salt causes the ice to melt, and in this way a cold of 20 or 30 degrees below the freezingpoint may be produced. Fere, in fact, the ice consumes its own warmth in the work of liquefaction. Such a mixture of ice and salt is called " a freezing mixture."

428. And if hy any other means ice at the temperature of $52^{\circ}$ Fahrenheit could be liquefied without access of heat from without, the water produced would be colder than the ice. Now Professor James Thomson has proved that ice may be liquefiea by mere pressure, and his brother, Sir William Thomson, lias also sliuwn that water under pressure requires a lower temperature to freeze it than when the pressure is removed. Professor Mousson subsequently licyuefied large masses of ice by a hydraulic press; and by a beautiful experiment Professor Helmloltz has proved that water in a vessel from which the air has been removed, and which is therefore relieved from the pressure of the atmosphere, freezes and forms ice-crystals when surrounded by melting ice. All these facts are summed up in the brief statement inat the freezing-point of water is lowered by pressure.

429. Sor our own instiuction we may produce the liquefaction of ice by pressure in the following way: You remember the beautiful flowers obtained when a sunbeam is sent through lake ice (\$11), and you have not forgotten that the Howers always form purallel to the surface of freezing. Let us cut a prism, or small column of ice with the planes of freezing 1 unning across it at right angles; we place that prism between two slabs of wood, and bring carefully to bear upon it the squeezing force of a small liydraulic press.

430. It is well to converge by means of a concave mirror a good light upon the ice, and to view it through a magnifying lens. You already see the resuit. IIazy surfaces are formed in the very body ct the ice, which gradually ex ardit as the pressure is slowly augmentcu. Heie and there you notice something resembling crystallization ; fern-shaped figures run will considerable rapidity through the ice, and when you look carefully at their points and edges you find them in visible motion. These hazy surfuces are spaces of liquefaction, and the motion you sec is that of the ice falling to water under the pressure. That water is colder than the ice was before the pressure was applien, and if the pressure be relieved. not only does the liquetaction cease, but the water re-freezes. The cold produced by its liquefaction under pressure is sufficient to re-congeal it when the pressure is removed.

431. If instead of diffusing the pressure over surfaces of consikleiable extent, we con. centrate it on a small surface, the liquefac. tion will of course be more rapid, and this is what Mr. Juttomley has recently done in au experiment of singular beauty and interest. Let us support on blocks of wood the two ends of a bar of ice 10 inches long, 4 inclies deep, and 3 wide, and let us loop over its middle a copper wire one twentieth, or even one tenth, of an inch in thickness. Connecting the two ends of the wire together. and suspending from it a weight of 12 or 14 pounds, the whole pressure of this weight is concentrated on the ice which supports the wire. What is the consequence? The ice underneath the wire liquefies; the water of liquefaction escapes round the wire, but the moment it is relieved from the pressure it freezes, and round about the wire, even before it has entered the ice, you have a frozen casing. The wire continues to sink in tho ice; the water incessantly escapes, freezing as it does so behind the wire. In half an hour the weight falls; the wire has give clean through the ice. You can plainly see where it lias passed, but the two serered pieces of ice are so firmly frozen together that they will break elsewhere as soon as aloug the surface of regelation.

432. Another beautiful experiment bear. ing upon this point has recently been made by M. Boussingault. He filled a hollow steel cylinder with water aud chilled it. In passing to ice, water, as you know, expands $(\$ 45)$; in fact, room for expansion is a necessary condition of solidification. But in the present case the strong steel resisted the ex. 
pansion, the water in consequence remaining fiquid at a temperature of more than $30^{\circ}$ Fahr. below the ordinury freezing-point. A bullet within the cylinder rattled about at this temperature sl owing that the water was stil! liquid. On onening the tap the liquid, relieved of the pressure, was instantly converted into ice.

433. It is only suhstances which expand on solidifying that behave in this manner. The metal bismuth, as we know, is an example similar to water ; while lead, wax, or sulphur, all of which contrast on solidifying, have their puint of fusion heightened by pressure.

434. And now you are prepared to understand Professor James Thomson's theory of regelation. When two pieces of ice are presser together, liquefaction, he contends, results. The water spreads out around the points of pressure, and when released refreezes, thus forming a kind of cement between the pieces of ice.

\section{63. Firaday's View of Regelation.}

435. Faraday's view of regelation is not so easily expressed, still I will try to give you some notion of it, dealing in the first place with admitted facts. Water, even in open vessels, may be lowered many degrees below its freezing temperature, and still remain liquid; it may also be raised to a temperature far higher than its boiling-point, and still resist boiling. This is due to the mutual chesion of the water particles, which resists the change of the liquid either into the solid or the vaporous condition.

436. But if into the over-chilled water you throw a particle of ice. the cohesion is ruptured, and congelation immediately sets inAnd if into the superleated water you introduce a bubble of air or of steam, colhesion is likwise ruptured, and ebullitıon imnediate. ly commences.

43\%. Faraday concluded that in the interior of any body, whether solid or liquid, where every particle is grasped, so to speak, by the surrounding particles, and grasps them in turn, the bond of cohesion is so strong as to require a higher temperature to change the state of aggregation than is necessary at the surface. At the surface of a plece of ice, for example, the molecules are free on one side from the control of other molecules; and they therefore yield to heat more readily than in the interior. The bubble of air or steam in overheated water also frees the molecules on one side; hence the ebullition consequent upon its introduction. Practically speaking. then, the point of liquefaction of the interior ice is higher than that of the superficial ice. Faraday also refers to the special solidifying power which bodies exert upon their own molecules. Camphor in a glass bottle fills the bottle with an atmosphere of camphor. In such an atmosphere large crystals of the substance may grow by the incessant deposition of camplior molecules upon camphor, at a temperature too high to permit of the slightest deposit upon the adjacent giass. A similar remark applies to sulphur, phospho- rus, and the metris in a state of fusion. They are deposited upon solid purtions of their own substance at temperatures not lnw enough to cause them to solidify against other substances.

438. Water furnishes an cminent example of this special solidifying power. It may bo cooled ten degrees and more below its freezing-point without freezing. But this is not possible if the smaliest fragment of ice be floating in the water. It then freezes accurately at $32^{\circ}$ Fahr., depositing itself, however, not upon tha sides of the containing vessel, but upon the ice. Faraday observed in a freezing apparatus thin crystals of ice growing in ice-cold water to a length of six, eight, cr ten inches, at a temperature incompetent to produce their deposition upon the sides of the containing vessel.

439. And now we are prepared for Faraday's view of regelation. When the surfaces of two pieces of ice, covered with a film of the water of liquefaction, are brought to. gether, the covering film is transferred from the surface to the centre of the ice, where the point of liquefaction, as hefore shown, is higher than at the surface. The special solidifying power of ice upon water is now brought into play on both sides of the film. Under these circumstances, Faraday held that the film would congeal, and freeze the two surfaces together.

440. The lowering of the freezing-point by pressure amounts to no more than one seventieth of a degree Fahrenheit for a whole atmosphere. Considering the intinitesimal fraction of this pressure which is brought into play in some cases of regelation, Fara. day thought its effect insensible. He suspended pieces of ice, and trought them into contact without sensible pressure, still they froze tugether. Professor James Thomson. however, considered that even the capillary attraction exerted between two such masses would be sufficient to produce regelation. You may make the following experiments, in further illustration of this subject :

411. Place a small piece of ice on water, and press it underneath the surface by a secund piece. The submerged piece may be so small as to render the pressure infivitesimal ; still it will freeze to the under surface of the superior piece.

442. Place two pieces of ice in a basin of warm water, and allow them to come together; they freeze together when they touch. The parts surrounding the place of contact melt away, but the pieces continue for a time united by a narrow bridge of ice. The bridge finally inelts, and the piects for :3 moment are separated. But capillary attraction immediately draws them together, and regelation sets in once more. $\Lambda$ new bridgo is formed, which in its turn is dissolved, the separated pieres again closing up. A kind of pulsation is thus established between the two pieces of ice. They touch, they freezc, a bridge is formed and inelted; and thus the rhythmic action continues until the ice dis appears. 
443. According to Professor James Thomson's theory, pressure is necessary to liquefy the ice. The heat necessary for liquefac. tion must be drawn from the ice itself, and the cold water must escape from the pressure to be re-frozen. Now in the foregoing experiments the cold water, instead of being allowed to freeze, issues into the warm water, still the floatirg fragments regelate in a moment. The touching surfaces may, moreover, be convex ; they may be reduced practically to points, clasped all round by the warm water, which indeed rapidly dissolves them as they approach each other ; still they ireeze immediately when they touch.

444. You may learn from this discussion that in scientific matters, as in all others, there is room for differences of opinion. The frame of mind to be cultivated here is a suspension of judgment as long as the meaning remains in doubt. It may be that Faraday's action and Thomson's action come both into play. I cannot do better than finish these remarks by quoting Faraday's own concluding words, which show how in his mind scientific conviction dwelt apart from dogmatism : "No doubt," he says, "nice exFeriments will enable us hereafter to criticise such results as these, and separating the true from the untrue will establish the correct theory of regelation.'

\section{§ 61. The Blee Veris of Glaciers.}

445. We now approach the end, one important question only remaining to be discussed. Hitherto we have kept it back, for a wide acquaintance with the glaciers was necessary to its solution. We had also to make ourselves familiar by actual experiment with the power of ice, softened by thaw, to yield to pressure, and to liquefy under such pressure.

446. Snow is white. But if you examine its individual particles you would call them transparent, not white. The whiteress arises from the mixture of the ice particles with small spaces of air. In the casc of all transparent bodies, whiteness results from such a mixture. The clearest glass or crystal when crushed becomes a white powder. The foam of champagne is white through the intimate arlmixture of a transparent liquid with transparent carbonic acid gas. The whitest paper, morenver, is composed of fibres which are individually transparent.

447. It is not, however, the air or the gas, kut the opticul severance of the particles, giving rise to a multitude of refiections of the white solar light at their surfaces, that produces the whiteness.

i48. The whiteness of the surface of a clean glacier (112), and of the icebergs of the Märgelin See (357), has been already referred to a similar cause. The surface is broken into innumerable fissures by the solar heat, the reflection of solar light from the sides of the little fissures producing the observed appearance.

449. In like manner if you freeze water in a test-tube by plunging it into a freezing mixture, the ice produced is white. For the most part also the ice formed in freezing machines is white. Examine such ice, and you will find it filled with smal! air-bubbles. When the freezing is extremely slow the crystallizing force pushes the air effectually aside, and the resulting ice is transparent; when the freezing is rapid, the air is entan. gled before it can escape, and the ice is translucent. 13ut even in the case of quick freezing Mr. Faruday obtained transparent ice by skilfully removing the air-bubbles, as fast as they appeared, with a feather.

450. In the case of lake ice the freezing is not uniform, but intermittent. It is sometimes slow, sometimes rapid. When slow the air dissolved in the water is effectually squeezed out and forms a lityer of bubbles on the under surface of the ice. An act of sudden freezing entangles this air, and hence we find lake ice usually composed of layers alter. nately clear, and filied with bubbies. Suci layers render it easy to detect the planes of freezing in lake ice.

451. And now for the bearing of these facts. Under the fall of the Geant, at the base of the Talèfre cascade, and lower down the Mer de Glace ; in the higher regions of the Grin. delwald, the Aar, the Aletsch and the Görner glaciers, the ice does not possess the transparency which it exhibits near the ends of the glaciers. It is white, or whitish. Why? Examination shows it to be filled with small air-bubbles; and these, as we now learn, are the cause of its whiteness.

452. They are the residue of the air orignally entangled in the snow, and connected, as before stated, with the whiteness of the snow. During the descent of the glacier, the bubbles are gradually expelled by the enormous pressures brought to bear upon the ice. Not only is the expulsion caused hy the mechanical ylelding of the soft thawing ice, but the liquefaction of the substance at places of violent pressure, opening, as it does, fissures for the escape of the air, innst play an important part in the consolidation of the glacier.

453. The expulsion of the lubbles is, however, not uniform ; for neither ice nor any other sulustance offers an absolutely uniform resistance to pressure. At the base of every cascade that we have visited, and on the walls of the crevasses there formed, we have noticed innumerable blue streaks drawn through the white translucent ice, and giring the whole mass the appearance of lamina tion. These hlue veins turned out upun ex. amination to be spaces from which the airbubbles had been almost wholly expelled, translucency being thus converted into trans parency.

454. This is the veined or ribboned structure of glaciers, regarding the origin of which diverse opinions are now entertained.

455. It is now our duty to take up the problem, and to solve it if we can. On the névés of the Col du Géant, and other rlaciers, we luave found greai cracks, and faults, and Bergschrunds, exposing deep sec- 
tions of the neve : and on these sections we have found marked the edges of half-consol. idated strata evidentiy produced by successive falls of snow. The névé is stratified because its supply of material from the atmosphere is intermittent, and when we first observed the blue veins we were disposed to regard them as due to this stratification.

456. But olsservatiou and reflection soon slispelled this notion. Indeed, it could hardly stanl in the presence of the single fact that at the bases of the ice falls the veins are always vertical, or neally so We saw no way of explaining low the horizontal strata of the névé could be so tilted up at the base of the fall as to be set on elge. Nor is the aspect of the veins thit of stratification.

457. On the central portions of the cascacies, morenver, there are no signs of the veins. At the bases they first appear, reaching in each case their maximum development a little below the base. $\Lambda$ s you and I stood upon the heights above the Zitsenberg and scrutinized the caseade of the Strahleck

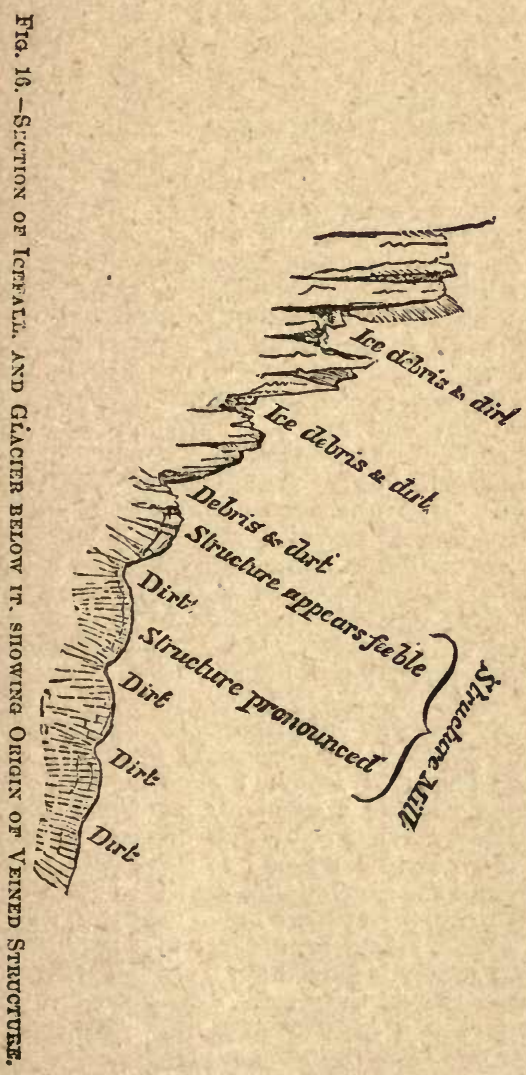

A.ranch of the Grinaelwald glacier, we could wot doubt that the kase of the fall was the birthplace of the veins. We called this portion of the glacier a "Structure Mill," inti- mating that here, and not on $17: 0$ i.eve, the veined structure was manufactured.

458. This, however, is, at bottom, the language of strong opinion merely, not that of dcmonstration; and in seience opinion ought to content us only so long as positive profof is unattainable. The love of repose must not prevent us from secking this pronf. There is no sterner conscience than the scientific conscience, and it demands, in every possible case, the substitution for privuto conviction of demonstration which shall he conclusive to all.

459. Let us, for example, be shown a case in which the stratification of the névé is prolonged into the glacier; let us see the plaues of bedding and the planes of lamination existing side by side, and still indubitably distinct. Such an observation would effectually exclude stratification from the problem of the veined structure, and through the removal of this tempting source of error we should be rendi.eci more free to pursue the trutl.

460. We sought for this conclusive test upon the Mer de Glace, but dir nut find it. We sought it on the Grindelivald, and the Aar glaciers, with an equal want of success. On the Aletsch glacier, for the first time, we observed the apparent coexistence of bedding and structure, the one cutting the other upon the walls of the same crevasse. Still the case was not sufficiently pronouncer to produce entire conviction, and we visited the Görner glacier with the view of following up our quest.

461. Here day after day added to the conviction that the bedding and the structure were two different things. Still day after day passed without revealing to us the final proof. Surely we have not let nur own ease stand in the way of its attainment, and if we retire baftled we shall do so with the consciousness of liaving done our best. Yonder, however, at the hase of the Matterhorn, is the Furgge glacier that we have not yet explored. Upon it our final attenupt must bo made.

462. We get upon the glacier near its end, and ascend it. We are soon fronted by a barrier composed of three successive walls of névé, th? one rising above the other, and each retreating behind the other. The bottom of each wall is separated from the top of the succeeding one by a ledge, on which threatening masses of broken névé now rest. We stand amid blocks and rubbisls which have been evidently discharged from theso ledges, on which other masses, rcady apparently to tumble, are now poised.

463. On the vertical walls of this barricr we see, marked with the utmost plainness, the horizontal lines of stratification, while something exceedingly like the veined structure appears to cross the lines of bedding at nearly a right angle. The vertical surface is, howe yer. wenthered, and the lines of structure, if liney be such, are indistinct. The problem now is to remove the surface, and expose the ice underneath. It is one of the 


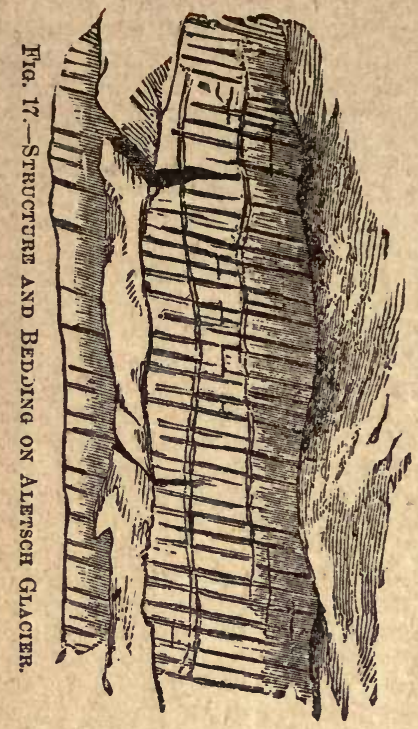

many cases that have come before us, where the value of an observation is to be balanced against the danger which it involves.

464. We do nothing rashly; but scanning the ledges and sclecting a point of attack. we conclude that the danger is not too great to be incurred. We advance to the wall, remove the surface, and are rewarded by the discovery underneath it of the true blue veins. They, morenver, are vertical, while the bedding is horizontal. Bruce, as you know, was defeated in many a battle, but he persisted and won at last. Here, upon the Furgge glacier, you also have fought and won your little Bannockburn.

465. But let us not use the language of victory too soon. The stratification theory has been removed out of the field of explanation, but nothing has as yet been offered in its place.

\section{$\S 65$. Relation OF StrdctuRe to} Pressure.

466. This vcined structure was first described by the distinguished Swiss naturalist, Guyot, now a resirlent in the United States. From the Grimsel Pass I have already pointed out to you the Gries glacier orerspreading the mountains at the opposite side of the valley of the Rhone. It was on this glacier that M. Guyot made his observation.

467. "I saw," he said, "under my feet the sirface of the entire glacier covered with regular furrows. from one to two inches wide, hollowed out in a half-snowy mass, and separated by protruding plates of harder and more transpareut ice. It was evident that the glacier liere was composed of two kinds of ice, one that of the furrows, snowy and more easily melted; the other of the plates, more perfect, crystalline, glissy, and resistant ; and that the unequal resistance which the two kinds of ice piesented to the atmosphere was the cause of the ridges.

468. " After having followed them for sevcral hundred yards, I reached a crevasse twenty or thirty feet wide, which, as it cut the plates and furrows at right angles, exposed the interior of the glacier to a depth of thirty or forty feet, and gave a beautiful transverse section of the structure. As far as my eyes could reach, I saw the mass of the glacier composed of layers of snowy ice, each two of which were separated by one of the hard plates of which I have spoken, the whole forming a regularly laminated mass, which resembled certain calcareous slates."

469. I have not failed to point out to you upon all the glaciers that we have visited the little superficial furrows here described; and Fou have, moreover, noticed that in the furFows mainly is lodged the finer dirt which is scattered over the glacier. 'They suggest the passage of a rake over the ice. And whenever these furrows were interrupted by a crevasse, the veined structure invariably ' $r c$ vealed itself upon the walls of the fissure. The surface grooving is indeed an infallible indication of the interior lamination of the iree. 
470. We have tracked the structure through the various parts of the glaciers at which its appearance was most distinct ; and we have paid particular attention to the condition of the ice at these places. The very fact of its cutting the crevasses at right angles is significant. We know the mechanical origin of the crevasses; that they are cracks formed at right angles to lines of tension. But siuce the crevasses are also perpendicular to the planes of structure, these plaues must be parallel to the lines of tension.

471. On the glaciers, howerer, tension rarely occurs alone. At the sides of the glacier, for example, where marginal crevasses are formed, the tension is always accompanied by pressure; the one force acting at right angles to the other. Here, therefore, the veined structure, which is parallel to the lines of tension, is perperdicular to the lines of pressure.

472. That this is so will be crident to you in s moment. Let the adjicent figure rep-

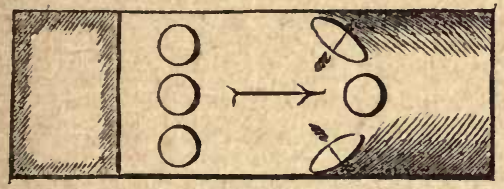

Fig. 19.

resent the channcl of the glacicr moving in the direction of the arrow. Suppose three circles to be marked upon the ice, one at the centre and the two others at the sides. In a glacier of unif $\mathrm{rm}$ inclination all these circles would move downward, the central one only remaining a circle. By the retardation of the sides the marginal circles would be drawn sut to ovals. The two circles would be elongated in one direction, and compressed in another. Across the long diameter, which is the direction of strain, we have the marginal crevasses: across the short diameter $m n$, which is the direction of pressure, we have the marginal veined structure.

473. This association of pressure and structure is invariable. At the bases of the cascades, where the inclination of the bed of the glacier suddenly clianges, the pressure in many cases suffices not only to close the crevasses but to violently squeez 3 the ice. At such places the structure always appears, swecping quite across the glacier. When two branch glaciers unite. their mutual thrusi istensifies the pre-existing marginal structure of the branches, and develops new planes of lamination. Under the medial morancs, therefore, we have usually a 'good derelopment of the structure. It is tinely displayed, for example, under the great medial moraine of the glacier of the Aar.

474. Upon this glacier, indeed, the blue voins were obeerved independently three years after M. Guyot had first described them. I say independently, because $M$. Guyot's description, though written in 1838, remained unprinted, and was unknown in
1841 to the obscrivers on the Aar. These were M. $\Lambda$ gassiz and Professor Forbes. To the question of structure Professor Forbes subsequently devoted much attention, and it was mainly his observations and reasoningy that gave it the important position now assigned to it in the phenomena of glaciers.

475. Thus without quitting the glaciers themselves, we establish the connection bo tween pressure and structure. Is there anything in our previous scientifis experience with which these facts may be connected? The new knowledge of nature must always strike its roots into the old, and spring from it as an organic growth.

\section{$\S$ 66. Slate Cleavage aNd Glacikr LaMination.}

476. M. Guyot threw out an exceedingly sagacious lint, when he compared the veined structure to the cleavage of slate rocks. We must learn something of this cleavage, for it really furnishes the key to the problem which now occupies us. Let us go then to the quarries of Bangor or Cumberland, and observe the quarrymen in their sheds splitting the rocks. With a sharp point struck skilfully into the edge of the slate, they cause it to divine into thin plates, fit for roofing or ciphering, as the case may be. The surfaces along which the rock cleaves are called its planes of cleavage.

$47 \%$. All tlirough the quarry you notice the direction of these planes to be perfectly constant. How is this laminated structure to be accounted for?

478. You might be disposed to consider that clcavage is a case of stratification or bedding ; for it is true that in various parts of England there are rocks which can be cloven into thin flags along the planes of bedding. But when we examine these slate rocks we verify the observation, first I bo lieve made by the eminent and venerable Professor Sedgwick, that the planes of bedding usually run across the planes of cleavarge.

4 i9. We have here, as you observe, a case exactly similar to that of glacier lamination, which we were at first disposed to regard as due to stratification. We afterward, however, found planes of lamination crossing the layers of the névé, exactly as the planes of cleavage cross the beds of slate rocks.

480. But the analogy extends further. Slate cleavage continued to be a pizzis 10 geologists till the late Mr. Daniel Sharpe made the discovery that shells and other fos. sils and bodies found in slate rocks are invariably flattened out in the plaues of cleavage.

481. Turn into any well-arranged museum -for example, into the School of Mines in Jormyn Street, and observe the eridence there collected. Louk particularly to the fossil trilobites taken frum the slate rock. They are in some cases squeezed to one third of their primitive thickness. Numerull. other specimens show in the most striking manner the flattening out of sheiis.

482. To the evidence adduced by $\mathrm{Mr}$. 
Sharpe, Mr. Sorby added other powerful evidence, founded upnn the microscopic examination of slate rock. Taling both into account, the conclusion is irresistible that such rocks have suffered enormous pressure at right angles to the planes of cleavage, exactly as the glacier has demonstrably suffered great pressure at right angles to its planes of lamination.

483. The association of pressure and cleavage is thus demonstrated; but the question arises, Do they stand to each other in the relation of cause and effect? The only way of replying to this question is to combine artificially the conditions of uature, and see whether we cannot produce her results.

484. The substance of slate rocks was once $a$ plastic mud, in which fossils were imbedded. Let us imitate the action of pressure upon such mud by employing, instead of it, softened white wax. Placing a ball of the wax between tho glass plates, wetted to prevent it from sticking, we alply jressure and flatten out the wax.

485. The flattened mass is at first too soft to cleave sliarply ; but you can see, by tearing, that it is laminated. Let us chill it with ice. We find afterwaid that no slate rock ever exhibited so fine a cleavage. The lamina, it need hardly be said, are perpendicular to the pressure.

486. One cause of this laminaticn is that the wax is an aggregate of granules the surfaces of which are places of weak coliesion; and that by the pressure these granules are squeezed flat, thus producing planes of wcakness at right angles to the pressure.

48\%. But the main cause of the cleavage I take to be the lateral sliding of the particles of wax over each other. Old attaclments are thereby severed, which the new ones fail to make good. 'Thus the tangential sliding produces lamination, as the rails near a station are caused to exfoliate by the gliding of the wheel.

488. Instead of wr.x we may take the slate itself, grind it to fire powrler, add water, and thus repreduce the pristine mud. By the proper compression of such mud, in one direction, the cleavage is restored.

489. Call now to mind the evidences we have had of the power of thawing ice to yield to pressure. Recollect the shortening of the Glacier du Geant, and the squeezing of the Glacier de Léchaud, at Trélaporte. Such a substance, slowly acted upon by pressure, will yield laterally. Its particles wi! slide over each other, the severed attachments being immediately made good by tegelation It will not yield uniformly, but :iong special planes. It will also liquefy, not uniformly, but along special surfaces. Both the sliding and the liquefaction will take place principally at right angles to the pressure, and glacier lamination is the result.

490. As long as it is sound the laminated glacicr ice resists cleavage. Regelation, as I have said, makes the severed attachments good. But when such ice is exposed to ita weather the structure is revealed, and the ice can then be cloven into tablets a square foot, or eren a square yard in urea.

\section{$\S 67$. Conclusion.}

491. Here, my friend, our labors close. It has been a true pleasure to me to have you at my side so long In the sweat of our brows we havo often reached the heights where our work lay, but you liave been steadfast and industrious throughout, using in all possible cases your own muscles instead of relying upon mine. Here and there I have stretched an arm and helped you to a ledge, but the work of climbing has been almost exclusively your own. It is thus that I should like to teach you all things; show. ing you the way to profitable exertion, but leaving the exertion to you-more anxious to bring out your manliness in the preserice of difficulty than to make your way smocth by toning difficultics down.

492. Steadfast, prudent, without terror, though not at all times without awe, I have found you on rock and ice,-and you have shown the still rarer quality of steadfastness in intellectual effort. As here set forth, our task seems plain enough, but you aud I know how often we have had to wrangle resolutely with the facts to bring out their meaning. The work, however, is now done, and you are master of a fragment of that sure anil certain knowledge which is founded on the faithful study of nature. Is it not worth the price paid for it? Or rather, was ant the paving of the price-the healthful, if some times hard, exercise of mind and body, upon alp and glacier-a portion of our delight?

493. Here then we part. And should we not meet again, the memory of these days will still unite us. Give me your haud. Good-by. 


\section{LESSONS IN ELECTRICITY.}

JOHN TYNDALL. 



\section{LESSONS ON ELECTRICITY.}

\section{CONTENTS:}

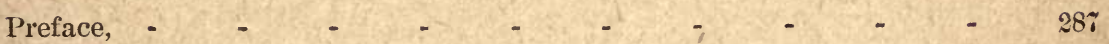

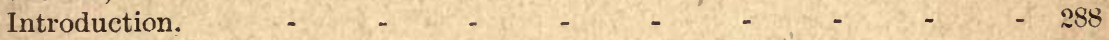

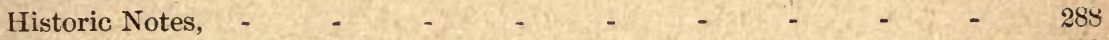

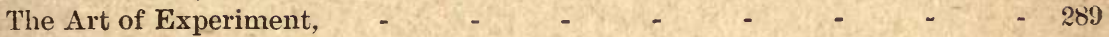

Matcrials for Experiment, - $\quad$ - $\quad$ - $\quad$ - $\quad$ - $\quad$ - 289

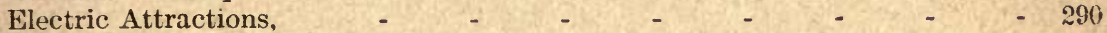

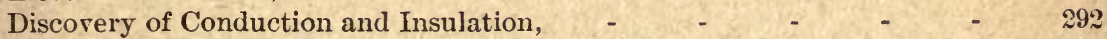

The Electroscope-Further Inquiries on Conduction and Insulation, - _ - 293

Electrics and Non-Electrics, - _ _ _ _ _ _ _ _ _ _ $\quad 295$

Electric Repulsions.-Discovery of Two Electricities, _ - _ _ _ - $\quad 296$

Fundamental Law of Electric Action, _ _ _ _ _ _ _ _ _ $\quad$ - $\quad 297$

Electricity of the Rubber.-Double or "Polar" Character of Electric Force, 293

What is Electricity?

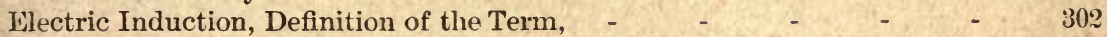

Experimental Researches on Electric Induction, _ _ - _ _ _ _ - _ - - 3033

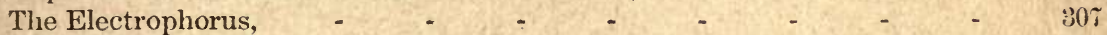

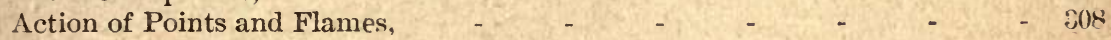

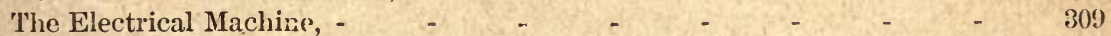

Further Experiments on the Action of Points.-The Electric Mili -The Golden

Fish.-Lightening Conductors, _ _ _ _ _ _ _ _ $\quad$ - 311

History of the Leyden Jar.-The Leyden Battery, - - _ _ _ _ _ _ 314

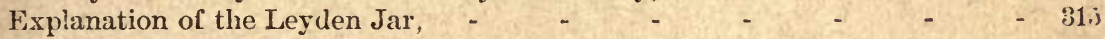

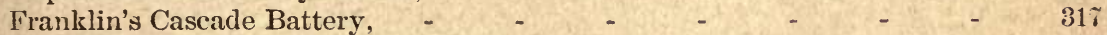

Novel Leyden Jars of the Simplest Form, _ _ _ _ _ _ - _ _ _ -

Seat of Charge in the Leyden Jar, _ _ _ _ _ _ _ _ 319

Ignition by Electric Spark.-Cottrel's Rubber.-The Tube Machine, - _ - 320

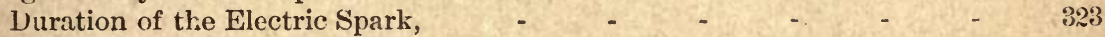

Electric Light in Vacim,

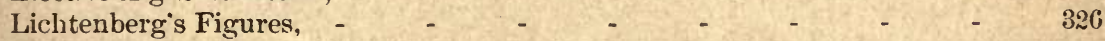

Surface Compared with Mass.-Distribution of Electricity in Hollow Concuctors, 326

Physiological Effects of Electric Discharges, _ _ _ _ _ _ _ _ $\quad 328$

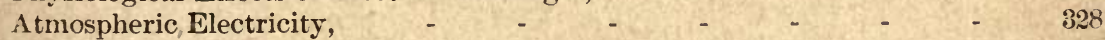

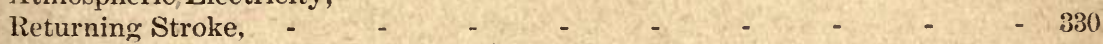

The Leyden Battery, Its Currents, and some of their Effects, _. _ _ _

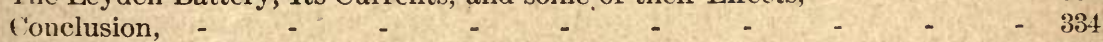

Appendix. - An Elementary Lecture on Magnetism, _ _ _ _ _ 334 



\section{LESSONS IN ELECTRICITY;}

TO TVHICH IS $\triangle$ DDED

\section{AN ELEIENTARY LECTURE ON MAGNETISII.}

BY

$$
\text { JOHN TYNDALL, D.C.L., LL.D., F.R.S., }
$$

PRCFESSOR OF NATCRAL PHILOSOPIIY IN THE ROYAL INSTITUTION OF GREAT DRITAIN.

WITH SIXTY ILLUSTRATIONS.

\section{PREFACE.}

Mors than fifty years ago the Board of Managers of the Royal Institution resolved to extend its usefulness, as a centre of scicntific instruction, by giving, during the Christmas and Easter holidays of each year, two courses of Lectures suited to the intelligence of boys and girls.

On December 12th, 1825, a Committec appointed by the Managers reported "that they had consulted Mr. Faraday on the subject of engaging him to take a part in the juvenile lectures proposed to be given during the Christmas and Easter recesses, and they found his occupations were such that it would be exceedingly inconvenient for him to engage in such lectures."
Faraday's holding aloof was, however, but temporary, for at Christmas 1827 we find him giving a "Course of Six Elementary Lectures on Chemistry, adapted to a Juvenile Auditory."

The Easter lectures were soon abandoned, but from the date mentioned to the present time the Christmas lectures have been a marked feature of the Royal Institution.*

Last Christmas it fell to my lot to give one of these courses. I had heard doubts expressed as to the value of sciencè-teaching in schools, and I had heard objections urged on the score of the expensiveness of apparatus. Both donlts and

* These brief historic references have al. ready appeared in the preface to the "Forus of Water." 
objections would, I considered, be most practically met by showing what could be done, in the way of discipline and instruction, by experimental lessons involving the use of apparatus so simple and inexpensive as to be within everybody's reach.

With some amplification, the substance of our Christmas Lessons is given in the present little volume.

\section{LESSONS IN ELECTRICITY.}

\section{§ 1. Introduction.}

Many centuries before Christ, it had been observed that yellow amber (elcktron), when rubbed, possessed the power of attracting light bodies.

Thales, the founder of the Ionic philos. ophy (B.C. 580), imagined the amber to be endowed with a kind of life.

This is the germ out of which has grown the scienee of electricity, a name larived from the substance in which this I) wer of attraction was first observed.

It will be iny aim, during six hours of these Christmas holidays, to make you, to some extent, acquainted with the history, facts, and principles of this science, and to teach you how to work at it.

The science has two great divisions: the one called "Frictional Electricity," the other "Voltalc Electricity." For the present, our studies will be confined to the first, or older portion of the science, which is called "Frictional Electricity," because in it the electrical power is obtained from the rubiing of bodies together.

\section{§ 2. Historic Notes.}

The attraction of light bodies by rubbed amber was the sum of the world's knowledge of electricity for more than 2000 years. In 1600 Dr. Gilbert, physician to Qucen Elizabeth, whose attention had been previously directed with great success to magnetism, vastly cxpanded the domain of electricity. He showed that not only amber, but various spars, gems, fossils, stones, glasses, and rusins, exhibited, when rubbed, the same power as amber.

Robert Boyle (1675) proved that a suspended piece of rubbed amber, which attracted other bodie.s to itseif, was in turn attracted by a body brought near it. He also observed the light of electricity, a diamond, with which he experimented, being found to emit light when rubbe 1 in the dark.

Bayle imagined that the electrified body threw out an invisible, glutinous substance, which laid hold of light bodies, and, returning to the source from which it emanated, carried them along with it.

Otto von Guericke, Burgomaster of Nagleburg, contemporary of Bovle, and inventor of the air-pump, intensified the electric power previously obtainei. He devised what may be called the first electrical machine, which vas a ball of sulphur, about the size of a child's head. Turned by a handle, and rubbed by the dry hand, the sulphur sphere emitted light in the dark.

Von Guericke also noticed, and this is important, that a feather, liaving been first attracted to his sulphur globe, was afterward repelled, and kept at a distance from it, until, having touched another body, it was argain attracted. He heard the hissing of the " electric fire," and also observed that an unclectrified body, when brought near his excited sphere, became electrical and capable of being attracted.

The members of the Academy del Cimento examined various substances electrically. They proved smoke to bo s'tracted, but not flame, which, they found, deprived an electrified body of its power.

They also proved liquids to be sensible to the electric attraction, silowing that when rubbed amber was held over the surface of a liquid, a little eminence was formed, from which the liquid was finally discharged against the amber.

Sir Isaac Newton, by rubbing a flat glass, caused light bodies to jump between it and a table. He also noticed the influence of the rubber in electric excitation. His gown, for example, was found to be much more effective than a napkin.

Newton imagined that the excited body emitted an elastic fluid which penetrated glass.

In the efforts of Thales, Boyle, and Newton to form a mental picture of electricity we have an illustration of the ten- 
dency of the human mind, not to rest satisfied with the facts of observation, lut to pass beyond the facts to their invisible causes.

Dr. Wall (1708) experimented with large, clongated pieces of amber. Ile found wool to be the best rubber of amber. "A prodigious number of little cracklings" was produced by the friction, every one of them being accompanied by a flash of light. "This light and crackling," says Dr. Wall, " seem in some degree to represent thunder and lightning." This is the first published allusion to thunder and lightning in connection with electricity.

Stephen Gray (1729) also observed the clectric brush, snappings, and sparks. $\mathrm{He}$ inade the prophetic remark that " though these effects are at present only minute, it is probable that in time there may be found out a way to collect a greater quantity of the electric fire, and, consequently, to increase the force of that power which by several of those experiments, if we are permitted to compure great things with small, seems to be of the same nature with that of thunder and lightning." This, you will observe, is far more definite than the remark of Dr. Wall.

\section{$\S$ 3. The Art of Experiment.}

We have thus broken ground with a few historic notes, intended to show the gradual growth of electrical science. Our next step must be to get some knowledge of the facts referred to, and to learn how they may be produced and extended. The art of producing and extending such facts, and of inquiring into them by proper instruments, is the art of experiment. It is an art of extreme importance, for by its means we can, as it were, converse with Nature, asking her questions and receiving from her replies.

It was the neglect of experiment, and of the reasoning based upon it, which kept the knowledge of the ancient world contined to the single fact of attraction ly amber for more than 2000 years.

Skill in the art of experimenting does not come of itself; it is only to be acquired by labor. When you first take; a billiard cue in your liand, your strokes are awkward and ill-directed. When you learn to dance, your first movements are neither graceful nor pleasant. By practice alone, you learn to dance and tu play. This also is tho only way of learning the art of experiment. You must not, therefore, be daunted by your clumsiness at first : you must overcome it, and acquire skill in tho art by repetition.

In this way you will come into direct contact with natural truth-you will think and reason not on what has been said to you in books, but on what has been said to you by Nature. Thought springing from this source has a vitality not derivable from mere book-knowledge.

\section{§ 4. Materials for Experiment.}

$\Delta t$ this stage of our labors we are to provide ourselves with the fallowing inaterials :

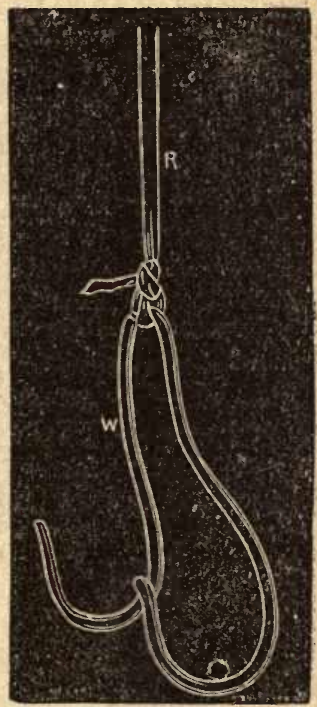

FIG. 1.

a. Some sticks of sealing-wax ;

3. Two pieces of gutta-percha tubing, about 18 inches long and $\frac{8}{4}$ of an incl outside diameter;

c. Two or three glass tubes, about is inches long and $\frac{3}{4}$ of an inch wide, closed at one end, and not too thin, lest they should break in your hand and cut it ;

$d$. T'wo or three pieces of clean flannel, capable of being folded into pads of two or three layers, about eight or ten inches square ; 
e. A couple of pads, composed of three or four layers of silk, about eight or ten inches square ;

f. A board about 18 inches square, and a piece of india-rubber ;

q. Some very narrow silk ribbon, $\mathrm{r}$, and a wire loop, w, like that shown in fig. 1, in which sticks of sealing-wax, tubes of gutta-percha, rods of glass, or a walking-stick, may be suspended. I choose a narrow ribbon because it is convenient to have a suspending cord that will neither twist nor untwist of itself.

(I usually employ a loop with the two ends, which are here shown free, soldered together. The loop would thus be unbroken. But yon may not be skilled in the art of soldering, and I therefore choose the free loop, which is very easily constructed. For the purpose of suspension an arrangement resembling a towelhorse, with a single horizontal rail, will be found convenient).

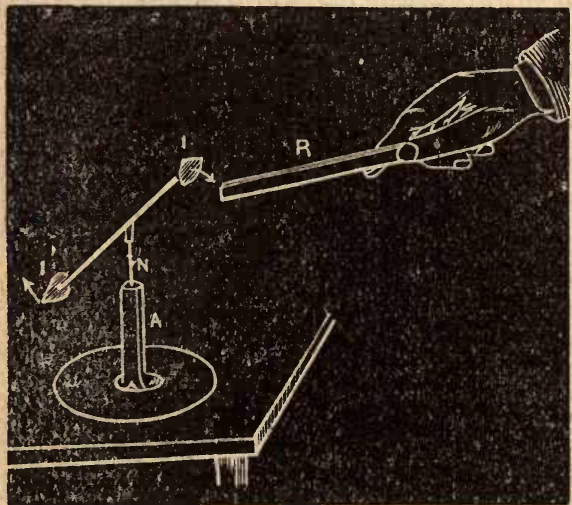

Fig. 2.

h. A straw, I I', fig, 2, delicately supported on the point of a sewing needle N. This is inserted in a stick of sealing-wax $A$, attached below to a little circular plate of tin, the whole forming a stand. In fir. 3 the straw is shown on a larger scale, and separate from its needle. The shori bit of straw in the middle, which serves as a cap, is stuck on by sealingrax.

$i$. The name "amalgam" is given to a mixture of mercury with other mzials. Experience has shown that the efficacy of a silk rubber is vastly increased when it is smeared over with an amalgam formed of 1 part by weight of tin, 2 of zine, and 6 of mercury. A littlo lard is to he first smeared on the silk, and the rmalgam is to be applied to the lard. The amalgam. if hard, must be pounded or lisuised with a pestle or a hammer until it is soft. You can purchase sixpenny-worth of it at a philosophical instrument maker's. It is to be added to your materials.

k. I should like to make these pages suitable for boys without much pocketmoney, and, therefore, aim at economy in my list of materials. But provide by all means, if you can, a fox's brush, such

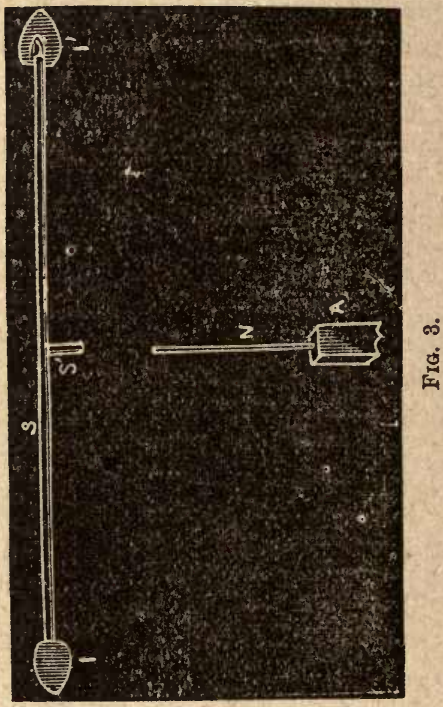

as those usually cmployed in dusting furniture.

\section{$\S$ 5. Electric Attractions.}

Place your scaling-wax, gutta-percha tubing, and tlannel and silk rubber's before a fire, to insure their dryness. Be specially careful to makc your glass tubes and silk rubbers not only warm, but hot. Pass the unied flannel briskly once or twice over a stick of sealing-wax or over a gutta-percha tube. A very small amount of friction will excite the power of attracting the suspended strav as shown in fig. 2. Repeat the exponment several times and cause the straw to follow the attracting budy round and round. Do the same witl a glass tube rubbed with silk.

I lay particular stress on the heating of the glass tube, because glass has the 
power, which it exercises, of condensing upun its surface into a liquid film, the anneons vapor of the surrounding air. This film must be removed.

I would also insist on practice, in order to render you expert. You will therefore

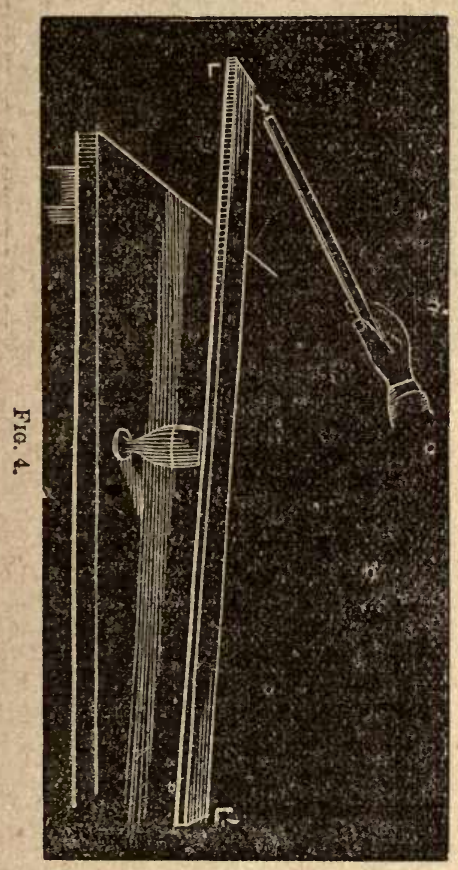

attract bran, scraps of paper, gold leaf, soap bubbles, and other light bodies by rulibed glass, sealing-wax, and guttapercha. Faraday was fond of making empty egg shells, hoops of paper, and other light objects roll after his excited tubes.

It is only when the electric power is rery weak, that you reynire your delicately suspended straw. With the sticks of wax, tubes, and rubbers here mentioned, even heavy bodies, when properly suspended, may be attracted. Place, for instance, a common walking stick in the wire loop attached to the narrow ribbon, fig. 1, and let it swing horizontally. The glass, rubbed with its silk, or the sealingwax, or gutta-pereha. mbbed with its flannil, will pull the stiek quite round.

Abandon the wire loop; place an egg in an cog-cup, and balanec a long lath upon the egrg, as shown in fig. 4. The lath, though it may be almost a plank, will obediently follow the rubbed glass, gutta-percha, or sealing-wax.

Nothing can be simpler than this lath and egg arrangement, and hardly anything could be more impressive. The more you work with it, the better you will like it.

Pass an ebonite comb through the hair. In dry weather it produces a crackling noise ; but its action upon the lath may be made plain in any weather. It is rendered clectrical by friction against the hair, and with it you can pull the lath quite round.

If you moisten the hair with oil, the comb will still be excited and exert attraction ; but if jou moisten it with water, the excitement ceases; a comb passed throngh wetted hair has no power over the lath. You will understand the meaning of this subsequently.

After its passage thronghli dry or oiled hair, balance the comb itself upon the egg : it is attracted by the lath. You thus prove the attraction to be mutual: the comb attracts the lath, and the lath attracts the comb. Suspend your rubbed glass, rubbed gutta-percha, and rubbed sealing-wax in your wire locp. They aro all just as much attracted liv the lath as the lath was attracted by them. This is an extension of Boyle's expeniment with the suspended amber $(\S 2)$.

How it is that any unelectrified body attracts, and is attracted by the excited glass, sealing-wax, and gutta-percha, we shall learn by and by.

A very striking illustration of electric attraction may be obtained with the board and india-rubber mentioned in our list of materials $(\S 4)$. Place the board before the fire and make it hot; heat also a sheet of foolscap paper and place it on the board. There is no attraction bo tween them. Pass the india-rubber briskly over the paper. It now elings firmly to the board. Tear it away, and hold it at arm's length, for it will move to your body if it can. Bring it near a door or wall, it will cling tenaciously to either. The electrified paper also powerfully attracts the balanced lath from a great distance.

The friction of the hand, of a cambric handkerchief, or of wash-leather fails to alectrify the paper in any high łegree. It requires friction by a 
spceral sulistance to make the excitement strong. This we learn by experience. It is alsu experience that has taught us that resiuous bodies are best excited by tlanilci, and vitreous budies by sil's.

Take nothing ror granted in this inquiry, and neglect no effort to render your knowledge complete and sure. Try various rubbers, find satisfy yourself that differences like ihat first observed by Newton exist between them.

Viry also the body rubbed. Excite by friction paraftine and composite candies, resin, sulphur, beeswax, ebonite, and shellac. Also rock-crystal and other vitreous substances, anil attract with all of thern the balanced lath. A film of collodion, a sheet of vulcanized indiarubber, or browa paper huated before the fire, rubbed briskly with the dry hand, attracts and is attracted by the lath.

Lay bare also the true influence of heat in the case of our rubbed paper. Spread a cold shect of foolscap on a cold buard-on a table, for example. If the air be not very dry, rubbing, even with the india-rubber, will not make them cling together. But is it because they were hot that they attracted each other in the first instanc? $\mathrm{No}$, for you may heat your board by plunging it into boiling vater, and your paper by holding it in a cloud of steam. Thus heated they cannot be made to cling together. The heat really acts by expelling the moisture. Cold weather, if it be only dry, is highly favorable to electric excitation. During frost the whisking of the hand over silk or flaunel, or over a cat's back, renders it electrical.

The experiment of the Florentine academicians, whereby they proved the electric attraction of a liquid, is pretty, and worthy of repetition. Fill a very snall watch-glass with oil, until the liquid forms a round curved surface, rising a little over the rim of the glass. A strungly excited glass tube, held over the oil, raises not one eminence onlr, but several, each of which finally discharges a shower of drops anainst the attracting glass. The effect is shown in fig. 5, where $G$ is the watch-glass on the stand $r$, and $\mathrm{R}$ the excited glass tube.*

Cause the excited glass tube to pass

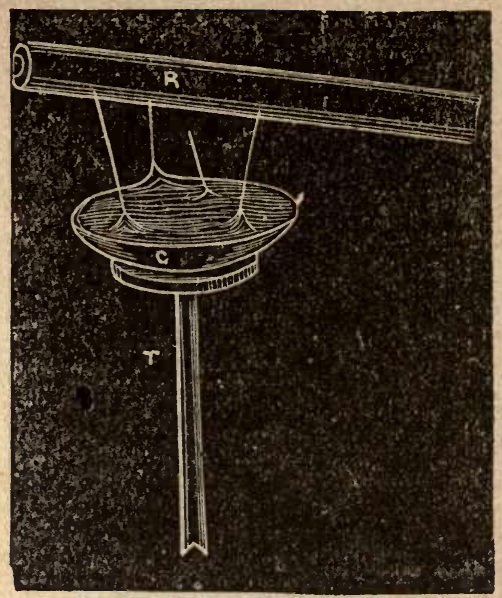

Fig. 5.

close by your face, without touching it. You feel, like IIauksbee, as if a cobweb were drawn over the face. You also sometimes smell a peculiar odor, due to a substance deveioped by the electricity, and called ozone.

Long ere this, while rubbing rour tubes, you will have heard the "liissing" ani " crackling" so often referred to by the eariier electricians ; and if you have rubbed your glass tube briskly in the dark, you will have seen what they called the "electric fire." Using, instead of a tube, a tall glass jar, rendered hot, a good warm rubber, and vigorous friction, the streams of electric fire are very surprising in the dark.

\section{$\S$ 6. Discovery of Condurtion and Insu- lation.}

IIere I must again refer to that most meritorious philosopher, Stephen Gray. In 1729 he experimented with a glisis tube stopped by a cork. When the tubo was rubbed, the cork attracted light bod. ies. Gray states that he was " much surprised" at this, and he "concluded that there was certainly an attractive vir. tue communicated to the cork." This was the starting point of our knowledire of electric Conduction.

A fir stick 4 inches long, stuck into the cork, was also found by Gray to attract light bodies. He made his sticks

* As a practical measure the watch-glass vught to rest upon a small starn, and not upon a surface of large area. The experiment is particularly well suited for projection on a screen. 
Innger, but still found a power of attraction at their ends. IIe then passed on to pack-thread and wire. Hanging a thread s, fig. 6 , from the top window of a house, so that the lower end nearly touned the ground, and twisting the upper end of the thread round his glass tube $\mathrm{R}$, on briskly rubbing the tube, light bodies were attracted by the lower end B of the thread.

But Gruy's most remarkable experiment was this: Ilo suspended a long hempen line horizontally by loops of packthread, but failed to transmit through it the electric power. He then suspended it hy loops of silk and succeeded in

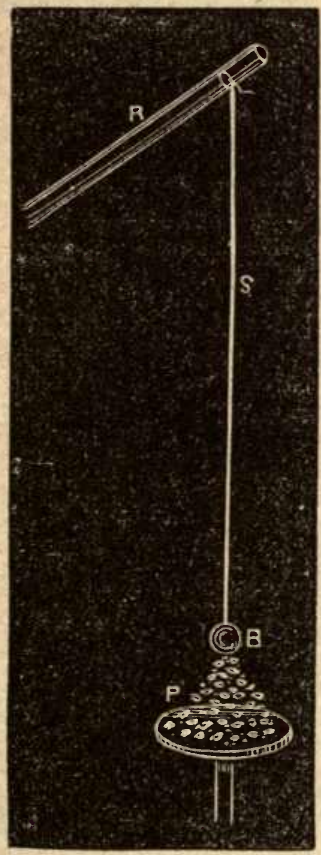

FIG. 6.

sending the "attractive virtue" through 765 feet of thread. He at first thought the silk was effectual because it was thin; but on replacing a broken silk loop by a still thinner wire, he obtained no action. Finally, he came to the conclusion that bis loops were effectual, not because they were thin but because they were silk. This was the starting-puint of our knowledire of Insulation.

It is interesting to notice the devotion of some men of science to their work. Dr. Wells, who wrote a beautiful cesay, wherein he explained the origin of dew, finished it when he was on the brink of the grave. Stephen Gray was so near dying when his last experiments were made, that he was unable fo write out an account of them. On his death-bed, and, indeed, the very day before his death, his description of them was taken from his lips by Dr. Mortimer, Secretary of the Royal Society, and afterward printel in the "Philosophical Transaclions.",

One word of definition will be useful here. Some substances, as proved by Stephen Gray, possess in a very high degree the power of permitting electricity to pass through them ; other substances stop the passage of the electricity. Bodies of the first class are called conductors; bodies of the second class are called insulators.

You cannot do better than repeat here the experiments of Gray. Push a cork into the open end of your glass tube ; rub the tube, carrying the friction up to the end holding the cork. The cork will attract the balanced lath, shown in fig. 4, with which you lave already worked so much.

Tiat the excited glass is here so near the end of the cork that you may not feel certain that the obserred attraction is that of the cork. You can, lowever, prove that the cork attracts by its action upon light bodies which eling to it. Stick a pen-holder into the cork and rub the grlasis tube as before. The free end of the holder will attract the lath. Stick a deal rod three or four feet long into the cork ; its free end will attract the lath when the glass tube is excited. In this way you prove to demonstration that the electric puwer is cunveyed along the rod.

\section{\& 7. The Electroscope. - Further Inquir. ies on Conduction and Insulation.}

A little addition to our apparatus will now be desirable. You can buy a book of "Dutch metal" for fourpence ; an I a globular flask like that sliown in fi s. $\eta$, for sixpence, or at the most a shi!ling. Find a cork, c, which fits the flask ; pis a wire, w, thromph the cork an I benl it near one end at a rirlit anirle. Attach by means of wax to the bent arm, which ought to be about three quarters of an iuch long, two strips, I, of the Dutch 


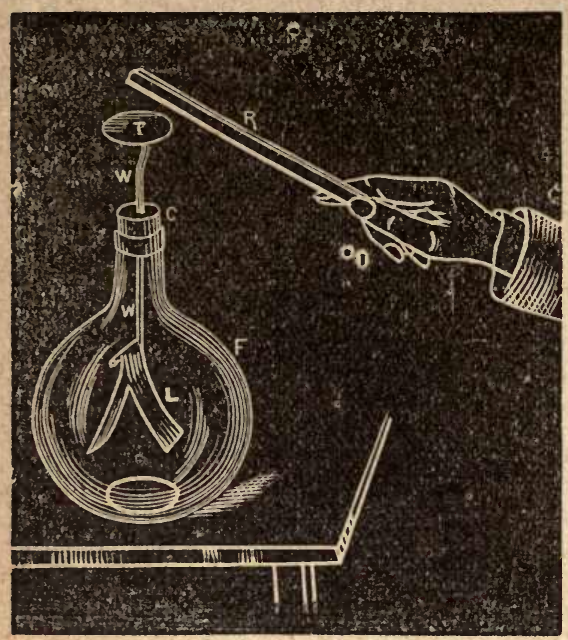

Fra. 7.

metal, about three inches long and from half an inch to three quarters of an inch wide. The strips will hang down face to face, in contact with each other. Stic's by sealing-wax upon the other end of the wire a little plate of tin or shect-zine, $r$, about two inches in diameter. In all eases you must be careful so to use your wax as not to interrupt the metallic connection of the varions parts of your apparatus, which we will name an electroscope. Gold-leaf, instead of Dutch metal, is usually employed for electroscopes. I reconimend the "metal" because it is cheaper, and will stand rougher usage.

See that your globular flask is dry and free froin dust. Bring your rubbed sealing-wax, R, or your rubbed glass, near the little plate of tin, the leaves of Dutch metal open out; withdraw the excited body, the leaves fall together. IVe shall inquire into the cause of this action immediately. Practise the approach and withdrawal for a little time. Now draw your subbed sealing-wax or glass along the edge of the tin plate, $T$. The leaves diverge, and after the sealing-wax or glass is withdrawn they remain divergent. In the first experiment you communieated no electricity to the electroscope ; in the second experiment you did. At present I will only ask you to take the opening out of the leaves as a proof that electricity has been communicated to them.
And now we are ready for Gray's ex. periments in a form different froin his. Connect the end of a lung wire with the tin plate of the clectroseope; coil the other end round your glass tube. Rub the tube briskly, carrying the friction close to the coiled wire. A single stroke of your rubber, if skilfully given, will cause the leaves to diverge. The electricity has obvionsly passed through the wire to the electroscope.

Substitute for the wire a string of common twine, rub briskly and you will cause the leaves to diverive; bat there is a notable difference is recards the promptness of the divergence. You soon satisfy yourself that the electricity , a ses with greater facility throngh the wire than through the string. Substitute for the twine a string of silk. No matter how vigorously you rub, you can now produce no divergence. The electricity cannot get through the silk at all.

This is the place to demonstrate in a manner never to be forgotten the intluence of moisture. Wet your dry silk string throughout, and squeeze it a little so that the water from it may not trick!? over your glass tule. Cuil it round the tube as before, and excite the tube. The leaves of the electroseope immediately diverge. The water is here the conductor. The influence of moisture was first demonstrated by Du Fay (1733 to 1737), who succeeded in sending electricity through 1256 feet of moist packthread.

It is hardly necessary to point out the meaning of Gray's experiment where he found that, with loops of wire or of pack-thread, he could not send the electricity from end to end of his suspended string. Obviously the electricity escaped in each of these cases through the conducting support to the earth.

$\mathrm{My}$ assistant, Mr. Cotírell, who has been working very hard for you and me, has devised an electroseope which we shall frequently cmploy in our lessons. M, fig. 8 , is a little plate of metal, or of wood covered with tin-foil, supported on a rod, $\mathrm{G}$, of glass or of sealing-wax. N is another plate of Dutch metal paper, separated about an inch from $\mathrm{M}$, aud attached by sealing wax to the long straw $\mathrm{I}^{\prime}$ (broken off in the figure); $\mathbf{A} \mathbf{A}^{\prime}$ is a horizontal pivot formed by a sewing 


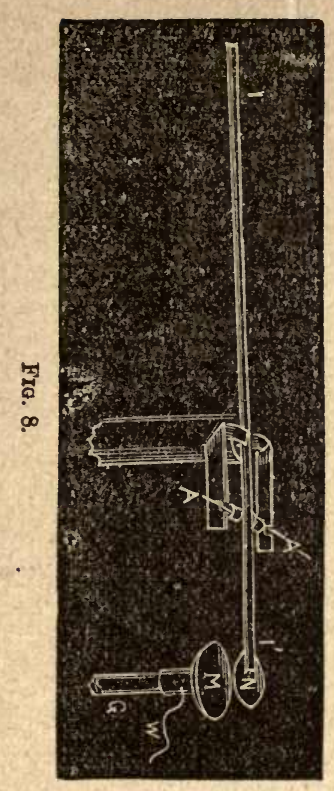

needle, and supported on a bent strip if metal, as shown in the figure. By weight. iug the straw with a fittle wire near $\mathrm{s}^{\prime}$, you so balance it that the plate $\mathrm{N}$ shall be just lifted away from $\mathrm{s}$, The wire $w$, which may be 100 feet long, procec'ds from a to your glass tube, round which it is coiled. A single vigorous stroke of the tube, by the rubber, sends electricity along $w$ to $\mathrm{M} ; \mathrm{N}$ is attracted downward, the other end of the long straw being lifted through a considerable distance. In subsequent figures you will see the complete straw-index, and its modes of application.

A few experiments with either of these instruments will enable you to classify bodies as conductors, semi-conductors, and insulators. Here is a list of a few of each, which, however, differ much atrong themselves.

\section{Conductors.}

The common metals.

Well-burned cluarcoal.

Conceutrated acids.

Silutions of salts.

Rain water.

Liuen.

Living regetables and animuls.

\section{Semi-conductors.}

Alcohol and ether. Paper.

Dry wochl.

Marble.

\section{Insulators.}

Fally oils.

Chall.

India-rubber.

Dry paper.

Haii:
Silk.

Glass.

Wax.

Sulplumr.

Shellac:
A little reflection will enable you to vary these experiments indefinitcly. liul, your excited scaling-wax or glass agrinst the tin plate of your clectroscupc, and cause the leaves to diverge. Tonch the plate with any one of the conducturs mentioned in the list; the clectroseope is immediately discharged. Touch it with a semi-conductor; the leaves fall as $1 \mathrm{e}$. fore, but lcss promptly. Touch the plate finally with an insulator, the elec. tricity cannot pass, and the leaves remain unchanged.

\section{\$ 8. Electrics and Non-Electrics.}

For a long period, bodies were divided into tiectrics and non-electrics, the former deemed capahle of being electritind. the latter not. Thus the amber of the ancients, and the spars, gems, fossils, stones, glasses, and resins, operated on by Dr. Gilbert, were called electrics, while all the metals were called non-electrics. We must now determine t!e true meaning of this distinction.

Take in succession a piece of brass, of wood coated with tin-foil, a lead bullet, apples, pears, turnips, carrots, cucum. bers-uncoated wood not very dry will also answer-in the hand, and strike them briskly with flannel, or the fox's brush ; none of thern will attract the balancerl lath, fig. 4 , or show any other symptom of electric excitement. All of them therefore would have been unce called non-electries.

But suspend them in succession by a string of silk held in the hand, and strike them again ; every one of them will now attract the lath.

Reflect upon the meaning of this experiment. We have introduced an insulator-the silk string-between the hand and the body struck, and we find that by its introdiction the non-electric has been converted into an electric.

The meaning is obvious. When held in the hand, though electricity was developed in each case by the friction, it passed immediately through the hand and body to tho easth. This transfer being prevented by tho silk, the electricity, 
once excited, is retained, and the attraction of the lath is the consequence.

In like manner, a brass tube, held in the hand and struck with a fox's brush, shows no attractive power; but when a stick of sealing-wax, ebonite, or guttapercha is thrust into the tube as a handle, the striking of the tube at once develops the power of attraction.

And now you see more clearly than you did at first the meaning of the ex periment with the heated foolscap and india-rubber. Paper and wood always imbibe a certain amount of moisture from the air. When the rubber was passed over the cold paper electricity was excited, but the paper, being rendered a conductor by its moisture, allowed the electricity to pass away.

Prove all things. Lay your cold foolscap on a cold board supported by dry tumblers; pass your india-rubber over the paper; lift it by a loop of silk which has been previously attached to it, for if you touch it it will discharge itself. You will find it electric ; and with it you can charge your electroscope, or attract from a distance your bilanced lath.

The human body was ranked innong the non-electrics. Make plain to yourself the reason. Stand upon the floor and permit a friend to strike you briskly with the fox's brush. Present your knuckle to the balanced lath, you will find no attraction. Ilere, however, you! stand upon the earth, so that even if electricity had been developed, there is othing to hinder it from passing away.

But, place upon the ground four warm glass tumblers, and upon the tumblers a board.* Stand upon the board and present your knuckle to the lath. A siugle stroke of the fox's fur, if skilfully given, will produce attraction. If you stand upon a cake of resin, of ebonite, or upon a sheet of good india-rubber, the effect will be the same. You can also charge your electroscope with this electricity.

Throw a mackintosh over your shoulders and let a friend strike it with the fox's brush, the attractire furce is greatly augmented.

After brisk striking, present your

* Snme caution is necessary here. A large class of cheap glass tumblers conduct s.3 freely that they are unfit for this and sinilar expetiments. See $\$ 19$. knuckle to the knnckle of your friend.

A spark will pass between you.

This experiment with the mackintosh further illustrates what you have already frequently observed-namely, that it is not friction alone, but the friction of special substances against each other, that produces electricity.

Thus we prove that non-electrics, like electrics, can lie excited, the condition of success being, that an insulator shall be interposed between the non-electric and the earth. It is obvious that the old division into elertrics and non-electries, really meant a division into insulators and conductors.

\section{§ 9. Electric Repulsions.-Discovery of two Electricities.}

We have hitherto dealt almost exclusively with electric attractions, but in an experiment already referred to $(\$ 2)$, Otto von Guericke observed the repulsion of a feather by his sulphur globe. I also anticipated matters in the use of our I atch metal electroscope $(\S 7)$, where the repulsion of the leaves informed us of the arrival of the electricity.

Du Fay, who was the real discoverer here, found a gold-leaf floating in the air to be first attracted and then repelled by the same excited body. He afterward proved that when the floating leaf was repelled by rubbed glass, it was attracted by rubbed resin-and that when it was repelled by rubbed resin it was attracted by rubbed gliss. Hence the important announcement, by Du Fay, that there are two kinds of eleetricity.

The electricity excited on glass was for a time called vitreous elcetricity, while that excited on sealing-wax was called resinous electricity. These terms are however inproper; because, by changing the rubber, we can obtain the electricity of sealing-wax upon glass, and the electricity of glass upon sealing-wax.

Roughen, for example, the surfaco of your glass tube with a grindstone, and rub it with flannel, the electricity of sealing-wax will be found upon the vitreous surface. Rub your sealing-wax with vulcanized india-rubber, the electricity of glass will be found upon the resinous surface. You will be able to prove this immediately. 
We now use the term positive or plus electricity to denote that developed on glass by the friction of silk; and negative or minus electricity to denote that developed on sealing-wax by the friction of fannel. These terms are adopted purely for the sake of convenience. There is no reason in nature why the resinous electricity should not be called positive, and the vitreous electrieity negative. Once agreed, however, to apply the terms as here fixed, we must adhere to this agrcement throughout.

\section{$\S 10$. Fundamental Law of Electric Action.}

In all the experiments which we have hitherto made, one of the substances operated on has been electrified $b$. friction, and the other not. But once ingaged in inquiries of this description, questions incessantly occur to the mind, the answering of which extends our knowledgre and suggests other questions. Suppose; instead of exciting only one of the bodies presented to each other, we were to 'xcite both of them, what would occur? This is the qucstion which was asked and answered by Du Fay, and which wo must now answer for ourselves.

Here your wire loop, fig. 1, comes again into play. Place an unrubbed gutta-percha tube, or a stick of sealingwax, in the loop, and be sure that it is unrubbed - that no electricity adheres to it from former experiments. If it fail to attract light bodies, it is unexcited ; if it attract them, pass your hand over it sevcral times, or, better still, pass it over or through the flame of a spirit lamp. This will remove every trace of clectricity. Satisfy yourself that the unrubbed gutta-percha tube is attracted by a rubbed one.

Remove the unrubhed tube from the loop, and excite it with its tlannel rubber. One end of the tulve is held in your hand and is therefore unexcited. Return the tube to the loop, keeping your eye upon the excited end. Bring a second rubbed tube near the excited end of the suspended olle: strong repulsion is the consequence. Drive the suspended tube round and round by this force of repulsion

Bring a rublued glass tube near the excited end of tise gutta-percha tube: strong attraction is the result.
Repeat this experiment step by step with two glass tubes. Prove that tle rubbed glass tube attracts the unrubbed one. Remove the unrubbed tube from the loop, excite it by its rubber, return it to the loop, and establish the repulsion of glass by glass. Bring rubbed guttapercha or sealing-wax near the rubbed glass : strong attraction is the consequence.

These experiments lead you directly to the fundamental law of electric action, which is this: Bodies charged with the same electricity repel each other, while bodies charged with opposite clectricities attract cach othcr. Positive repcls positive, and attracts negative. Negative repels negative and attracts positive.

Devise experiments which shall still further illustrate this law. Repeat, for example, Otto von Guericke's experiment. IIang a feather by a silk thread and bring your rubbed glass tube near it : the feather is atiracted, touches the tube, charges itself with the electricity of the tube, and is then repelled. Cause it to retreat from the tube in various directions. Du Fay's experiment with the gold-leaf will be repeated and explained further on. See $\$ 18$.

Hang your feather by a commos thread ; if no iusulating substance intervenes between the feather and the earth, you can get no repulsion. Why? Obviously because the charge of positive electricity communicated by the rod is not retained by the feather, but passes away to the earth. Hence, you have not positive acting against positive at all. Why the neutral body is attracted by the electrified one, will, as alraady stated, appear by and by.

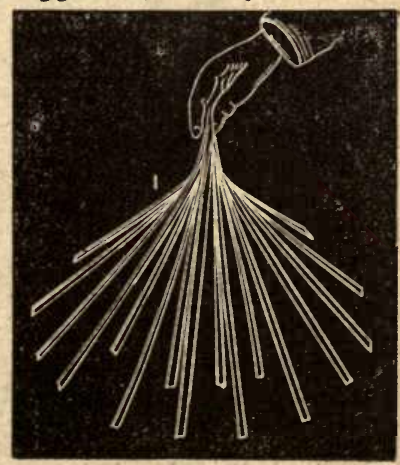

Fra. 11. 


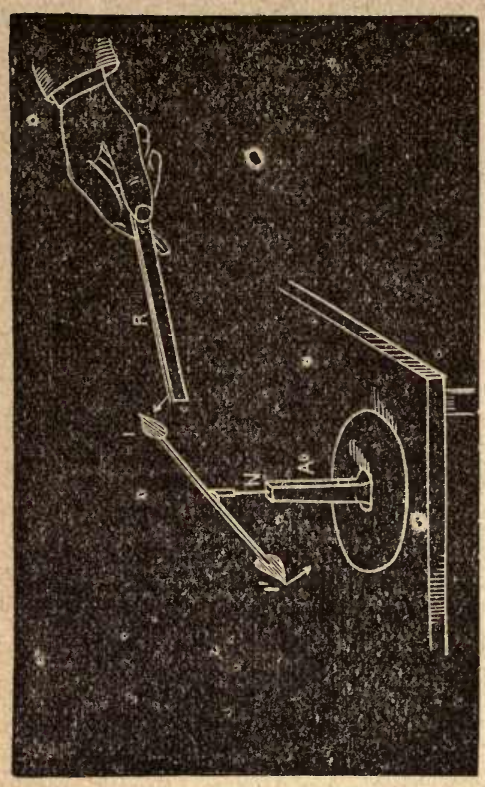

Attract your straw needle by your rubbed glass tube. Let the straw strike the tulic, so that the one shall rub against the other. The straw aceepts the clectricity of the tube, and repulsion immediatcly follows attraction, as shown in fig. 9.

Mr. Cuttrell has devised the simplo electroscope represented in fig. 10 to show repulsion. A is a stem of sealingwax with a small circle of tin, $T$, at the top. $w$ is a bent wire proceeding from $\mathrm{T}$, with a small disk attashed to it by wax. I $I^{\prime}$ is a little straw index, supported by the needle $\mathrm{N}$, as shown in fig. 10. The stem $A^{\prime}$, also of sealing-wax, is not quite vertical, the object being to cause the bit of paper, $1^{\prime}$, to rest close to $w$ when the apparatus is not electrified. When electricity is imparted to $T$, it fows through the wires $\mathrm{w}$ and $w$, over both disk and index : immediate repulsion of the straw is the consequence.

No better experiment can be made to ilinstrate the self-repulsive character of electricity than the following one. Heat your square board ( $(5)$, and warm, as before, your sheet of foulscap. Spread the paper upon the board, and excite it by the friction of india-rubber. Cut from the sheet two long strips with your

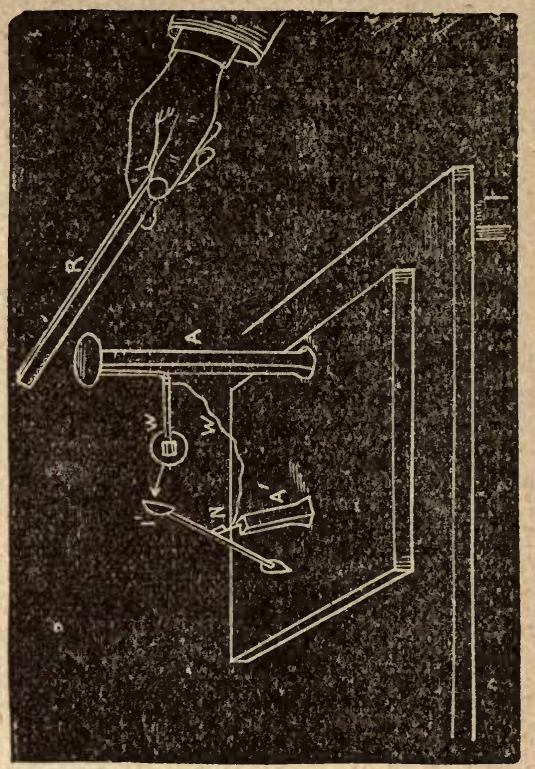

움

penknife. Hold the strips together at one end. Separate them from the board, and lift them into the air : they foreibly dive each other apart, producing a wide divergence.

Cut reveral stipss. so as to form a kind of tasscl. Ilold them together at ono end. Separate them from the board, and lift them into the air : they are driven asuuder by the self-repellent electricity, presenting an appearance which may to. mind you of the hair of Medusa. The effect is represented in fig. 11.*

Another very beantiful experiment fits in here. Let fine silver sand, s, fig. 12, issue in a stream from a glass funnel, through an aperture one eighth of an inch in diameter. Conncet the sand in the funnel by a fine wire $w$, fig. 13 , with your warm glass tube. Unelectrified, the

* In one of my carliest lectures at the Royul Institution, having rubbed a sheet of foulsean, I was ahout to lift it bodily from the hot board, and to place it aguinst the wal!, when the thought of cuttiug it into strips, and allowing them to act upon each other, crcuried 10 me. The 1esult, of course, was that ahove described. Simple and obviuus as it was. it gave Faraduy, who was present at the lime, the most lively pleasure. The simplest experiment, if only suited to its object, delighted him. 


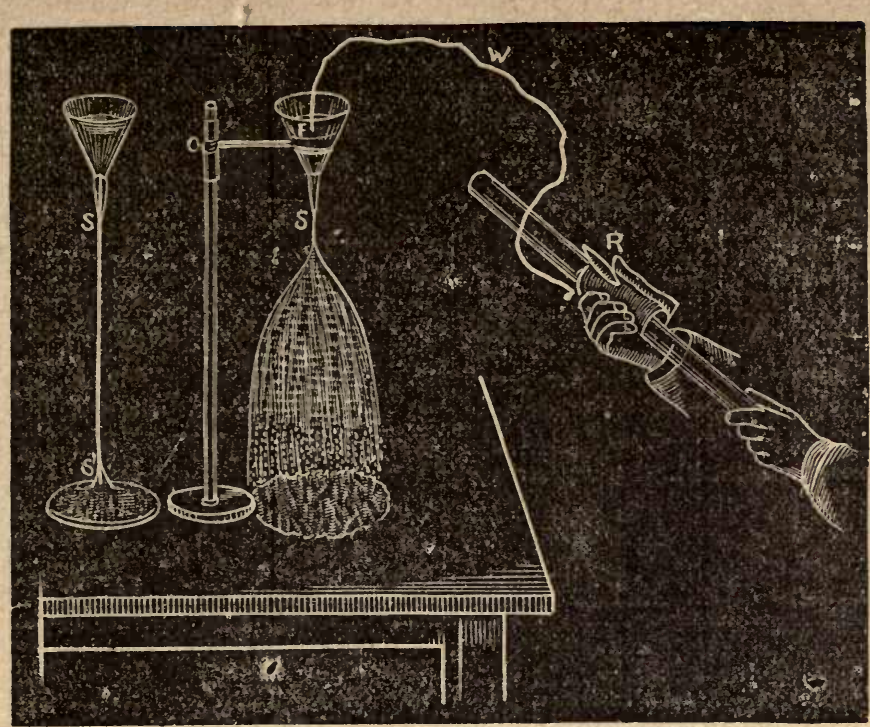

Fig. 12.

Fra. 13.

sand particles descend as a continuous stleanil, s s', fig. 12, but at erery stroke of the rubber they fly asunder, as ir. fig. 13, through self-repulsion. $\dagger$

Or let thrce or four fine fillets of water issue from three or four pin-holes in the bottom of a vessel close to each other. Connect the water of the ressel with your glass tube, and rub as before. The liquid veins are scattered into spray by every stroke of the rubber.

These experiments are best made with " Cottrell's rubber," described in $\S 24$.

And now you must learn to determine with certainty the quality of the electricity with which any lody presented to you may be charged. You see immediatcly that attraction is no sure test, because unelectrified bodies are attracted. Further on $(\$ 14)$ you will be able to grapple with another possible source of error in the employment of attraction.

In determining quality, you must ascertain, by trial, the kind of electricity by which the charged body is repelled; if, for example, any electrified body repel, or is repelled by, sealing-wax rubbed with flannel, the electricity of the bodv

+ For these, and also for experiments with the electruscupe, the teacher of a large class will find the lime light shadows upon a white screen (or better still, those of the electric light) exceedingly useful. 'The effects ure thus rendered visible to all at once. is negative ; if it repel, or is repelled hy, glass, rubbed with silk, its electricity is positive. Iu Fay had the sagacity to propose this mode of testing quility.

Apply this test to the strips of foolscap paper excited by the india-rubber. Bring a rubbed gutta-percha tube near the electrified strips, you have strong attraction. Bring a rubbed glass tube between the strips, you have strong repulsion and augmented divergence. IIence, the electricity, being repelled by the positive glass, is itself positive.

\section{§ 11. Electricity of the Rubbcr. -Doublo or "Polar" Character of the Electric Force.}

We have examined the action of each kind of electricity upon itself, and upon the other kind; but hitherto we have kept the rubber out of view. One of the questions which inevitably occur to the inquiring scientific mind would be, How is the rubber affected by the act of friction? Here, as elsewhere, you must examine the subject for yourself, and base your conclusions on the facts you establish.

Test your rubber, then, by your bal. anced lath. The lath is attracted by the flannel which has rubbed against guttapercha ; and it is attracted by the silk, which has rubbed against glass. 
Regarding the quality of the electricity of the flannel or of the silk rubber, the attraction of the lath teaches you nothing. But, suspend your rubbed glass tube, and bring the flannel rubber near it : repulsion follows. The silk rubber, on the contrary, attracts the glass tube. Suspend your rubbed gutta-percha tube, and bring the silk rubber near it : repulsion follows. The flannel, on the contrary, attracts the tube.

The conclusion is obvious : the electricity of the flannel is positive, that of the silk is negative.

Jut the flannel is the rubber of the gutta-percha, whose electricity is negative; and the silk is the rubber of the glass, whose electricity is positive. Consequently, we have not only proved the ribber to be electritied by the friction, but also proved the electricity of the rubber to be opposite in quality to that of the body rulbed.

All your subsequent experience will verify the statement that the two electricities always go together; that you cannot excite one of them without at the same time exciting the other, and that the lectricity of the rubber, though opprsite in quality, is in all cases precisely cqual in quantity to that of the body rubbed.

And now we will test these principles ly a new experiment. In $\$ 5$ we learned that an ebonite comb is electrified by its passage throwgh dry hair. You can readily prove the electricity of the comb to be negative. But the hair is here the rubber, and, in accordance with the principle just laid down, an equal quaniity of positive electricity has been excited in the hair. If you stand on the cround nninsulated, the electricity of the hair passes freely through your body to the earth.

But stand upon an insulating stool* on your board, for example, supported by four warm cumblers-while I, standing on the ground, pass the comb briskly through your hair. I pass it ten, twenty, thinty times, and then ask you to attract

* A stool with glass legs wnich, to protect them from the moisture of the air. are usually coated with a solution of shicllac. Regarding the attraction of glass for alınospheric humidity, you will call to mind what has been said in $\$ 5$. your balanced lath. You present your knuckle, but there is no attraction.

Here the coinb and the hair soon reach their maximum excitement, beyond which no further development of electricity occurs. Now, though the comb, as shown in $\S 5$, is competent to attract the lath, while your body is here incompetent to do so, this may be because the small quantity of electricity existing in a concentrated form upon the comb becomes, when ditfused over the body, too feeble to produce attraction.

Can we not exalt the electricity of your body? Guided by the principles laid down, let us try to do so. First I pass the unelectrified comb through your hair ; it comes away electrified. After discharging the comb by passing my hand closely over it, I pass it again through the hair. As before, it quits the hair electrified, and I again discharge it. I do this ten or twenty times, always depriving the comb of its electricity after it has quitted the hair. Now present your knuckle to the balanced lath. It is powerfully attracted.

Here, as I have said, the unclectrified comb carried in each case eiectricity away with it ; but, in accordance with the foregoing principles, it left an equal quantity of the opposite electricity behind it. And though the amount of electricity corresponding to a single charge of the comb, when diffused over the body, proved insensible to our tests, that amount ten or twenty times inultiplicd became not only sensible, but strong. Indeed, by discharging the comb, and passing it in each case unelectrified through the hair, the insulated human body cam be rendered highly electrical.

Near the beginning of this section I said, in rather an off-hand way, thas rubbed flannel repels rubbed glass, while rubbed silk repels rubbed gutta-percha. Now, while it is generally easy to obtain the repulsion by the flinnel, it is by no means always easy to obtain the repulsion by the silk. Over and over again I har. been foiled in my attempts to show this repulsion. I wish you, therefore, to be aware c $f$ an infallible method of obtaining it.

Stand on your insulating stool, and rub your glass tube briskly with the amalgamated silk; hand me the tube. I pass 
niy hand closely over its surface, remoring from that surface nearly the whole of its clectricity. I hand you the tube again, and you again excite it. You hand it to me, and I again discharge it. In each case, therefore, you cxcite an unclectrified glass tube, and in each case the tube leaves behind upon the rubber an amount of negative electricity equal in quantity to the positive carried away. $\mathrm{Bv}$ thus adding charge to charge, the rubber is rendered highly electrical ; and even should its insulating power be impaircd by the amalgam, it can now afford to yield a portion of its clectricity to your hand and hody, and still powerfully repel rubbed gutta-pereha. The principle, which snight be further illustrated, is obiously the sarne as that applied in the ease of the comb.

\section{12. What is Electricity?}

Thus far we hare proceeded from fact to fact, acquiring knowledge of a very valuable kind. But facts alone cannot satisfy r.s. We seek a knowledge of the principles which lis behind the facts, and which are to be discerned by the mind alone. Thus, having spoken as we have dune, of electricity passing hither and thither, and of its being prevented from passing, hardly any thoughtful boy or girl can avoid asking what is it that thus passes?-what is electricity? Hoyle and Nelitor betrayed their need of an answer to this question when the one imagined his unctuous threads issuing from and returning to the electrified bordy ; and when the other imagined that an elastic fluid existed which penetrated his rubbed glass.

When I say " imagined "I do not intend to represent the notions of these great men as vain fancies. Witlout imagination we can do nothing liere. By imagination I mean the power of picturing inenta!ly things which, though they have an existence as real as that of the world around us, cannot be touched directly by the organs of sense. I mean the purified scientific imagination, without the exercise of which we cannot take a single step into the region of causes and principles.

It was by the exerciso of the scientific imagination that Franklin devised the thenry of a single electric fluid to explain eloctrical phenomena. This fluid he sup- posed to be self-repulsive, and diffused in definite quantities through all bodies. IIe supposed that when a body has more than its proper share it is positively, when less than its proper share it is negatively electrified. It was by the exercise of the same faculty that Symmer devised the theory of two electric fluids, each self-repuisive, but both mutually attractive.

At first sight Franklin's theory secms by far the simpler of the two." But its simplicity is only apparent. For though Franklin assumed only one fluid, he was obliged to assume three distinct actions. $E_{1 z}$ stly, he had the self-repulsion of the iectric particles. Secondly, the mutual ittraction of the electric particies anc iho oonderable particles of the body through which the electiluity was diffused. Thirdly, these two : assamptions when strictiy followed out ica. is the unavoidable conclusion that the inaterial particles also mutually rence? eaci sther. Thus the theory is by no means $s u$ simple as it appears.

The theory of Symmer, though at first sight the most complicated, is in reality by far the simpler of the two. According to it electrical actions are produced by two flinids. cacl self-repulsive, but buth mutua!ly attractive. These fluids cling to the atoms of matter, and carry the matter to which they eling along with them. Every loody, in its natural condition, possesses both fluids in equal quantities. $\Lambda$ s long as the fluids are mixed togetlier they neutralize each other, the body in which they are thus mixed being in its natural or unelectrical condition.

By friction (and by various other means) these two fluids may be torn asunder, the one clinging by preference to the rubber, the other to the body rubbed.

According to this theory there must always be attraction between the rubber and the body rubbed, because, as we have proved, they are oppositely electrified. This is in fact the case. And mark what I now say. Over and abovo the common friction, this electrical attraction lias to be overomze vhencper we

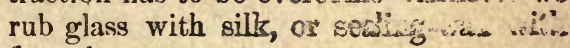
flannel.

You are too young to fully grasp this subject yet; and indeed it would lead us too far away to enter fully into it. But 


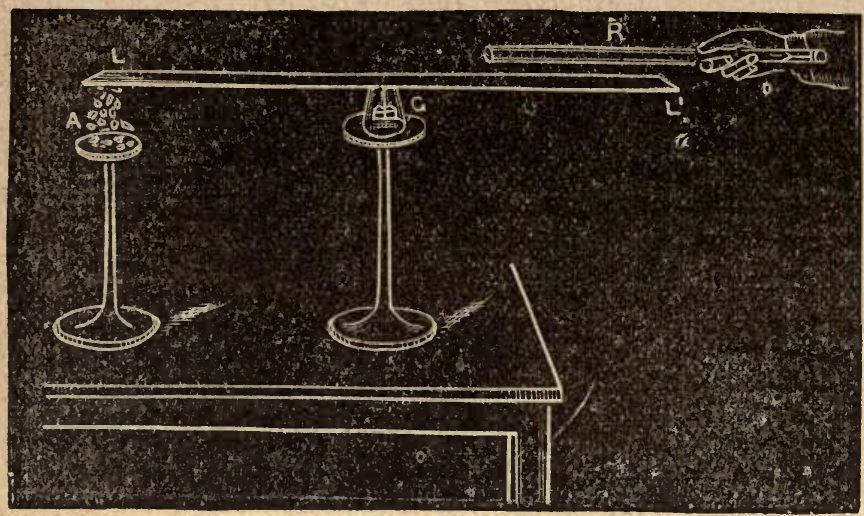

FLo. 14.

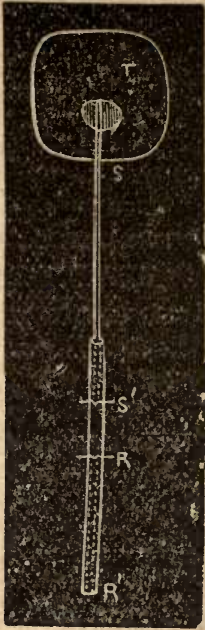

FIG. 15.
I will throw out for future reflection the remark, that the overcoming of the ordinary friction produces heat then snd there upon the surfaces rebbed, while the foree expended in orercoming the electric attracison may be converted into heat which alall appoar a thousand miles away from the place where it was generated.

Theoretic conceptions are incessantlv checked and correrted by the advance of knowledge, and this theory of electic fluids is doubted hy many cininent scien. tifie men. It will, at all events, have to be translated into a form which shall connect it with heat and light, hefore it can be accepted as complete. Nicrertlicless, keeping ourselves uupledged to the theory, we shall find it of exceeding service both in unravelling and in connecting togetlice electrical phenumena.

\section{$\S$ 13. Electric Induction. Definition of the Term.}

We have now to apply the theory of electric fluids to the important subject of electric induction.

It vits noticed by early obscrvers that conlact was not necessary to e!ectrical excitcment. Otto ron Guericke, as wc have already seen $(\S 2)$, found that a body brought near his sulphur globe becamc clectrical. By bringing his excited glass tube near one end of a conductor, Stephen Gray attracted light bodies at the other end. He also obtained attraction through the human body. From the human body also Du Fay, to his astonishment, obtained a spark. Canton, in 1753 , suspended pith-balls by thread, and holding an excited glass tube, at a considcrable distance from them, caused them to diverge. On removing the tube the balls fell together, no permanent charge being impasted to thein. Such phenomena were further studien und developed by Wilcke and Aipinus, Coulnmb and Poisson.

'These and all similar results are cmbraced by the law, that when an electrified body is brought near an unclectrified conductor, the neutral fluid of the latter is decomposed; one of its constituents being attracted, the other repelled. When the electrified body is withdrawn, the suparated e!ectricities flow again together and render the conductor unelectric.

This decomposition of the neutral fluid by the mere presence of an electrificd body is called induction. It is also called clectrification by influence.

If, while it is under the influence of the clectrified body, the body influenced be touched, the free electricity (which is always of the same kind as that of the influencing body) passes away, the opposite electricity being held captive.

On removing the electrified body the captive electricity is set free, the conductor being charged with electricity opposite in kind to that of the body which 
electrified it.

Yol cannot do better here than repeat Steplien Gray's experiment. Suppoit is small plank or lath, L L', Fig. 14, upon a warm tumbler, $\mathrm{a}$, and bring under one of its ends, $\mathbf{L}$, and within four or five inches of that end, scraps of light paper or of gold leaf. Excite your glass tube, R, vigorously, and bring it over the other end of the plank, without touching it. The cnds may be six or cight feet apart; the light bodies will be attracted. The c.pcrimert is casily made, and you are not to rest satisfied till you can mako it with casc and certainty.

This is a fit place to repeat that you must lieep a close eye upon the tumblers you cmploy for insulation. Some of them, made of common glass, are hardlv to lie accounted insulators at all.

\section{14. Experimcntal Rescarches on Elcc- tric Induction.}

Our mastcry orcr this subject of induction must be complete ; for it underies all on subsequent inquirics. Without reference to it nothing is to be explained ; possessed of it you will enjoy not only a wonderful power of explanation, lut of prediction. We will attack it, therefore, with the determination to exhaust it.

And here a slight addition must be made to our apparatus. We must be in a condition to take saunples of electricity, and to conrey them, with the view of testing them, from place to place. For this nurpose the little " carrier," shown in fig. 15, will be found convenient. T i. a t bit of tin-foil, two or three inches squarc. A straw stem is stuck on to it hy sealing-wax, the lower end of the stem being covered by sealirg-wax. To make the innulation sure, the part between $R$ and $s^{\prime}$ is wholly of sealing-wax. You can have stems of ebonitc, which are stronger, for a few pence; but you can have this one for a fraction of a penny. The end $\mathrm{r}^{\prime}$ is to he held in the hand : the electrified body is to be touched by $\mathrm{r}$, and the electricity conveyed to an clectrosenpe to be tested.

Tuich your rubbed glass rou' with $\mathrm{T}$, and then touch your electroscope: the leaves diverge with positive electricity. Toch your rubbed gutta-percha or scaling-wax with $\mathrm{T}$, and then touch your clec- troscope: the leaves diverge with negative electricity. If the electricity of any body augment the divergence produceil by the glass, the electricity of that body is positive. If it augment the divergence produced by the gutta-percha, the electricity is negative. And now we are ready for further work.

Place an egg, E, fig. 16 , on its sid

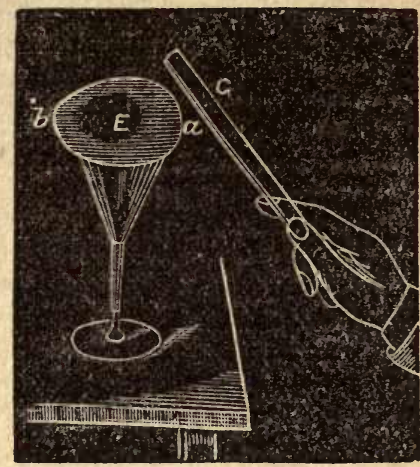

Fra. 16.

upon a dry wine-glass ; bring your creiv ed glass tube, $\mathrm{a}$, within an inch or so of the end of the egg. What is the condition of the egg? Its electricity is decumposed; the negative fluid covering the end $a$ adjacent to the glass, the positive covering the other end $b$. Remove the glass tube : what occurs? The two electricities flow together and neutrality is restored. Prove this neutrality. Neither a carrier toucling the cgr, nor the eger itself, has any power to affect your clectroscope, or to attract your balanced lath.

Again, bring the excited tube near the egg. To:sch its distant part bith your carrice. The carrier now attracts the straw (fig. 2) or the balanced lath (fig. 4). It also causes the leaves of your electroscope to diverge. What is the qieality of the electricity? It repels and is repelled by rubled glass ; the electricity at $b$ is therefore positive. Discharse the carrier by touching it, and bring it into contact with the end $a$ of the egre nearest to the glass tuhe. The electricity you take away repels and is repelled by guttapercha. It is therefore negative. Test the quality also by the electroscops.

While the tube $a$ is near the ega touch the end $b$ with your finger; now tiy to charge the carrier by touching $b$ : you cannot do so-the positive electricity has disappeared. Has the negative disap- 
peared also? No. Remore the glass tube, and once more tonch the ege at 6 by the carrier. It is charged, not with positive, but with negative electricity. Cleurly understand this experiment. The ncutral electricity of the excr is first decomposed into negative and positive; the former attracted, the latter repelled by the excited glass. The repelled elercricity is free to escape, and it has escaped on your touching the egg with your finger. Sut the attracted clectricity cannot escape as long as the influencing tube is held near. On removing the tube which holds the negative fluid in bondage, that fluid inınediately diffuses itself over the whole egr. An apple, or a turnip, will auswer for these experiments at least as well as an egg.

Discharge the egg by touching it. Rcexcite the glass tube and bring it again near. Touch the exy w th a wire or with your finger at $a$. Is it the negative at $a$, int) which you plenge your finger, thit escapes? No such thinis. The free positive fluid passes through the negittive, and through your finger to the earth. Prove this by removing, first, your finger, and then the glass tube. The egg is charged negatively.

Again ; place two eggs, E r, fig. 17,

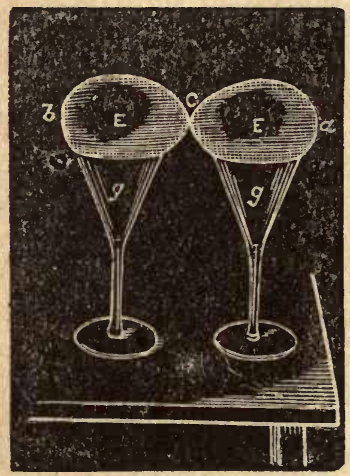

Fig. 17.

lengthwise on two dry wine-glasses, $g g$, and cause two of their cnds to touch each other, as at c. Bring your rubbed glass rod near the end $a$, and while it is there separate the eggs by moving one glass away from the other. Withdraw the rod and test both eggs. a repels rubbed sealing-wax, and $b$ repels rubbed giass ; $a$ is therefore negative, $b$ is posi- tive. The two charges, moreover, exsctly neutralize cach nther in the ejectro. scope. Aqain hringr the eggs together and restore the rubbed tube to its places near $a$. Touch $a$ and then separate tho eggs. Remove the glass rod anil tust the egrs. $a$ is regative, $b$ is reutral. Its electricity has escaped through the finger, though placed i.t $a$.

Equally good, if not inceed more handy, fir these experiments are two apples $\Lambda \Lambda$, fig. 13, silpported on stems of scaling-wax. $\Lambda$ necdle is lientcl a:. 1 sunk in cach case into the rtick of wax at the top, and on to the nceile the apple is pushed. The sealing-wax stems are stuck on by melting to little foot-boards. By arangements of this kind you make experiments which are more instructive than those usually made wilh insiruments twenty times more expensire.

Push your researches still farther, and instead of bringing the exges or apples together place them six fuet or so apart,

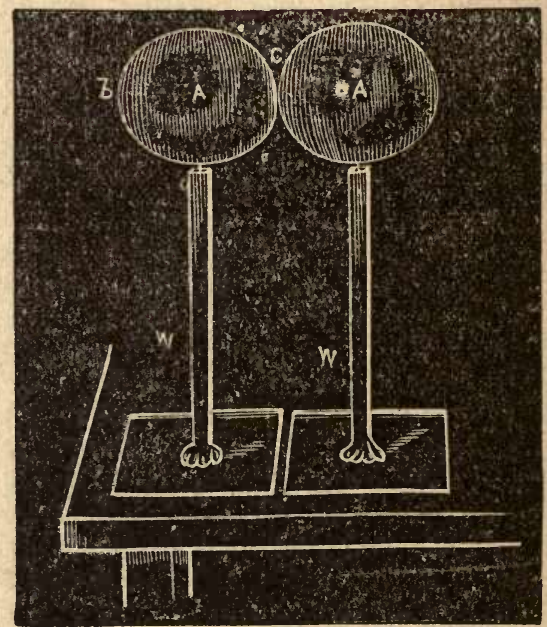

FIG. 18.

and let a light chain, c, fig. 19, or a wire, stretch from one to the other. Two brass balls, or wooden halls covered with tin-foil, supported by tall drinking glasses, $\mathbf{G G}^{\prime}$, will be better than the eggs for this experiment, for they will bear better the strain of the chain; but you can make the experiment with the eggs, or very readily with the two apples or two turnips. For the present we will suppose the straw-index $I I^{\prime}$ not to be there. Rub 


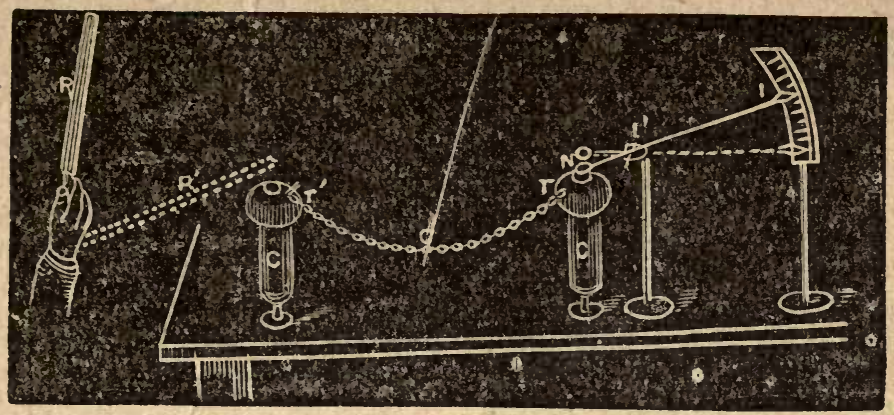

Fig. 19.

vonr glass tube $\mathrm{r}$, and hring it near one of the balls ; test both : the near one, $\mathbf{T}^{\prime}$, is negative, the distant one, $\mathrm{r}$, positive. Touch the rear one, the positive electricity, which had been driven along the chain to the remotest part of the system, returns along the chain, passes through the nerative, which is held captive by the tube, and escapes to the earth. When the tube $\mathrm{R}$ is removed, negative electricity overspreads both chain and balls.

In fig. 8 you made the acquaintance of the plate $N$, and the straw-index $I r^{\prime}$, shown on a smaller scale in fig. 19. By their means you immediately see both the effect of the first induction, and the consequence of touching any part of the system with the finger. The plate $\mathrm{N}$ rests over the ball or turnip $\mathrm{T}$, the position of the straw-index being that shown by the dots. Bring the rubbed tube near $\mathrm{T}^{\prime}$ : the end $\mathrm{N}$ of the index inmediately rescends and the other end rises along the graduated scale. Remove the glass rod; the index $\mathbf{I} \mathbf{I}^{\prime}$ immediately falls. Practice this approach and withdrawal, and observe how promptly the index delares the separation and recomposition uf the fluids.

While the tube is near $\mathrm{T}^{\prime}$, and the end $\checkmark$ of the index is attracted, let $\mathbf{T}^{\prime}$ be louched by the finger. The end $\mathrm{s}$ is immediately liberated, for the electricity which pulled it down escapes along the chain and through the finger to the eartl. Now remove your excited tube. The captive negative electricity diffuses itself over both balls, and the index is again attracted.

Instead of the chain you may interpose between the balls 100 feet of wirc sup- ported $h_{j}$ silk loops. This is done in tig. 20 , which shows the wire $w$ supported by the silk strings s s s, For the bal or turnip $\mathrm{T}^{\prime}$, fig. 19, the cylinder $\mathrm{c}$, on a glass support G, is substituted, the little table $\mathrm{M}$-taking the place of the ball $\mathrm{T}$. Every approach and withdrawal of the rubbed glass tube $\mathbf{R}$ is followed obediently by the attraction and liberation of $\mathrm{N}$, and the corresponding motion of the index NI.

Repeat here an experiment, first mads

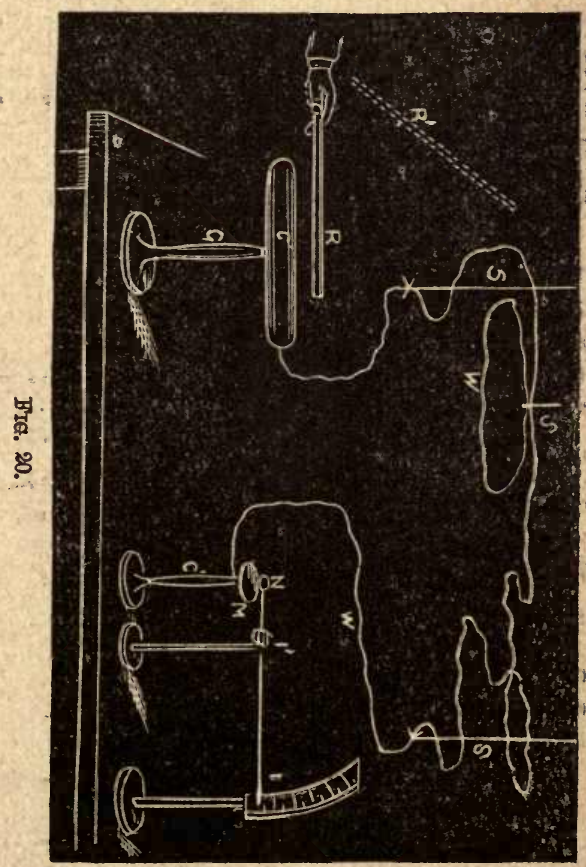


by a great electrician named Apinus. I wish you to make these historic experiments. Insulate an elongated metal conductor, c c', fig. 21 , or one formed of rood coated with tin-foil-even a carrot, cucumber, or parsnip, so that it be insulated, will answer. Let a small weight, w, suspended from a silk string, s, rest on one end of the conductor, and hold

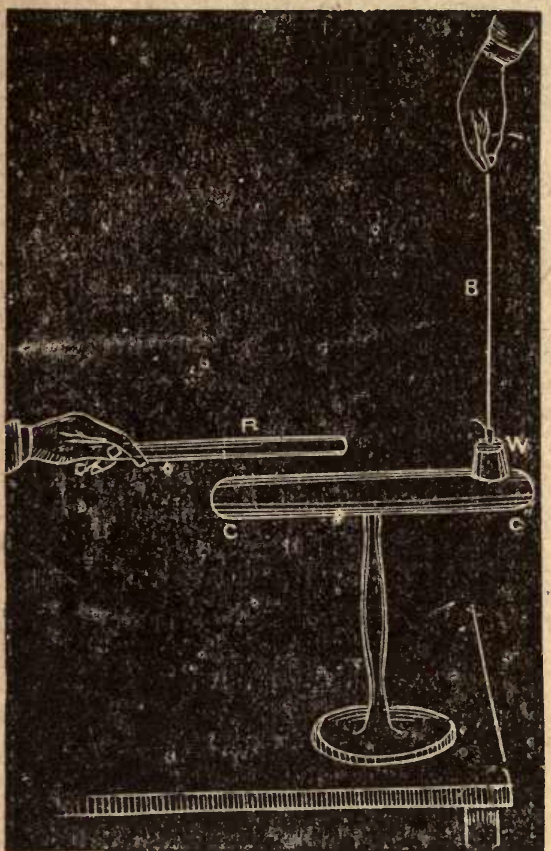

Firg. 21.

your rubbed glass tube, $\mathrm{R}$, over the other end. You can predict leforehand what will oceur when you remove the weight. It carries away with it eleetricity, which repels rubbed glass, and attracts your balanced lath.

Stand on an insulating stool ; or make one by placing a board on four warm tumblers. Present the knuclilez of your right hand to the end of the balanced lath, and stretch forth your left arm. There is no attraction. But lat $a$ friend or an assistant bring the rabbed glass tube over the left arm ; the lath immediately follows the right hand.

'Touch the lath, or any cilier uninsulated body ; the " attractive virtne," as it was called by Gray, disappears. After this, as long as the excited tube is held orcr the arm there is no attraction. But when the tube is removed the attractive power of the hand is restored. IIere the first attraction was by pusitive clectricity driven to the rimht hand from the left, and the second attrartion by ncgative electricity, libcrated by the removal of the glass rod. Expcriment prores the logic of thcory to be without a flaw.

Stand on an insulating stool, and place your right hand on the electroscope ; there is no action. Stretch forth the left arm and permit an assistant alternately to bring ncar, and to withdraw, an excited glass tube. The gold leares open s.nd collapse i.s similar alternation. At evcry approach, positive electricity is driven over the gold lcarcs; at every with. drawal, the cyuilibrium is restored.

We are row in a condition to repcat, with casc, the cepcrimcrit of Du Fay mentioned in $\S 13$. $\Lambda$ bourd is suyported by four silk ropes, and on the board is stretched a boy. Ining lis forcliead, or better still his nose, under the end of your straw-index $\mathrm{Ix}^{\prime}$, fig. 22. Then bring down over lis legs your rullied glass tube ; instantly the cnd $\mathrm{s}^{\prime}$ is attracted and the end I rises along the graduated scalc. Before the cnd $\mathrm{I}^{\prime}$ comes into contact with the nose or forelicad a spark passes between it and the boy.

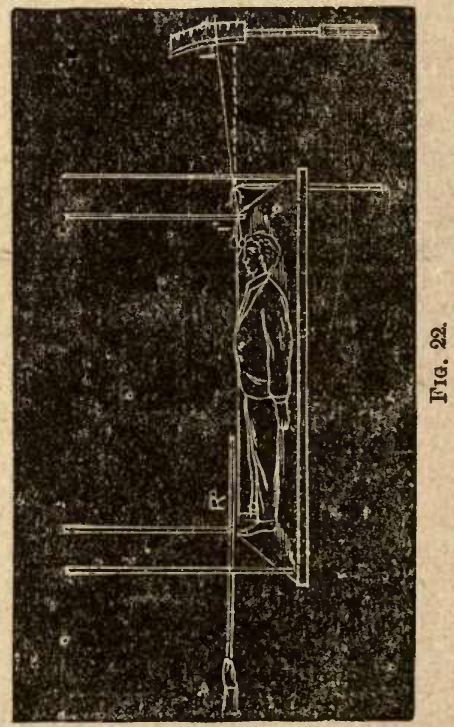


1 will now ask you to charge your Dutch metal electroscope (fig. 7) positively by rubbed gutta-perelia, and to cluarge it negatively by rubbed glass. A moment's reflection will enable you to do it. You bring your excited body near : the same clectricity as that of the excited body is driven over the leaves, and they diverge by repulsion. Touch the electroscope, the leares collapse. Withdraw your finger, and withdraw afterwards the excited body: the leaves then diverge with the opposite electricity.

The simplest way of testing the quality of electricity is to charge the electroscope with electricity of a known kind. If, on the approach of the budy to be tested, the leaves diverge still wider, the Imare and the body are similarly electrified. The reason is obvious.

Omitting the last experiment, the wealth of knowledge which these researches involve might be placed within any intelligent boy's reach by the wise expenditure of half-a-crown.

Once firmly possessed of the principle of induction and versed in its application, the difficuities of our subject will melt away before us. In fact our subsequent work will consist mainly in unravelling phenomena by the aid of this principle.

Without a knowledge of this principle we could render no account of the attraction of neutral bodics by our excited tubes. In reality the attracted bodies are not neutral : they are first electrificd by influence, and it is because they are this electrified that they are attracted.

This is the place to refer more fully to a point already alluded to. Neutral bodies, as just. stated, are attracted, because they are really converted into electrified bodies by induction. Suppose a body to be feebly electrified positively, and that you bring your rubbed glass tube to bear upon the body. You clear. ly see that the indueed negative electricity maly be strong enough to mask and overcome the weak positive charme possessed by the body. We should thus have two bodies electrified alike, attracting each nther. This is the danger against which I promised to warn you in $\& 10$, where the test of attraction was rejected.

IVe will now apply the principle of induetion to explain a very beautiful invention, made known hy the celebrated
Volta in 1775.

\section{$\S$ 15. The Electrophorus.}

Cut a circle, $\mathrm{T}$, fig. 23,6 inches in diameter out of sheet zinc, or out of common tin. Heat it at its centre by the

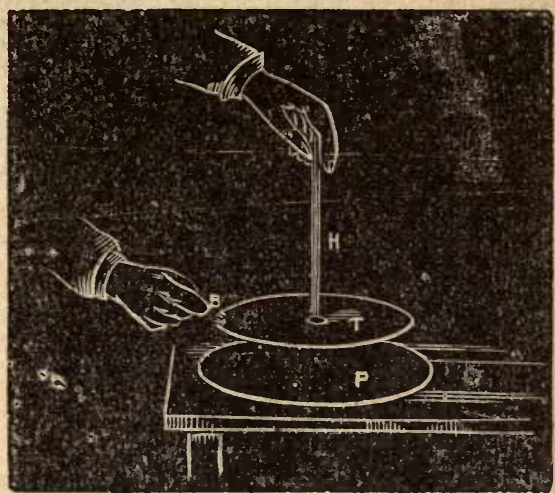

FIG. 23.

flame of a spirit-lamp or of a candle. Attach to it there a stick of sealing-wax, II, which, when the metal cools, is to serve as an insulating handle.-You have now the licl of the electrophorus. A resinous surface, or what is simpler a sheet of vulcanized india-rubber, $\mathbf{P}$, or even of hot brown paper, will answer for the plate of the electrophorus.

Rub your "plate" with flannel, or whisk it briskly with a fox's brush. It is thereby negatively electrified. Place the "lid" of your ulectrophorus on the excited surface : it touches it at a few points only. For the most part lid and plate are separated by a film of air.

The excited surfaco acts by induction across this film upon the lid, attracting its positive and repelling its negative electricity. You Livo in fact in the lid two layers of electricity, the lower one, which is " bound," positive ; tho upper one, which is "free," negative. 'Lifi the lid: the clectricities fiow again together ; neutrality is restored, and ycux lid fails to attract your balanced latin.

Once more place the lid upon the excited surface : tourh it with the finger. What occurs? You ought to know. The free electricity, which is negative, will escape through your body to the earth, leaving the chaincd pesitive behind.

Now lift the lid by the handle : what is its condition? Again I say you ought 


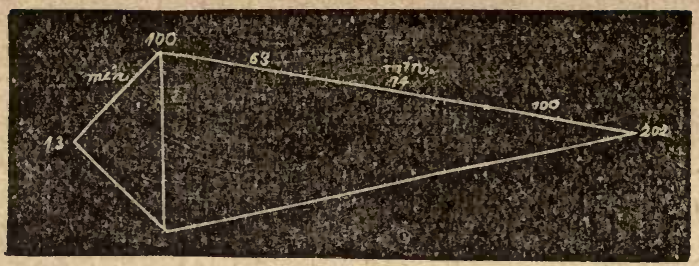

Fเ6. 24.

to know. It is covered with free positive electricity. If it be presented to the lath it will strongly attract it : if it be presented to the knuckle it will yield a spark.

A smooth half-crown, or a penny, will answer for this experiment. Stick to tho coin an inch of sealiug-wax as an insulating handle : bring it down upon the excited india-rubber : touch it, lift it, and present it to your lath. The lath may be six or eiglit feet long, three inches wide and half an inch thick; the little electrophorus lid, formed by the half crown, will pull it round and round. The experiment is a very impressive one.

Scrutinize your instrument still further. Let the end of a thin wire rest upon the lid of your electrophorus, under a little weight if necessary; and connect the other end of the wire with the electruscope. As you lower the lid down toward the excited plate of the electrophorus, what must occur? The power of prevision now belongs to you and you must exercise it. The repelled electricity will flow over the leaves of the electroscope, causing them to diverge. Lift the lid, they ollapse. Lower and raise the lid several times, and observe the corresponding rhythmic action of the electroscope leaves.

A little knob of scaling-wax, B, coated with tin-foil, or indeed any knob with a conducting surface, stuck to the lid of the electrophorus, will enable you to obtain a better snark. The reason of this will immediately appear.

More than half the ralne of your present labor consists in arranging each experiment in thought before it is realized in fact; and more than half the delight of your work will consist in observing the verification of what you have foreseen and predicted.

\section{\$ 16. Action of Points and Flames.}

The course of exposition proceeds naturally from the electrophorus to the electrical machine. But before we take up the machine we must make our minds clear regarding the manner in which electricity diffuses itself over conductors, and more especially orer elongated and pointed conductors.

Rub your glass tube and draw it over an insulated sphere of metal-of wood covered with tin-foil, or indeed any other insulated spherical conductor. Repeat the process several times, so as to impart a good charge to the spliere. Touch the charged sphere with your carrier, and transfer the charge to the electroscope. Note the divergence of the leaves. Discharge the electroscope, and repeat tho experiment, tonching, however. some other point of the sphere. Thr, electroscope shows sensibly the same amount of divergence. Even when the greatest exactness of the most practised experimenter is brought into play, the spherical conductor is found to be equally charged at all points of its surface. You may figure the electric fluid as a little ocean encornpassing the sphere, and of the same depth erery where.

But supposing the conductor, instead of being a sphere, to be a cube, an elongated cylinder, a cone, or a disk. The depth, or as it is sometimes called the density, of the electricity, will not be everywhere the sanc. The corners of the cube will impart $₫$ stronger charge to your carrier than the sides. The end of the cylinder will impart a stronger charge than its middle. The edge of the disk will impart a stronger charge than its flat surface. The apex or point of the cone will impart a stronger chargo than its curved surface or its base.

You can satisf y yourself of the t:ıt'. of all this in a rough, but certain way, by charging, after the sphere, a turnip cut into the 
form of a cubc ; or a cigar-box coated with till-foil ; a metal cylinder, or a worden one coated with tin-foil ; a disk of tin or of sheet zinc ; a carrot or parsnip with its natural shape improved so as to make it in sharp cone. You will find the charge imparted to the carrier by the sharp corners and points of such bodies, when electrified, to be greater than that communicated by the gently rounded or flat surfaces. The difference may not be great, lut it will be distinct. Indeed au egg laid on its side, as we have already used it in our experiments on induction (fig. 16), yiclds a stronger charge from its ends than from its middle.

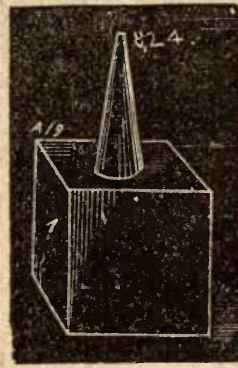

Fra. 25.

Let me place before you an example of this distribution, taken from the excellent work on "Frictional Electricity" by Professor Riess of Berlin. Two cones, fig. 24 , are placed together base to base. Calling the strength of the charge along the circular edge where the two bases join each other 100, the charge at the apex of the blunter cone is 133 ; and at the apex of the sharper one 202. The other numbers give the charges taken from the points where they are placed. Fig. 25, moreover, represents a cube with a cone placed upon it. The charge on the faco of the cube being 1 , the charge's at the corners of the cube and at the apex of the cone are given by the otlier numbers; they are all far in excess of the electricity on the flat surfice.

Riess found that he rould deduce with great accuracy the shurpmess of a point, from the charge which it imparted. He compared in this way the sharpness of various thoins, with that of a fing Einglish scwing needle. The following is the result :-Euphorlia thorn was slianper tlian the needle; gooseberry thorn of the same sharpness as the needle; while cactus, blackthorn, and rose, fell inore and more behind the needle in sharpness. Calling, for example, the charge obtained from cuphorbia 90 ; that obtained from the needle was 80 , and from the rose only 53.

Considering that cach electricity is self-repulsive, and that it heaps itself up upon a point, in the manner here shown, you will have little difficulty in conceiving that when the charge of a conductor carrying a point is suffieiently strong, the clectricity will finally disperse itself by streaming from the point.

The following experiments are theoretically important: Attach a stick of sealing-wax to a small plate of tin or of wood, so that the stick may stand upright. Heat a needle and insert it into the top of the stick of wax; on this needle mount horizontally a carrot. You have thus an insulated conductor. Stick into your carrot at one of its ends a sewing needle; and hold for an instant your rubbed glass tube in front of this needle without touching it. What occurs? The negative electricity of the carrot is inmediately discharged from the point against the glass tube. Remove the tube, test the carrot : it is positively electrified.

And now for another experiment, not so casily made, but still certain to succeed if you are careful. Excite your glass rod, turn your needle away from it, and bring the rod near the other end of the carrot. What occurs? The positive electricity is now repelled to the point, from which it will stream into the air. Remove the rod and test the carrot : it is negativoly clectrificd.

Again turn the point toward you, and place in front of it a plate of dry glass, wax, resin, shellac, paraffin, gutta-percha or any other insulator. Pass your rubbed glass tube once clownwards or upwards, the insulating plate being between the excited tabe and the point. The point will discharge its electricity against the insulating plate, which on trial will be found negatively electrified.

\section{§ 17. The Electrical Machine.}

An clectrical machine consists of two principal parts : the insulator which is 


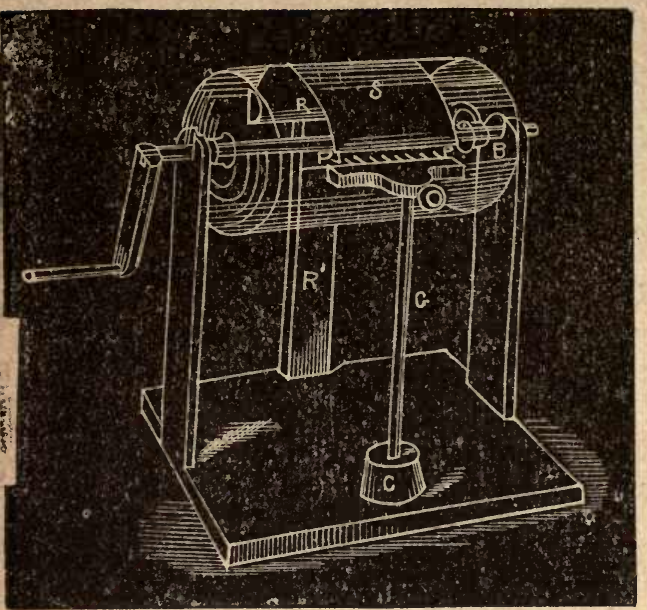

F'ta. 26.

excited by friction, and the " prime con ductor."

The sulphur sphere of Otto von Gucricke was, as already stated, the first clectrical machinc. The land was the rubber, and indecd it long continued to be so. For the sulplux sphere, IIaulssbee and Vincller substituted globes of glass. Boze of Vittenberg (1741) added the prime conductor, which was at fir t a tin tubo supperted by resin, or suepenced by sill:. Soon afterward Gordon substituted a glass cylinder for the globe. It was sometimes mounted vertically, sometimes horizontally. Gordon so intensificd li.3 discharges is to bo able to kill small Lirds with them. In 1760 Planta introdrecel the plete machine now commonly in use.

Mr. Cottrell has constructed for these Lessuns the small cylinder machine shown in fig. 20. The gylase cylinder is about 7 inches long end 4 inches in diameter; its cost is cighteen pence. Through the cylinder passes tightly, as an axis, a picce of lath, rendered secure by scalingwax where it enters and where it quits the cylinder. a is a glass rod supporting the conductor c, which is a picce of lath coated with tin-foil. Into the lath is driven the scries of pin points, $r, r$. Ths rubber $\mathrm{n}$, is seen at the further side of the cylinder, supported by the upriglt lath $r^{\prime}$, and caused to press against the glass. s' is a flap of silk attached to the ruibber. Trhen the handle is turned

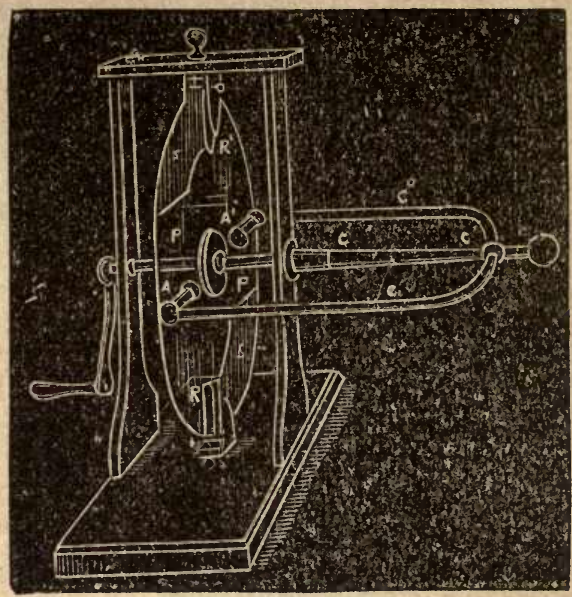

FIa. 27.

sparks may be taken, or a Leyden jar charged at the linob c.

$\Lambda$ plate machine is shown in fig. $\subseteq 7$. P i3 the plate, which turn on an axis passing throug!l its centre ; $r$ and $r^{\prime}$ are two rebbers which clasp the plate, wit'. the flaps of silk $\& \mathrm{~s}^{\prime}$ attached to them. A and $\Lambda^{\prime}$ are rows of points forming part cf the prime conductor, c. $\quad a^{l}$ is an insulating rod of glass, which cuts off the connection between the conductor and the handle of the machine.

The prime conductor is charged in the following manner. When the glass plato is turned, as it passes each rubber it is positively electrified. Facing the electrified glass is the row of points, placed midway between the two rubbers. On these points the glass acts by induction, attracting the negative and repelling the positive. In accordance with the principles already explained in $\S 10$, the negative electricity streams from the points against the excited glass, which then passes on neutralized to the next rubber, where it is again excited.

Thus the prime conductor is charged, not by the direct communication to it of positive clectricity, but by depriving it of its negatirc.

If when the conductor is charged you bring the lnuckle near it, the electricity passes from the conductor to the linuckle in the form of a spark.

Take this spark with the blunt knucklo while the machine is being turned; and 


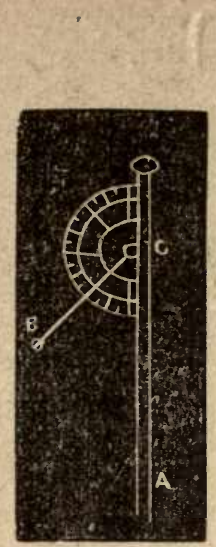

Erส. 28.

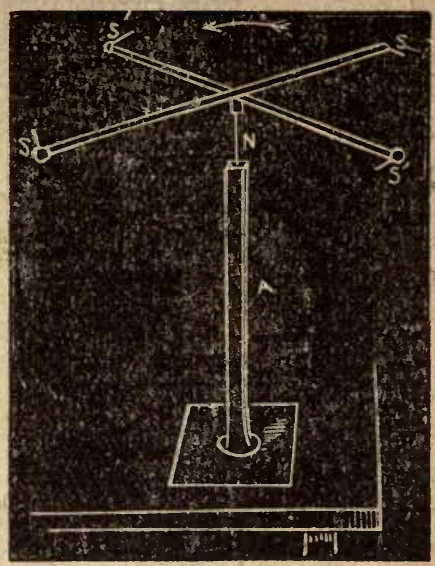

FIG. 29. then try the effect of presenting the finger ends, instead of the knuckle, to the conductor. The spark falls exceedingly in brilliancy. Sabstitute for the finger ends a needle point : you fail to get a spark at all. To obtain a good spark the electricity up.m the prine conductor must reash a suff:cient density (or tersion as it is sometimes called); and to secure this no points from which the electrieity can strean out must exist on the conductor. or be presented to it. All parts of the conductor are therefore carefully rounded off, sharp points and edges being avoided.

It is usual to attach to the conductor an electroscope consisting of an upriglit metal stem, A c, fig. 28, to which a straw with a pith ball, $\mathrm{B}$, at its free end, is attiched. The straw turns loosely upon a pivot at $c$. The electricity passing from the conductor is diffused over the whole electroscope, and the straw and stem being both positively electrified, repol each other. The straw, being the innvable body, flies away. The amount of the divergence is measured upon a graduated arc.

\section{\$ 18. Further Experiments on the Action} of Points.--The Electric Mill.-The Galden Fish.-Lightning C'onductor3.

If no point exist on the conductor, \& single turn of the handle of the machine usually suffices to cause the straw to stand out at a large angle to the stem. If, on the contrary, a point be attached to the conductor, you cannot produce a large divergence, because the electricity, as fast as it is generated, is dispersed by the point. The same effect is observed when you present a point to the eonductor. The conductor acts by induction upon the point, causing the negative electricity to stream from it against the conductor, which is thns nentralized almost as fast as it is charred. Flames and glowing embers act like points ; they also rapid!y discharge electricity.

The electricity escaping from a point or flame into the air renders the air self repulsive. The consequence is that when the hand is placed over a point mounted on the prime conductor of a machirie in good action, a cold blast is distinctly felt. Dr. Watson noticed this hlast from a flame placed on an electrified conductor ; while Wilson noticed the blast from a point. Jallabert and the Abbe Nollet also observed and described the influence of points and flames. The blast is called the " electric wind." Wilson moved bodies by its action : Faraday caused it to depress the surface of a liquid: IIamilton einployed the reaction of the clectric wind to inake pointed wires rotate. The "wind" was also found to promote evaporation.

Hamilton's apparatus is called the " electric mill." Nake one for yourself thus : Place two straws s s', $\mathrm{s}^{\prime}$, fig. 29, about eight inches long, across cach other it a right angle. Stick them together at their eentres by a bit of séaling-wax. Pass a fine wire through cach straw, and bend it where it issues from the straw, so as to form a little pointed arm perpen- 


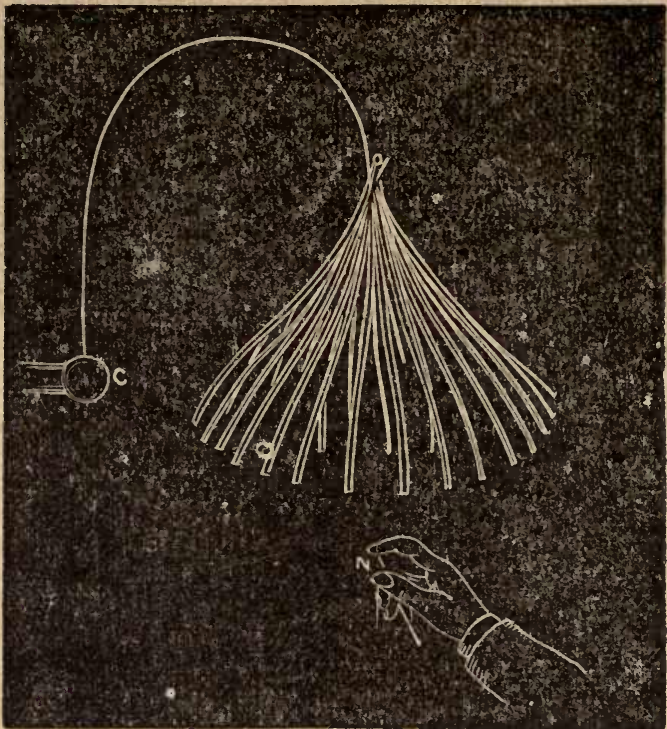

FrG. 30.

dicular to the straw, and from half an inch to three quarters of an inch long. It is easy, by means of a bit of cork or sealing-wax, to fix the wire so that the little bent arnis shall point not upward or downward, but sideways, when the cross is horizontal. The points of sewing needles may also be employed for the bent arms. A little bit of straw stuck into the cross at the centre forms a cap. This slips over a sewing needle, $\mathrm{N}$, supported by a stick of sealing-wax, A. Connect the sewing needle with the electric machine, and turn. A wind of a certain force is discharged from every point, and the cross is urged round with the same force in the opposite direetion.

You might casily, of course, so arrange the points that the wind from some of them would neutralize the wind from others. But the little pointed arms are to be so bent that the reaction in every case shall not oppose but add itself to the others.

The following experiments will yield you important information regarding the action of points. Stand, as you have so often done before, upon a board supportcd by four warm tumblers. Hold a small sewing needle, with its point defended by the forefinger of your right hand, toward your Dutch metal electroscope.
Place your left hand on the prime conductor of your machine. Let the handlo

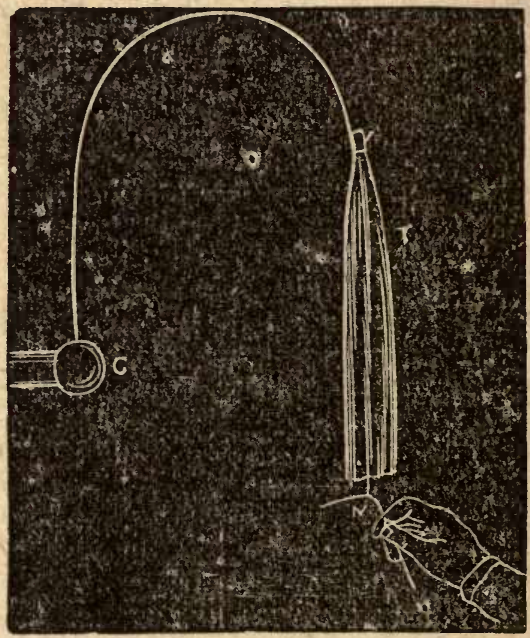

Fre. 31.

be turned by a friend or an assistant : tho leaves of the electroscope open out a little. Uncover the needle point by the removal of your finger; the leaves at once fly violently apart.

Mount a stout wire upright on the conductor, c, fig. 30 , of your machine ; or sapport the wire by sealing-wax, gutta- 


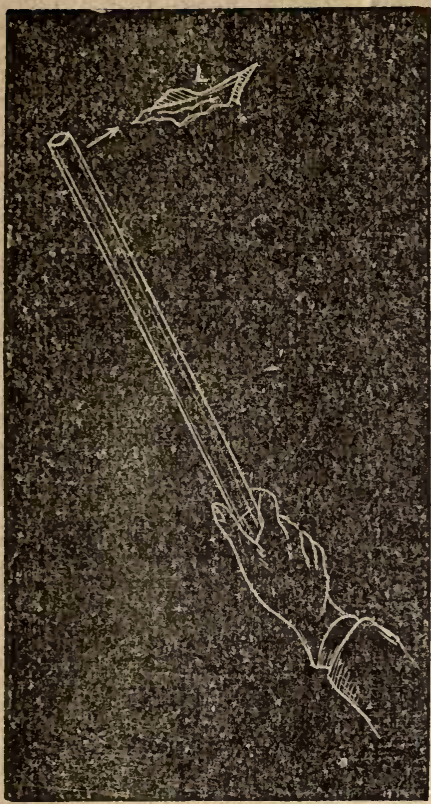

Fic. 32.

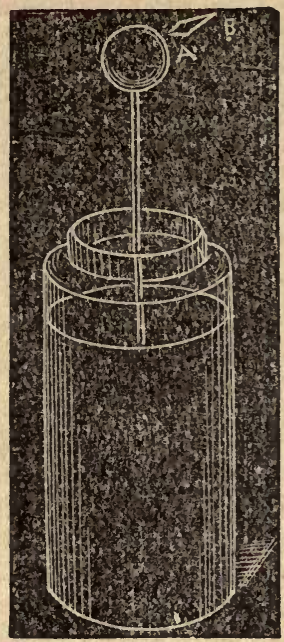

Fia. 33.

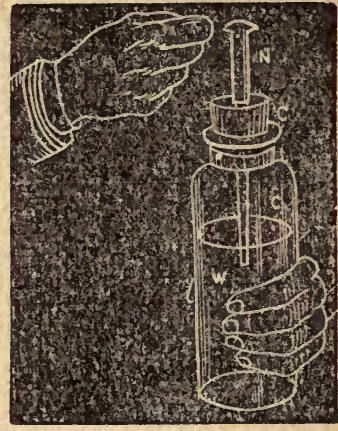

Fic. 34. percha or glass, at a distance from the conductor, and connect both by a fine wire. Bend your stout wire into a look, and hang from it a tassel, $T$, composed of many strips of light tissue paper. Work the machine. Electricity from ths conductor flows over the tassel, and the strips diverge. Hold your closed fist toward the tassel, the strips of paper stretch toward it. Hold the needle, defended by the finger, toward the tassel: attraction also ensues. Uncover the needle without moving the hand; the strips retreat as if blown away by a wind. Holding the needle, $\mathrm{s}$, fig. 31, upright underneath the tassel, its strips dischargo themselves and collapse utterly.

And now repeat Du Fay's experimet which led to the discovery of two electricities. Excite your glass tube, and hol! it in readiness while a friend or an assistant liberates a real gold or silver leaf in the air. Bring the tube near the leaf : it plunges toward the tube, stops suddenly, and then flies away. You may chase it round the room for hours without permitting it to reach the ground. The leaf is first acted upon inductively by the tube. It is powerfully attracted for a moment, and rushes toward the tube. But from its thin edges and corners the negative electricity streans forth, leaving the l.af positively electrified. Repulsion then sets in, because tube and leaf are electrified alike, as shown in fig. 32. The retreat of the tassel in the last experiment is due to a similar cause.

There is also a discharge of positive clectricity into the air from the more distant portions of the gold-ieaf, to which that clectricity is repelled. Both discharges are accompanied by an electric wind. It is possible to give the goldleaf a shape which shall enable it to float securely in the air, by the reaction of the $t$ wo winds issuing from its opposite ends. This is Franklin's experiment of the Golden Fish. It was first made with tho charged conductor of an elcetrical machine. M. Sitsezek revived it in a more convenient form, using instead of the eonductor the knob of a charged Iseyden jar. You may walk round a room with the jar in your hand; the "fish" will obediently follow in the air an inch or two, or even three iuches, from the knob. See A s, fig. 33. Even a hasty motion of the jar will not shake it away. 
Well - pointed lightning conductors, when acted on by a thunder cloud, discharge their induced electricity against the cloud. Franklin saw this with great clearness, and illustrated it with great ingenuity. The under side of a thunder ciond, when vicwed horszontally, he observed to be regged, composed, in fact, of fragments one below the other, sometimes reaching near the earth. These he regarded as so many steppingstures wilich assist in conducting the stroke of the clond. To represent these by experiment lie took two or three locks of fine loose cotton, tied them ir, a row, and hung them from lis prinie conductor. WThen this was excited the locks stretched downward toward the earth ; but by presenting a sharp point erect under the lowest bunch of ciston, it shrunk upward to that above it, nor did the shrinking cease till all the locks had relreated to the prime conductor itself. "May not," says Frankliu, "the small electrified cloud, whose equilibrium with the carth is so soon restored by the point, rise up to the main body, and by that means occasion so large a vacancy that the grand cloud cannot strike in that place?"'

\section{\$ 19. History of the Leyden Jar. - The Leyden Battery.}

The next discovery which we have to master throws all former ones into the sliade. It was first announced in a letter addressed on the 4 th of November, 1745, to Dr. Licberküln, of Berlin, by Kileist, a clergyman of Cammin, in Pomerania. By means of a cork, c, fig. 34 , lie fixed a nail, $\mathrm{s}$, in a phial, $\mathrm{a}$, into which he had poured a little mercury, spirits, or water, w. On clectrifying the n:ill he was ablo to pass from one roorn into another wit? the phial in his hand and to ignite spirits of wine with it. "If," said lie, " while it is electrifying I put my finger, or a piece of gold which I hold in my hand, to the nail, I receive a slock which stuns my arms and shoulders."

In the following yeur Cunaus of Leyden made substantially the same discovcry. It caused great worider and dread, which arose chiefly from the excited imagination. Musschenbroek felt the shock, and declared in a letter to a friend that he would not take a second one for the crown of France. Blecding at the nose, ardent fever, a heaviness of head which endured for days, were all ascribed to the shock. Boze wished that he might die of it, so that he might enjoy the honor of having his death chronicled in the Paris "Academy of Sciences." Kleist missed the explanation of the phenomenon ; while the Leyden philosopiers correctly stated the conditions necessary to the success of the experiment. Hence the pinial received the name of the Leyden phial, or Leyden jar.

This discovery of Kleist and Cunxus excited the most profound interest, and the subject was explored in all directions. Wilson in 1746 lilled a phial partially with water, and plunged it into water, so as to bring the water surfaces, within and without the phial, to the same level. On charging such a phial the strength of che shock was found greater than had oeen observed before.

Two years subsequently Dr. Watson and Dr. Bevis noticed how the charge grew stronger as the area of the conductor in contact with the outer surface of the phial increased. They substituted shot for water inside the jar, and obtained substantially the same effect. Dr. Bevis then coated a plate of glass on both sides with silver foil, to within about an inch of the edge, and obtainci from it discharges as strong as those obtained froin a phial containing half a pint of water. Finally Dr. Watson coated his phial inside and out with silver foil. $\mathrm{By}$ these steps the Leyden jar reached the form which it possesses to-day.

It is easy to repeat the experiment of Dr. Bevis. Procure a glass plate nine inches square ; cover it on both sides, as he did, with tin-foil seven inches square, leaving the rim uncovered. Connect one silde with the earth, and the other with the machine. Charge and discharge: you obtain a brilliant spark.

In our experiment with the Golden Fish (fir. 33), we employed a common form of the Leylen j:r, only with the dlfference that to gुet to a cufilicient distance from the glass, so as to avoid the attraction of the fish by the jar itself, the knob was placed higher than usual. But with a good flint-glass tumbler, a piece of tin-foil, ard a bit of stout wire, you can 
make a jar for yoursclf. Sild glass, renember, is not rare. In fig. 35 you have such a jar. $T$ is the outer, $x_{4}^{\prime}$ the inner coating, reaching to within an inch of the edge of the tumbler $G$. $\quad x$ is the

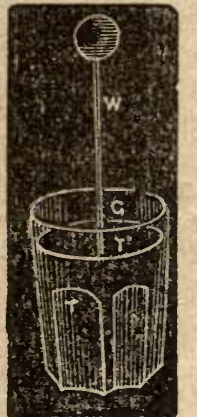

FIG. 35.

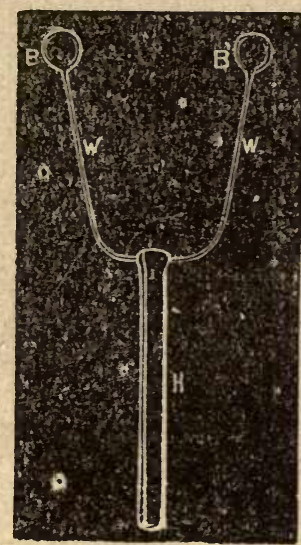

Fic. 36. wire fastened below by wax, and surmounted by a knob, which nay be of uctal, or of wax or wood, coutcd with tin-foil. In charging the jar you connect the outer coating with the earthsay with a gas-pipe or a water-pipe-anil present the knob to the conductor of your machine. A few turns will charge the jar. It is discharged by laying one knob of a "discharger" against the outer coating, and causing the other knob to approach the lnob of the jar. Before contast, thic electricity flics from knob to knob in the form of a spark.

A " discharger" suited to our means and purposes is shown in fir. 36 . II is a stick of sealing-wax, or, better still, of ebonite ; w w a stout wire bent as in the figure, and onding in the knobs $\mathrm{B} \mathrm{B}^{\prime}$. These may be of wax coated with tirifoil. Any other light condueting knobs would of course answer. The insulating handle II protects you efiectually from the shock.

You must render yourself expert in the use of the discharger. The mude of using it is shown in fir. 37 .

By augmenting the size of a Leyden jar we render it capable of accepting a larger charge of electricits. But there is a limit to the size of a jar. When therefore, larger charges are required than a single jar can furnish, we make use of a number of jars. In fig. 38 nine of them are shown. All their interior coatings are united logether by brass rods, while all the outer coatings rest upon a metal surface in free communication with the earth.

This cumbination of Leyden jars constitutes the Leyden Battery, the effect of which is cqual to that of a single jar if nine times the size of one of the jars.

\section{20. Explanation of the Leyden Jar.}

The principles of electrical induction

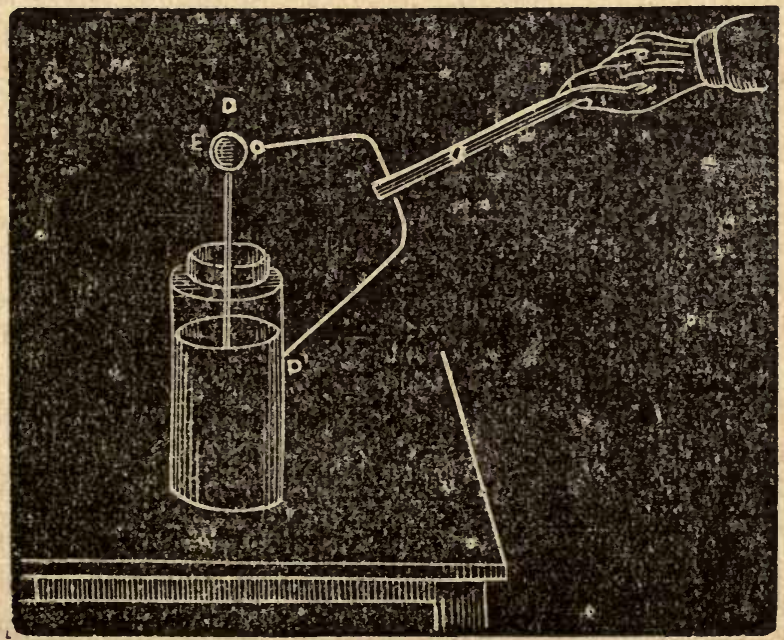

T5a. 32 


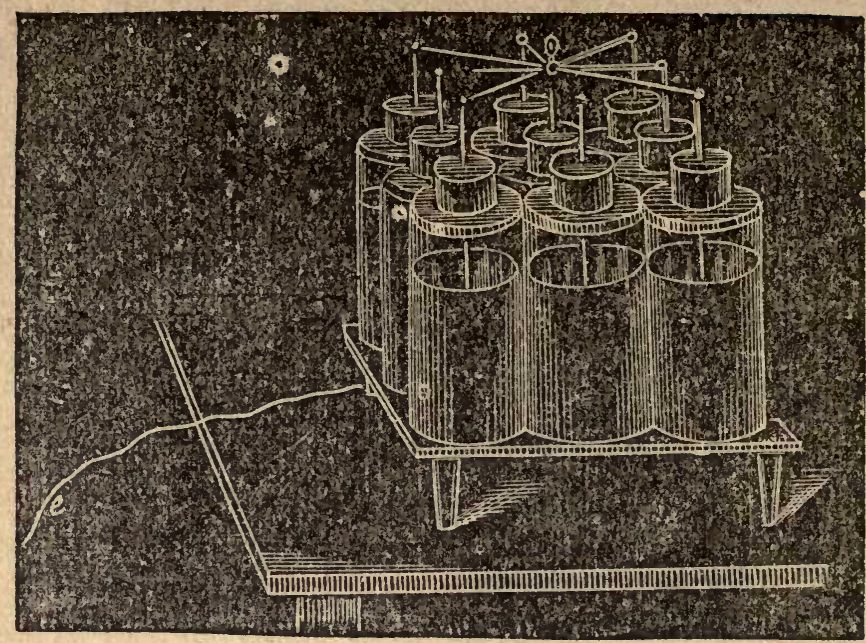

F1G. 38.

with which yon are now so familiar will enable you to thororghly analyze and understand the action of the Leyden jar. In charging the jar the outer coating is connceted with the earth, and the inner coating with the electrical machine. Let the machine, as usual, be of glass yielding positive electricity. When it is worked the electricity poured into the jar acts inductively across the glass upon the outer coating, attracting its negative and repelling its positive to the earth. Two mutually attractive electric layers are thus in presence of each other, being scparated unerely by the glass. When the machine is in good order and the glass of the jar is thin, the attraction way be rendered strong enough to perforate the jar. $\mathrm{Bv}$ means of the discharger the opposite electricities are cnabled to unite in the form of a spark.

Franklin saw and announccd with clear. ness the cscape of the electricity from the outer coating of the jar. His statement is that whaterer be the quantity of the " electric fire" thrown into the jar, an equal quantity was dislodged from the outside. We have now to prove by ar:tual expcriment that this explanation is correct.

Place your Leyden jar upon a table, and connect the outer coating with your electroscope. There is no divergence of the leaves when electricity is poured into the jar.

But here the outer coating is connect- ed through the table with the carth. Let us cut off this communication by an insulator. Place the jar upon a board enpported by warm tumblers, or upon a picec of vulcanized india-rubber cloth, and again connect the outer coating with the electroscope. The mument electricity is communicated to the knob of the jar the leaves of Dutch metal diverge. Detach the wire by your discharger and test the quality of the clectricity - it is positive, as theory declares it must be.

Consider now the experiment of Kleist and Cunaus (fig. 34). You will, I doubt not, penetrate its meaning. You will see that in their case the hand formed the outer coating of the jar. When electricity was communicated through the nail to the water within, that electricity acted across the glass inductively upon the hand, attracting the one fluid and repelling the other to the earth.

Again, I say, prove all things ; and what is here affirmed may be proved by the following beautiful and conclusive experiment : Stand on your boari, I I' fig. 39 , insulated by its four tumblers ; or upon a sheet of gutta-percha, or vulcanired india-rubber. Seize the old Leyden phial, J, with your left hand, and present the knuckle of your right hand to your balanced lath, $\mathbf{L}^{\prime} \mathbf{L}$. When electricity is communicated to the nail, the lath is immediately attracted by the knuckle. Or touch your electroscope with your right hand; when the phial is charged 


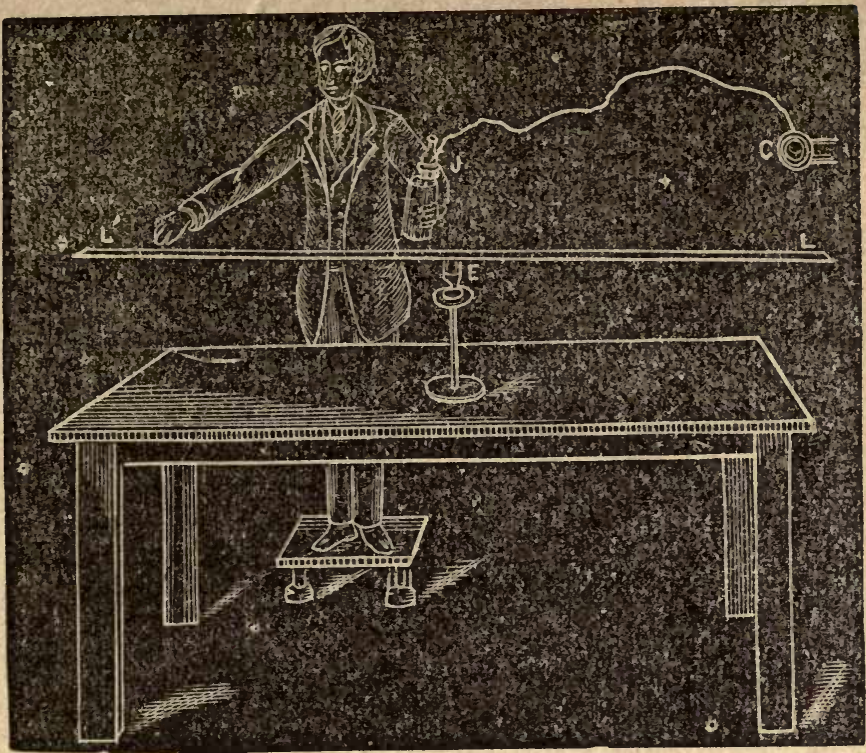

Fra. 39.

the leaves immediately diverge, by the clectricity driven from your left hand to the electroscope.

IIere the nail may be electrified either by connecting it with the prime conductor oft he machine, or by rubbing it with an excited glass rod. Indeed, I should prefer your resorting to the simplest and cheapest means in making these experiments.

\section{§ 21. Franklin's Cascade Battery.}

As a thoughtful and reflective boy or girl you cannot, I think, help wondering at the power which your thorough mastery of the principles of induction gives you over these wonderful and complicated phenomena. By those principles the various facts of our science are bound together into an organic whole. But we liave not yet exhausted the fruitfulness of this principle.

Cunsider the following problem. Usually we allow the electricity of the outer coating to escape to the earth. Suppose we try to utilize it. Place, then, your jar, ^ B, fig. 40, upon vulcanized india-rubber, and connect by a wire B C its outer coating with the knob or inner coating of a second jar C D. What will oceur when the first jar is charged? Why, the second one will be charged also by the electricity which has escaped from the outer coating of the first. And suppose you connect the outer coating of the second insulated jar with the inne:

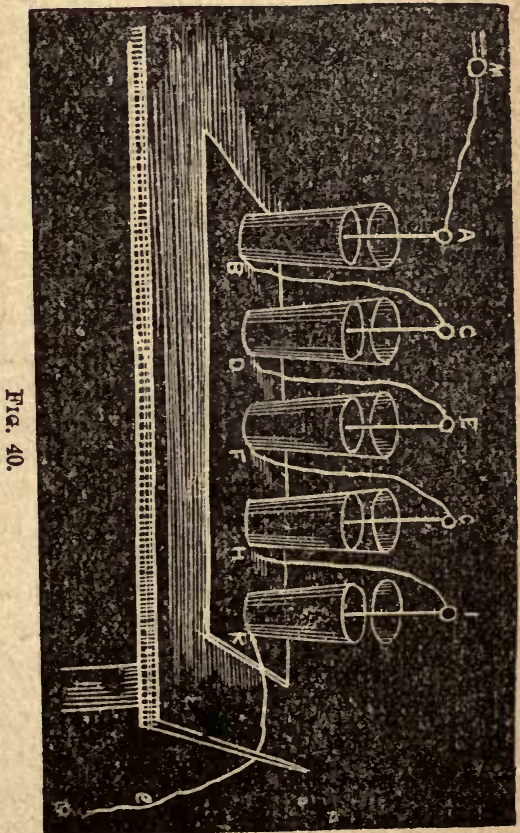


coating of a inird, E F ; what occurs? The third jar will obviously be charged with the electricity repelled from the outer coating of the second. Of course we need not stop here. We may have a long series of insulated jars, the outer coating of each bcing connected with the inner cuating of the next succeeding one. Connect the outer coating of the last jar $I \mathrm{~K}$ by a wire $c$ with the easth, and charge the first jar. You charge thereliy the entire series of jars. In this simple way yoil master practically, and grisp the theory of Franklin's celebrated " cascade battery.",

You must see that before making this important experiment you could really lasie predicted what would occur. This power of prerision is one of the most striking characteristics of science.

\section{\$ 22. Fovel Leyden Jars of the Simplest Form.}

Possessed of its principles, we can reduce tle Leyden jur to far simpler forms than any hitherto dealt with. Spread a sheet of tin-foil smoothly upon a table, and lay upon the foil a paue of glass. Remember that the glass, as usual, must be dry. Stick on to the glass by sealing-wax two loops of narrow silk ribbon, by which the pane may be lifted; and then lay smoothly upon the glass a second slicet of tin-foil, less than the pane in size, leaving a rim of uncotercel glass all round. Carry a fine wire from the uppar shect of tin-foil to your electro. scope. A little weight will keep the end of the wire attached to the tin-foil.

Rub this weight with your excited glass tube, two or three times if necessary, until you see a slight divergence of the Dutch metal leares. Or connecting the weight with the conductor of your machine, turn rery carefully until the slight divergense is obserred. What is the condition of things here? You have poured, say positire electricity on to the upper sheet of metal. It acts inductirf Is across the glass upon the under sheet, the positive fluid of which escapes to the earth, leaving the negative behind. You see before your mind's cye two layers holding each other in bondage. Now take hold of your loops and lift the glass plate, so as to separate the upper tin-foil from the lower. What would you ex- pect to occur? Freed from the grasp of the lower laver, the electricity of the upper one will diffuse itself over the electroscope so promptly and powerfully, that if you are not careful you will destroy the instrument by the mutual repulsion of its leaves.

Practise this experiment, which is a very old one of mine, by lowering and lifting the glass plate, and observing the corresponding rhythmic action of the leaves of the electroscope.

Cominon tin-plate may be used in this experiment instead of tin-foil, and a slieet of rulcanized india-rubber instead of the pane of glass. Or simpler still, for the tin-foil a sheet of common unwarmed foolscap may be emploved. Satisfy yourself of this. Spread a sheet of foolsciap on a table; lay the plate of glass upun it, an l spread a lcaf of foolscap, less than the gylass in size, on the plate of glass. Connect the leaf with the electroscope, and charge it, exactly as you charged the tin-foil. On lifting the glass with its leaf of foolscap, the leares of the electroscope instantly fly apart; on lowering the glass they again fall together. Abandon the under sheet altogether, and make the table the outer coating; if it be not of very dry wood, or corercd by an insulating varnish, you will obtain with it the results obtained with the tin-foil, tin, and foolscap. Thus by the simplest means we illustrate great principles.

The withdrawal of the electricity from the electroscope, by lowering the plate of glass, so as to bring the electricity of the upper coating within the grasp of the

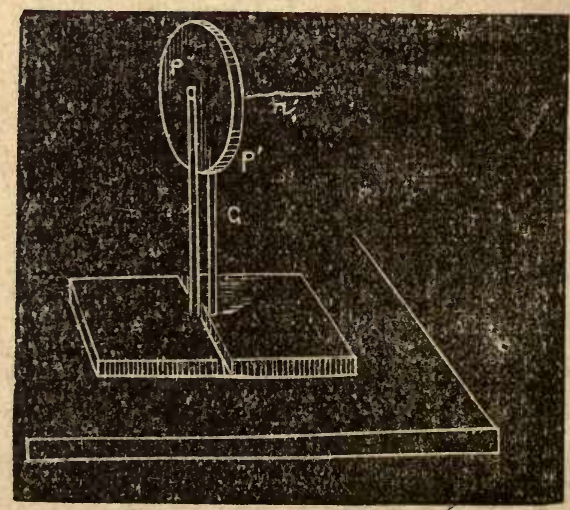

Fik. 41. 


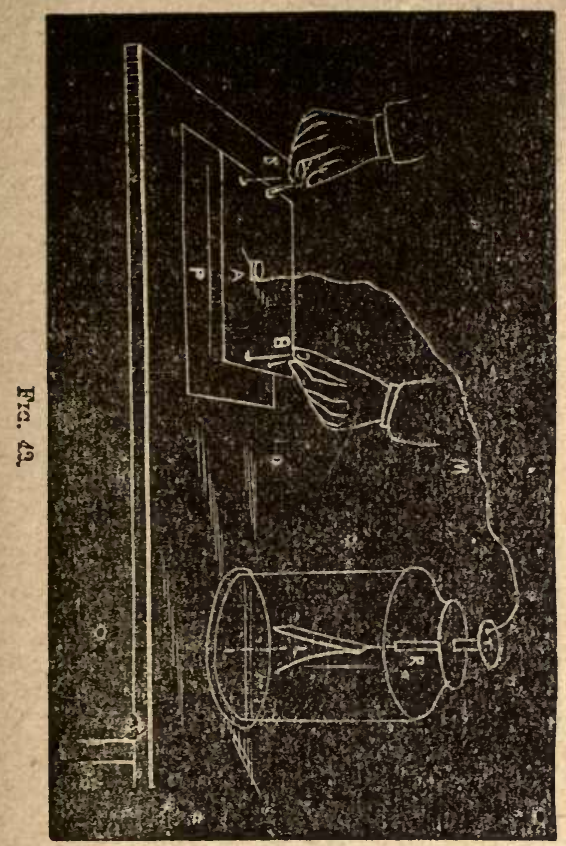

lower one, is sometimes called " condensation." The electricity on one plate or sheet was figured az squeczed together, ar condensed, by the attraction of the other. A special instrument called a comdenser is constructed by instrument makers to illustrate the action here explained.

You mav readily make a condenser for yourself. Take two circles, p' p', fig. 41, of tin or of sheet zinc, and support thic one, $\mathbf{r}^{\prime}$, by a stick of sealing-wax or glass, $\mathrm{G}$ : the other, $P$, by a metal stem, counected with the earth. The insulated plate, $\mathbf{P}^{\prime}$, is called the collecting plate; the uninsulated one, $\mathbf{P}$, the condensing plate. Connect the collecting plate with your clectroscope by the wire $a$, and bring tha condensing plate near it, leaving, how ever, a thin space of air between them. Charge the collector, $r^{\prime}$, or the wire, $w$, with your glass rod, until the leaves of the electroscope begin to diverge. Withdraw the condensing plate, the leaves fly asunder; bring the condensing plate near, the leaves again collapse.

Or vary your construction, and inakc your condenser thas. Employing the table, or a sheet of foolscap if the table be an insulator, as one plate of the condenser, sproad upon it tho sheet of india- rubber, $P$, fig. 42 , and lay upon the rubber the shect of biock-tin, A B. Connoct the tin by the wire, 20 , with the electroscope, T. Impart electricity to the little weight, $\mathrm{A}$, till the leaves, $\mathrm{L}$, begin to direrge ; then lift the tin plate by its two silk loops; the leaves at once fly ewinder.

Finally, show your complete knowledge of the Leyden jar, and your freedom from the routine of the instrument makers, by making a "jar" in the followioz norel way. Stand upon a board supported by warm tumblera. Iold in your right hand a sheet of walcanized indiarubber, and clasp, with it between you, tho left hand of a friend in connection with the earth. Place your left hand on the conductor of the inachine, and let it bo worked. You and your friend soon foel a crackling and \& tickling of the hands, due to the heightening attraction of the opposite clectricities across the india-rubber. The "hand-jar" is then charged. To dischargo it you have only to bring your other hands together : tho shock of the Leyden jar is then felt and its spark seen and heard.

By the discharge of the hand-jar you can fire gunpowder. But this will be referred to more particularly further on. (Sec § 25.)

\section{23. Seat of Charge in the Leyden Jar.}

Franklin sought to determine how tho charge was hidden in the Leyden jar. He charged with electricity a bottle balf filled with water and coated on the outside with tin-foil ; dipping the finger of one hand into the water, and touching the ontside coating with the other, ho received a sliock. He was thus led to inquire, Is the electricity in the water? IIe poured the water into a second botUle, examined it, and found that it had carried no electricity along with it.

His conclusion was "that the electrio fire must either have been lost in the do canting, or must have remained in the bottle. The latter he found to be truo; for, filling the charged bottle with fress water, he obtained the shock, and was therefore satisfied that the power of giving it resided in the glass itself." *\%

* Priestley's "History of Electricity," id cdition, p. 149 
(An ascount of Franklin's discoreries was given by him in a scries of letters addressed to P'eter Cullinson, Iisq., F.I.S., from 1747 to 1754 ).

So much for history ; but yon are to verify the history by repeating Franklin's experiments. Place water in a wide glass vesscl ; place a second glass vessel within the first, and fill it to the same height with water. Connect the outer water by a wire with the eath, and the inner water by a wire with the clectric machine. One or two turns furnish a sufficient cliarge. Remoring the inner wire, and dipping one finger into the outside and the other into the inside water, a smart shock is felt. This was Franklin's first experinent.

Pass on to the second. Coat a glass jar wihh tin-foil (not too high); fill it to the samo licight with water, and place it on india-rubber eloth. Clarge it by connecting the outside coating with the carth, and the water inside (by means of a stem cemented to the bottom of the and ending above in a knol) with an clectric machine. You obtain a bright spark on discharging. This proves your apparatus to be in good order.

Recharge. Tate hold of the charged jar with the india-rubber, and pour the water into a second similar jar. No sensible charge is imparted to the latter. Pour fresh unelectrified water into the first jar, and discharge it. The retention of the charge is shown by a brilliant spark. Be careful in these experiments, or you will fail, as I did at first. The edge of the jar out of which the water is poured bas to be surrounded by a band of libulous paper to catch the finnl drop, which, trickling down, would discharge the jar.

Experiments like those of Franklin are now made by rendering the coatings of the Leyden jar movable. Such a jar being charged, the interior coating may be lifted out and proved unelectric. The glass may then be remored from the outer coating and the latter prored unclectric. Restoring the jar and coatings, on connecting the two latter, the discharge passes in a brilliant spark.

Miske a jar with movable coatings thus : Roll cartridge paper round a good flint-glass tumbler, a, fig. 43 , to within about an inch of the top. Paste down the lower edge of the paper, and put a paper bottom to it corresponding to the buttom of the glass. Coat the paper, $r$, inside and out with tin-foil. Make as similar coating, $\mathrm{r}^{\prime}$, for the inside of the tumbler, attaching to it an upright wire,

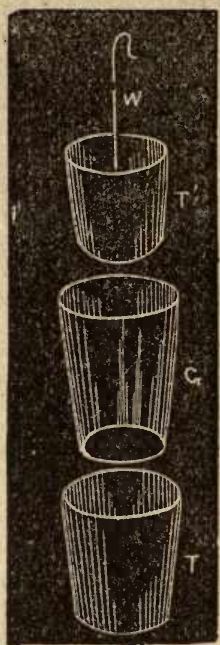

Fit. 43.

w, ending in a hook. You have then to all intents and purposes a Leyden jar.

Put the pieces together and charge the jar. By means of a rod of glass, sealing-wax, or gutta-percha, lift out the interior coating. It will carry a little electricity away with it. Place it upon a table and discharge it wholly. Then by the hand lift the glass out of the outer coating. Neither of the coatings now shows the slightest symptom of electricity. Restore the tumbler to its outer coating, and by incans of the hook and insulating rod, restore the inuer coating to its place. Discharge the jar: you obtain a brilliant spark. The electricity which produces this spark must have been resident in and on the glass.

Here, as in all other cases, you can charge your jar with a rubbed glass tube, though a machine in good working order will do it more rapidly. With "Cottrell's rubber," described in the next section, you may greatly exalt the performance of your glass tube.

§ 24. Ignition by the Electric Spark. - Cottrell's Rubber. - The Tube-ma. chine.

Various attempts had been vainly macie by Nollet and others to ignite inflam- 


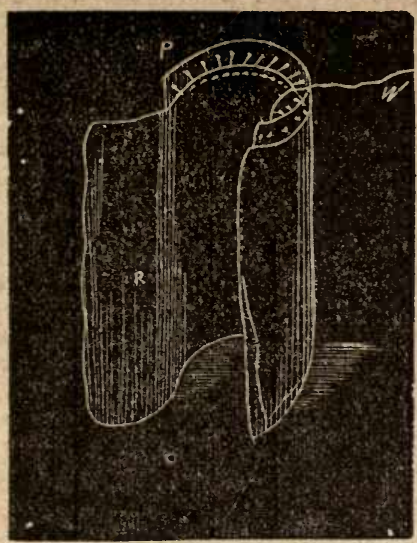

Fra. 44.

mable substances by the electric spark. This was first effected by Ludolf, at the opening of the Academy of Sciences by Frederick the Great at Berlin, on the 33d of January, 1744. With a spark from the sword of one of the court cavaliers present on the occasion, Ludolf ignited sulphuric ether.

Dr. Watson also made numerous experiments on the ignition of bodies by the electric spark. He fired gunpowder and discharged guns. Causing, moreover, a spoon contrining ether to be held by an electrified person, he ignited the ether by the finger of an unelectrified person. He also noticed that the spark raried in color when the substances between which it passed varied.

These, and numerous other experiments may be made with a far simpler " machine" than ang hitherto described. It was devised for your benefit by $\mathrm{Mr}$. Cottrell. In the electric machinc, as we have learned, the prime conductor is flooded with positive electricity through the discharge of the negrtio from the points against the excited glass. Your glass tube and rubber may be similarly turned to account. A strip of sheetbrass or copper, $P$, fig. 44 , is sewn on to the edge of the silk pad, $\mathrm{R}$, employed as a rubber. Through apertures in the strip. about twenty pin-points are introduced, and soldered to the metal. When the tube is clasped by the rubber, the rnetal strip and points quite encircle the tube.

When a fine wire, $v$, connects the strip of metal with the knob of a Leyden jar, by every downward stroke of the rubber the glass tubo is powerfully excited, and

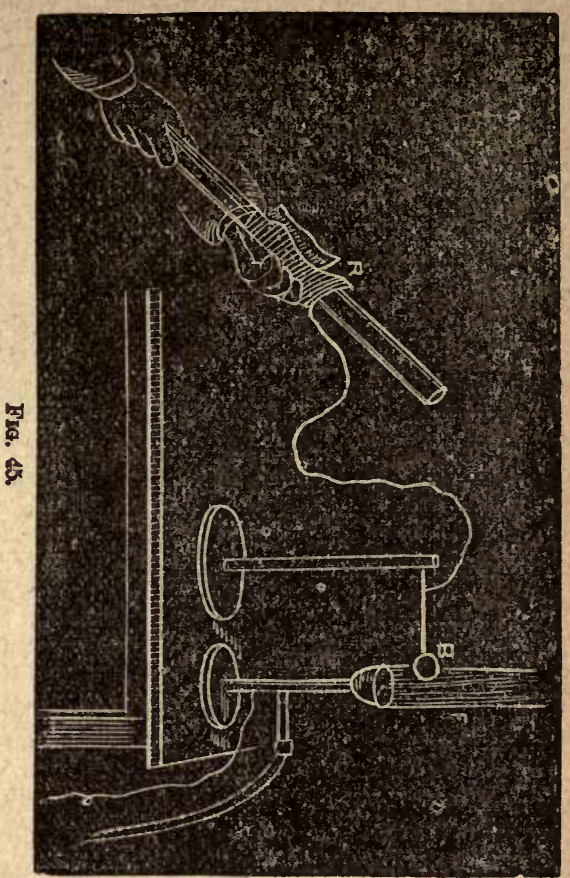

hotly following the exciting rubber is ti= circle of points. From these, against the rod, negative electricity is discharged, the free positive electricity escaping along: the wire to the jar, which is thus rapid-. ly charged.

The ignition of gas is readily effected! by Cottrell's rubber. Connecting the: strip of metal, $\mathrm{R}$, fig. 45 , with an insulat-ed rnetallic knob, B, placed within a quarter or an eighth of an inch of anc uninsulated argand burner connected with. the earth, at every downward stroke of the rubber a stream of sparks passes between the knob and burner. If gas bo turued on, it is immediately ignited by. the stream of sparks. Blowing out the. flame and repeating the experiment, every stroke of the rubber infallibly ignites the gas.

Sulphuric ether, in a spoon which has, been previously warmed, is thus ignited :; but the ether soon cools by evaporation; its vapor is diminished by the cold, and it is then less easy to ignite. Bisulphido of carbon may be substituted for the ether, with the certainty that every stroke of the rubber will set it ablaze. The spark thus obtained also fires a mixture of oxygen and hydrogen. The two gases 


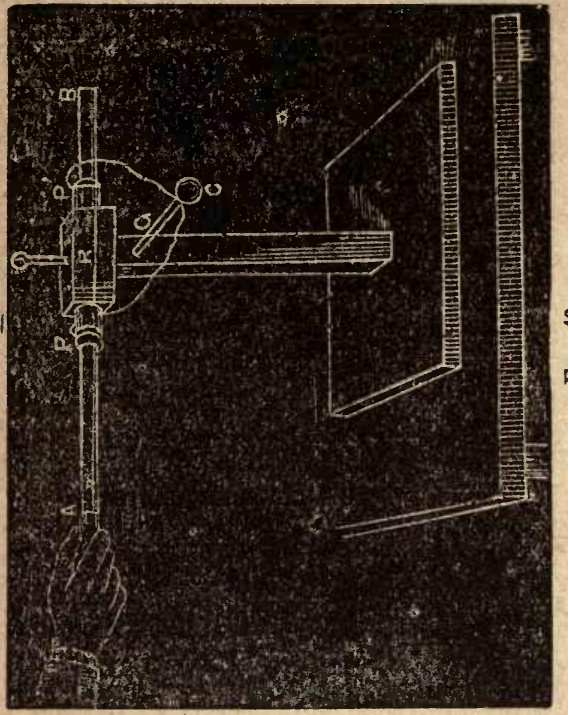

unite with explosion to form water, when an clectric spark is passed through them.

Mr. Cottrell has also mounted his glass tube so as to render friction in both directions arailable. The tube-machine is represented in fig. 46. $\mathrm{A} \mathrm{B}$ is the glass tube, ciasped by the rubber, $\mathrm{n}$. $\mathbf{P} \mathrm{P}^{i}$ are two strips of metal furnished with rows of points. From $\mathbf{P} \mathrm{p}^{\prime}$ wires proceed to the knob c, which is insulated by the horizontal stem, G. This insulating stem may be abolished with advantage, the wires from $P$ and $P^{\prime}$ bcing rendered strong enough to support the ball c. At $c$ sparks may be taken, a Lerden jar charged, the electric mill turned, while wires carried from it may be employed in experiments on ignition. I however strongly recommend to your attention the more simple rubber shown in fig. 44.

"Seldom," says Riess, " has an experiment done so mnch to derelop the peience to which it belongs as this of the ignition of bodies br the electric sparks." It aroused unirersal interest; and was repeated in all Roval houses. Money was ready for the firther prosecution of olectrical rescarsh. The experiment afterward spread among the poople. liess considers it probable that the genersl interest thus excited led to the discovery of the ley den jar, whieh was inado soon sterward.

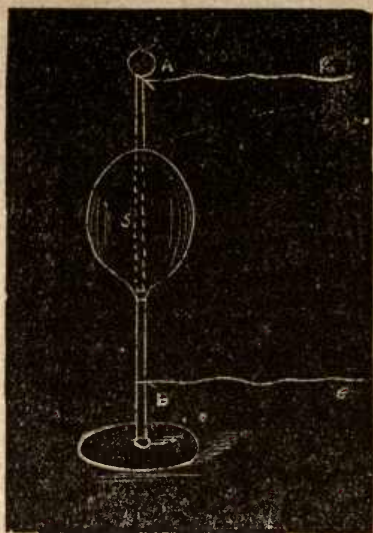

Fia. 47.

Klingenstierna astonished King Frederick of Sweden by igniting a spoon of alcohol with a piece of ice. With Cottrell's rubber and bisulphide of carbon this striking experiment is casily made, and you ought to render your knowledge complete by repeating it. $\mathrm{At}$ every stroke of the rubber the spark from the end of a pointed rod of ice infallibly sets the bisulphide on fire.

Cadogan Morgan, in 1785, sought to produce the electric spark in the interior of solid bodies. He inserted two wires into wood, and caused the spark to pass between them: thewood was illuminated with blood-red light, or with yellow light, according as the depth at which the spark was produced was greater or less. Tha spark of the Leyden jar produecd within an ivory ball, an orange, an apple, or.under the thumb, illuminates these bodies throughout. A lemon is especially suited to th:s

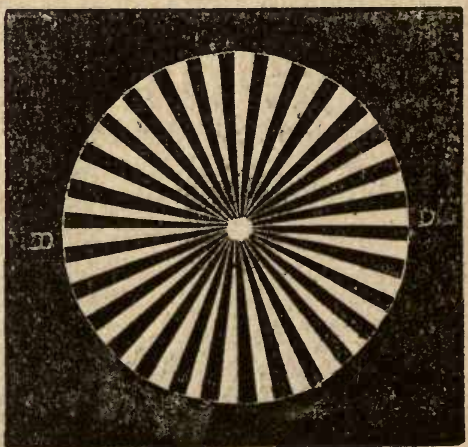

J36. 48. 
experiment, flashing forth at every spark as a spheriod of brilliant golden light. The manner in which the lemon is mounted on the brass stem $B$ is shown in fig. 47. The spark occurs at $s$, in the interval between the stems $A$ and $B$. A row of eggs in a glass cylinder is also brilliantly illuminated at the passage of every spark from a Leyden jar.

\section{\$25. Duration of the Electric Spark.}

The duration of the electric spark is very brief ; in a special case Sir Charles Wheatstone found it to be $\frac{1}{2} \frac{1}{00}$ th of a second. This, however, was the maximum duration. In other cases it was less than the millionth of a second.

When a body is illuminated for an instant, the image of the body remains upon the retina of the cye for about onefifth of a second. If, then, a body in swift inotion be illuminated by an instantancous flash, , it will be seen to stand motionless for one-fifth of a second at the point where the flash falls upon it. A rifle bullet passing through the air, and illuminated by an electric flash, would be seen thus motionless ; a circle lite D $\mathrm{D}^{\prime}$, fig. 48 , divided into black and white sectors, and rotating so quickly is to cause the sectors to blend to a uniform gray, appears, when illuminated by the spark of a Leyden jar, perfectly motionless, with all its sectors revealeil. A falling jet of water, which appears contin- uous, is resolved by the electric flash into its constituent drops. Lightning, as shown by Professor. Dove, is similarly rapid in its discharge.

For a long time it was found almost impossible to ignite gunpowder by the electric spark. Its duration is so brief that the powder, when the discharge occurred in its midst, was simply scattered violently about. In 1787 Wolff introduced into the circuit through which the discharge passed a glass tube wetted on the inside. He thereby rendered the ignition certain. This was owing to the retardation of the spark by the imperfect conductor. Gun-cotton, pliosphorus, and amadou, which are torn asunder by the unretarded sparks are ignited when the discharge is retarded by a tube of water. $A$ wetted string is the usual means resorted to for retardation when gunpowder is to lie discharged.

The instruncut usually employed for the ignition of powder is the uliversal discharger. We make our own d:.-

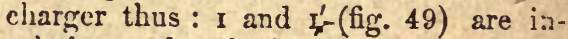
sulating rods of glass or scaling-wax, supporting two netal arms, the ends of which can be brought down upon the little central table s. One of the metal arms of the discharger being connected by a wire $e$ with the eartl, the separated ends of the two arms are surrounded with powder 8. Sending through it the unretarded charge, the poirder is scatter

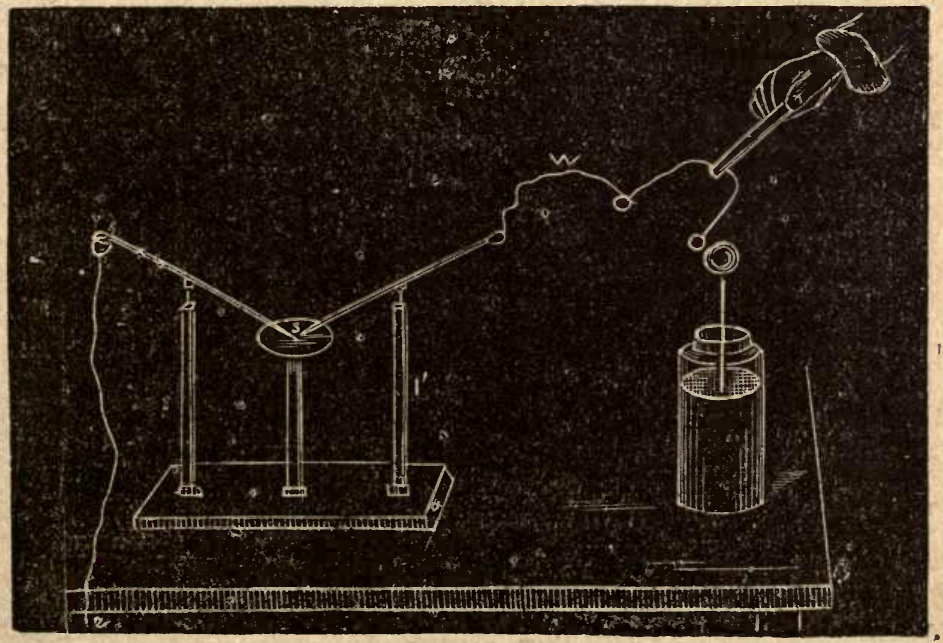

Fra. 49 


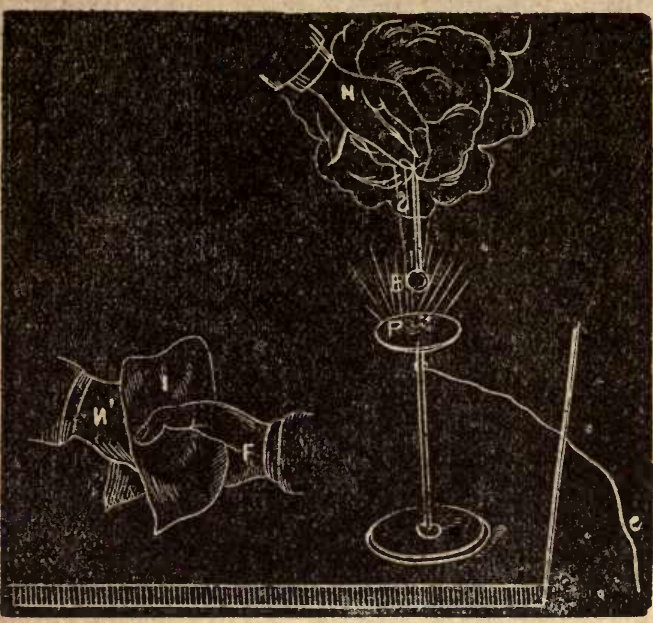

FIG. 50.

ed mechanically. Introducing the wet string $w$ into the circuit, ignition infallibly occurs when the spark passes.

This is the place to fulfil our promise tn ignite gunpowder by the " hand-jar." Fig. 50 explains the arrangement. $\quad \mathrm{I} \mathrm{n}^{\prime}$ are the hands of the insulated person. F the hand of the uninsulated friend, I the india-rubber betwcen both hands. The lead ball $B$ is suspended by a wet string $s$. On the little stand $P$, connected with the earth, is placed the powder. The charging of the liand-jar is described iil $\$ 22$. When charged, it is only necessary to bring the ball $B$ down upoy the powder to cause it to explode.

\section{20. Electric Light in Vacuo.}

The electric light in vacuo was first observed by Picard in 1675. While carrying a barometer from the Observatory to the Porte St. Michel in Paris, he eniv light in the upper portion of the islue. Sebastien and Cassini observed it sifterwards in other baroineters. John isurnouilli devised a "mercurial phosphorus," ly shaking mercury in a tube which had been exhausted by an airpump. This was handed to the King of Hrussia-Frederick 1. - who awarded for it a medal of forty ducats value. The great mathematician wrote a poem in honor of the occasion.

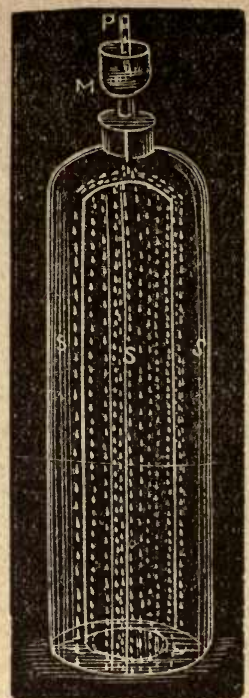

Fie. 51.

Bernouilli failed to explain the effect. The explanation was reserved for IIauksbee, who in 1705 took up the subject and experimented upon it before the Royal Society. On the plate of an airpump lie flaced two bell-jars, one orer the other. Th; outer and larger jar was open at line top. Into the opening IIauksbee fixed, air-tight, a funnel, which he stopped with a plug of wood and filled with mercury. He exhausted the space between the two jars, withdrew the wooden plug and allowed the mercury to streain against the outer surface, of the inner jar. IIe thus obtained a shower of fire. This is a truly beautifuit experiment when witnessed by an observer close at hand.

A copy of Ilauksbee's own figure illustrating this experiment is annexed, fig. 51. $M$ is the fumel containing the mercury, $p$ the plug of wood, s the, outer and $s^{\prime}$ the iuner bell-jar. Instead of the plug $\mathbf{P}$, an india-rubber tube, held by a clip, may be employed with advantage to counect the funnel with the exhausted jar. By gradually relaxing the clip the mercury may be made to fall at a rate corresponding to the inaximum luminous effect. The streams of light produced are very beautiful, but they are more continuous than they are shown to be by IIanksbec.

In 1700 IJauksbee referred the phe- 
nomenon to its true cause, namely, the friction between mercury and glass in the highly rarefied air. John Bernouilli ridiculed Hauksbee's explanation. But truth outlives ridicule, and it is now universally admitted that Hauksbee was right.

Hauksbee also made the following experiment, which, as shown by Riess, is explained by reference to the principle of induction. A hollow glass globe was mounted so as to be capable of quick rotation. It was exhausted, and while it rotated the hand was placed against it in the dark. It was positively electrified by the hand. This positive electricity acted inductively on the glass itself, attracting its negative, but discharging its positive as a luminous glow through the rarefied air within. Maukshee was able to read by the light thus produced.

By such experiments it was shown that rarefied air favored the passage of electricity. Dry air is in fact an insulator, which must be broken through to produce the electric spark. Through an exhausted glass tube six feet long a discharge freely passes which would be incompetent to leap over the fifticth part of this interval in air. But whereas the spark in air is dense and brilliant, the discharce in vacuo fills the exhausted tube with a diffuse light.

(lt is here wortlyy of remark that at a very early period Grummert, a Yole, proposed the employment of this diffuse clectric light to illuminate coal mines-a notion which has been revived in our day. The light in this form is not cornpetent to ignite the explosive gases which produce such terrible disasters in mines.)

Priestley, in his " History of Electricity," thus describes the light in vacuo. "Take a tall receiver, very dry, and in the top of it insert with cement a wire not very acutely pointed, then exhaust the receiver and present the knob of the wire to the conductor, and every spark will pass through the vacuum in a broad stream of light, visible through the whole length of the receiver, be it ever so tall. This stream often dirides itself into a variety of lieautiful rivulets, which are continually changing their course, uniting and dividing again in the most pleasing manner. If a jar be discharged through this vacuum, it gives the appearance of a very dense body of fire, darting directly through the centre of the vacuum without ever touching the sides."

Carendish emplored a double barometer-tube, bent into a form of a borseshoe, with its curred portion empty, to show the passage of electricity through a vacuum. It is really not the racuum which conducts the electricity, but the highly attenuated air and vapor which fill the space above the barometric columns. When the mercury employed is carefully purged of air and moisture by previous boiling, the space above the mercury, as proved by Walsh, De Luc, Morgan, and Davy, is wholly incapable of conducting electricity. Similar experiments have been made in the laboratory of Mr. Gassiot, to whom we are indebted for so many beautiful electrical experiments. Professor Dewar has also brought his experimental skill to bear with success upon this subject.

Electricity, therefore, does not pass through a true racuum; it requires ponderable matter to carry it. If a goldleaf electroscope be kept at a'distance from all conductors, it may be kepr charged for an almost indefinite period in a good air-pump vacuum.

The matter rendered thus luminous by the electrical discharge is attracted and repelled like other electrified matter. "A finger," says Priestley, " put on the outside of the glass will draw it [the luminous stream] wherever a person pleases. If the vessel be grasped with both hands, cvery spark is felt like the pulsation of a great artery, and all the tire makes towards the hands. This pulsation is felt at some distance from the receiver; and in the dark a light is seen betwixt the hands and glass.",

"All this," continues the historian of electricity, "while the pointed wire is supposed to be electrified positively ; if it be electrified negatively the appearance is remarkably differcnt. Instead of streams of fire, nothing is secn but one uniform luminous appearance, like 8 white cloud, or the milky-way on a clear starlight night. It seldom reaches the whole length of the ressel, but is generally only like a lucid ball at the end of the wire."

Of the two appearances here described 


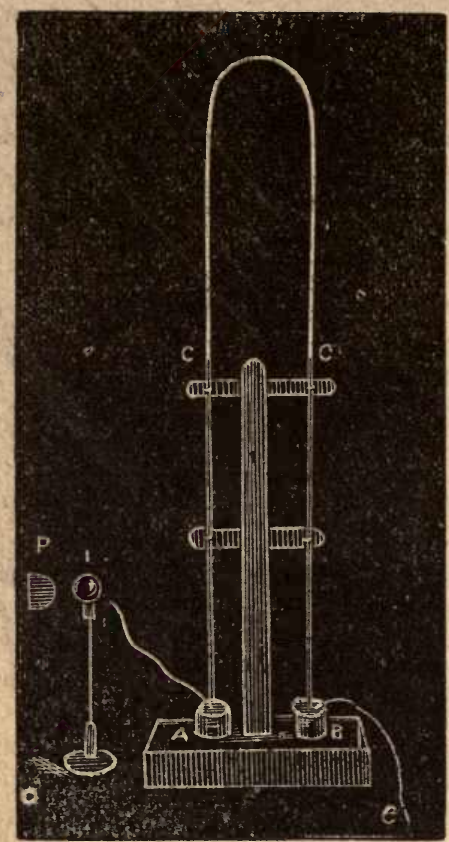

Fเน

the former is now known as the electrie bruak, and the latter sis tho eloctric glow. Toth can lie produced in naconfined air. The glow is sometimesseen on the masts. of slips, and it is mentioned by the ancients ss appering on the points of kesces. It is called St. Ermo's or St. Elmo's fire, ifter the :ailors' saint, Erasmus, who suffered murtyrdon at Gaeta, at the lieginnirig of the fourth century.

The jurple color of the diffused light in attcnuated air was noticed by Hanks. bee. The color depends upon the residue of attenuated gas, or vapor, through which the discharge passcs. If it be un axygen-residue the light is whitish, if it be a hydrogen-residue the light is red, if a nitrogen-residue the light is purple, wactly resembling that displayed at times I.y 1 : $:$ e aurora bnrealis-ab color doubtless cive to the discharge of electricity through the attenuated nitrogen of the air.

Electric light in vacno is readily produced by the friction of an amalgamated rutxirer against the outside of an exhausted tube. The light is also produced by the friction of mercury within a barometric vacuum. The discharges through tubes many fect in length and exhausted by sn air-pump are very fine. The double barometer tube of Cavendish also yields a truly splendirl bow of light, when a streng electric discharge is sent through it. For this experiment fig. 52 shows the best arrangement. $P$ is the prime conductor of an electrical machine, I a. insulated metal ball, connected by a wire with the mercury trough A. The trungh $\mathbf{B}$ is connected by a wiro with the carth. c and $\mathrm{c}^{\prime}$ mark the height of the mereurial columns. When the machine is worked siparks pass from $P$ to $I, a$ virid bow of light at cach passage stretching from o to $c^{\prime}$. By causing $I$ to approach $\mathrm{p}$, the discharges become more frequent, but more feeble; by augmenting the distance $P I$, the sparks become rarer, but more strong. When very strong, a bow of dazzling brilliancy accompanies every spark.*

Small tubes for these experiments are bost obtained from philosophical instrument makers

\section{§ 27. Lichtonberg's Figures.}

Lichtenberg derisod a me:-ns of revosling the cundition of an electrifer surfaco ly dusting it with powder. Rod lead, in passing llirough meslin, is pue: tively electritied; flower of sulphur is negatively clectrified. . Whisking a fox's brush over a cake of resin and drawiar over the surface the knob ef a Leyden jus, positively charged, the rexin is rendered in part negafive and in part positire. Dusting the mixed powder orer the surface, the sulphur arrangex itself over the positive places, and the red lead over the negative places, a ver: beautiful puttern being the rusult.

This experiment of Liclitenberg's constituted the germ of Chlarini's important accustical researches. "Culadni's figures" were the direct offspring of " Lichtenberg's figures."

8 28. Surface Compared with Mass. Distribution of Electricily in Hollow Conductors.

Monnier proved that the eharge of a

* It is well to have tho interval $P$ I at some distance from the bow, so thst the light of the apork shall not impair the effect of tho discharge upon the eye. 


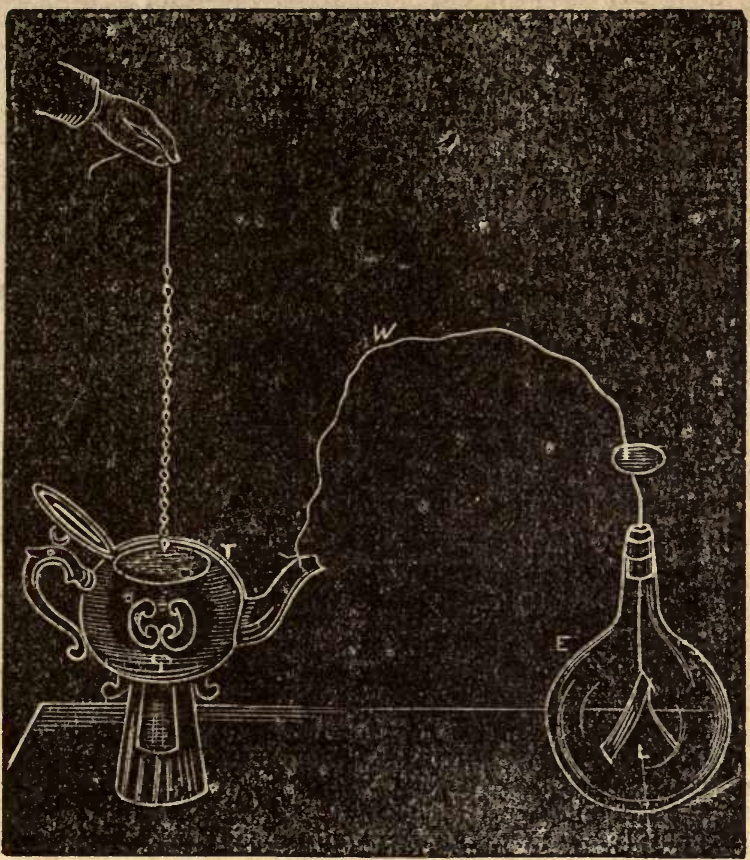

ins a

conductor depended upon its surface, and not upon its solid contents. An anvi! weighing 200 pounds grare a smaller sp:rk than a speaking trumpet wcighing 10 poun's. $\Lambda$ solid ball of lead gave a spark only of the same force as that obtained from a piece of thin lead of the same superlieies, bent into the form of a huup. . Final'y Monnicr obtained a strong spark from a long strip of sheet lead, but a very small one when it was rolled into a larnp.

Le Roi and D'Arcy showed that a hollow sphere accepted the same charge when empty as when filled with mercury, which augmented its weight sixty-fold. And this proves the intluence of surface as distinguished from snass.

The distribution of electricity is well illustrated ly the deportment of hollow bodies. Impart liy jour carrier (fig. 15) successive measures of electriciry to the interior of an insulated ice-pail, or a pewter pot. On testing the interior of the vessel with the carrier and an electroscope no.electricity is found there ; but it is found on the external surface. A hat suspended by silk strings answers as well as the ice-pail.
This experiment with the hat is a rery instructire ons. The hat may be charged either rith Cottrell's rubber or with yowr rubbed glass tube.

Notice, when testing, that roil take your strongest charges from the edfos and not from the round or hit surface of the liat. The strungest charce of $2 ! !$ is communicated to the carticr by the leet of the hat.

The successivo charges may be corkmunicated to the hat by a metal liall su: pended by silk. The charged ball, co touching the interior surface, becorness completely unclectric.

Franklin placed a long chain in 2 :ilver tea-pot which he eiectrified. Cos. necting his teapot with a pith-ball ed:troscope he produced a divergeces, Then lifting the chain by a silk string : found that over the portion outside the teapot the clectricity diffused itself, this withdrawal of the electricity from the electroscope being announced by the paxtial collapse of the divergent pith-lialls.

The mode of repeating this experimest is shown in fig. 53 , where $T$ is the tes pot, supprerted on a good glass tumbler $G$, and connected by the wire $w$ with tho 
electroscope r. The effect is small, but distinct.

The greatest experiment with hollow conductors was made by Faraday, who placed himself in a cubical chamber built of laths and covered with paper and wire ganze. It was suspended by silk ropes. Within this chamber he could not detect the slightest sign of electricity, however delicate his electroscope, and however strongle the sides of the chamber might be electrified.

\section{\$ 29. Physiological Effects of the Elec- tric Discharge.}

The physiological effect of the electric shock lias been studied in varions ways. Graham cansed a number of persons to lay hold of the same metal plate, which was connected with the outer coating of a charged Leyden jar, and also to lay hold of a rod by which the jar was discharged. The shock divided itself equally among them.

The Abbé Nollet formed a line of one hundred and eighty guardsmen, and sent the discharge through them all. He also killed sparrows and ishes by the shock. The analogy of these effects with those produced by thunder and lightning could not escape attention, nor fail to stimulate inquiry.

Indeed, as experimental knowledge increased, men's thoughts became more definite and exact as icgards the relation of electrical effects to thunder and lightning. The Abbe Nollet thus quaintly expresses himself : "If any one should take upon him to prore, from a well-connected comparison of phenomena, that thunder is, in the liands of Nature, what electricity is in ours, and that tho wonders which we now exhibit at our pleasure are little imitations of those great effects which frighten us; I avow that this idea, if it was well supporter, would give me a great deal of pleasure.' He t'len points out the analogies lietween both, and continues this : "All those points of analogy, which I have been some time meditating, hegin to make me believe that one inight, by taking electricity as the model, form tr one's self in relation to thunder and lightning, more perfect and more probable ideas than what have been .offered hitherto."**

* Priestley's "IIstory of Electricity," pp.
These views were prevalent at the time now referred to, and nut of them grew the experimental pronf by the great physical philosopher, Franklin, of the substantial identity of the lightning flash and the electric spark.

Franklin was twice struck senseless by the clectric shock. II afterwards sent the discharge of two large jars through six robust men ; they fell to the ground and got up again without knowing what had happened; they neither heard nor felt the discharge. Priestley, who made many raluable contributions to clectricity, received the cliarge of two jars, but did not find it painful.

This experience agrees with mine. Some time ago I sinor in this room with a charged battery of tifteen large Leyden jars beside me. Through some awkwardness on my part I touched the wire leading from the battery, and the discharge went through me. live a sensible interval life was absolutely blotted out, but there was no trace of pain. After a little time consciousness returned; I saw confusedly both the audience and the apparatus, and concluded from this, and from my own condition, that I had received the discharge. 'To prevent the audience from being alarmed, I made the remark that it had often been my desire to reccive such is shock accidentally, and that my wish had at length been fulfilled. But though the intellectual consciousness of my position returned with exceeding rapidity, it was not so with the optical consciousness. For, while making the foregoing remark, my body presented to my eyes the appearance of a number of separate pieces. The arms, fur example, were detached from the trunk and suspended in the air. In fact, memory and the power of reasoning appeared to be complete, long befure the resturation of the optic nerve to healthy action.

This may be regarded as an experimental proof that people killed by lightning sufier no pain.

$\S 30$. Aimosphcric Electricity.

The air at all times can be proved to be a reservoir of electricity, which undergoes periodic variatios. Wre have seen that ingenious men began soon to suspect at common origir for the crack151-52. 


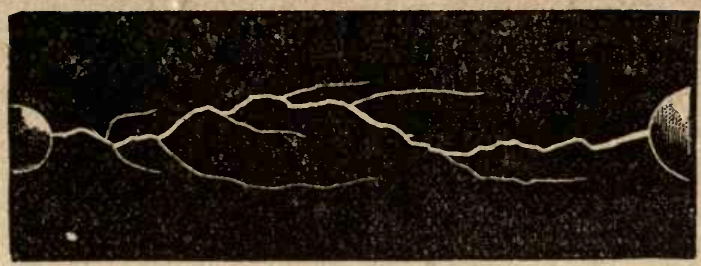

Fig. 54

ling and light of the electric spark, and thunder and lightning. The greatest investigator in this field is the celebrated Dr. Franklin. He made an cxhaustive comparison of the effects of electricity and those of lightning. The lightning flash he saw was of the same shape as the elungated electric spark ; like electricity, lightning strikes pointed objects in prefcrence to others; lightning pursues the path of least resistance; it burns, dissolves metals, rends bodies asunder, and strikes men blind. Franklin imitated all these efiects, striking a pigeon blind, and killing a hen and turkey by the electrical discharge. I place before you in fig. E. with a view to its comparison with a Acharge of forked lightning, the long spark obtained from an effective cbonite inachine, furnished with a conductor of a special construction, which farors length of spark.

IIaving completely satisfied his mind by this comparison of the identity of both agents, Franklin proposed to draw electricity from the clouds by a pointed rod erected on a ligh tower. But before the tower could be built he succeeded in his object by means of a kite with a pointed wire attached to it. The electricity descended by the hempen string which held the kite, to a key at the end of it, the key being separated from the observer by a silken string held in the hand. Franklin thus obtained sparks, and charged a Leyden phial with atmospheric electricity.

But, spurred by Franklin's researches, an observer in France had previously proved the electrical character of lightning. A translation of Franklin's writings on the subject fell iuto the hands of the naturalist Buffon, who requested his friend I')Alibard to revise the translation. D'Alibard was thus induced to erect an iron rod 40 feet long, supported by silk strings, and ending in a sentry- box. It was watched by an old dragoon named Coiffier, who on the 10th of May, 1752, heard a clap of thunder, and immediately afterwards drew sparks from the end of the iron rod.

The danger of experiments with metal rods was soon illustrated. Professor Richmann of St. Petersburg had a rod ruised three or four feet above the tiles of his house. It was connected by a chain with another rod in his rooin ; the latter rod resting in a glass vessel, and being therefore insulated from the earth. On the 6th of Angust, 1753 , a thunder cloud discharged itself against the external rod; the electricity passed downwards along the chain; on reaching the rod below, it was stopped by the glass vessel, darted to Richmann's liead, which was about a foot distant, and killed him on the spot. IIad a perfect communication existed between the lower rod and the earth, the lightning in this case would have expended itself harmlessly.

In 1749 Franklin proposed lightning conductors. IIe repeated his recommendation in 1753. He was opposed on two grounds. The Abbé Nollet, and those who thought with him, considered it as impioces to ward off heaven's lightnings, as for a child to ward off the chastening of its father. Others thought that the conductors would " invite" the lightning to break upon them. $\Lambda$ long discussion was also carried on as to whether the conductors should be blunt or pointed. TVilson advocated blune conductors against Franklin, Cavendish, and Watson. IIe so influenced George III., hinting that the points were a republican device to injure his Majesty, that the pointed conductors on Buckinghain Ilouse werc changed for others end. ing in balls. Experience of the most varied kind has justified the employment of pointed conductors. In $1769 \mathrm{St}$. 


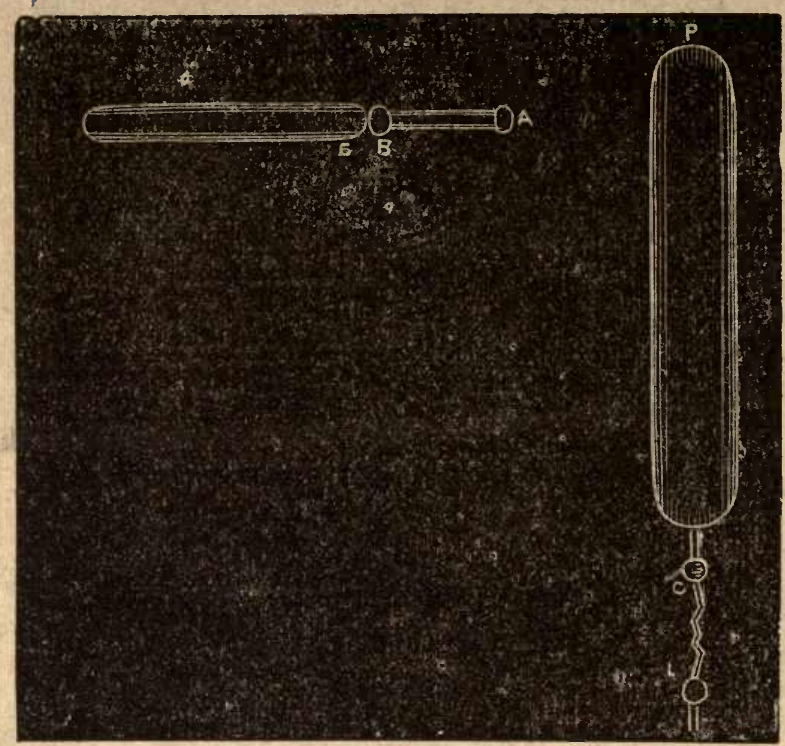

FI. 55.

Paul's Cathedral was first protected.

The most decisive eridence in favor of cunductors was obtained from ships; and Euch evidence was needed, to overcome the obstinate prejudiee of seamen. Case after case occurred in which ships unprotected by conductors were singled out from protected ships, and shattered or destruyed by lightning. The conductors were at first inade movable, being boisted on the approach of a thundersturm; but these were finally abandoned for the fixed lightning conductors devised by the late Sir Snow Harris. The saving of property and life by this obvious outgruwth of electrical rescarch is incalculable.

\section{\$ 31. The Returning Stroke.}

In the year 1779 Charles, Viscount Malion, afterward Earl Stanhope, published his "Principles of Electricity." Un the title-page of the book stands the following remark :- "This truatise compreliends an explanation of an electrical returning stroke, by which fatal effects jnay be prodiceel even at a rast distance from the place where the lightning falls."

Lord Mahon's experiments, which are models of scientific: clearness and precision, will be readily understood by ref- erence to the principles of electric induo. tion, with which you are now so familiar. It need only be noted here that whenerer he speaks of a body being plunged in an " electrical atmosphere," he means that the body is exposed to the inductive action of a second electrified body, which latter he supposed to be surrounded by such an atmosphere.

A few extracts from his work will giro a clear notion of the nature of his discovery :

"I placed an insulated inetallic cylinder, $\mathrm{A} \mathrm{B}$, figr. 55 , within the electrical atmosphere of the prime conductor $\left[\begin{array}{ll}\mathrm{P} & \mathrm{C}\end{array}\right]$ when charged, but beyond the strikin distance. The distanec between the nene end $A$ of the insulated metallic body and the side of the prime condurtor was 20 inches. The body A IB wro of brass, of a cylindrical form, 18 inctes long, by two inches in diameter. I then placed another insulated brass borly $\mathrm{n}$ F, 40 inches long by about 3 is inches in diameter, with its end $\mathrm{E}$ at tho distance of alout one-tenth of an inch from the end $n$ of the other inctallic bodly A B. I electrified the prime conductor. All the time that it was receiving its plus charge of electricity there passed a great number of weak (red or 


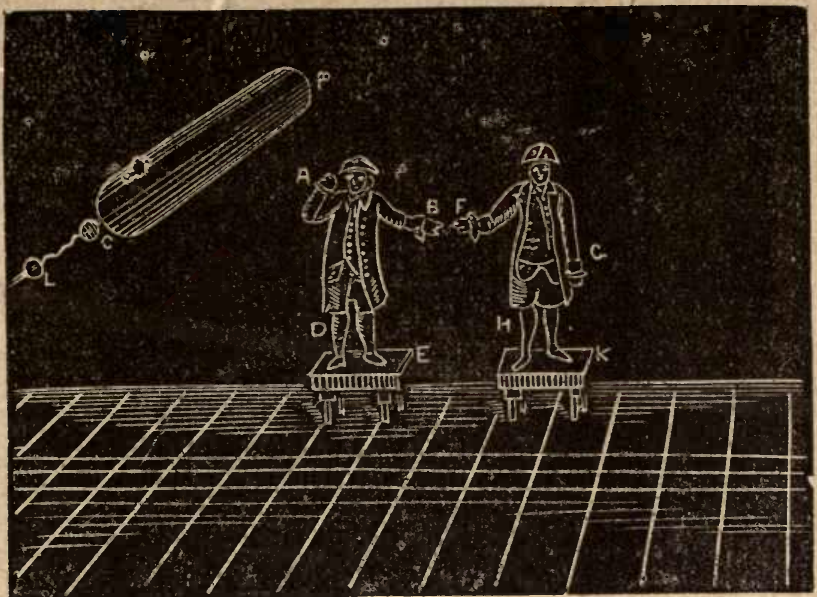

Fre.

vurple) sparks from the end $\mathrm{B}$ of the nens body $\mathrm{A} B$ into the $\mathrm{cnd}$ of the remote body $\mathrm{x}$ r."

Make clear to your wind tho origin of this stream of weak rol or purplo sparts. It is obviously due to the inductive action of the prime conductor $\mathrm{P} \mathrm{C}$ upon the body A s. The positive electricity of $\mathrm{A}$ i being repelled ly the prime conductor, passed as a strcam of sparks to IE $\mathbf{F}$.

"When the prime conductor, having received its full charge, came suduenly to discharge, with an explosion, its superabundant electricity on a large brass ball L, which was made to communicate with the cartb, it always luappened that the electrical fluid, which had been gradually expelled from the body a saldriven into the body E r, did sudilenly return from the body $\mathbf{F} \mathbf{F}$ into the body $A \mathrm{~s}$, in $\mathbf{a}$ sirong and bright spark, at the rery inetant that the explosion took place upon the ball $\mathrm{L}$.

"This I call the electricai returning stroke."

For the two conductors Lord Mialion then substituted his own body and that of another person, both of them standing upon insulating stools. He continues thus :

"I placed myself upon an insulating stool E (fig. 56), so as to have my right arm $A$ at the distance of about 20 inches from a large prime conductor; another person, standing upon another insulating stool $\pi$, brought his right hand $\mathrm{F}$ within ono. quarter of an inch of my left hand $B$.

"When the prime conductor hegan to receive its plus charge of electricity, we felt the clectrical fluid running out of my hand $B$ into his hand $r$.

"When we separated our hands $B$ and $F$ a little, the clectricity passed between us in small sparks, which sparks increased in sharpness tle farther we removed our hanus 5 and $r$ asunder, until we liad brought them quite out of a striking distance. The intervals of time between these departing sparks increased also the more the distance between our lands $B$ and $y$ was increased, as must nccessarily be the case.

"As soon as the prime conductor came suddenly to dischsrige itx electricity upon the ball $\mathrm{z}$, the superabundant electricity which the other person had received from my body did then $r$ turn from him to me in a sliarp spark, which issued from his hand $F$ at the very in-tant that the explosion of the prime conductor took place upon the ball $\mathrm{L}$.

"I still cuntinued upon tho insulating stool $x$, and I desired the other person to staud upon the floor. The returning stroke between us was still stronger than it had yet been. The reason of it was this : The other person being no longer insulated, transmitted his superabundant electricity freely into the earth. I consequently became still more negative than before.

"Now, when the returning stroke 
came to take place, not only the electricity which had passed from my body into the body of the other person, but also the electricity which had passed from my body into the earth (through the other persen), did suddenly return upon une from his hand $F$ to $m y$ hand $B$, at the same instant that the discharge of the prime conductor took place upon the ball $\mathrm{L}$. This caused the returning stroke to be stronger than before."

Lord Mainon fused metals, and produced strong physiological cficets by the return stroke.

In nature disastrous effects may be produced by the return stroke. The earth's surface, and animals or men upon it, may be powerfully influenced by one end of an electrified cloud. Discharge may occur at the other end, possibly miles away. The restoration of the electric equilib. rium by the return shock, may be so violent as to cause death.

This was clearly soen and illustrated by Lord Mahon. Fig. 57 is a reduced copy of his illustration. A B C is the electrified cloud, the two ends of which, $A$ and c, come near the earth. The discharge occurs at $c$. A man at $F$ is killed by the returning stroke, while the people at $D$, nearer to the place of discharge, but farther from the cloud, are uninjured.
With the viow of still further testing your knowledge of induction, I have bere copied a portion of this admirable essay ; but the entire memoir of Lor' Mahur. would constitute a most useful and interesting lesson in electricity.

For our own instruction we can illustrate the return shock thus :-Connect one arm of your universal discharger, fig. 49 , with a conductor like c, fig. 20 , and the other arm with tho earth. Bring C within a few inches of your prime conductor, but not within striking distance ; on working the machine a stream of feeble sparks will pass from point to point of the discharger. Let the prime conductor be discharged from time to time by an assistant; at every discharge the returning stroke is announced $b v$ a flash between the points of the discharger at $s$. If gun-cotton with a little fulminating powder scattered on it, or a fine silver rire, be introduced between the points of the discharger, the one is exploded and the other deflagrated.

The stream of repelled sparks first seem may be entirely abolished by establishing an imperfect connection between the conductor $\mathbf{c}$ and the carth : a chain resting upon the dry table on which the conductor stands will do. The chain permits tho feebler sparks to pass through it in

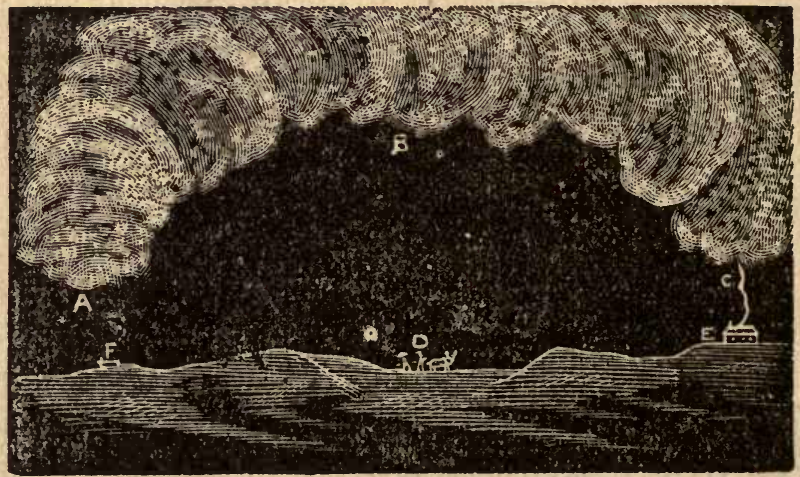

Fig. $5 \%$.

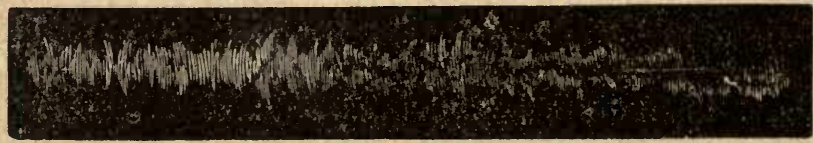

Fra. 58. 
preference to crossing the space $s$; but the returning stroke is too strong and sudden to find a sufficiently open channel through the table and chain, and on the lischarge of the prime conductor the spark is seen.

It was the action of the return shock upon a dead frog's limbs. observed in the laboratory of Professor Galvani, that led to Galvani's experiments on animal electricity ; and led further to the discovery, by Volta, of the electricity which bears his name.

\section{§ 32. The Leyden Battery, its Currents, and some of their Effects.}

In the ordinary Leyden battery described in $\$ 19$ all the inner coatings are connected together, and all the onter coatisgs are also connected together. Such a battery acts as a single large jar of extraordinary dimensions.

Wires are warmed by a moderate electric discharge ; by augmenting the charge they are caused to glow ; with a strengthencel charge the metai is torn to pieces ; fusion follows; and by still stronger chariges the wires are reduced to metallic dust and vapor.

For such experiments the wire must be thin. Without resistance we can have no heat, and when the wire is thick we have little resistance. The mechanism of the discharge, as shown by the figures produced, is different in different wires. The figure produced by the dust of a deflagrated silver wire on white paper is shown in fig. 58.

When the discharge of a powerful battery is sent through a long steel chain with the ends of its links unsoldered, the sparks between the unsoldered links carry the incandescent particles of the steel along with them. These are consumed in the air, a momentary blaze occurring along the entirc chain. Chain cables have been fused by being made the channels of a flash of lightning.

Retaining our conception of an electric fluid, at this point we naturally add to it the conception of a current. It is the electric current which produces the effects just described. In many of our former experiments we had electricity at rest (static electricity), here we have electricity in motion (dynamic electricity).

Sending the current from a battery through a flat spiral (the primary) formed of fifty or sixty feet of copper wire, and placing within a little distance of it a second similar spiral (the secondary) with its ends connected; the passage of the current in the first spiral excites in the second a current, which is competent to deflagrate wires, and to produce all the other effects of the electrical discharge. Even when the spirals are some feet asur.der, the shock produced by the sccondary current is still manifest.

The current from the sccondary spiral may ve carried round a third; and this third spiral may be allowed to act upon a fourth, cxactly as the primary did unon the secondary. A tertiary current is thus sooked by the secondary in. the fourth spiral.

Carrying this tertiary current round a fifth spiral, and causilg it to act inductively upon a sixth, we obtain in the latter a current of the fourth crder. In this way we generate a long progeny of currents, all of them having the currect sent from the battery throngh the first spirad for a common progenitor. To Yrof. IIenry of the United States, and to Prof. Riess of Berlin, we are indebted for the investigation of the laws of these currents. These researches, however, were subsequent to, and were indeed strgested by, experiments of a similar character previously made by Faraday with Voltaic clectricity.

Besides the electricity of friction and induction we have the following sources and forms of this power.

The contact of dissimilar metals produces elcctricity.

The contact of metals with liquids produces electricity.

A mere variation of the character of the contact of two bodies produces electricity.

Chenical action produces a continuous flow of electricity (Voltaic electricity).

Heat, suitably applied to dissimilar metals, produces a contiuuous flow of electricity (thermo-electricity).

The heating and cooling of certain crystals produce electricity (pyro-electricity).

The motion of magnets, and of bodies carrying electric currents, produces electricity (magneto-clectricity).

The friction of sand against a metal 
piate prodices flectricity.

The friction r.f conderisea water-particles against a safety valve. or better still against a box-wond nozzle through which steam is driven, produces clectricity (Armstrong's hydro-clectric machine).

These are difierent manifestations of one and the same power; and they are all evoked by an equiralent expenditure of some other power.

\section{Conclusion.}

Our experimental researches end here. I would now bespeak your attention for five minutes !onger. The expensiveness of apparatus is sometimes urged as an obstacle to the introduction of science into sehools. I liope it has lieen shown that the obstacle is not a real one. Leaving out of aceount the few jarger experiments, which have contributed but little to our knowledge, it is manifest that the wise expenditure of a couple of guineas would enable any competent teacher to place the leading facts and principles of frictional electricity complete! $\bar{y}$ at the cornmand of his pupils ; giving them thereoy precious knowledigc. anc still more precin:s intellectual discipline-a discipline which involes obscrvation, reflection, prevision by the exereise of reason, and experimental rerification.

And here, if I might renture to do so, I would urge upon the science teachers of our public and other schools that the immediato future of science as a factor in English cducation depends mainly upon them. I would respectfully submit to them whether it would not be a mistake to direct their attention at present to the collection of costly apparatus. Their principal function just now is to arouse a loro for scientific study. This is best done by the exhibition of the needful facts and principles with the simplest possible appliances, and by bringing their pupils into contact with actual expcrimental work.

The very timo and thought spent in derising such simple instruments will give the teacher himself a grasp and mastery of his subject which he could not otherwise obtsin ; but it ought to be known by the head mosters of our schools that time is necded, not only for devising such instruments, but also for preparing tho experiments to be made with them aftor they have been devised. No science tercher is fit to meet his class witholt this distinct and special premaration before every lesson. Ilis experiment.s are part and parcel of his langunge, and they ought to be as strict in logic, and as fren from stammering, as his spoken words. To make them so may imply an expenditure of time which few head masters now contemplate, but it is a necessary expen. diture, and they will act wiscly in making provision for it.

'To them, moreover, in words of friendly warning, I would say, make roo:n for science by your own healthy and spuntaneons action, and do not wait until it is forced upon you by revolutionary pressure from witlont. The condition of things now existing cannot continac. Its simple statement suffices to call down upon it the condemnation of every thoughtful mind. With refereneo io the report of a Commission appointex? .ast year to inquire into the scicntific instruation of this country, Sir Joln Lub. bock writes as follows:--" The Commissioners have published returns from more than a hundred and tiventy of the lareer endowed schools. In more tian lialf of these no science whatever is tulught; only thirtec n have a l.boratorf, and only cighteen possess any scientific apparatus. Out of the whole number, lis.s than tiventy schools devote as much - f four hours a week to science, and only thirteen attach any weight at all to sciontific subjects in the examinations."

Well may the Comınissioners pronounce such a state of things to be nothing less than a national calamity ! If persisted in, it will assuredly be followed by a reaction which the truest friends of classical culture in England will have the greatest reason to deplore.

\section{APPENDIX.}

\section{AN ELFMENTARY IACTUIE ON MAGNETISM. *}

Ws hare no reas in ta believe that the sheep or the dogr. or, inleed, any of the lower animuls, feel an interest in the laws

- From the author's volumz, "Fragrents of 
by which natural phen omena are regulated.

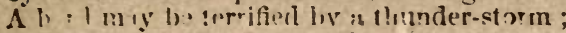

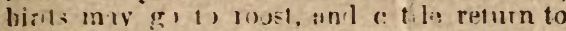
thri stalls duriner as an e lit s: but neither hirls no callin. as far a we knist, ever think of mouiting int, the canses of thete things. It is ulleerwise with in:n. The presence of nutu:al oljects, the occurrences of ritural eveuts, line ru·iell apnearances of 1h: universe in which he llwil's, penctrate heyoul his organs if sense, aml appenl to an inner power of which the senses are the mere instruinents and exritants. No fact is to him either final or original. He cannot limit hinself to the contemplation of it alone, but endeavers to uscertain its position in a series 10 which the constitillinn of his minl 1 assures him it must belong. II e regirds all that he witnesses in the iresent as the efflux and sequence of s melhing that has gone before, an 1 a's the suirce of $n$ system of events whirh is to follorr. The notion of spontanrits, in which in his rutler state he accounteri for natural erents, is alondoned; the ilen that Nature is an aggregate of independeut pats ulso clisappears, as the connection an $i$ mutual dependence of physical powers b-irme mise and more manifest: until he is finally led, and that chiefly by the sci(nce) of whitel $I$ happen this evening to be the cxponent, 10 regaud Nature as an organic whole, is " hady each of whose members symerathizes with the rest, changing, it is true, from ures to ages, but without one real break of enntiunity, or a single interruption of the fixed relutinus of cause and effect.

The system of things which we call Nature is, however, too vast and various to be studied first-han I by any single miud. As knowledgo exten ts there is always a tendency to subdivide the fieli of investiustion, its varions paits licing taken up by different individuals, and thus receiving a greater umount of attention than could possibly be bestowed on them if each investigator aimerl at the mastery of the whole. East, west, north, anil south, the human min'l pushes its cunquests; but the centripetal form in which knowledge, as a whole, all vances, epreading cver wider on all sides, is clue in reality to the exertions of indivi:iuals, each of whom directs his efforts, inore or liss, alonir a single line. Accepting, in many respects, his culture from his fellow. mav, taking it from spoken words and from written borks, in sonse one direction, the student of nalure milet actually touch his work. Ile may otherwise be a distributor of knowlmily:, but not a creutnr, and fails to attain that ritality of thouglit und correctness of juitgment which direct and habitual contact with nutural truth can alone impart.

One large department of the: system of $\mathrm{Na}$ ture which forms the chief subject of my own itudies, and to which it is nes duty to call

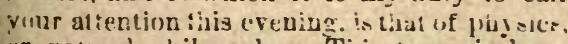
or natural philuse phy. Tuis term is large inough tin civer the siady of Nature generally, but it is usually sestricted to a depert ment which, perhaps, lies closer to our per. septions than any uther. It deals with the phenomena anil laws of light and heat-with the pheumena and laws of magnetism and electricity - with thuse of sound-with the pressures and motiuns of liquids and gases, whetherin a state of translation or of undulation. The science of mechanics is a portion of natural philosnphy, hough at present so large as to necel the exclusive attention of him who would cultivate it profoundly. Astre:omy is the application of physies to the motions of the heavenly bodies, the rastness of the field causing it, however, to be regarded as a department in ilself. In chemistry physical agents play imporiant parts. By heat and light we cause jodies to combine, and by hest anil light we decompose them. Elcetricity tears nsunder the ?ocked atoms of compounde, through their power of scparating carbonic acid into its constituents; the solar beams build up the whole vegctable world, and by it the animal, while tlee touch of the self-same beums causes hydrogen and eblorive to unite with sutiften explission and form by their combination a poiverful acid. Thus physics and chemistry intermiugle, physical ageuts being empluyel hy the chemist as a means to an encl; while in plyysicy proper the laws and phenomeva of the agents themselves, buth qualitative ani! quiantitatire, are the primary objects of aticntion.

My duty heo to-night is to spenel an hour in telling how this subject is ? ) be studied, and how a knowlerge ef it is is bu imparted to others. When first invited in do this, I lesitated before accepting the 1 csponsibil.ty. It would be easy to chteitain you with an account of what nutural philosurhy har accomplished. I might point in those applicatiuns of science regarding which we hear s' $^{\circ}$ inuch in the newspapers, and which we often find mistalien for science itself. I might, of course, sing changes on the stcam-engrine and the telegraph, the electrotype and the photograph, the medical applications of pliysies, aud the million other inlets by which scientific thought fi!ters intu practical life. That would be easy compared with the task of informing you how ycu arc to make tise study of physics the instrument of your own culture, how you aic in possuss its furtis and make them living seed s which sh:a!l take rost nud grow in the mind, and not lie like dead lum. ber in the storehouse of memory. This is a task much heavier than the mere cataloguing of scientific achievements; and it is one which, feeling my own wani cí iime and power to execute it aright, I raight well hesi. tate to uccept.

But let me sink excuses, and attack tho work to the best. of my ability. First and foremost, then. I would advise you to get a knowledge of facts from actual observition. Facts lookel at directly are vital; when they pass into words liale the sap is talien out $c$ f them. Fou wish, for example, to get a knowlerlge of inıgnetism; witl, proride yoursolf wit! : goo.l bixk on the subject, if ycu can, lust is not be content with what the book tells you ; do nct be satistiea with its descriptive wood-cuts; see the actsal thing 
yourstif. IIalf of our book-writers describe ixperiments which they never made, and their descriptions often lack both force and truth ; hut nu matter how clever or conscienthous they may he, their w ritten words cannot supply the place of nctual ubservation. Every fact has numerous radiations, which are shorn off by the nıan who describes it. Go, then, to a philosophicul instrumentmaker, and give, according to your means, for a straight bar.magnet say, half a crown, or, if you can afford it, five shillings for a pair of them ; or get a smith to cut a length of ten inches from a bar of steel an inch wide and half an inch thick; file its ends decently, harden it, and get somebody like myself to magnctize it. Two liar-maynets are better than one. Procure sonie darning-needies such as these. Provide yourself also with a little unspun silk : which will give you a suspending fibre void of torsion; make a little loop of paper or of wire, thus, and uttach your fibre to it. Do it neatly. In the loop place your darning-needle, and bring the two ends or poles, as they are called, of your magnet successively up to either end of the ucedle. Buth the poles, you find, attract both cnds of the needle. Replace the needle by a bit of annealed iron wire, the same effects ensur. Suspend successively little rods of lead, copper, silver, or brass, of wood, glass. ivory, or whalebone; the magnct produces nn sensible effect upon any of these sub. stances. You thence iufer a special property in the case of steel and iron. Multiply your expuriments, however, and you will find that some other sulistances besides iron are acted upon by your magnet. A rod of the metal nickel, or of the metal cobalt, from which the blue color used by painters is derived, exhibits powers similar to those observed with tho iron and steel.

In studying the character of the furce you may, however, coufine yourself to iron and steel, which are always at hand. Make your experiments with the darning-needlo over and over again; uperute on both ends of the needle; try both ends of the magnet. Do not think the work stupid; you are conversing with Nature, and must accuire a cerıin grace and mastery over her language; nod these practice cau alone impart. Let every movement be made with care, and avoid slovenliness from the outset. In every one of your experiments endearor to feel the responsibility of i moral agent. Experiment, as I have said, is the language by which we addross Nature, and through which she sends her replies; in the use of this language a lack of struiglitforwardness is as possible and ns prejudicial as in the spoken language of the tongue. If you wish to become acyuaintell with the truth of Nuture, you must from the first resolve to deal with her sincercly.

Now remore your needle from its loop, and draw it from end to end ulong one of tho ends of tho magnet; re-suspend it, $\mathrm{s}$ nd repeat your former experiment. You fnd the result different. You now fiud that each extremity of the magnet attracts ono end of the seodle and repels the other. The simpie attraction observed in the first instance is now replaced by a dual force. Repeat the experiment till you lave thoroughly observed the ends which attract and those which repel each other.

Witlidraw the magnet entirely from the vicinity of your needle, and leave the lotter freely suspended by its fibre. Shelter it as well as you can from currents of air, and if you have iron buttons on your coatt or a stce? penknife in your poeket. lieware of their ac tion. If you work at right, heware of iron candlesticks, or of hrass unes with iron rods inside. Freed from such disturbarees, the needle takes up a certain determinate po: sition. It sets its length nearly north an'? south. Draw it asile from this position and let it go. After eeveral oscillations it will again come to it. If yuu have obtained your magnet from a philosuphical instrumentmaker, you will see a mirk on une of its endis. Supposing, then, that you drew your needle along the end thus marked, and that the eyeend of your needle was the last to quit tho magnet, you will find that the eye turns to the south, the point of the needle turning toward the north. Make suic of this, and do not take this statement on my authority.

Now take a second darning-needle like the first, and magnetize it in precisely the same manner : freely suspeuded it also will turn its point to the nurth and its eye to the south. Your next step is to examine the action of the two needles which you have thus magnetiz:r? upun euch other.

Take one of them in your hand, and leave the other suspended: hring the eye-epd of the furmer vear the eye-end of the latter: the suspended needle retreats : it is repelled. Make the same experiment with the two points, you obtain the same result, the suspended needle is repelled. Now cause tho dissimilar ends to act on each other - you have attraction-point attracts eye und eye attracts point. Prove the reciprocity of this uction by removing the suspended needle, and putting the other in its place. You $o b$ tain the same result. The attraction, then, is mutual, and the repulsion is mutual, and you have thus demonstraled in the clearest inanner the fundamental law of magnetism, that like poles repel, and that unlike poles attract each other. You may say that this is all easily understood without doing ; but do $i t$, and your knowledge will not be confined to what I have uttered here.

I have said that one end of your magnet has a mark upon it ; lay several silk tibres together, so as to get sufflcient strength, or employ a thin silk ribbon, and form a lonp large enough to hold your maguet. Suspend it ; it turns its marked end toward the north. This marked end is that which in England is called the north pole. If a common smith has made your magnet, it will be conveuient to deternine its nom pole yourself, and to matk it with a file. You vary your experiments by causing your magnetized darning needle tis attract and repel your large mag. net; it is quite computent to do so. In mass 
netizing the needle I hare supnosed the eycend to be the list in gut the markerl ent of the magnet; that end of the needile is a south pole. The end which la it quits the magnet is always opp seel in priarily to the enil of the maenet with which it has been in contact. Brought near each Gher they mutually attrat, and thus demons: rute that they ane unlik': pules.

You may perliaps learn all this in a single hour; liut spend sevetal at it, if necessary ; and rememler, usulesstanding it is not sufiicient : you must nbtain a mautul aptitude in addressing Nature. If you speak to your fellow-man, you are not eutilled to use jargon. Bad experiments are jug gon adhresseil to $\mathrm{Na}$. ture, and just as mueh is be deprecated. A manual dexterity in illustraling the interaction of magnetic poles is of the utmost importance at this stage of your progress, and you must not neglect attaiuing this power orer your implements. As you proccell, moreover, you will be tempted to do inore than I can possibly suggest. Thoughts will cccur to you which you will endeavor to follow out ; questions will arise which you will try to answer. The same expetiment may be twenty things to twenty people. Having witnessed the action of pole on pole through the alr, you will perhaps try whether the mag. petic power is not to be screened off. You use plates of glass, wood, slate, pasteboaid, or gutla-percha, bit find them all pervious to this wondrous force. One magnetic polo acts upon unother through these bodies as if they were not present. And should you becomo a patentee fur the regulation of ships' compasses, you will not fali, as some projectors have done, into the error of screening off the mugnetism of the ship by the interpusition of such substances.

If you wish to teach a class you must contrive that the effects which you have thus far witnessed for yourself slall be wituessed by twenty or thiriy pupils. And here yuur nrivate ingenuity must come into play. You will atluch biis of paper to your needics, so as to render their movements visible at a distance, denoting the north and south poles by different colors, say green and red. You may also improve upon your darnıng-needle. Take a strip of sheet-steel, the rib of a lady's Mays will answer, heat it to vivid redness and plunge it into cold water. It is therehy hardened-rendered. in tact, almost as brittle as glass. Six inches of this, magnetized in the inanner of the daruing-needle, will be better atile to carry your paper indexes. Having ser thred such a strip, you proceed thus :

Maruetize a small sewing-needle and determine its poles: or, break half un inch or an inch cff your magnetized durning-needle, and suspent it by a fine silk fibre. The sewingnecdle or the fragment of the darning-reedle is now to be used as a test-needle to examine the distribution of the magnetism in your strip of steel. Hold the strip upright in your left hand, and cause the test-needle to approach the lower end of your strip : one end is attracted the other is repelled. Raisc your necdle along the strip ; its oseillations, which at first were quick, become slower ; t.pposite the midllle of the strip they cease enti ely; neither end of the needle is attracted ; nbeve the mirdlle the test-needle turns suddenly rourd, its other end being now attracted. Go through the experiment thoroughly: ydu thus learn that the entire lower half of the etrip attracts one end of the needle, while the entire upper half attracts the opposite cnd. Supposing the north end of your little needie to he that attracted below, you infer thut the entire luwer half of your magnetized strip exhibits south magnetism, while the cutite npper half exhibits uurlh magnetism. Su far, then, you have determined the rlistribution of magnetism in your strip of stecl.

You louk at this fact, you think of it : in its suggestiveness the value of the (xperiment chiefly cunsists. The thought arises, "What will occur if 1 break my stlip of stcel nernss iu the niddle? Shall I obtain 1 wo magncta, cach nussessing a single pole?" Try the ex. periment; break your stip of steel, and test each half as you tested the whole. The mere presentation of its 1 wo ends in succession ta your test-needle sultices to show you that you have not a magnet with a single pule, that each half possesses two poles with a dicu. tral point between them. And if you again break the half into two other halces, you wilk fiut that cach quater of the original strip es. hibits precisely the same magnetic distibur tion as the strip itself. You nuy contiuue the breaking process; no matter hew small youx fragment may be, it still posscests two op posite poles and a neutral point between them. Well, your liand censes io break w here bicaking becomes a mechanical impossibility : but does the mind stop there? No: you follow the breaking process in idea when you can no longer icalize it in fact; your thoughts wan. der amid the very atoms of your steel, and you crinclude that cach atom is a magnet. and that the force exerted by the strip of steet is the mere summation or lesultaut of the forces of its ultimate particles.

Here, then, is an exhibition of puwer which we cun call forth or cause to disanpear at I Jeasure. We magnetize our stip of steel by drawing it alung the pole of a ningnet; wo can demagnetize it, or reverse its magnetirn, ly properly drawing it along the same pole in the opposite direction. What, then, $i-$ the real nature of this wondrous change? What is it that takes place umong the stcms of the steel when thesubstance is magnetized ? The question leads us beyond the legion of sense, and into that of imagination. This faculty, indecd, is the divining 10 d of the man of science. No, liowever, an imaginalien which catches its creations ficm the air. lut one informed and inspired by facts, cal alule of seizing firmly on a physical image as a pinciple, of discerning its consequences, and of levising means whereby these fi recasts of thought may be brrught to un experimental test. If such a principle be sdequate to account for all the phenomenn, if from an assumed cruse the ob. werved facts necessarily follow, we cuil the as 
sumption a theor , und, once possessing it, we ran $n$ t only revive at pleasure facts already kilnown, but we can predict others which we hilve never seen. Thus inen in the prosecution of physical science, nur powers of ob serration, memory, magination, and in. ference, are all drawn upon. We observe fitcts and store them up ; imagration brooda upon these memories, snd by the uid of Jeason tries to discern their interdepentence. The theoretic principle flashes, or slussly diswns upun the mind, and then the deductive faculty interposes to carry out the principle to its logical cousequences. A perfect theory gives domiuion over natural facts; and even an assumption which can only purtially stand the test of a comparisnn with facts, may be of ominent 1 ec in ewabling us ta ennnect and classify grouns of phenninena. The theory of magnetic fluids is of this latter character, and with it we must now mike ourselves fảniliar.

With the view of stamping the thing more firmly on your minds, I will inike use of a strong and vivid image. In optics, red and green are called complementary colors; their mixture produces white. Now I ask you to imagine cuch of these colors to poseess a self. repulsive power; thut red reprels red, and that green repels green ; but that red attracts greeu and green attracts red, the attraction of the dissimilar colors being equal to the repulsion of the similar ones. Inagine the two colors mixed so as to produce white, and suppose two strips of wood painted with this white; what will be their action upon each other? Suspend one of them freely as we suspended our darning-needle, and bring the other near it; what will occur? The red component of the strip you hold in your hand will wepel the reil component of your suspendod strip, but then it will attract the green; and the forces being equal they neuiralize cach other. In fact, the least reflection s!ows you that the strips will be as indifferent to each other as two unmagnetized darning-needles would be under the same circumstauces.

But suppose, instend of mixing the colors, we painted oue half of cach strip from centre to end red, and the other lialf green, it is perfectly manifest that the two strips would now bchave toward each other exuctly as our two magnetized darning - needles - the red end would repel the red and attract the green, the green would repel the green and attract the red; so that, assuming two colors thus related to each other, we cuuld by their mixture produce the neutrality of an unmus. netized body, while by their separution we could produce the duality of action of mag. netized bodies.

But you have ulready anticipated a dofect in my conception : for if we break one of our strips of wood in the middle we have one half entirely red anil the sther entirely green, and with these it would he impossible to initate the action of our broken magnet. How, then, must we modify our conception? We must evidently suppose each atom of roood painted green on one face and red on the opposits one. If this were done the risultant action of all the atoms would exactly resemble the actiou of a magnet. Here, ilso, if the $(\mathrm{w}$ ) opposite colors of each atim eould he caused tu mix so as to produce white, we should have, as before, peifect neutrality.

Sibstitute in your minds for these two self repeilant and mulually attractive colors two invisible self-repellant and mutually attractive fluils, whicl in ordinary steel are mixed to form a neutral compound, but which tho act of magnelization separates from each other, placing the opposite flitids on the opposite faces of each atom, and you luve a perfectly distinct conceptiun of the celebrated theory of maguetic fluids. The strength of the magnetism excited is supposed to be proportional to the quantily of neutral fluid decomposed. According to this theory nuthing is actuaily trausferred from the exciting magnet to the excited steel. The act of magnetization cousis:s in the forcible separation of two powers which existed in the steel before it was magnetizes, but which then neutralized each other by their coalescence. And if you test your magnet after it has excited a hundred pieces of steel, you will find that it has lost no force-no more, indeed, thun I shuuld luse had my words sich a magnetic in. thence on your minds as to excite in them a strong resnlve to study natural philosophy. I should, in fact, be the gainer by my own utterance und by the reaction of your strength ; and so ulso the magnet is the gainer by the reaction of the body which it ungnetizes.

Look now to your excited piece of steel; figure each atom to your miuds with its opposed fluids sprend over its upposite faces. How can this state of things be permanent? The fluids, by hypothesis, attract each other : what, then, leeps them upart ? Why do they net instantly rush together across the eyuatur of the atom, and thus neutralize euch other? To meet this question, philosophers huve been obliged to infer the existence of a special force which holds the fluids asunder. They call it coerceve force; and it is found that those kiuds of steel which offer most resistance to being mugnetized, which require tlie greatest amount of coercion to tear their fluids asuncicr, are the very ones which offer the greatest re sistance to the reunion of the fluids after they have been once separated. Such kinds of steel are most suited to the formation of permanent magnets. It is manifest, indeed, that without coercive force a permanent mag. net would not he at all possible.

You have not forgotten that, previous to magnetizing your darning-needle, both its ends were attracted by your magnet; and that both euds of your bit of iron wire were actel upon in the same way. Probably also long before this you will have dipped the end of your magnet anong iron filings, and observed low they cling to $\mathrm{it}$, or into a nailbox, and found how it drags the nails after it. I know very well that if you are not the slaves of routine, you will have by this tine 
Jone many things that I have not told jou to do, and thus multiplied your experience beyond what 1 have iudicated. You are almost bure to have caused a bit of iron to hang from tho end of your magnet, and you have probably succeeded in causing a second piece to attach itself to the first, a third to the second ; until finally the force has become too feeilo to bear the weight of more. If you have operated with nails, you may have observed that the points and elges hold together with the greatest teuacity; and that a lit of iron clings more firmly to the corner of your magnet than to one of its flat surfaces. In short, you will, in all likelihood, have enriched your experience in many ways without any special direction from me.

Well, the magnet attracts the nail, and that nail attructs a second one. This proves that the nail in contact with the magnet has had the magnetic quality developed in it by that contact. If it be withdrawn from the magnet, its power to attract its fellow-nail ceases. Contact, however, is not necessary. A sheet of glass or paper, or a space of air, may exist between the magnet and the nail; the latter is still magnetized, though not so forcibly as when in actual contact. The nail then presented to the magnet is itself a temporary magnet. That end which is turned toward the magnetic pole bas the opposite nagnetism of the pole which excites it ; the eud most remote from the pole has the same magnetism as the pole itsclf, and between the two poles the nail, like the magnet, possesses a maguetic equator.

Conversant as you now are with the theory of magnetic fluids, you hive al ready. I doubt not, anticipated me in inngining the exuct condition of the iron under the intluence of the magnet. You picture the iron as possessing the neutral fluid in abundance; you picture the magnetic pole, when bronght near. decomposing the flicid; repelling the fluid of a like kind with itgelf, and attracting the unlike fluid; thus excting in the parts of the iron nearest to itself the opposite polarity. But the iron is incapable of becoming a permanent magnet. It only shows its virtue as long as the magnet acts upon it. What, then, does the iron lack which the steel possesses? It lacks coercive force. Its fluids are separated with ease, but, once the separating cause is removed, they flow together again, and neutrality is restored. Your imagnaticn must be quite nimble in picturing these changes. You must-lie able to see the fluids dividing and reuniting according as the magnet is brought near or withdrawn. Fixing a definite pole in your imagination, you must picture the precise arrangement of the two fluids with referepce to this pole. And you must not only be well drilled in the use of this mental imagery yourself, hut you must bo able to arowe the same pictures in the minds of your pupils, and satisfy yourself that they posseas this power of placing actually before themselves magnets and iron in various pnsitions, and describing the exsct magnetic state of the irou in each ranticular case. The mere fucts of magnetism will have their interest immensely augniented by an acquaintance with those hidden principles whereon the facts depend. Still, while you use this theory of magnetic fluids to track out the phenomena and link them together, bo sure to tell your pupils fhat it is to be regarded as a symbol merely - a symbol, moreover, which is incompetent to eover all the facts,* but which does good practical service while we are waiting for the actual truth.

This state of excitement into which the soft iron is thrown by the influence of the mugnet, is sometimes called "magnetization by influence." More commonly, however, the magnetism is said to bo "induced" in the soft iron, and lience this way of magnetizing is called "magnetic induction." Now, there is uothing theoretically perfect in Nuture: there is ro iron so soft as not to possess u certain amount of coersive force, and no steel so hard as nut to be capahle, in some degree. of mugnetic induction. The quality of steel is in some measure possessed by iron, and the quality of iron is shared in some degree by steel. It is in virtue of this latter fact that the unmagnetized durning needle was attracted in your first experiment; and frum this you may at once deduce the consequence that, after the steel lias been magnetized, the iepulsive action of a magnet must he always less than its attractive action. For the ropulsion is opposed by the inductive action of the magnet on the steel, while the attraction is assisted by the same inductive action. Make this clear to your iniuds, and verify it by your experiments. In sume cases you can nctually make the attraction due to the temporary magnetism overbalance the repulsion due to the permanent magnetism, and thus cause two poles of the same kind apparently to attract each other. When, however, gond hurd magnets act on each other from a sufficient distance, the inductive action practically vanishes, and the repulsion of like poles is sensibly equal to tho attraction of unlike ones.

I dwell thus long on elementury principles, because they are of the first importance, und it is the temptation of this age of unherlthy cramming to neglect them. Now follow mio a littie further. In examining the distribution of maguetism in your strip of steel, you raised the needle slowly from lonttom to top, and found what we called a neutral pnint at the centre. Now does the magntt really exert no influence on the pole presented io its centre? Let us see.

Let S N, Fig. 1, be your magnet, and let $n$ represent is particle of north magnetism placed exuctly opposite the middJe of the magnet. Of course this is an imaginary case, as you can never in reulity thus detach your north magnetism from its neighbor. What is

* This theory breaks down wben applied to diamagnetic bodies. which are repelled by magnets. Like soft iron, snch bodies ore thrown into a state of temporary excilement in virtue of which they are repelled, hut any uttempt io explain such a repulgion by the decomposition of a fluid will demonstrate its own fuliity. 
the action of the two poles of the magnet on $n$ ? Your reply will of course be that the pole $\mathrm{S}$ attracts $n$ while the pole $\mathrm{N}$ repels it. Let the magnitude and direction of the attraction be expressed by the line $n m$, and the magnitude and direction of the repulsion by the line $n$ o. Now the particle $n$ being equally distant from $\mathrm{S}$ and $\mathrm{N}$, the line $n o$, expressing the repulsion, will be equal to $m n$, which expresses the attraction, and the particle $n$, acted upon by two such forces, must evidently muve iu the direction $p$, exactly midway between $m n$ and $n o$. Hence you see that, although there is no tendency of the particle $n$ to move toward the magnetic equator, there is a tendency on its part to move parallel to the magnet. If instead of a particle of north magnetism we placed a particle of south magnetism opposite to the mag-

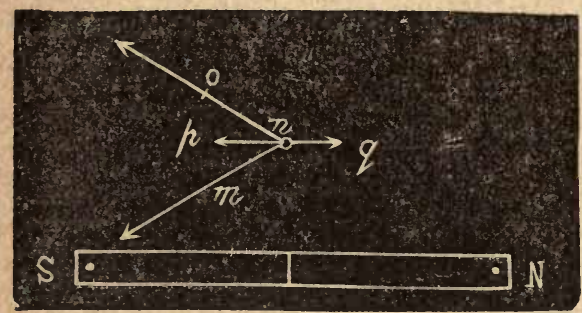

F'r. 1.

netic equator, it would evidently be urged along the line $n q$; and if instead of two separate particles of mannctism we place $r$ little magnetic: needle, containing both north and south magnetism, opp ssite the mugnetic equator, its south pole being urged along $n q$, and its north along $n p$, the little needle will be compelled 10 set itself parallel to the mag. net $\mathbf{S}$. Make the experiment, and satisfy yourselves that this is the case.

Substitute for your magnetic needle a bit of iron wire, dovoid of permanent mugnetism, and it will set itself exactly as the needle does. Acted upon by the maynet, the wire, as you know, becomes a magnet and behaves as such ; it will, of course, turn its north pole toward $p$, and south pole toward $q$, just like the needle.

But supposing you shift the pusition of your particle of north waynetism, and bring it nearer to one end of your magnet. than to the other, the forces acting on the particle are no longer equal; the nearest pole of the magnet will act more powerfully on the par-

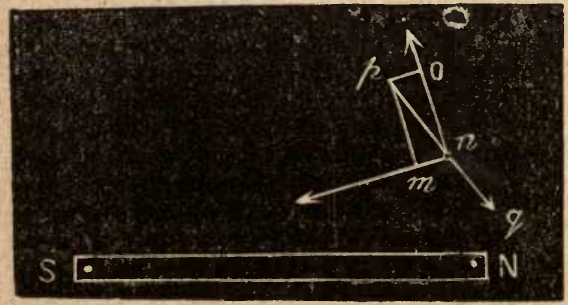

Fro. 2 ticle than the more distant one. Let $\mathrm{S} N$, Fig. 2 , be the magnet and $n$ the particle of north magnetism in its new position. Well, it is repelled by $\mathbb{N}$, and attracted by $S$. Let the repulsion be represented in magnitude and direction by the line $n o$, and the attraction by the shorter line $n m$. The resultant of these two forces will be found by completing the parallelogram $m n \circ p$, and drawing its diagonal $n p$. Along $n p$, ihen, a particle of north magnetism would be urged by the simultaneous action of $\mathrm{S}$ and $\mathrm{N}$. Substituting a particle of south magnetism for $n$, the same reasoning would lead to the conclusion that the particle would be urged along $n q$, aud if we place at $n$ a short ruagnetic needle, its north pole will be urged along $n p$, its south pole along $n \%$, and the onlv nosition pussible to the needle, thus acted on, is along the line $p q$, which, as you see, is no longer parallel to the magnet. Verify this by actual experiment.

In this way we might go round the entire magnet, and considerine its two poles as two cenires from which the force emanates, we could, in accordance with ordinary mechanical principles, assign a definite direction to the magnetic needle at every particular place. And substituting, as before, a bit of iron wire for the magnetic needie, the positions of both will be the same.

Now, I think, without further preface, you will be able to comprehend for ycurselves, and explain to others, one of the most interesting effects in the whole domuin of mag. netism. Iron filiugs you know are particles of iron, irregular in shape, being longer in some directions than in others. For the present experiment, moreover, instead of the iron filings, very small scraps of thin iron wiro might be employed. I place a sheet of paper over the magnet; it is all the better if the paper be stretclied on a wooden frame, as this enables us to keep it quite level. I scutter the filings, or the scraps of wire, from \& sieve upon the paper, and tap the latier gently, so as to liberate the particles for $u$ mornent from its friction. The magnet acts on the filings through the paper, and see how it arrunges them ! They embrace the magnet in $a$ series of beautiful curves, which are technically called mugnetic curves, or lines of magnetic force. Does the meaning of these lines yet flash upon you ? Set your magnetic needle or your suspended bit of wire at any point of one of the curves, and you will find the direction of the needle or of ihe wire to be exactly that of the particle cf iron, or of the magnetic curve at the point. Go round and round the magnet ; the direction of your needle always coincides with the direction of the curve on which it is pliced. These, then, are the lines alung which a particle of south magnetism, if you could detach it, would more to the north pole, and a bit of north magnetism to the south pole; they are the lines along which the decomposition of the neutral fluid takes place, and in the case of the maguetic needle, one of its poles being urged in one direction, and the other 
pole in the opposite direction, the needle must necessarily set itself as a tangent to the curre. I will not seck to simplify this suliject further. If there be anything obscure or confused or incomplete in my statement, you ought now, by patient thuught, to be able to clear away the obscurity, to rednce the confusion to order, and to supply what is neeiled to render the explanation complete. Do not quit the subject until you thoronghly understand it; aud if your are able to look with your mind's eye ut the play of forces around a magnet, and see distinctly the operation of those forces in the production of the magnetic curves, the time which we have spent together lias not been spent in vain.

In this thorough manner we must master our materials, reason upon them, and, by determined study, attain to clearuess of conception. Facts thus dealt with exercise an e:spausive force upon the houndaries of thought; tiney widen the mind to generalization. We soon recognize a brotherhood between the larger phenomenn of Nature and the minute effects which we have observed in our private chumbers. Wiy, we inquire, does the magnetic needle set north and south? Evidently it is compelled to do si by tho carth; the great globe which we inherit is itself a magnet. Let us learn a little mure about it. By means of a bit of wax or otherwise, attach your silk fibre to your magnetic necdle by a single poiut at its niddle, the necrile will thus be uninterfered with hy the paper loop, and will enjoy to some extent a power of dipping its point or its eye below the horiz nn. Lay your magnet on a table, and hold the needle over the equator of the magnet. The needle sets horizuntal. Move it loward the north ond of the magnet; the south end of the needle dips, the dip augmenting as you rpproach the north pole, over which the needle if free to inove, will set itself exuctly vertical. Hove it hack to the centre, it resumes its bortzontality; pass it on toward the south pole, its north end now dips, and directly over the south pole the needle becomes vertical, its north end being now turned downward. Thus we learn that on the one side of the magnetic equator the north end of the needle clips; on the other side the south end dips, the dip varying from nothing to ninety degrees. If we go to the equatoilal regions of the earth with a suitubly suspended ncedle, we shall find there the position of the ncedle horizontal. If we sail north, one end of the necdle dips; if we sail south, the opposite euil dips ; and over the north or south terrestrial magnetic pole the needle sets vertical. The south magnetic pole has not yet been found. hut Sir James Ross discovered the north magnetic pole on the 1st of June, 1831. In this manner we establish a complete parallelism letween the acticin of the tarth aud that of an ordinary magnet.

The terrestrial magnetic poles do not coincide with the geographical ones; nor does the earth's magnetic equator quite crincide with the geographical eatuator. The direction of the magnetic necile in Loudun, which is called the magnetic meridian, incluses an an. gle of 24 degrees with the tute astronomical meridian, this angle being called the declination of the reedle for London. The vorth pole of the needle now lies tn the west of the true meridian: the declination is westerly. In the year 1660 , however, the declination was notuing, while before that time it was castenly. Ail this proves that the earth's magnetic constituents are gradually changing their distributiou. This change is very sluw: it is technically c:nlied the secular change, and the oliservation of it has not yet extended over a sufficient period of time to enable us to guess, even approximatcly, at its laws.

Having thus discovered, to some extent, the secret of the earth's power, we cun turn it to account. I hold in my liand a poker formed of good soft iron; it is now in the line of dip, a tangent, in fact, to the carth's line of magnetic force. The earth, acting as a magnet, is at this moment constraining the two fluids of the poker to scparatc, making the lower end of the polier a north pole, and the upper end a south polc. Mark the experiment : I hold the knob uppermost, and it attracts the north end of a inagnetic needlc. I now reverse the poker, bringing its knob undermost; the knob is now a nurth pole and attracts the south end of a magnctic needie. Get such a poker and carefully repeat this experiment; satisfy yourselves that the fluids siift their position according to the munner in which the poker is presented to the carth. It has alrcady been stuted that the softest iron possesses a certain amount of coercive force. The earth, at this moment, finds in this force an untagnuist which opposes the full decomposition of the neutral fluid. The component fluids may he figured as meeting an amount of friction, or possessing an amount of adhesion, which prevents them from gliding uver the atoms of the poker. Can we assist the earth in this case? If we wish to remove the residue of a powder from the interior surface of a glass to which the powder clings, we invert the glass, tap it, loosen the liold of the powder, and thus enatile the force of gravity to pull it down. So also by tapping the end of the poker we loosen the adhesion of the fluid to the utoms and enable the eurth to pull them apart. But what is the consequence? The portion of fluid which has been thus furcibly dragged over the atoms refuses to return when the poker has been removed from the line of dip; the iron, as yoir sce, has become a permanent magnet. By reversing its position and tapping it again we reverse its magnetism. A thoughtful and competent teacher will well know how to place these remarkabl' facts before his pupils in a manner which will $e x$ site their interest ; he will know, and if not, will try to learn, how, by the use of sensible images, mnie or less gross, to give those he teaches definite conceptious, purifying these conceptions more and more as the minds of his pupils become more capable of abstraction. He will cause his logic to run like a line of light through these imiges, and by thus act- 
Ing he will cause his boys to march at his eide with a profit and a joy, which the mere exhibition of facts without principles, or the appeal to the bodily senses and the power of memory alone, could never inspire.

As an expansion of the note at page 339 the vollowing extrict niay find a pluce here :

"It is well known that a voltaic current exerts an attractive force upon a second current, flowing in the same direction ; and that when the directions are opposed to each other the force exerted is a repulsive one. By coiling wires into spirals. Ampère was enabled to make them produce all the phenomena of attraction and repulsion exhibited by magnets, and from this it was but a step to his celebrated theory of molecular currents. He supposed the molecules of a magnetic body to be surrounded by such currents, which, however, in the natural state of the body mutually neutralized each other, on account of their confused grouping. The act of magnetization he supposed to consist in setting these moiecular currents parallel to each other ; and, starting from this principle, he reduced all the phenomena of magnetism to the mutual action of ecletric currents.

"If we reflect upon the cxperiments recorded in the foregsing pages from tirst to last, we can hari:y fail to be convinced that diamagnetic bodies operates on by magnetic forces possess a polarity "the sume in kind us, but the reverse in direction of, that acquired by magnetic boches.' But, if this be the case, how are we to conceive the physical mechanism of this polarity? According to Coulcoinb's aud Poisson's theory, the act of mugnetization cousists in the decompusition of a neutral magnetic: fluil : the north pole of a magnet, for example, possesses an atraction for the south flund of a piece of sott iron sub. mitted to its influence, druws the said fluid toward it, and with it the material particles with which the fluid is assuciated. To account for diamagnetic phenomena this theory seems to fail altogether : according to it, in. deed, the oft used phrase, "a north pole exciting a north pole, and a south pole a south pole, involves a contradiction. For if the north fluid be supposed to be attrneted toward the influencing north pole, it ${ }^{\circ}$ absurd to suppose that its presence there could produce re. pulsion. The theory of Ampire is equally at a loss to explain diamagnetuc action; for if we suppose the priticles of bismuth sur roundeil by molecular currents, then, accord. ing to all that is known of electro-dynamic laws, these currents would set themselves parallel to. and in the same direction as those of the muguet, and hence attraction, and not repulsion, would be the result. The fact, however, of this not being the case proves that these molecular curients are not the mechanism by which diamagnetic induction is effected. The consciousness of this, I doubt not, drove M. Weber to the assumption that the phenomena of diumagnetism are produced by molecular currents, not dirceted, but rctually excited in the lismuth by the magnet. Such induced currents would, according to known laws, hare a direction opposed to those of the inducing magnet, and hence would produce the phenomena of repulsion. To carry out the assumption lere made. $M$. Weber is obliged to suppose that the molecules of diamagnetic bodies are surrcunded by channels, in which the induced molecular currents, ouce excited, continue to flow without resistance.' - Diam agnetism and Magnecrystallic Action, pp. $136,13 \%$.

THE END.

\section{CONTENTS.}

\begin{tabular}{|c|c|}
\hline otro Juction .......... & The Electrical Machine... \\
\hline Ii-toric Notra & The Ieyden Jar.......... \\
\hline Art of Experim & Erankliu's Cascade Battery \\
\hline tiic Attractions. & Leyilen Jars of the Simplest Form. \\
\hline very of Conduction & Ignition by the Electric Spark. \\
\hline Electroscopo.... & Duration of the Electric Spark. \\
\hline 3 an 1 Non-Electric & Electrie Light in Vacuo...... . \\
\hline R $\bullet$ pulsions.. & Lichtenberg's Figures.... \\
\hline ientis Law of Electric Action......... 297 & Surface Comparted \\
\hline or "Polar" Character of the Electric & the Electrical Discharge $3 x$ \\
\hline .. 299 & Atmospheric Elrctricit5.. \\
\hline Electricity?. & The Returning Stroke.. \\
\hline ric Induction... & The Leyden Battery.. \\
\hline ..... & ( \\
\hline
\end{tabular}




\section{SIX LECTURES ON LIGHT.}

$\mathrm{BY}$

JOHN TYNDALL. 



\section{LECTURES ON LIGHT.}

\section{CONTENTS :}

\section{LECTURE I.}

Introduction, - $\quad-\quad-\quad-\quad+\quad-\quad-\quad+\quad-2$

LECTURE II.

Origin of Physical Theories,

LECTLRE III.

Relation of Theories to Experience,

LECTURE IV.

Chromatic Phenomena produced by Crystals,

LECTURE V.

Range of Vision and Range of Radiation, - _ _ _ _ _ _ _ _ 34

LECTURE VI.

Spectrum Analyses,

LeC. 



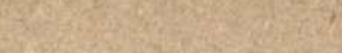

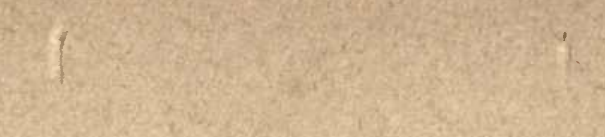

.

\section{SIX LECTURES ON LIGHT.}

\section{BY Prof. JOHN TYNDAI,L, F.R.S.}

\section{PREFACE.}

MY eminent friend, Prof. Joseph Henry, of Washington, did ine the honor of taking these lectures under his personal direction. and of arranging the times and places at which they were to be delivered.

Deeming that my home-duti.s could not, with propriety, be suspended for a longer period, I did not, at the outset, expect to be able to prolong my visit to the United States beyond the end- of 1872 .

Thus limited as to time, Prof. Henry began in the North, and, proceeding southwards, arranged for the successive delivery of the lectures in Boston, New York, Philadelphia, Baltimore, and Washington.

By this arrangement, which circumstances at the time rendered unavoidable, the lectures in New York were rendered coincident with the period of the presidential election. This was deemed unsatisfactory, and when che fact was represented to me $I$ it once offered to extend the time of my visit so as to make the lectures in New Yirk succeed those in Washington. The proposition was cordially accepted by my friends.

To me personally this modified arrangement has proved in the highest degree satisfactory. It gave me a much-needed holiday at $\mathrm{N}$ iagara Falls ; it, moreover, rendered the successive stages of my work a kind of growth, which reached its most impressive develop. ment in New York and Brooklyn.
In every city that $I$ have visited, my reception has been that of a friend; and, now that my visit has become virtually a thing of the past, I can look back upon it with unqualified pleasure. It is a memory without a stain -an experience of deep and genuine kindness on the part of the American people never, on my part, to be forgotten.

This relates to what may be called the fos. itive side of my visit-to the circumstances attending the work actually done. My only drawback relates to work undone; for I carry home with me the consciousness of having been unable to respond to the invitations of the great cities of the WVest: thus, I fear, causing, in many cases, disappointment. Would that this could have been averted! But the character of the lectures, and the weight of instrumental appliances which they involved, entailed loss of time and heavy labor. The need of rest alone would be a sufficient adınonition to me to pausc here ; but, besıdes this, each success:-re mai! from Londou brings me intelligence of work suspended and duties postponed through ny absence. These are the considerations which prevent me from responding, with a warmth commensurate with their own, to the wishes of my friends in the West.

On quitting England. I had no intention of publishing these lectures, and, except a fragment or two, not a line of them was writtes 
when I reached this city. They have been begun, continued, and ended in New York. and bear only ioc evident marks of the rapidity of their production. I thought it, however, due. boin to those who heard them with such marked attention, and to those who wished to hear them, but were unable to do so, to leave $t: \mathrm{em}$ behind $\mathrm{me}$ in an authentic form. The execution of this work has cut me off from many social pleasures; it has also preverted me from making myself acquainted with institutions in the working of which I feel a deep interest. But human power is finite, and mine has been expended in the way which I decmed most agreeable, not to my more intimate friends, but to the people of the United States.

In the opening lecture are mentioned the names of gentlemen to whom I am under lasting obligations for their friendly and often laborious aid. The list might readily be extended, for in every city I have visited willing helpers were at hand. I must not, however, omit the name of Mr. Khecs, Professor Henry's private secretary, who, not only in Washington, but in Boston, gave me most important assistance. To the trustees of the Cooper Institute my acknowlergments are due; also to the directors of the Mercantile Library at Brooklyn. I would add to these a brief but grateful reference to my high-minded friend and kinsman, General Hector Tyndale, for his long-continued care of me, and for the thoughtful tenderness by which he and his family suftened, both to me and to the parents of the yuuth, the pain occasioned by the death of my junior assistant in Philadelphia.

Finally, I have to mention with warm commendation the integrity, ability, and devotion, with which, from first to last, I have been aided by my principal assistant, $\mathrm{Mr}$. John Cottrell.

NEW YORK, February, 1873.
LECTURE I.

INTRODUCTORY: Uses of Experiment : Early Scientific Notions: Sciences of Observation : Knowledye of the Ancien:s Regarding Light: Nature judged from Theory defective: Defects of the Eye: Our Instruments: Rectilineal Propagation of Light: Law of Incidence and Reflection: Sterility of the Middle Ages: Refraction: Discovery of Snell: Descartes and the Kainbow: Newton's Experiments on the Composition of Solar Light: His Mistake as rega:ds Achromatism: Synthesis of White Lixht: Yellow and Blue Lights proved to produce White by their Mixture: Colors of Natural Bodies: Absorption: Mixture of Pigments contrasted with Mixture of Lizhts.

Some twelve years ago I published, in England, a little book entitled the "Glaciers of the Alps," and, a couple of years subsequently, a second volume, entitled "Heat as a Mode of Motion." These volumes were followed by others, written with cqual plainness, and with a similar aim, that aim being to develop and deepen sympathy between science and the world outside of science. I agreed with thoughtful men* who deemed it good for neither world to be isolated from the other, or unsympathetic towards the other, and, to lessen this isolation, at least in one department of science, I swerved aside irom those original rescarches which had previously been the pursuit and pleasure of my life.

These bnoks were, for the most part, republished by the Messrs. Appleton, under

*Among whom may be mentioned, specially, the lave Sir Edmund Head, Bart. the auspices of a man who is untiring in his efforts to diffuse sound scientific knowledge among the people of this country; whose energy, ability, and single-mindedness, in the prosecution of an arduous task, have won for him the sympathy and support of many of us in "the old country." I allude to Professor Youmans, of this city. Quite as rapidly as in Enriand, the aim of these works was understood and appreciated in the United States, and they brought me from this side of the Atlantic innumerable evidences of good-will, Year after year, invitations reached me* to visit America, and last year I was honored with a request so cordial, and signed by five-and-twenty names so distinguished in science, in literature, and in administrative position, that I at once resolved to respond to it by braving, not only the disquieting oscillations of the Atlantic, but the far more disquieting ordeal of appearing in person before the people of the United States.

This request, conveyed to me by my accomplished friend, Professor Lesley, of Philadelphia, and preceded by a letter of the same purport from your scientific Nestor, Professor Joseph Henry, of Washington, desired that I would lecture in some of the principal cities of the Union. This I agreed to do, though much in the dark as to what form such lectures ought to to take. In

* One of the earliest came from Mr. John Amory Lowell, of Boston. 
answer to $\mathrm{m}$ ? inquiries, however, I was given to understand (by Professor Youmans principally) that a course of experimental lectures would mate:ially promote scientific cducation in this country, and $I$ at once resolved to meet this desire, as far as my time allowed.

Experiments have two uses-a use in cliscovery, and a use in tuition. They are the investigator's language addressed to Nature, to which she sends intelligible replies. These replies, however, are, for the most part, at first too feeble for the public ear ; for the investigatcr cares little for the loudness of $\mathrm{Na}$. ture's voice if he can only unravel its meaning. But after the discoverer comes the teacher, whose function it is so to exalt and modify the resu ts of the uiscoverer as to render them fit for pubiic presentation. This secondary function I shall endeavor, in the piesent instance, to fulfil.

I propose to take a single department of natural philosophy, and illustrate, by means of it, the growth of scientific knowledge under the guidance of experiment. I wish, in this fi st lect:sre, to make you acquainted with certain elementary phenomena; then to point out to you how those theoretic principles $h y$ which phenomena are explained, take root, and fourish in the human mind, and afterwards to apply these principles to the whole be dy of knowledge covered by the lectures. The science of optics lends itself to this mode of reatment, and on it, therefore, I propose to draw for the materials of the present coursc. It will be best to begin with the few simple facts regarding light which we:e known to the ancients, and to pass from them in historic gradation to the more atstruse discoveries of modern times.

All o::- notions of Nature, however exalted or however grotesque, have some foundation in experience. The notion of personal volition in Nature had this basis. In the fury and the serenity of natural phenomena the savage saw the transcript of his own varying moods, and he accordingly ascribed these phenomena to beings of like passions with himself, but vastly transcending him in power. Thus the notion of causality - the assumption that natural things did not com 3 of themselves, but had unseen antecedents-lay at the root of cren the savage's interpretation of Nature. Out of this bias of the human mind to seek for the antecedents of phenomena all science has sprung.

The development of man, indeed, is ultimatcly due to his interaction with Nature. Natural phenomena arrest his attention and excite his questionings, the inteilectual activity thus provoked reacting on the intellect itself, and adding to its strength. The quantity of power added by any single effort of the inteilect may be indefinitely small ; but the integration of innumerable increments of this kind has raised iltellectual power from its rudiments to the magnitude it possesses today. In fact, the indefinite smallness of the single increment is made good by the indefinite number of such increments, summed up in what may be regarded as practically infinite time.

We will not now go back to man's first intellectual gropings ; much less shall we enter upon the thorny discussion as to how the groping man arose. We will take him at a certain stage of his development, when, by evolution or sudden endowment, he became possessed of the apparatus of thought and the power of using it. For a time-and that historically a long one-he was limited to mere observation, accepiing what Nature offered, and confining intellectual action to it. The apparent motions of sun and stars first drew towards them the questionings of the in. tellect, and accordingly astronomy was the first science developed. Slowly, and with diff:culty, the notion of natural forces took root in the mind, the seedling of this notion being the actual observation of clectric and magnetic attractions. Slowly, and with difficulty, the science of mechanics had to grow out of this notion; and slowly at last came the full application of mechanical principles to the motions of the heavenly bodies. We trace the progress of astronomy through Hipparchus and Ptolemy; and, after a long halt, through Copernicus, Galileo, Tycho Brahe, and Kepler; $w$ ile, from tha high table-land of thought raised by these men, Newton shoots upward like a peak, overlooking all others from his dominant elevation.

But other objects than the motions of the stars attracted the attention of the ancient world. Light was a familiar phenomenon, and from the earliest times we find men's r.inds busy with the attempt to render some account of it. But, without experiment, which belongs to a later stage of scientific development, little progress could be made in this subject. The ancients, accordingly, were far less successiul in dealing with light than in dealing with solar and stellar motions. Still, they did make some progress. They satisfied themselves that light moved in straight lines; they knew, also, that these lines or ray's of light were reflected from polished surfaces, and that the angle of incidence was equal to the angle of reflection. These two results of ancient scientific curiosity constitute the starting-point of our present course of lectures.

But, in the first place, it may be useful to say a few words regarding the source of light to be cmployed in our experiments. The rusting of iron is, to all intents and purposes, the slow burning of iron. It develops heat. and, if the heat be preserved, a high temperature may be thus attained. The destruction of the first Atlantic cable was probably due to heat developed in this way. Other metals are still more combustible than iron. You may light strips of zinc in a candicflame, and cause them to burn almost like strips of paper. But, besides combustion in 
the air, we may also have combustion in a liquid. Water, for example, contains a store of oxygen which may unite with and consume a metal immersed in it. It is from this kind of combustion that we are to derive the heat and light employed in the present course.

Their generation merits a moment's attention. Before you is an instrument-a small voltaic battery - in which zinc is immersed in 'a suitable liquid. Matters are so arranged that an attraction is set up between the metal and the oxygen, actual union, lowever, being in the first instance avoided. Uniting the two ends of the battery by a thick wire, the attraction is satisfied, the oxygen unites with the metal, the zinc is coisumed, and heat, as usual, is the result of the combustion. A power, which, for want of a better name, we call an electric current, passes at the same time through the wire.

Cutting the thick wire in two, I unite the severed ends by a thin one. It glows with a white heat. Whence comes that heat? The question is well worthy of an answer. Suppose in the first instance, when the thick wire was employed, that we had permitted the action to continue until roo grains of zinc were consumed, the amount of heat generated in the battery would be capable of accur-te numerical expression. Let the action now continue, with this thin wire glowing, until roo grains of zinc are consumed. Will the amount if heat generated in the battery be the same as before? No, it will be less by the precise amount generated in the thin wire outside the battery. In fact, by adding the internal heat to the external, we obtain for the combustion of roo grains of zinc a total which never varies. By this arrangement, then, we are able to burn our zinc at one place, and to exhibit the neat and light of its combustion at a distant place. In New York, for example, we have our grate and fuel; but the heat and light of our fire may be made to appear at San Francisco.

I now remove the thin wire and attach to the severed ends of the thick one two thin rods of coke. On bringing the rods together we obtain a small star of light. Now, the light to be employed in our lectures is a simple exaggeration of this star. Instead of being produced by ten cells, it is produced by fifty. Placed in a suitable camera, provided with a suitable lens, this light will give us all the beams necessary for our experiments.

And here, in passing, let me refer to the common delusion that the works of Nature, the human eye included, are theoretically perfect. The degree of perfection of any organ is determined by what it has to do. looking at the dazzling light from our large battery, you see a globe of light, but entirely fail to see the shape of the coke-points whence the light issues. The cause may be thus made clear: On the screen before you is projected an image of the carbon-points, the zuhole of the lens in front of the camera being employed to form the image. It is not sharp, but sur. rounded by a halo whic's nearly obliterates it. This arises from an imperfection of the lens, called its spherical aberration, due to the fact that the circumferential and central rays have not the same focus. The human eye labors under a similar defect, and, when you looked at the naked light from fifty cells, the blur of light upon the retina was sufficient to destrov the definition of the retinal image of the car. bons. $A$ long list of indictments might indeed be brought against the eye-its opacity, its want of symmetry, its lack of achromatism, its absolute blindness, in part. All these taken together caused an eminent German philosopher to say that, if any optician sent him an instrument so full of defects, he would send it back to him with the severest censure. But the eye is not to be judger? from the standpoint of theory. As a practi. cal instrument, and taking the adjustments by which its defects are neutralized into account, it must ever remain a marvel to the reflecting mind

T ue ancients, as I have said, were aware of the rectilineal propagation of light. They knew that an opaque body, placed between the cye and a point of light, intecepted the light of the point. Possibly the terms "ray" and "beam" may have been suggested by those straight spokes of light which, in car. tain states of the atmosphere, dart from ths sun at his rising and his setting. The recti-l lineal propagation of light may be illustrated at home in th:s way: Make a small hole in a closed window-shutter, before which stands a house or a trec, and place within the darkened room a white screen at some distance from the orifice. Every straight ray proceeding from the house or tree stamps its color upcn the screen, and the sum of all the rays foras an image of the object. But, as the rays cross each other at the orifice, the image is inverted. Here we may illustrate the subject thus: In front of our camera is a large opening, closed at present by a sheet of tinfoil. Pricking by means of a common sewing-needle a small aperture in the tin-foil, an inverted image of the carbon-points starts forth upon the screen. $\Lambda$ dozen apertures will give a dozen images, a hundred a hundred, a thousand a thousand. But, as the apertures come closer to each other, that is to say, as the tin-foil between the apertures vanishes, the images overlap more and more. Removing the tin-foil altogether, the screen becomes uniformly illuminated Hence the light upon the screen may be regarded as the overlapping of innumerable images of the carbon-points. In like manner the light upon every white wall on a cloudless day may be regarded as produced by the superposition of innumerable images of the sun.

The law that the angle of incidence is equal to the angle of reflection is illustrated in this simple way: A straight lath is placed as an index perpendicular to a small looking- 
glass capable of rotation. $\Lambda$ beam of light is received upon the glass and reflected back upon the line of its incidence. Though the incident and the reflected beams pass in opposite directions, they do not jostle or displace each other. The index being turned; the mirror turns along with it, and at each side of the index the incident and the reflected beams are scen tracking themselves through the dust of the room. The mere inspection of the two angles enclused betwe: $n$ the index and the two beams suffices to show their equality. The same simple apparatus enables us to illustrate a law of great practical importance, name y, that, when a mirror rotates, the angular velocity of a beam reflected from it is twics that of the reflecting mirror. One experiment wil! make this pla $n$ to you. The mirror is now vertical, and both the incident and the reflected beams are horizontal. Turning the mirror through an angle of $45^{\circ}$ the reflected beam is vertical; that is to say, it has moved $90^{\circ}$, or through twice th: angle of the mirror.

Ons of the problems of science, on which scientific progress mainly depends, is to help the senses of man by carrying them into regions which could never be attained without such help. Thus we arm the eye with the telescope when we want to sound the depths of space, and with the miscroscope when we want to explore motion and structure in their infinitesimal dimensions. Now, this law of angular reflection, coupled with the fact that a beam of light possesses no weight, gives us the means of magnifying small motions to an extraordinary degree. Thus, by attaching mirrors to his suspended magnets, and by wa ching the images of scales reflected from the mirrors, the celebrated Gauss was able to detect the slightest thrill or variation on the part of the earth's magnetic force. The minute elongation of a bar of metal by the mere warmth of the hand may be so magnified by this method as to cause the index-beam to move from the ceiling to the floor of this room. The elongation of a bar of iron when it is magnesized may be thus demonstrated. By a similar arrangement the feeble attractions and repulsions of the diamagnetic force have been made manifest; while in Sir WVilliam Thompson's reflecting galvanometer the principle receives one of its latest applications.

For more than I, 000 years no step was taken in optics beyond this law of reflection. The men of the Middle Ages, in fact, endeavored on the o.e hand to develop the laws of the universe out of their own consciousness, while many of them were so occupied with the concerns of a future world that they looked with a lofty scorn on all things pertaining to this one. Notwithstanding its demonstrated failure during 1,500 years of trial, there are still men among us who think the riddle of the universe is to be solved by this appeal to consciousness. And, like most people who support a delusion, they maintain theirs warmly, and show scant respect for those who dissent from their views. * As regards the refrastion of light, the course of real inquiry was resumed in I Ioo by an Arabian philosopher named Alhazen. Then it was taken up in succession by Roger Bacon, Vitellio, and Kepler. One of the most important occupations of science is the determination, by precise measurements, of the quantitative relations of phenomena. The value of such measurements depends upon the skill and conscientiousness of the man who makes them. Vitellio appears to have been both skilful and conscientious, while Kepler's nabit was to rummage through the ob=ervations of his predecessors, look at them in all lights, and thus distill from them the principles which united them. He had done this with the astronomical measurements of Tycho Brahe, and had extracted from them the celcbraied "laws of Kepler." He did it also with the measurements of Vitellio. Sut in the case of refraction he was not successful. The principle, though a simple one, escaped him. It was firs discovered by Wille. brod Snell, about the year I62I.

Less with the view of dwelling upon the phenomenon itself than of introducing it to you in a form which will render intelligible the play of theoretic thought in Newton's mind, I will show you the fact of refraction. The dust of the air and the turbidity of a liquid may here be turned to account. A shallow circula: vessel with a glass face, half filled with water, rendered barely turbid by the precipitation of a little mastic, is placed upon its edge with its glass face vertical. Through a slit in the hoop surrounding the vessel a beam of light is admitted. It impinges upon the water, enters it, and tracks itself through the liquid in a sharp, bright band. Meanwhile the beam passes unseen through the air above the water, for the air is not competent to scatter the liglit. A puff of tobacco smoke into this space at once reveals the track of the incident-beam. - If the incidence be vertical, the beam is unrefracted. If oblique, its re. fraction at the common surface of air and water is rendered clearly visible. It is also seen that reflection accompanies refraction, the beam dividing itself at the point of incidence into a refracted and a reflected poition.

The law by which Snell connected together all the measurements executed up to his time, is this : Let $\Lambda \mathrm{BCD}$ represent the outline of our circular vessel (Fig. I), A C being the water-line. When the beam is incident aiong $\mathrm{B} \mathrm{E}$, which is perpendicular to $\mathrm{A} \mathrm{C}$, there is no refraction. When it is incident along $m$ $\mathrm{E}$, there is refraction: it is bent at $\mathrm{E}$ and strikes the circle at $n$. When it is incident

* Schelling thus expresses his contempt for experimental knowledge : "Newton's Optics is the greatest illustration of a whole structure of fallacies, which in all its parts is founded on observation and experiment." "There are some small imitators of Schelling still in Germany. 
along $m^{\prime} \mathrm{E}$, therc is also refraction at $\mathrm{E}$, the beam striking the point $n^{\prime}$. From the ends of the incident beams, let the perpendiculars $m 0, m^{\prime} o^{\prime}$ be drawn upon $\mathrm{I} \mathrm{D}$, and from the ends of the refr:cted beams let the perpendiculars $p n, p^{\prime} n^{\prime}$ be also drawn. Measure the lengths of $0 m$ and of $p n$. and divide the

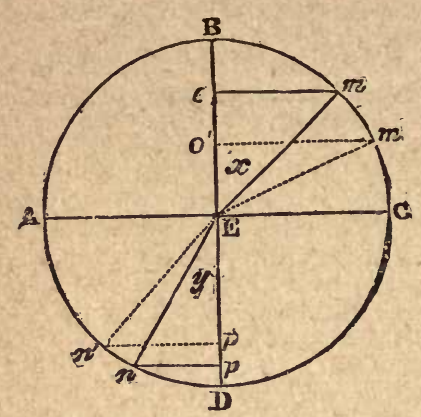

FIG. I.

one by the cther. You obtain a certain quotient. In like manner divide $n^{\prime} d^{\prime}$ by the corresponding perpendicular $p^{\prime} n^{\prime}$; you obtain in each case the samequotient. Snell, in fact, found this quotient to be a constant quantity for each particular substance, though ic varied in amount from substance to subst:ince lle called the quotient the index of nfraction.

This law is olle of the corner-stones of optical science, and its applications to-day are million-fold. Immediately after its discovery, Descartes applied it to the explanation of the rainbow. The bow is seen when tbe back is turned to the sun. Draw a straight line through the spectator's eye and the sun, the bow is always seen at the same angular distance from this line. This was the great difficulty. IVhy shouid the bow be always and at all its parts, forty-one degrees from this lire? Takilig a pen and calculating the track of every ray through a raindrop, Descartes found that, at one particular angle, the rays emerged from the drop : 1 most parallel to each other; being $t$ : us enabled to preserve their intensity through long atmospheric distances; at all other angles the rays quitted the drop divergent, and through this divergerce became so enfeebled as to be practically iost to the eye. The particular angle here referred to was the toregoing angle of forty-one degrees, which observation had proved to be invariably that of the rainbow.

But in the rainbow a new phenomenon was introduced-the phenomenon of color. And here we arrive at one of those points in the history of science, when men's labors so intermingle, that it is difficult to assign to each worker his precise meed of honor. Descartes was at the threshold of the discovery of the composition of solar light. But he failed to attain perfect clearness, and it is certain tirat he did nct enunciate the true law. This was reserved for Newton, who went to work in this way: Through the closfd window-shutter of a room he pieiced an orifice, and allowed a thin sunbeam to pass through it. The beam stamped a round image of the sun on the opposite white wall of the rcom. In the path of this beam Nev:ton placed a prism, expecting to see the beam refracted, but also expecting to sce the image of the suil, af'er refiaction, round; 10 lis astonishment, it was drawn out to an image whose length was five times its bteadth; and this image was divided into bands of different colors. Newton saw immediately that solar light was composite, not simple. His image revealed to him the fact that some coisstituents of the solar light were more deflected by the prism than others. and he conclud. ed, therelore, that white solar light was a mixtur: of lights of different colors and of different degrees of refrangibility.

Let us reproduce ihis celebrated experiment. On the screer is now stamped a luminous disk, which may stand for Newton's image of the sun. Causing the beam wl ich produces the disk to pass through a prism. we obtain Newton's elongated colored image, which he called a spectrum. Newton diviued the spectrum into seven parts-red, orange, yellow, green, blue, indigo, violet-which are commonly called the seven primary or prismatic colors. This drawing out of the white light into its constituent colors is callud dispersion.

This was the first analysis of solar light bv Newton; but the scientific mind is fond of verification, and never neglects it where it is possible. It is this stern conscientiousness in testing its conclusions that gives adamantine strength to science, and renders all assaults on it unavailing. Newton completed his proof by synihesis in this way: The spectrum now befor: you is produced by a glas; prism. Causing the decomposed beam to pass through a second similar prism, but so placed that the colors are refracted back and reblended, the perfectly white image of the slit is restored. Here, then, refraction and dispersion are simultaneously abolished. Are they always so? Can we have the one with. out the other? It, was Newton's conclusion that we could not. Here he erred, and his error, which he maintained to the end of his life, retarded the progress of optical discovery. Dolland subsequently proved that, by conbining two different kinds of glass, the colur; could be extinguished, still leaving a residue of refraction, and he employed this residuc in the construction of achromatic lenses lenses which yield no color-which Newion thought an imposs.bility. By setting a wates. prism-water contained in a wedge-shaped vessel with glass sides-in opposition to a prism of glass, this point can be illustrated before you. We have first the position of the unrefracted beam marked upon the screen; 
then we produce the water-spectrum ; finally, by introducing a flint glass prism, we refract the beam back, until the color cisappears. The image of the slit is now white; but you see that, though the dispersion -is abolished, the refraction is not.

This is the place to illustrate another point bearing upon the instrumental means employed in these lectures. Note the position ot the water-spectrum upon the screen. Altering, in no particular, the wedge-shaped vessel, but simply substituting for the water the transparent bisulphide of carbon, you notice how much higher the beam is thrown, and how much richer is the display of color. This will explain to you the use of this substance in our subsequent experiments.

The synthesis of white light may be effected in three ways, which are now worthy of special attention: Here, in the first instance, we have a rich spectrum produced by a prism of bisulphide of carbon. One face of the prism is protected by a diaphragm with a longitudinal slit, through which the beam passes into the prism. It emerges decomposed at the other side. I permit the colors to pass through a cylindrical lens, which so squeezes them together as to produce upon the screen a sharply-defined rect- angular image of the longitudinal slit. In that image the colors are re-blended, and you see it perfectly white. Between the prism and the cylindrical lens may be seen the colors tracking themseives through the dust of the room. Cutting off the more re'sangible fringe by :a card, the rectangle is seen red; cutting off the less refrangible fringe, the ractangle is seen blue. By means of a thin glass prism, I deflect one portion of the colors, and leave the residual portion. On the screen are now two colored rectangles produced in this way. These are complementary colors-colors which, by their union, prcduce white. Note that, by judicious management, one of these colors is iendered yellow, and the other blue. I withdraw the thin prism; yellow falls upon blue, and we have white as the result of their union. On our way, we thus abolish the fallacy. first exposed by Helmholtz, that the mixture of t.lue and yellow lights produces green.

Again, restoring the circular aperture, we obtain once more a spectrum like that of Newton. "By means of a lens, we gather up these colors, and build them together not to an image of the aperture, but to an image of the carbon points themselves. Finally, in virtue of the persistence of impressions upon the retina, by means of a rotating disk, on which are spread in sectors the colors of the spectrum, we blend together the prismatic colors in the cye itself, and thus produce the impression of whiteness.

Having unravelled the interwoven constituents of white light, we have next to inquire, What part the constitution so revealed enables this agent to play in Nature?
To it we owe all the phenomena of color; and yet not to it alone. for there must be a certain relationship between the ultimate particles of natural bodies and light to enable them to extract from it the luxuries of color. But the function of natural bodies is here selective, not creative. There is no color generated by any natural body whatever Natural bodies have showered upon them, in the white light of the sun, the sum total of all possible colors, and their action is limited to the sifting of that total, the appropriating from it of the colors which really belong to them, and the rejecting of those which do not. It will fix this subject in your minds if I say that it is the portion of light which they rej_ct, and not that which belongs to them, that gives bodies their colors.

Let us begin our experimental inquiries here by asking, What is the meaning of blackness? Pass a black ribbon in succession through the colors of the spectrum; it quenches all. This is the meaning of blackness-it is the result of the absorption of all the constituents of solur light. Pass a red r.bbon through the spectrum. In the red light the ribbon is a vivid red. Why? Because the light that enters the ribbon is not quenched or absorbed. but sent back to the eve. Place the same rib. bon in the green or blue of the spectrum; is black as jet. It absorbs the green ard blue light, and leaves the space on which they fall a space of intense darkness. Place a. green ribbon in the green of the spectrum. It shines vividly with its proper colar: transfer it to the red, it is black as jet. Here it absorbs all the light that falls upon it, and offers mere darkness to the eye. When whitc light is employed, the red sifts it by quenching ibc green, and the green sifts it by quenching the red, both exhibiting the residual calor. Thus the process through which natural bodies acquire their colors is a negative one. The colors are produced by subtraction, not by addition. This red glass is, red because it destroys all the more refrangible rays of the spectrum. This blue liquid is blue becausc it destroys all the less refrangible rays. Both together are opaque because the light transmitted by the one is quenched by the other. In this way by the union of two transparent substances we obtain a combination as dark as pitch to solar light. This other liquid finally is purple because it destroys the gree. and the yellow and allows the terminal colors of the : pectrum to pass unimpeded. From the blending of the blue and the red this gorgeous color is produced.

These experiments prepare us for the further consideration of a point already adverted to, and regarding which error has found currency for ages. You will find it stated in books that blue and yellow lights mixed together produce green. But blue and yellow nave been just proved to be complementary colors, producing white by their mixture. The mixture of blue and yellow pigments un- 
doubtedly produces green, but the mixture of pigments is totally different from the mixture of lights. Helmholtz, who first proved yellow and blue to complementary "colors, has revealed the cause of the green in the case of the pigrments. No natural color is pure. A blue liquid or a blue powder permits not only the blue to pass through it, but a portion of the adjacent green. A yellow powder is transparent not only to the yellow light, but also in part transparent to the adjacent green. Now, when blue and yellow are mixed together, the blue cuts off the yellow, the orange, and the red; the yellow, on the other hand, cuts off the violet, the indigo, and the blue. Green is the only color to which both are transparent, and the consequence is that, when white light falls upon a mixture of yellow and blue powders, the green alone is sent back to the eye. I have already shown you that the fine blue ammonia-sulphate of copper transmits a large portion of green, while cutting off all the less refrangible light. A yellow solution of picric acid also allows the green to pass, but quenches all the more refrangrible light. What must occur when we send a beam through both liquids? The green band of the spectrum alone remains upon the screen.

This question of absorption is one of the most subtle and difficult in molecular physics. Jie are not yet in a condition to grapple with *. but we shall he by-and-by. Meanwhile, we may profitably giance back on the web of relations which these experiments reveal to us. We have, in the first place, in solar light au agent of exceeding complexity, composed of innumerable constituents, refrangibic in different degrees. We find, secondly, the atoms and molecules of bodies gifted with the power of sifting solar light in the most various ways, and producing by this : ifting the colors observed in nature and art. To do this they must possess a molecular struciure commensurate in complexity with that of light itself. Thirdly, we have :he human cye and brain so organized as to be able to take in and distinguish the multitude of impressions thus generated. Thus, the Iight at starting is conplex; to sift and select it as they do natural bodics must be complex. Fimally, to take in the impressions thus gencrated, the human eye and brain must be inighly complex. Whence this triple compixi:y? If what are called material purposis were the only end to be served, a much sinipler mechanism would be sufficient. But, instead of simplicity-instead of the principle of parsimony - we have prodigality of relation and adaptation, and this apparently for the sole purpose of enabling us to see things robed in the splendor of color. Would it not seem that Nature harbored the intention of educating us for other enjoyments than those derivable from meat and drink? At all events, whatever Nature meant-and it would be mere pres mption to dogmatize as to what she meant-we find ourselves here as the issue and upshot of her operations, endowed with capacities to enjor not only the materially useful, but endowed with others of indefinite scope and application, which deal alone with the beautiful and the true.

\section{LECTURE II.}

Origin of Physical Theories: Scope of the Imagination: Newton and the Emission Theory: Veritication of Physical Theories: The Lunniniferous; Ether: Wave-Thecry of Light : Thomas Young: Fresnel and Arago: Conceptions of Wave-Motion: Interference of Wavis: Constitution of SoundWaves: Analogies of Sound and Light: Illustrations of Wave-Motion: Interference of SoundWaves: Optical lllustrations: Pitch and Co'or: Lengths of the Waves of Light and Kates of Vibration of the Ether-Particles: Interference of Light: Phenomena which first suggested the Undulatory Theory: Hooke and the Colors of Thin Plates: The Soap-Bubble: Newton's Rings: Theory of "Fits:" Its Explanation of the Kings: Overthrow of the Theory: Colors of Mother-ufPearl.

We might vary and extend our experiments on light indefinitely, and they certainly would prove us to possess a wonderful mastery over the phenomena. But the vesture of the agent only would thus be revealed, not the agent itself. The human mind, however, is so cor.stituted and so educated as regards natural things, that it can never rest satisfied with this outward view of them. Brightness and freshness take possession of the mind when it is crossed by the light of principles, which show the facts of Nature to be organically connected.

Let us, then, inquire what this thing is that we have been generating, reflecting, refracting, and analyzing.

In doing this, we shall learn that the life of the experimental philosopher is twolold. He lives, in his vocation, a life of the senses, using his hands, eyes, and ears in his experiments, but such a question as that now before us carries him beyond the margin of the senses. He cannot consider, much less an1swer, the question, "What is light?" without transporting himself to a world which indelies the sensible one, and out of which, in accordance with rigid law, all optical phenomena spring. To realize this subsensible world, if I may use the term, the mird must possess a certain pictorial power. It has to visualize the invisible. It must be able to form detinite images of the things which that subsensib!e world contains ; and to say that, if such or such a state of things exist in that world, then the phenomena which appear in ours must, of necessity, grow out of this state of things. If the picture be correct, the phenomena are accounted for; a physical theory has been enunciated which unites and explains them all.

This conception of physical theory implies, as you perceive. the exercise of the imagina. tion. Do not be afraid of this word, which seems to render so many respectable people, 
both in the ranks of science and out of them, uncomfortable. That men in the ranks of science should feel thus is, I think, a proof that they have suffered themselves to be misled by the popular definition of a great faculty instead of observing its operation in their own minds. Without imagination we canrot take a step beyond the bourne of the mere animal world, perhaps not even to the edge of this. But, in speaking thus of magination, I do not mean a riotous power which deals capriciously with facts, but a well-ordered and disciplined power, whose sole function is to form conceptions which the intellect imperatively demands. Imaginat:on thus exercised never really severs itself from the world of fact. This is the storehouse from which all its pictures are drawn; and the magic of its art consists, not in creating things anew, but in so changing the magnitude, position, and other relations of sensible things, as to render them fit for the sequirements of the intellect in the subsenvible world.*

I will take, as an illustration of this subject, the case of Newton. Before he began to deal with light, he was intimately acquainted witi the laws of elastic collision, which all of jou have seen more or less perfectly illustrated on a billiard-table. As regards the coilision of sensible masses, Newton knew the angle of incidence to be equal to the angle of reflection, and he also knew that experiment, as shown in our last lecture, had established the same law with regard to light. He thus found in his previous knowledge the mateiial for theoretic images. $\mathrm{He}$ had only to change the magnitude of conceptions already in his mind to arrive at the Emission Theory of Light. He supposed light to consist of elastic particles of inconceivable minuteness shot out with inconceivable iapidity by luminous bodies. Such particles impinging upon smooth surfaces were reflected in accordance with the ordinary law

* The following charming extract, bearing upon this point, was discovered and written out for me by my friend, Dr. Bence Jones, Hon. Secretary to the Royal Institution

"In every kind of magnitude there is a degree or sort to which our sense is proportioned, the perception and knowledge cf which is of the greatest use to mankind. The same is the groundwork of philosophy : for, though all sorts and degrees are equally the object of philosophical speculation, yet it is from those which are proportioned to sense that a philosopher must set out in his inquiries, ascending or descending afterwards, as his pursuits may require. He does well indeed to take his views from many points of sight, and supply the defects of sense by a wellregulated imagination; nor is he to be confined by any limit in space or time; but, as his knowledge of Nature is founded on the observation of sensible things, he must begin with these, and must often return to them to examine his progress by them. Here is his secure hold; and as he sets out from thence, so if he likewise trace not often his steps backwiards with caution, he will be in hazard of losing tis way in the labyrinths of Nature."-(Maclaurin: in Account of Sir I. Nervton's Philosophical Discoveries. Written I728; sicond edition, 1750 ; pp. 28, $x$. of elastic collision. The fact of optical reflection certainly occurred as if light consist. ec of elastic particles, and this was Newton's sole justification for introducing them.

But this is not all. In another important particular, also. Newton's conceptions regarding the nature of light were influenced by his previous knowledge. He had been working at the phenomena of gravitation. and had made himself at home amid the operations of this universal power. Perhaps his mind at this time was too freshly and too deeply imbued with these notions to permit of his forming an unfettered judgment regarding the nature of light. Be that as it may, Newton saw in refraction the action of an attractive force exerted on the light-particles. $\mathrm{He}$ carried his conception out with the most severe consistency. Dropping vertically downwards towards the earth's surface, the motion of a body is accelerated as it approaches the earth. Dropping in the same manner downwards on a horizontal surface, say through air on glass or water, the velocity of the light-particles, when they come ciose to the surface, was, according to Newton, also acceleraied. Approaching such a surface obliquely, he supposed the particles, when close to it, to be drawn down upon it, as a projectile is drawn by gravity to the surface of the earth. This deflection was, according to Newton, the refraction seen in our last lecture. Finally, it was supposed that differences of color might be due to differences in the sizes of the particles. This was the physical theory of light enunciated and defended by Newton; and you will observe that it simply consists in the transference of conceptions born in the world of the senses to a subsensible world.

But, though the region of physical theory lies thus behind the world of senses, the verifications of theory occur in that world. Laying the theoretic conception at the ruot of matters, we determine by rigid deduction what are the phenomena which must of necessity grow out of this root. If the phenomena thus deduced agree with those of the actual world, it is a presumption in favor of the theory. If as new classes of phenomena arise they also are found to harmonize with theo. retic deduction, the presumption becomes still stronger. If, finally, the theory confers prophetic vision upon the investigator, enabling him to predict the existence of phenomena which have never yet been seen, and if those predictions be found on trial to be rigidly correct, the persuasion of the truth of the theory becomes overpowering. Thus working backwards from a limited number of phenomena, genius, by its own expansive force, rezches a conception which covers all the phenomena. There is no more wonderful performance of the intellect than this. And we can render no account of it. Like the scriptural gift of the Spirit, no man can tell whence it cometh. The passage from fact to principle is some. 
times slow, sometimes rapid, and at all times a source of intellectual joy. When rapid, the pleasurc is concentrated and becomes a kind of ecstasy or intoxication. To any one who has experienced this pleasure, even in a moderate degree, the action of Archimedes when he quitted the bath, and ran naked, crying "Eureka!" through the streets of Syracuse, becomes intelligible.

How, then, did it fare with the theory cf Newton, when the deductions from it were brought face to face with natural phenomena? 'To the mind's eyc, Newton's elastic particies present themselves like particles of sensible magnitude. The same reasoning applies to both; the same experimental checks exist for both. Tested by experiment, then, Newton's theory was found competent to explain many facts, and with transcendent ingenuity its author sought to make it account for all. $\mathrm{He}$ so far succeeded, that men so celebrated as Laplace and Malus, who lived till ISI2, and Biot and Brewster, who lived till our own time, were found among his disciples.

Still, even at an early period of the existence of the Emission Theoiy, one or two great names werc found recording a protest aga:nst it ; and they furnish another illustration of the law that, in forming theories, the scientific imagination must draw its materials from the world of fact and experience. It was known long ago that : ound is conveyed in waves or pu'ses through the air; and no sooner was this truth well housed in the mind than it was transformed into a theoretic conception. It was supposed that light, like sound, might also be the product of wave-motion. But what, in this case, could be the material forming the waves? For the waves of sound we have the air of our atmosphere ; but the stretch of imagination which filled all space with a luminiferous ether trembling with the waves of light was so bold as to shock cautious minds. In one of my latest conversations with Sir David Brewster he said to me that his chief objection to the undulatory theory of light was that he could not think the Creator guilty of so clumsy a contrivance as the filling of space with ether in order to preduce light. This, I may say, is very dangerous ground, and the quarrel of science with Sir David, on this point, as with many other persons on other points, is, that they profess to know too much about the mind of the Creator.

This conception of an ether was advocated and indeed applied to various phenomena of optics by the celebrated astronomer, Huy$\mathrm{g} h: n s$. It was espoused and defended by the calcbrated mathematician, Euler. They were, lowever, opposed by Newton, whose authority at lie time bore them down. Or shall I say it was authority mercly? Not quite so. Ncwton's preponderance was in some degrec dic to the fact that, though IIuyghe::s and Euler were right in the main, t..ey did not Dossess sufficient data to prove themselves right. No human authority, however high, can maintain itself against the voice of Nature speaking through experiment. But the voice of Nature may be an uncertain voice, through the scantiness of data. This was the case at the period now referred to, and at such a period by the authority of Newton all antagonists were naturally overborne.

Still, this great Emission Theory, which held its ground so long, resembled one of those circles which, according to your countryman Emerson, the force of genius periodically draws round the operations of the iniellect, but which are eventually broken through by pesiure from behind. In the year 1773 was born, at Milverton, in Somer. setshire, one of the most remarkable men that England ever produced. He was educated for the profession of a physician, but was too strong to betied down tu professional routine. He devoted himself to the study of natural philosophy, and became in all its departments a master. He was also a master of letters. Languages, ancient and modern, were housed within his brain, and, to use the words of his epitaph, "he first penetrated the obscurity which had veiled for ages the hieroglyphics of Egypt." It fell to the lot of this man to discover facts in optics which Newton's theory was incompitent to explain, and his mind roamed is search of a sufficient theory. He had made himself acquainted with all the phenomena of wave-moti-n; with all the phenomena of sound; working successfully in this domain as an original discoverer. Thus informed and disciplined, he was pre pared to detect any resemblance which might reveal itseif between the phenomena of light and those of wave-motion. Such resem. blances he did detect; and, spurred on by the discovery, he pursued his speculations and his experiments, until he finally succecded in placing on an immovable basis the Undulatory Theory of Light.

The founder of this great theory was Thomas Young, a name, perhaps, unfamiliar to many of you. Permit me, by a kind of geometrical construction which I once employed in London, to give you a notion of the magnitude of this man. Let Newton stand erect in his age, and Young in his. Draw a straight line from Newton to Youns, which shall form a tangent to the heads of both. This line would slope downwards from New: ton to Young, because Newton was certainly the taller man of the two. But the slope would not be steep, for the difference of stature was not excessive. The line would form what engineers call a gentle gradient from Newton to Young. Place underneath this line the biggest man born in the interval between both. He would not, in my opinion, reach the line; for if he did he would be taller intellectually than Young, and there was, I believe, none taller. But I do not want you to rest on English estimates of Young; the German, Ifelmholtz, a kindred genius, thus speaks of him: "Ilis was one 
of the most profound minds that the world has ever seen; but he had the misfortune to be too much in advance of his age. He excited the wonder of his contemporaries, who, however, were unab'e to follow him to the heights at which his daring intellect was accustomed to soar. His most important ide s lay, therefore, buried and forgotten in the folios of the Royal Society, until a new generation gradually and painfully made the same discoveries, and proved the exactness of his assertions and the truth of his demonstrations."

It is quite true, as Helmholtz says, that roung was in advance of his age ; but something is to be added/which illustrates the :-sponsibility of our public writers. Fol twenty years this man of genius was quenched -hidden from the appreciative intellect of his countrymen-deemel in fact a creamer, inrough the vigorous audacity of a writer who had then possession of the public ear, and who in the Edinburgh Reviers poured ridicule upon Young and his specularions. To the celebrated Frenchmen, Fresnel and Arago, lie was first indebted for the restitution of lis rights, for they, especially Fresnel, remade independently, as Helmholtz says, snd vastly extended lis discoveries. To the students of his works Joung has loug since appeared in his true light, but these twenty blank years pushed him from the public mind, which became in turin filled with the fame of Young's colleague at the Royal In stitution, Davy, and afterwards with the fame of Faraday. Carlyle refers to the remark of Novalis, that a man's self-trust is enormously increased the moment lie finds that others believe him. If the opposite remark be true-if it be a fact that public disbelief weakens a man's force-there is no calculating the amount of damage these twenty years of neglect may have done to Young's productiveness as an investigator. It remains to be s:ated that his assailant was Mr. Henry Brougham, afterwards Lord Chancellor of England.

Our hardest work is now before us. And, as I have often had occasion to notice that capacity for hard work depends in a great measure on the antecedent winding up of the will and de:ermination, I would call upon you to gird up your loins for our coming labors. If we succeed in climbing the hill which faces us to-night, our future efforts will be comparatively light.

In the carliest writings of the ancients we find the notion that sound is conveyed by the air. Aristotle gives expression to this notion, and the great architect Vitruvius compares the waves of sound to waves of water. But the real mechanism of wave-motion was hidden from the ancients, and indeed was not mad: clear until the time of Newton. The central difficulty of the subject was, to distinguish between the motion of the wave itself and the motion of the particles which a.t any moment constitut $z$ the wave.

Stand upon the sea-shore and observe the advancing rollers before they are distorted by the friction of the bottom. Every wave has a back and a front, and, if you clearly seim the image of the moving wave, you will see that every particle of water along the front of the wave is in the act of rising, while cvery particle along its $\mathrm{tack}$ is in the act of sinking. The particles in front reach in succession the crest of the wave, and as soon as the crest is passed they begin to fall. They then reaci the furrow or simus of the vave, and can sink no farther. Immediately afterwards they become the front of the succeeding wave, rise again until they reach the crest, and then sin"k as before. Thus, while the waves pass onward horizontally, the individual particles are simply lifted up and down vertically. Observe a sea-fowl, or, if you are a swimmcr, abandon yourself to the action of the waves; you are not carried forward, but simply rockid up and down. The propagation of a wave is the propagation of a form, and not the transference of the sub. stance which constitutes the wave.

Tire length of the wave is the distance from crest to crest, while the distance through which the individual particles oscillate is cailed the amplitude of the oscillation. You will notice that in this description the parti. cles of water are made to vibrate across the line of propagation.*

And now wic have to take a step forward, and it is the most importan: step of all. You can picture two serie; of waves proceecing from different origins through the same water. When, for cxamp!e, you throw two stoncs into still water, the ring-waves procceding from the two centres of disturbance intersect each other. Now, no mater low numerous these wares may bc: the law holds good that the mo:ion of every particle of the water is the aigebraic sum of a.l the motions imparted to it. If crest coincide with crest, the ware is lifted to a double hcight; if furrow coincide with crest, the motions are in opposition, and thei sum is zero. We have then sti!l water, which we shall learn presently corresponds to what we call darkness in reference to our present subject. This action of wave upon wave is technically called interference, a term to be remembeted.

'Thomas Young's fundamental discovery in optics was that the principle of Interference applied to light. Long prior to his time, an Italian phiiosopher, Grimaldi, had stated that, under certain circumstances, two thin beams of light, each of which, acting singly. produced a luminous spot upon a white wall, when caused to act together, partially

* I do not wish to encumber the conception here with the details of the motion, but I may draw attention to the beautiful model of Pr=fessor Lymsn, wherein waves are shown to be produced by $\mid$ br: cir. cular motion if the particles. This. as wroved by the brothers Weber, is the real motic : : : : e case of water-waves. 
quenched each other and darkened the spot. 'i his was a statement of fundamental significance, but it required the discoveries and the genius of Young to give it meaning. How he did so, I will now try to make clear to you. You know that air is compressible; that by pressure it can be rendered more dense, and that by dilatation it can be rendered more rare. Properly agitated, a tuning-fork now sounds in a manner audible to you all, and most of you know that the air through which the sound is passing is parcelled out into spaces in which the air is condensed, followed by other spaces in which the air is rarefied. These condensations and rarefactions constitute what we call waves of sound. You can imagine the air of a room traversed by is series of such waves, and you can imagine a second series sent through the same air, and so related to the first that condensation coincides with condensation and rarefaction with rarefaction. The conse. quence of this coincidence would be a louder sound than that produced by cither system of waves taken singly. But you can also imagine a state of things where the condensations of the one system fall upon the rarefactions of the other system. In this case th: two systems would completely neutralize each other. Each of them, taken singly, produces sound; both of them, taken together, produce no sound. Thus, by adding sound to sound we produce silence, as Grimaldi in his experiment produced darkness by adding light to light.

The analogy between sound and light here at once flashes upon the mind. Young gen eralized this observation. He discovered a multitude of similar cases, and determined their precise conditions. On the assumption that light was wave-motion, all his experiments on interference were explained; on the assumption that light was flying particles, nothing was explained. In the time of Huyghens and Euler a medium liad been assumed for the transmission of the waves of light ; but Newton raised the objection that, if light consistid of the waves of such a medium, shadows could not exist. The waves, he contended, would bend round opaque bodies and produce the motion of light behind them, as sound turns a corner, or as waves of water wash round a rock. It was proved that the bending round referred to by Newton actually occurs, but that the inflected waves abolish each other by their mutual interference. Young also discerned a fundamental difference between ti:e waves of light and those of sound. Could you see the air through which sound-waves are passing, you would observe every individual particle of air oscillating to and fro in the direction of propagation. Could you see the ether, you would also find every individual particle making a small excursion to and fro, but here the motion, like that assigned to the water-particles above referred to, would be across the line of propa- gation. The vibrations of the air are longitudinal, the vibrations of the ether are transversal.

It is my desire that you should realize with clearness the character of wave-motion, both in ether and in air. And, with this view. I bring befcre you an experiment wherein the air-particles are represented by small spots of light. They are parts of a spiral. drawn upon a circle of blackened glass, and, when the circle rotates, the spots move in successive pulses over the screen. You have here clearly set before you how the pulses travel incessantly forward, while the particles that compose them perform oscillations to and fro. 'This is the picture of a sound-wave, in which the vibrations are longitudinal. By another glass wheel, we produce an image of a trans. verse wave, and here wc observe the waves travelling in succession over the screen, while each individual spot of light performs an excursion to and fro across the line of propagation.

Notice what follows when the glass wheel is turned very quickly. Objectively considered, the transverse waves propagate $1 \mathrm{~h} \mathrm{~cm}$. selves as before, but subjectively the effect is totally changed. Because of the retention of impressions upon the retina, the spots of light simply describe a series of parallel luminous lines upon the screen, the length of these lines marking the amplitude of the vibration. The impression of wave-motion has totally disappeared.

The most familiar illustration of the interference of sound-waves is furnished by the beats producea by two musical sounds slightly out of unison. These two tuning-forks are now in perfect unison, and when they are agitated together the two sounds flow without roughness, as if they were but one. But, by attaching to one of the forks a two-cent piece, we cause it to vibrate a little more slowly than its neighbor. Suppose that one of them performs roI vibrations in the time required by the other to perform 10o, and suppose that at starting the condensations and rarefactions of both forks coincide. At the rorst vibration of the quickest fork they will again coincide, the quicker fork at this point having gained one whole vibration, or one whole wave upon the other. But a little reflection will make it clear that, at the 5 oth vibration, the two forks are in opposition; here the one tends to produce a condensation where the other tends to produce a rarefaction; by the united action of the two forks, therefore, the sound is quenched, and we have a pause of silence. This occurs where one fork has gained half a wuave-lcrgth upon the other. At the xorst vibration we have again coinci dence, and, therefore, augmented sound; at the 15 oth vibration we have again a quenching of the sound. Here the one fork is three lialf-waves in advance of the o:her. In general terms, the waves conspire when the one series is an even number of half-wave lengths, 
and they are destroyed when the one series is an odd number of half-wave lengths in advance of the other. With two forks so circumstanced, we obtain those intermittent shocks of sound separated by pauses of silence, to which we give the name of beats.

I ncw wish to show you what may be called the optical expression of those beats. Attached to a large tuning-fork, F (Fig. 2), is a small mirror, which shares the vibrations of the fork, and on to the mirror is thrown a thin beam of light, which shares the vibrations of the mirror. The beam reflected from the fork is received upon a piece of looking-glass, and thrown back upon the screen, where it stamps itself as a small luminous disk. The agitation of the fork by a violin-bow converts that disk into a band of light, and if yo I simp.y move your heads to and fro you cause the image of the band to sweep over the retina, drawing it out to a sinuous line, thus proving the periodic character of the motion which produces it. By a sweep of the looking-glass, we can also cover the screen from side to side by a luminous scroll, $m n$. Fig. 2, the depth of the sinuosities indicating the amplitude of the vibration.

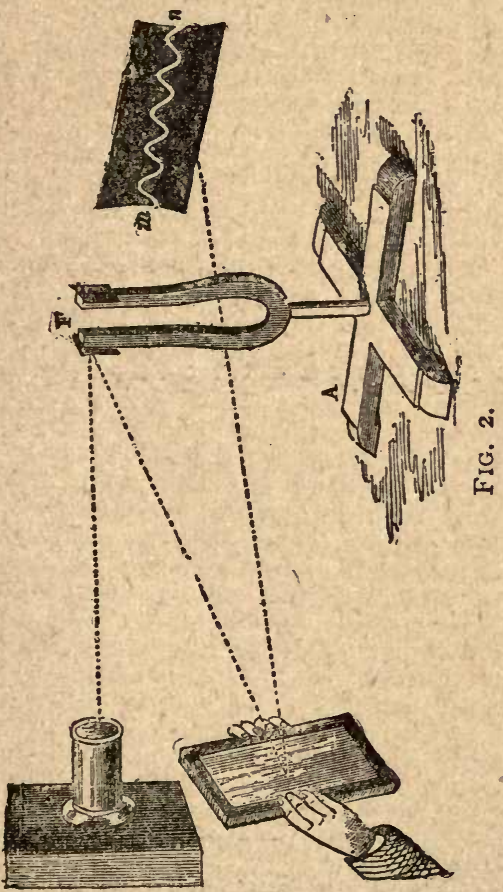

Instead of receiving the beam reflected from the fork on a piece of looking-glass, we now receive it upon a second mirror attached $t$ ) a second fork, and cast by it upon the screer. Both forks now act in combination upon the beam. The disk is drawn out, as before, the band of light gradually shortening as the saotion subsides. until, when the motion ceases, we hare our luminous disk restored. Weighting one of the forks as we did before, with a two-cent piece, sometimes the fork ; conspire, and then you have the band of light drawi out to its maximum length ; sometimes they oppose each other, and then you have the band of light diminished to a circle. Thus, the beats which address the ear express them. selves optically as the alternate elongation and shortening of the band of light. If I move the mirror of this second fork, you have a sinuous line, as before; but the sinuosities are sometimes deep, and sometimes they almost disappear, as in Fig. 3, thus expressing the alternate increase and diminution of the sound, the intensity of which is expressed by the depth of the sinuosities. To Lissajous we owe this mode of illustration.

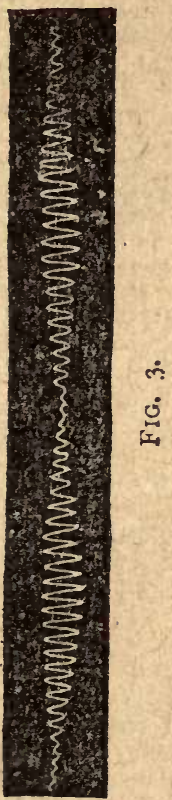

The pitch of a sound is wholl / celertumest by the rapidity of the vibration, d's the intensity is by the amplitude. The sise of pitch with the rapidity of the impulses ray be illustrated by the syren, which consists of a perforated disk rotating over a cylinder into which air is forced, and the end of which is also perforated. When the perforations of the disk coincide with those of the cylinder, a puff escapes; and, when the puffs succeed each other with sufficient rapidity, the impressions upon the auditory nerve link themselves together to a continuous musical note. The more fapid the rotation of the disi the quicker is the succession of the impulses, and the higher the pitch of the note. Indeed, by; 
meins of the syren the number of vibrations due to any musical no $e$, whether it be that of an instrument, of the human voice, or of a ayying insect, may be accurately determined.

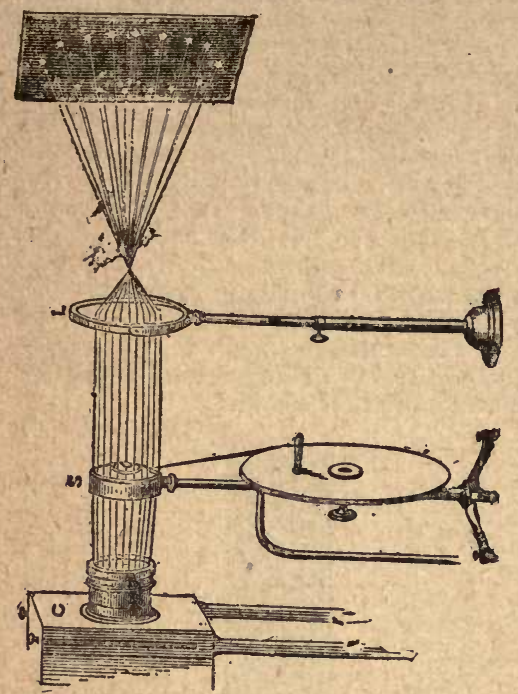

In front of our lamp now stands a very homcly instrument, S, Fig. 4 , of this character. The perforated disk is turned by a wheel and band, and, when the two sets of perforations coincide, a series of spots of light, sharply defined by the lens $L$, ranged on the circumference of a circle, is seen upon the screen. On slowly turning the disk, a ficker is produced by the alternate stoppage and transmission of the light. At the same time air is urged into the syren, and you hear a fluttering sound corresponding to the flickering light. But, by augmenting the rapidity of rotation, the light, though intercepted as before, appears perfectiy steady, through the persistence of impressions upon the retina; and, about the time when the optical impression becomes continuous, the auditory impression becomes equally so; the puffs from the syren linking themselves then together to a continuous musical note, which rises in pitch with the rapidity of the rotation. A movement of the head causes the image of the spots to swcep over the retina, producing beaded lines: the same effect is produced upon our scrcen by the sweep of a looking glass which has received the thin beams from the syren.

In the undulatory theory, what pitch is to the ear, cclor is to the eye. Though never seen, the lengths of the waves of light have been determined. Their cxistence is proved by their effects, and from their effects also their lengths may be accurately deduced. This may, moreover, be done in many ways, and, when the different determinations are compared, the strictest harmony is found to exist between them. The shortest waves of the visible spectrum are those of the extreme violet; the longest, those of the extreme red ; while the other colors are of intermediate pitch or wave-length. The length of a wave of the extreme red is such that it would require 36,918 of them placed end to end to cover one inch, while $64,63 \mathrm{r}$ of the extreme violet waves would be required to span the same distance.

Now, the velocity of light, in round numbers, is 190,000 miles per second. Reducing this to inches, and multiplying the number ihus found by 36,918 , we obtain the number of waves of the extreme red in 190,000 miles. All-these waves enter the cye, and lit the retina at the back of the eye in one second. The number of shocks per second recessary to the production of the impression of red is, therefore, four hundred and fifty-one millions of millions. In a similar manner, it may be found that the number of shocks corresponding to the impression of violet is seven hundred and eighty-nine millions of millions. All space is tilled with matter oscillating at such rates. From every star waves of these dimensions move with the veocity of light like spherical shells outwards. And in the cther, just as in the water, the mction of cvery particle is the algebraic sum of all the separate motions imparted to it. Still, one motion c'oes not blot the other out; or, if extinction occur at one point, it is atoned for at some other point. Every star declares by its light its undamaged individuality, as if it alone had sent its thrills through space.

The principle of interference applies to the waves of light as it does to the waves of water and the waves of sound. And the condi ions of interference are the same in all three. If two serics of light-waves of the same length start at the same inoment from a common origin, crest coincides with crest, sinus with sinus, and the two systems blend together to a single system of double amplitude. If both series start at the same moment, one of them being, at starting, a whole wave-length in advance of the other, they also add themselves together, and we have an augmented luminous effect. Just as in the case of sound, the same occurs when the one system of waves is any even number of semi-undulations in advance of the other. But if the one system be half a wave-length, or any odd number of half wave-lengths in advance, then the crests of the one fail upon the sinuses of the other; the one system, in fact, tends to lift the particles of ether at the precise places where the other tends to depress them; hence, through their joint action the ether remains perfectly sti:l This stillncss of the ether is what we call darkness, which corresponds, as already stated, with a dead level in the case of water.

It was said in our first lecture, with reference to the colors produced by absorption, 
that the function of natural bodies is selective, not creative; that they extinguish certain constituents of the white solar light, and appear in the colors of the unextinguished light. It must at once flash upon your minds that, inasmuch as we have in interference an agency by which light may be self-extinquished, we may have in it the conditions for the production of color. But this would imply that certain constituents are quenched by interference, while others are permitted to remain. This is the fact ; and it is entirely due to the difference in the lengths of the waves of light.

The subject is most easily illustrated by the class of phenomena which first suggested the undulatory theory to the mind of Hooke. These are the colors of thin films of all kinds, which are known as the colors of thin plates. In this relation no object in the world possesses a deeper scientific interest than a common soap-bubbic. And here let me say emerges one of the difficulties which the student of pure scienc 2 cncounters in the presence of "practical" communitics like those of America and England; it is not to be expected that such communities can entertain any profound sympathy with labors which seem so far removed from the domain of practice as many of the labors of the man of science are. Imagine Dr. Draper spending his days in blowing soap-bubbles and in studying their colsrs! Would you show him the necessary patience, or grant him the necessary support? And yet, be it remembered, it was thus that Newton spe:-t a large portion of his time : and that on such cxperiments has been founded a theory, th: issues of which are incalculable. I see no other way for you laymen than to trust the scientific man with the choice of his inquiries; he stands before the tribunal of his peers, and by their verdict on his labors you ought to abide.

Whence, then, are derived the colors of the soap-bubble? Imagine a beam of white light impinging on the bubble. When it reaches the first surface of the film, a known fraction of the light is reflected back. But a large portion of the beam enters the film, reaches its second surface, and is again in part reflected. The waves from the second surface thus turn back and hotly pursue the waves from the first surface. And, if the thickness of the film be such as to cause the necessary retardation, the two systems of waves interfere with each other, producing augmented or diminished light, as the case may be. But, inasmuch as the waves of light are of different lengths, it is plain that, to produce self-extinction in the case of the longer waves, a greater thickness of film is necessary than in the case of the shorter ones. Different colors, therefore, appear at different thicknesses of the film.

Take with you a little bottle of spirit of turpentine, and pour it into one of the ponds in the Central Park. You will then see the flashing of those colors over the surface of the ivaier. On a small scale we produce them thus: A common tea-tray is filled with water, beneath the surface of which dips the end of a pipette. A beam of light falls upon the water, and is reflected by it to the screen. Spirit of turpentine is poured into the pipette; it descends, issues from the end in minute drops, which tise in 'uccession to the surface. On reaching it, each drop spreads suddenly out as a film, and glowing colors immediately flash forth upon the screen. The colors change as the thickness of the film changes by evaporation. They are also arranged in zones in consequence of the gradual diminution of thickness from the centre outwards.

Any film whatever will produce these colors. The tilm of air between two plates of windowg!ass, squeezed together, exhibits ricln fringes of color. Nor is even a:r necessary ; the nere rupture of optical continuity suffices. Smite with an axe the black, transparent iceblack, because it is transparent and of great depth-under the moraine of a glacier; you readily produce in the interior flaws which no air can reach, and from these flaws the colors of thin plates sometimes break like fire. The colors are commonly seen in flawed crystals ; they are also formed by the film of oxide which collects upon molten lead. It is the coiors of thin plates that guide the tempering of stecl. But the origin of most historic interest is, as already stated, the soap-bubblc. With one of those mixtures employed by the cminent blind philosopher Plateau in his researches on the cohesion figures of thin films, we obtain in still air a bebble twclive or fifteen inches in diameter. You-may look at the bubble itself, or you may look at its projection upon the screen, ich colors arranged in zones are, in both cases, cxhibited. Kendering the beam parallel, and permitting it to impinge upon the sides, bottom, and top of the bubble, gorgeous fans of color overspread the screen, which rotate as the beam is carried round the circumference of the bubble. By this experiment the internal motions of the film are also strikingly displayed.

Newton sought to measure the thickness of the bubble corresponding to each of these colors; in fact, he sought to determine gencrally the relation of color to thickness. His first care was to obtain a film of variable and calculable depth. On a plano-convex glass lens of very feeble curvature he laid a plate of glass with a p'ane surface, thus obtaining a tilm of air of graduallyincreasing depth from the point of contact outwards. Un looking at the film in monochrcmatic light he saw su:rounding the place of contact a series of bright rings separated from each other by dark ones, and becoming more closely packed together as the distance from the point of conta $t$ augmented. When he employed red light, his rings had certain diameters; when he employed blue light, the diameters were less. Causing his glasses to pass through the syeo. 
trum from red to blue, the rings contracted ; when the passage was from blue to red, the rings expanded. When white light fell upon the glasses, inasmuch as the colors were not superposed, a series of iris-colored circles were obtained. They became paler as the film became thicker, until finally the colors became so intimately reblended as to produce white light. A magnified image of Nezuton's rings is now before you, and, by employing in succession red, blue, and white light, we obtain all the effects observed by Newton.

He compared the tints thus obtained $r$ ith the tints of the soa--bubble, and he calculated the corresponding thickness. How he did this may be thus made plain to you: Suppose the water of the ocean to be absolutely smooth ; it would then accurately represent the earth's curved surface. Let a perfectly horizontal plane touch the surface at any point. Knowing the earth's diameter, any engineer or mathematician in this room could tell you how far the sea's surface will lie below this plane, at the distance of a yard, ten yards, a hundred yards, or a thousand yards from the point of contact of the plane and the sea. It is common, indeed, in levelling operations, to ailow for the curvature of the earth. Newton's calculation was precisely similar. His plane glass was a tangent to his curved cne From its refractive index and focal distance he determined the diameter of the sphere of which his curved glass formed a segment, he measured the distances of his rings from the place of contact, and he calculated the depth between the tangent plane and the curved surface, exactly as the engineer would calculate the distance between his tangent plane and the surface of the sea. The wonder is, that, where such infinitesimal distances are involved, Newton, with the means at his disposal, could have worked with such marvellous exactitude.

To account for these rings was the greatest difficulty that Newton ever encountered. He quite appreciated the difficulty. Orer his eagle-cye there was no film-no vagueness in his conceptions. At the very outset his theory was confronted by the question, Why, when a beam of light is incident on a transparent body, are some of the lightparticles reflected and some transmitted? Is it that there are two kinds of particles, the one specially fitted for transmission and the other for reflection? This cannot be the reason; for, if we allow a beam of light which has been reflected from one piece of glass to fall upon another, it, as a general rule, is also divided into a reflected and a transmitted portion. Thus the particles once reflected are not always reflected, nor are the particlis once transmitted always transmitted. Newton saw all this; he knew he had to ex piain why it is that the self-same particle is at one moment reflected and at the next moment transmitted. It could only be through ane change in the condition of the particle itself. The self-same particle, he affirmed, was affected by "fits" of easy transmission and reflection.

If you are willing to follow me while I unravel this theory of fits, the most subtle, perhaps, that ever entered the human mind, the intellectual discipline will repay you for the necessary effort of attention. Newton was chary of stating what he considered to be the cause of the fits, but there cannot be a doubt that his mind rested on a mechanical cause. Nor can there be a doubt that, as in all attempts at theorizing, he was compelled to fall back upon experience for the materials of his theory. His course of observation an $q^{\circ}$ of thought may have been this: From a magnet he might obtain the notion of attracted and repelled poles. What more natural than that he should endow his lightparticles with such poles? Turning their attracted poles towards a transparent substance, the particles would be sucked in and transmitted; turning their repilled poles, they would be driven away or reflected. Thus, by the ascription of poles, the transmission and reflection of the self-same particle at different times might be accounted for.

Regard these rings of Newton as seen in pure red light: they are alternately bright and dark. The film of air corresponding to the outermost of them is not thicker than an ordinary soap-bubble, and it becomes thinner on approaching the centre; still Newton, as I have said, measured the thickness corre. sponding to every ring and =howed the difference of thickness between ring and ring. Now, mark the result. For the sake of con. venience, let us call the thickness of the film of air corresponding to the first dark ring $d$, then Newton found the distance correspond. ing to the second dark ring $2 d$; the thick ness corresponding to the third dark ring $3 d$; the thickness correspording to the tenth dark ring Io $d$, and so on. Surely there must be some hidden meaning in this little distance $d$, which turns up so constantly? One can imagine the intense interest with which Newtor pondered its meaning. Observe the probably outcome of his thought. He had endowed his light-particles with poles, but now he is forced to introduce the notion of periodic iscurrince. How was this to be done? By supposing the light-particles animated, not only with a motion of translation, but also with a motion of rotation. Nervton's astronomical knowledge would render all such conceptions familiar to him. The earth has such a motion. In the time occupied in passing over a million and a half of miles of its orbit-that is in twenty four hours-our. planet performs a complete rotation, and, in the time required to pass over the distance $d$, Newton's light-particle must be supposed to perform $a$ complete rotation. True, the light-particle is smaller than the planet and the distance $d$, instead of being a million and a half of miles, is a little over the nizety:- 
thousandth of an inch. But the two conceptions are, in point of intellectual quality, identical.

Imagine, then, a particle entering the film of air where it possesses this precise thickness. To enter the film, its attracted end must be presented. Within the film it is able to turn once completely round; at the other side of the film its attracted pole will be again presented; it will, therefore, enter the glass at the opposite side of the film and be lost to the c\%. All round the place of contact, wherever the film possesses this precise thickness, the light will equally disappear-we shall have a ring of darkness.

And now observe how well this conception falls in with the law of proportionality discovered by Newton. When the thickness of the film is $2 d$, the particle has time to perform two complete somersaults within the film; when the thickness is $3 d$, three complete somersaults ; when Io $d$, ten complete somersaults are performed. It is manifest that in each of these cases, on arriving at the second surface of the film, the attracted pole of the particle will be presented. It will, therefore, be transmitted, and, because no light is sent to the eye, we shall have a ring of darkness at each of these places.

The bright rings follow immedia'ely from the same conception. They occur between the dark rings, the thicknesses to which they correspond being also intermediatc between those of the dark ones. Take the case of the first bright ring. The thickness of the film is $1 / 2 d$; in this interval the rotating particle can perform only half a rotation. When, therefore, it reaches t.:e second surface of the film, its repelled pole is presented; it is, thereforc, driven back and reaches the eye. At all distances round the cen're correspond$\mathrm{i}-\mathrm{g}$ to this thickness the same effect is produced, and the consequence is a ring of brightness. The other bright rings are similarly accounted for. At the second one, where the thickness is $I 1 / 2 d, a$ rotation and $a$ half is performed; at the third, two rotations and a half; and at each of these places the particles present their repelied poles to the lower surface of the film. They are therefore sent back to the eye, producing the impression of brightness. Here, then, we hav: unravelle $\perp$ the most subtle application that Newton ever made of the Emission Theory.

It has been stated in the early part of this lecturc, that the Emission Theo:y assigned a greater velocity to light in glass and water, than in air or stellar space. Here it was at direct issue with the theory of undulation, which makes the velocity in air or stellar space less than in glass or water. By an experiment proposed by Arago, and executed with comsummate skill by Foucault and Fizeau, this question was $\mathrm{b}$ :ought to a crucial test, and decided in favor of the theory of undulation. In the present instance also the two theories are at variance. Newton as- sumed that the action which produces the al. ternate bright and dark rings took place at a single surface; that is, the second surface of the film. The undulatory theory affirms that the rings are caused by the interference of waves reflected from bot/h surfaces. This also has been demonstrated by experiment. By proper devices we may abolish reflection from one of the surfaces of the film, and when this is done the rings vanish altogether.

Rings of feeble intensity are also formed by transmittcd light. These are referred by the undulatcry theory to the interference of waves which have passed directly th rough the film, with others wisich have suffered trwo reflections within the film. They are thus com. pletely accounted for.

Newton, by the foregoing exceedingly subtle assumption, vaulted over the difficulty preserted by the colors of thin plates. And, as further difficulties in process of time thickened round the theory, his disciples tried to sustain it with an ingenuity worthy of their master. The new difficulties were not anticipated by the theory, but were met by new assumptions, until at length the Emission Theory became what a distinguished writer calls a " mob of hypotheses." In the presence of the phenomena of interference, the theory finally broke down, while the whole of these phenomena lie, as it were, latent in the theory of undulation. Newton's " fits," for example, arc immediately translatable into the lengths of the ether-waves. We have the observed periodic recurrence as the thickness varies so as to produce a retardation of an odd or even number of semi-undulations.*

Numerous other colors are due to interference. Fine scratches drawn upon glass or polished metal reflect the uaves of light from their sides; and some, being reflected from opposite sides of the same furrow, interfere with and quench each other. But the ob. liquity of reflection which extinguishes the shorter waves does not extinguish the longer ones, hence the phenomena of color. These are called the colors of striated surfaces. They are well illustrated by mother-of-pearl. This shell is composed of exceedingly thin layers, which, when cut across by the polishing of the shell, expose their edges and furnish the necessary small and regular grooves. The most conclusive proof that the colors ar. due to the mechanical state of tise surface $\mathrm{i}$; to be found in the fact, established by Brew ster, that, by stamping the shell carefully

* In the explanation of Newton's rings, something besides thickness is to be taken into account. In the case of the first surface of the film of air, the waves pass from a denser to a rerer medium, while in the case of the second surface, the waves pass from a rarer to a denser medium. This difference at the two reflecting surfaces can be proved to be equivalent to the addition of loalf a wave-length to the thickness of the film. To the absolute thickness, as determined by Newton, half a wave-length is in each case to be added. When this is done, the dark and bright rings follow each other in cxact accordance with the law of interference already cnunciated. 
upon black sealing-wax, we transfer the grcoves, and produce upon the wax the colors of nother.of-pearl.

\section{LECTURE III.}

Relation of Theories to Experience: Origin of the Notion of the Attraction of Gravitation: Notion of Polarity, how generated: Atomic Polarity: Structural Arrangements due to Polarity: Architecture of Crystals considered as an-Introduction to their Action upon Light: Notion of Atomic Polarity applied to Crystalline Structure: Exper1mental lllustrations: Crystallization of Water: Expansion by Heat and by Cold: Deportment of Vater considered and explained: Molecular Action illustrated by a Model: Force of Solidification: Bearings of Crystallization ' on Optical Phenomena: Refraction: Double Refraction: Polarization: Action of Tourmaline: Character of the Beams emergent from Iceland Spar: Polarization by ordinary Refraction and Reflection: Depolarization.

IN our last lecture we sought to familiarize our minds with the characteristics of wavemotion. We drew a clear distinction between the motio, of the wave itself and the motion of its constituent particles. Passing through water-waves and air-waves, we prepared our $\mathrm{mi}$ ds for the conception of light-waves propagated through the luminiferous ether. The analogy of sound will fix the whole mechanism in your minds. Here we have a vibrating body which originates the wave motion, we have, in the air, a vehicle which conveys it, and we have the auditory nerve which receives the impressions of the sonorous waves. In the case of light we have in the vibrating atoms of the luminous body the originators of the wave-motion, we have in the ether its vehicle, while the optic nerve receives the impression of the luminiferous waves. IVc learned, also, that color is the analogue of pitch, that the rapidity of atomic vibration augmented, and the length of the cther-waves decreased, in passing from the red to the blue end of the spectrum. The fruitful principle of interference we also found applicable to the phenomena of light ; and we learned that, in consequence of the different lengths of the ether-waves, they were extinguished by different thicknesses of a transparent film, the particular thickness which quenched one color glowing, therefore, with the complementary one. Thus the colors of thin plates were accounted for.

But one of the objects of our last lecture, and that not the least important, was to illustrate the manner in which scientific theories are formed. They, in the first place, take their rise in the desire of the mind to fenetrate to the sources of phenomena. This desire has long been a part of human nature. It frompted Cresar to say that he would exchange his victories for a rlimpse of the sources of the Nile; it may be seen working in Luctetius ; it impels Darwin to those daring speculations which of late years have so agitated the public mind. We have learned thit in framing theories the imagination does not create, but that it expands, diminishes, moulds, and refines, as the case may be, mater als derived from the world of fact and observation.

This is more evidently the case in a theory like that of light, where the motions of a sub. sensible medium, the ether, are presented to the mind. But no theory escapes the condition. Newton took care not to encumber gravitation with unnecessary physical conceptions ; but we have reason to kuow that he indulged in them, though he did not connect them with his theory. But even the theory as it stands did not enter the mind a: a revelation dissevered frum the world of experience. The germ of the conception that the sun and planets are held together by a force of attraction is to be found in the fact that a magnet had been previously seen to attract iron. The notion of matter attracting matter came thus from without, not from within. In our present lecture the magnetic force must serve us : till further ; but here we must master its elementary phenomena.

The general facts of magnetism are most simply illustrated by a magnetized bar of stee!, commonly calied a bar magnet. Placing such a magret up'sht upon a table, and bringing a magne, seedle near its bottom, one end of the nasue promptly retreats from the magnet, $w^{\prime}$ the other as prompily approaches. " meedle is held quivering there by some ...visible influence exerted upon it. Raising the needle along the magnet, but still avoiding contact the rapidity of its oscillations decreases, because the force acting upon it becomes weaker. At the centre the oscillations cease. Above the centre, the end of the needle which had been previously drawn towards the magnet retreats, and the opposite end approaches. As we ascend higher, the oscillations become mcre violent, because the force becomes stronger. At the upper end of the magnet,

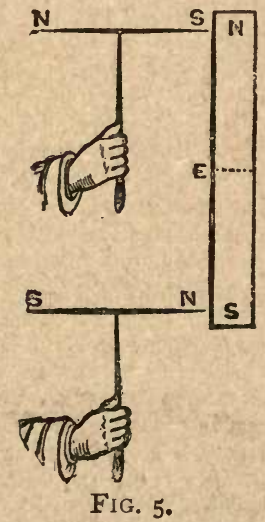

as at the lower, the force reaches a maximum, t,ut all the lower half of the magnet, from $\mathrm{E}$ to $\mathrm{S}$ (Fig. 5), attracts one end of the 
needle, while all the uppcr haif, from $\mathrm{E}$ to $\mathrm{N}$, attracts the opposite end. This doubleness of the magnetic force is called polarity, and the points near the cnds of the magnet in which the forces seem concentrated are cailed its poles.

What, then, will occur if we break this magnet in two at the cent:e $\mathrm{E}$ ? Will each of the separate halves act as it did when it formed part of the whole magnet? No; each half is in itself a perfect magnet, pos sessing two poles. This may be proved by breaking something of less value than the magnet - the steel of a lady's stays, for extxample, hardened and magnetized. . It acts like the magnet. When broken, each half acts like the whole; and when these parts are again broken, we have still the perfect magnet, possessing, as in the first instance, two poles. Push your breaking to its utmost limit; you will be driven to prolong your rection of the needle, and no other. A needle of iron will answer as well as the magnetic needle; for the need e of iron is magnetized by the magnet, and acts exactly like a needle independently magnetized.

If we place two or more needles of iron near the magnet, the action becomes morc comp!ex, for the the iron needles are not only acted on by the magnet, but they act upon each other. And if we pass to smaller masses of iron-to iron filings, for example-we find that they act substantially as the needles, arranging themselves in definite forms, in obedience to the magnetic action.

Placing a sheet of paper or glass over this bar magnet and showering iron filings upon the paper, I notice a tendency of the filings to arrange themselves in determinate lincs. They cannot freely follow this tendency, for they are hampered by the friction against the paper. They are hielped by tapping the

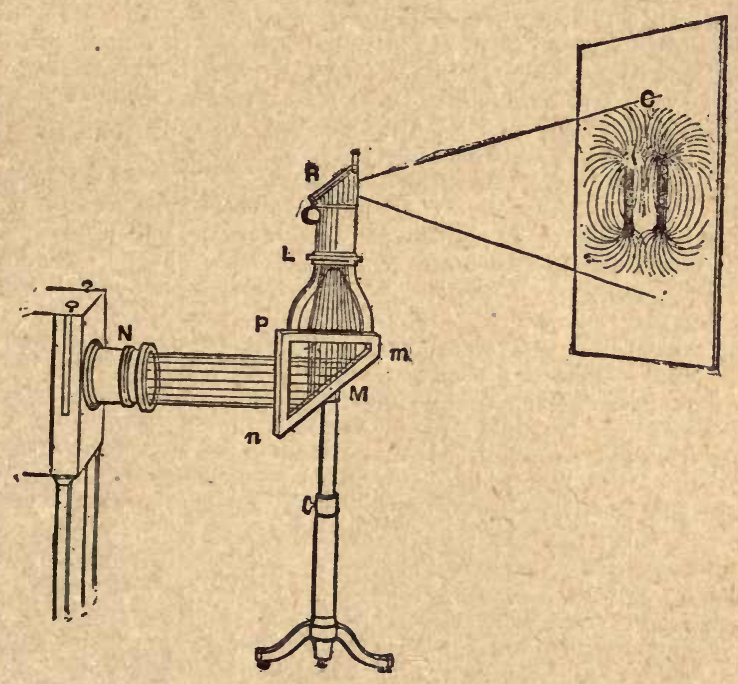

Fig. 6 .

$\lambda$ is the nozzle of the lamp: M a plane mirror, reflecting the beam upwards. At $P$, the magnets and iron filings are placed; $\mathrm{L}$ is a lens which forms an image of the magnets and filings; and $R$ is a totally-reflecting prism which casts the image, $G$, upon the screen.

vision beyond that limit, and to contemplate this thing that we call magnetic polarity as resident in the ultimate particles of the magnet. Each atom is endowed with this polar force.

Like all other forces, this force of magnetism is amenable to mechanical laws; and knowing the direction and magnitude of the force, we can predict its action. Placing a small magnetic needle near a bar magnet, it takes up a determinate position. That position might be deduced theoretically from the mutual action of the polcs. Moving the needle round the magnet, for each point of the surrounding space there is a definite di- paper: each tap releases them for a moment' and enables them to follow their bias. Bu this is an experiment which can only be seen by myself. To enable you to see it, I take a pair of sinall magnets and by a simple optical. arrangement throw the images of the magnet; upon the screen. Scattering iron filings over the glass plate to which the small magnets are attached, and tapping the plate, you see the arrangement of the lron filings in those magnetic curves which have been so long familiar to scientific men.*

* Very beautiful specimens of these curves have been recently obtained, and fixed, by Prof. Mayer, 
The aspect of these curves so fascinated Faraday that the greater portion of his intellectual life was devoted to pondering over them. He invested the space through which they run with a kind of materiality; and the probability is, that the progress of science by connecting the phenomena of magnetism with the luniniferous ether, will prove these "lines of force," as Faraday loved to call the magnetic curves, to represent a condition of this mysterious substratum of all radiant action.

But it is not with the magnetic curves, as such, that I now wish to occupy your attention ; it is their relationship to theoretic conceptions that we have now to consider. By the action of the bar magnet upon the needle we obtain the notion of a polar force ; by the breaking of the strip of magnetized steel, we attain the notion that polarity can attach itself to the ultimate particles of matter. The experiment with the iron filings introduces a new idea in to the mind; the idea, namely, of structural arrangement. Every pair of filings rossesses four poles, two of which are attractive and two repulsive. The attractive poles approach, the repulsive poles retreat; the consequence being a certain definite arrangement of the particles with reference to each other.

Now, this idea of structure, as produced by polar force, opcns a way for the intellect into an entirely new region, and the reason you are asked to accompany me into this region is, that our next inquiry relates to the action of crystals upon light. Before I speak oi this action, I wish y $\mathrm{y}$ u to realize the process of crystalline architecture. Look then into a granite quarry, and spend a few minutes in examining the rock. It is not of perfectly uniform texture. It is rather an agglomeration of pieces, which, on examination, present curiously-defined forms. You have there what mineralogists call quartz, you have felspar, you have mica. In a mineralogical cabinet, where these substances are preserved separately, you will obtain some notion of their forms. You will see there, also, speciriens of beryl, topaz, emerald, tourmaline, heavy spar, fluor-spar, Iceland spar-possibly a full-formed diamond, as it quitted the hand of Nature, not yet having got into the hands of the lapidary. These crystals, you will observe, are put together according to law; they are not chance productions : and, if you care to examine them mors minutely, you will find their architecture capable of being to some cxtent revealed. They split in certain directions before a knife-edge, ex$\mathrm{p}$ sing smooth and shining surfaces, which are called planes of cleavage ; and by following these planes you sometimes reach an in ternal form, disguised beneath the external form of the crystal. Ponder these beautiful edifices of a hidden builder. You cannot help asking yourself how they were built; and familiar as you now are with the notion of a polar force, and the ability of that force to produce structural arrangement, your inevitable answer will be, that those crystals are built by the play of polar forces with which their ultimate molecules are endowed. In virtuc of these forees, atom lays itself to atom in a perfectly definite way, the final visible form of the crystal depending upon this play of its molecules.

Everywhere in Nature wc observe this tendency to run into definite forms, and nothing is easier than to give scope to this tendency by artificial arrangements. Dissolve nitre in water, and allow the water slowly to evaporate; the nitre remains, and the solution soon becomes so concentrated that the liquid form can no longer be preserved. The nitre-molecules approach each other, and come at length within the range of their polar forces. They arrange themselves in obedience to these forces, a minute crystal of nitre being at first produced. On this crystal the molecules continue to deposit themselves from the surrounding liquid. The crystal grows, and finally we have large prisms of nitre, each of a perfectly definite shape. Alum crystallizes with the utmost ease in this fash.on. The resultant crystal is, however, different in shape from thit oi nitre, because the poles of the molecules are differently disposed; and, if they be only nursed with proper care, crystals of these substances may be caused to grow to a great size.

The condition of perfcct crystallization is, that th : crystallizing force shall act with deliberation. There should be no hurry in its operation; but cvery molecule ought to be permitted, without disturbance from its neighbors, to exercise its own molecular ights. If the crystallization be too sudden, the regu. larity disappears. Water may be saturated with sulphate of soda, dissolved when the water is hot, and afterward permitted to cool. When cold, the solution, is supersaturated ; that is to say, more solid matter is contained in it than corresponds to its temperature. Still the molecules show no signs of building themselves together. This is a very rematkable, though a very common fact. The molecules in the centre of the liquid are so hampered by the action of their neighbors that freedom to foliow their own tendencies is denied to them. Fix your mind's eye upon a molecule within the mass. It wishes to unite with its neighbor tu the right but it wishes equally to unite with its neighbor to the left; the one tendency neutralizes the other, and it unites with neither. We have here, in fact, tránslated into molecular action the well-known suspension of animal volition produced by two equally inviting bundles of hay. But, if a crystal of sulphate of soda be dropped into the solution, the molecular indecision ceases. On the crystal the adjacent molecules will immediately precipitate themselves; on these again others will be precipi- 
tat $=d$, and this act of precipitation will continue from the top of the flask to the bottom, until the solution has, as far as possible, assumed the solid form. The crystals here formed are small, and confusedly arranged. The process has been too hasty to a $1 \mathrm{mit}$ of the pure and crderly action of the crystallizing 1orce. It typifies the state of a nation in which natural and healthy change is resisted, until society becomes, as it were, supersaturated with the desire for change, the change being effected through confusion and revolution, which a wise foresight might have avoided.

Let me illustrate the action of crystallizing force by two examples of it: Nitre might be employed, but another well-known substance enables me to make the experiment in a better forn. The substance is common salammoniac, or chloride of ammonium, dissolved in water. Cleansing perfectly a glass plate, the solution of the chloride is poured over the glass, to which, when the plate is set on edge, a thin film of the liquid adheres. Warming the glass slightly, cvaporation is promoted; the plate is then placed in a solar microscope, and an image of the film is thrown upon a white screen. The warmth of the illuininating beam adds itself to that alseady impa ted to the glass plate, so that after a moment or two the film can no longer exist in the liquid condition. Molecule then closes with molecule, and you have a most impressive display of crystallizing energy overspreading the whole screen. You may produce something similar if you breathe upon the frost ferns which overspread your windowpanes in winter, and then observe through a lens the subsequent recongelation of the film.

Here the crystallizing force is hampered by the adhesion of the film to the glass; nevertheless, the play of power is strikingly beautiful. Sometimes the crystals start from the edge of the film and run throngh it from that edge, for, the crystallization being once started, the molecules throw themselves by preference on the crystals already formed. Sometimes the crystals start from definite nucies in the centre of the film ; every small crystallin ? particle which rests in the film furnishes a starting-point. Throughout the process you notice one feature which is perfectly unalterable, and that is, angular magnitude. The spiculæ branch from the trunk, and from these branches others shoot; but the angles enclosed by the spiculre are unalterable. In like manner you may find alum-crystals, quartz-crystals, and all other crystals, distorted in shape. They are thus far at the mercy of the accidents of crystallizaiion ; but in one particular they assert their superiority over all such accidents-angrular magnitude is always rigidly preserved.

My second example of the action of crystallizing force is this: i y sending a voltaic current through a liquid, you know that we decompose the liquid, and if it contains a metal, we liberate this metal by the electrolysis. This small cell contains a solution of acetate of lead, and this substance is chosen because lead lends itself freely to this crystallizing power. Into the cell dip two very thin plati um wires, and these are connected by other wires with a small voltaic battery. On sending the voltaic current through the solution, the 1 ad will be sl.wly sevired from the atoms with which it is now combined; it will be liberated upon one of the wires, and at the moment of its liberation it will obey the polar forces of its atoms, and produce crystalline forms of exquisite beauty. They are now before you, sprouting like ferns from the wire, appearing indeed like vegetable growths rendered so rapid as to be plainly visible to the naked eye. On reversing the current, these wonderful lead-fror ds will dissolve, while from the other wire filaments of lead dart through the liquicl. In a moment or two the growth of the lead-trees recommences, but they now cover the other wire. In the process of crystallization, Nature first reveals herself as a builder. Where do her operations stop? Does she continue, by the play of the same forces, to form the vegretable, and afterwards the animal? Whatever the answer to these questions may be, trust me that the notions of the coming generations regarding this mysterious thing, which some have called "brute matter," will be very different from those of the generations past.

There is hardly a more beautiful and instructive example of this play of molecular force trian that furnished by the case of water. You have seen the exquisite fern-like forms produced by the crystallization of a film of water on a cold window pane. You have also probably noticed the beautiful rosettes tied together by the crystallizing force during the descent of a snow-shower on a very calm day. The slopes and summits of the Nlps are loaded in winter with these blossoms of the frost. They vary infinitely in detail of beauty, but the same angular magnitude is preserved throughout. An inflexible power binds spears and spicule to the angle of 60 degrees. The common ice of our lakes is also ruled in its deposition by the same angle. You may sometimes see in freezing water small crystals of stellar shapes, each star consisting of six rays, with this angle of $60^{\circ} \mathrm{be}$ tween every two of them. it his structure may be revealed in ordinary ice. In a surbeam, or, failing that, in our electric beam, we have an instrument delicate enough to unlock the frozen molecules without disturbing the osder of their architecture. Cutting from clear, sound, regularly-frozen ice a slsb parallel to the planes of freezing, and sending a sunbeam through such a slab, it liquefies internally at special points, round each point a six-petalled liquid flower of exquisite beauty being formed. Crowds of such flow: ers are thus produced. 
A moment's further devotion to the crystallization of water will be well repaid; for the sun of qualities which renders his substance fitted to play its part in Nature may well excite wonder and stimulate thought. Like almost all other substances, water is expanded by heat and contracted by cold. Let this expansion and contraction be first illustrated:

A small fla $\mathrm{k}$ is filled with cofored vater, and stopped with a cork. Through the coik passes a glass tube water-tight, the liquid standing at a certain height $\left(t^{\prime}\right.$, Fig. 7$)$ in the tube. The flask and its tube resemble the bulb and stem of a thermometer. Applying the heat of a spirit-lamp, t'se water rises in the tube, and finally trickles over the top $(t)$. Expansion by heat is thus illustrated. the definite temperature of $39^{\circ}$ Fahr. Crgstallization has virtually here commenced, the molecules preparing themselves for the subsequent act of solidification which occurs at $32^{\circ}$, and in which the expansion suddenly culminates. In virtue of this expansion, ice, as you know, is lighter than water in the proportion of 8 to 9 . $^{*}$

It is my desire, in these lectures, to lead you as closely as rossible to the limits hitherto attained by scientific thought, and, in pursuance of this desire, I have now to invite your attention to a molecular problem of grcat interest, but of great complexity. I wish you to obtain suc 1 an insight of the molecular world as shall give the intellect satisfaction when reflecting on the deportInent of water before and during the act of

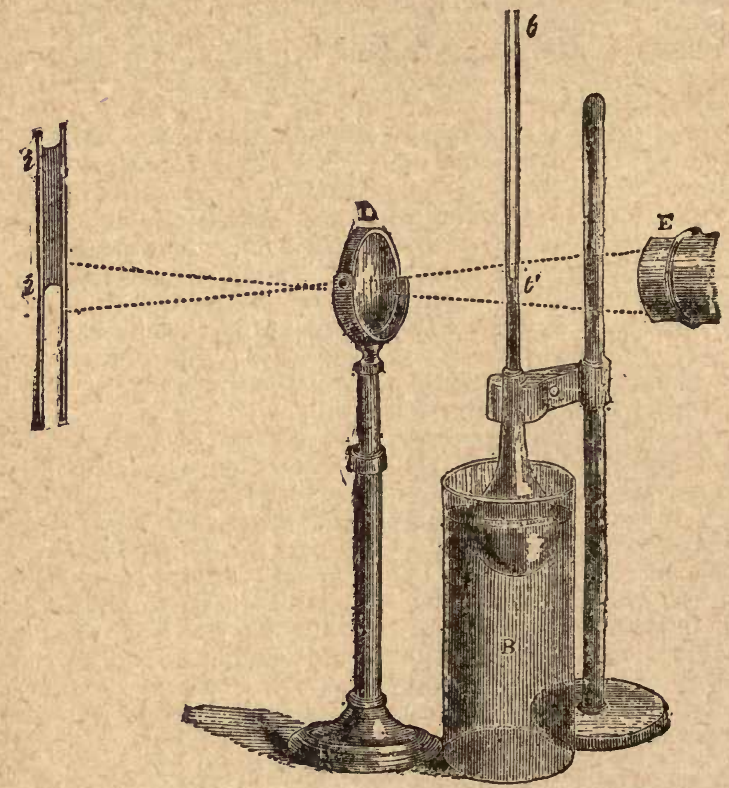

FIG. 7 .

Projection of experiment : $E$ is the nozzle of the lamp, $\mathrm{L}$ a converging lens, and $i$ the image of the liquid column.

Removing the lamp and piling a freezing mixture in the vessel (B) round the flask, the liquid column falls, thus : showing the contraction of the water by the cold. But let the freezing mixture continue to act: the Falling of the column continues to a certain point ; it then ceases. The top of the column remains stationary for sone seconds, and afterwards begins to rise. The contraction has ceased, and expansion by cold sets in. Let the expansion continue till the liquid trickles a second time over the top of the tube. The freezing mixture has here produced to all appearance the same effect as the ffame. In the case of water, contraction by cold ceases and expansion by cold sets in at crystallization. Consider, then, the ideal case of a number of magnets deprived of

*In a little volume entitled "Forms of Water," I have mentioned that cold iron floats upon molten iron. In company with my friend Sir Wiliiam Armstrong. I had repeated opportunities of witnessing this fact in his works at Elswick, in 1863 . Faraday, I remember, spoke to me subsequently of the completeness of iron castings as probably due to the swelling of the metal on solidification. Beyond : his, I have given the subject no special attention, and I know that many intelligent iron-founders doubt the fact of exparsion. It is quite possible that the solid floats because it is not avetted by the molten iron, its volume being virtually augmented by capillary repulsion. Certain flies walk freely upon water in virtue of an action of this kind. With bismuth, however, it is easy to burst iron bottles by the force of solidification. 
weight, but retaining their polar forces. If with the force of contraction until the freezing we had a liquid of the specific gravity of temperature is attained. Here the polar steel, we might, by making the magnets forccs suddenly and finally gain the victory. float in it, realize this state of things, for in The molecules close up and form solid cryssuch a liquid the magnets would neither sink tals, a considerable augmentation of volume nor swim. Now, the principle of gravitation being the immediate consequence.

is that every particle of matter attracts every other particle with a force varying as the ininverse square of the distance. In virtue of the atiraction of gravity, then, the magnets, if perfectly free to move, would slowly approach each other.

But besides the unsolar force of gravity, which belongs to matter in general, the magnets are endowed with the polar force of nagnetism. For a time, however, the polar forces do not sensibly come into play. In this condition the magnets resemble our water molecules at the temperature say of $50^{\circ}$.

We can still further satisfy the intellect by showing that these conceptions can be realized by a model. The molecule of water is composed of two atoms of hydrogen, united to one of oxygen. We may assume the molecule built up of these atoms to be pyramidal. Suppose the triangles in $F_{1 g} .8$ to be drawn touching the sides of the molecule, and the disposition of the polar forces to be that irdicated by the letters; the points marked A being attractive, and those marked $\mathrm{R}$ repellent. In virtue of the general attraction of the molecules, let them be drawn towards the

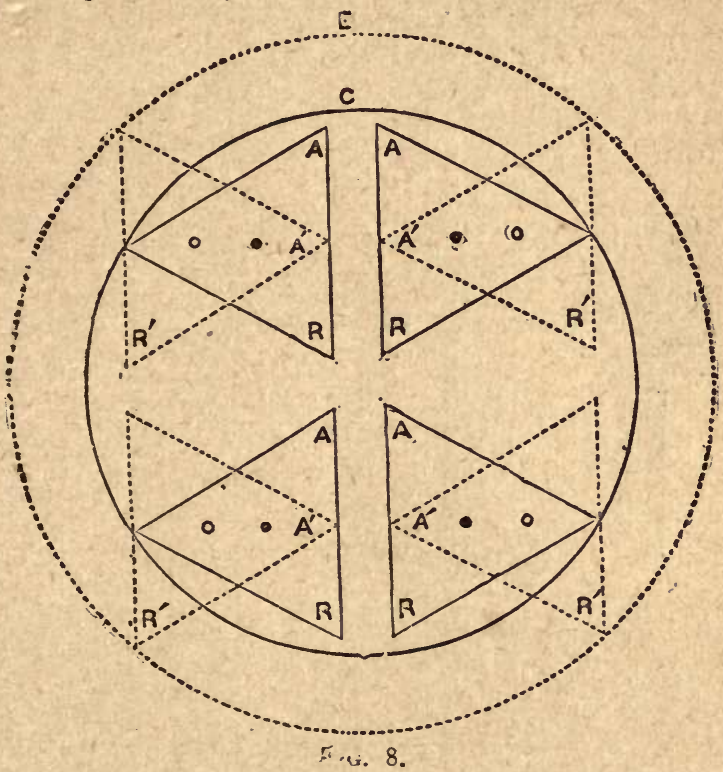

But the magnets come at length suffici"iily positions marked by the full lines, and then near each other to enable their poles to vitcract. From this point the action ceases to be a general attraction of the masses. In attraction of special points of the masses and a repulsion of other points now come into play; and it is easy to see that the rearrangement of the magnets consequent upon the introduction of these new forces may be such as to require a greater amount of room. 'This, I take it, is the case with our water-molccules. Like the magnets, they approach each other as wholes, until the temperature $39^{\circ}$ is reached. Previous to this temperalure, doubtless, the polar forces had begun to act, and at this temperature their action exactly balances the contraction due to cold. At lower temperatures the polar forces predominate. But they carry on a gradual struggle suppose the polar attractions and repulsions to act. A will turn towards $A^{\prime}$, and $R$ will retreat from $R^{\prime}$. The molecules will be caused to rotate, their linal positions being that shown by the dotted lines. But the circle surround ing the latter is larger than that surrounding the full lines, which shows that the molecules in their new positions require more room. In this . ay we obtain an image of the molecular mechal ism active in the case of water. The demand for more room is made with an energy sufficient to overcome all ordinary resistances. Your lead pipes yield readily to this power; but iron does the same, and bomb-shells, as you know, can be burst by the freezing of water. Thick iron bottles filled with water and placed in a freezing mixture are shivered into fragments by the resistless vigor of molecular force. 
We have now to exhibit the bearings of crystallization upon optical phenomena. According to the undulatory theory, the velocity of light in water and glass is less than in air. Consider, then, a small portion of a wave issuing from a point of light so distant that the portion may be regarded as practically straight. Moving vertically downwards, and impinging on an horizontal surface of glass, the wave would go through the glass without change of direction. But, as the velocity in glass is less than the velocity in air, the wave would be retarded on passing into the denser medium.

But suppose the wave, before reaching the glass, to be oblique to the surface ; that end of the wave which first reaches the glass will be the first retarded, the other portions as they enter the glass being retarded in succession. This retardation of the one end of the wave causes it to swing round and change its front, so that when the wave has fully entered the glass :ts course is oblique to its original direction. According to the undulatory theory, light is thus refracted.
In water, fcr cxampie, there is nothing in the grouping of the molecules to interfere with the perfect homogeneity of the ether: but, when water crystallizes to ice, the case is different. In a plate of ice the eldsticity of the ether in a direction perpendicular to the surface of freezing is different from what it is parallel to the surface of freezing ; ice is. therefore, a double refracting substance. Louble refraction is displayed in a particularly impressive manner by Iceland spar, which is crystallized carbonate of lime. The difference of ethereal density in two directions in this crystal is very great, the separation of the beam into the two halves being, therefore, particularly striking.

Before you is now projected an image of our carbon-points. Introducing the spar, the beam which builds the image is permitted to pass through it: instantly you have the single image divided into two. Projecting an image of the aperature through which the light issues from the electric lamp, and introducing the spar. two luminous (i k: insteaciof one, appear immediately upont the screen. (See Fig. 9.)

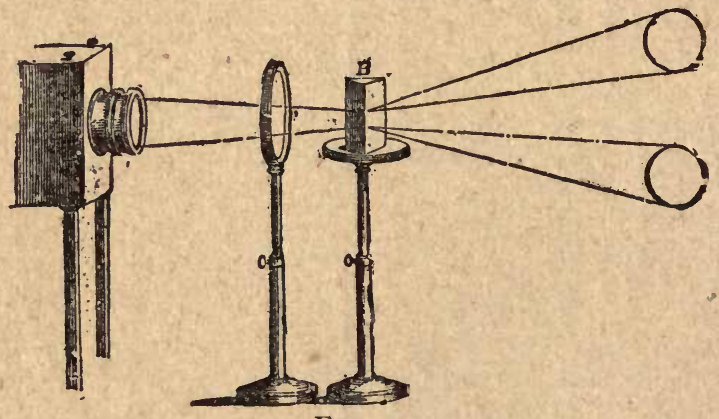

FIG. 9.

The two elements of rapidity of propagation, both of sound and light, in any substance whatever, are elasticity and density, and the enormous velocity of light is attainable because the ether is at the same time of infinitesimal density and of enormous elasticity. It surrounds the atoms of all bodies, but seems to be so acted upon by them that its density is increased without a proportionate increase of elasticity; this would account for the diminished velocity of light in refracting bodies. In virtue of the crystalline architecture that we have teen considering, the ether in many crystals possesses different densities in different directions ; and the consequence is, that some of these media transmit light with two different velocities. Now, refraction depends wholly upon the change of velocity on entering the refracting medium ; and is greatest where the change of volicity is greatest. Hence, as, in many crystals, we have two different velccities, we have also two different refractions, a beam of light being divided by such crystals into two. This effect is called double refraction.
The two beams into which the spar divides the single incident-beam do not belhave alike. One of them obeys the ordinary law of refraction discovered by Snell, and this is called the ordinary ray. The other does not obey the ordinary law. Its index of refraction, for example, is not constant, nor do the incident and refracted rays always lie in the same plane. It is, therefore, called the $c x$ traordinary ray. Pour water. and bisulphide of carbon into two cups of the same depth; looked at through the liquid, the cup that contains the more strongly-refracting liquid will appear shallower than the other. Place a piece cf Iceland spar over a dot of ink; two dots are seen, but one appears nearer than the other. The nearest dot belongs to the most. strongly-refracted ray, which in this case is ths ordinary ray. Turn the spar round, and the extraordinary image of the spot rotates ro: nd the ordinary one.

The double refraction of Iceland spar was first treated in a work published by Erasmus Bartholimus, in 1669. The celebrated Huyghens sought to account for the phenomenon 
on the principles of the wave theory, and he succeeded in doirg so. He made highly important observations on the distinctive character of the two beams transmitted by the spar. Newton, reflecting on the observations of IIuyghens, came to the conclusion that each of the beams had two sides; and from the analogy of this two sidedness with the two cndedness of a magnet, wherein consists its polarity, the two beams came subsequently to be described as polarized.

We shall study this subject of the polarization of liglit with great case and profit by means of a crystal of tourmaline. But let us start with a clear conception of an ordinary beam of light. It has been already explained that the vibrations of the individual etherparticles are executed across the line of propagation. In the case of ordinary light we are to figure the cther particles as vibrating in all directions, or azimuths, as it is sometimes expressed, across this line.

Now, in a plate of tourmaline cut parallel to the axis of the crystal, the beam of incident light is divided into two, the one vibrating parallel to the axis of the crystal, the other at right angles to the axis. The grouping of the molecules, and of the ether associated with the molecules, reduces all the vibrations incident upon the crystal to these two directions. One of these beams, namely that one whose vibrations are perpendicular to the axis, is quenched with exceeding rapidity by the tourma ine, so : hat, after having passed througls a very small thickness of the crystal, the light emerges with all its vibrations reduced to a single plane. In this condition it is what we call a beam of plane polarized light.

A moment's reflection will show, if what has been stated be correct, that, on placing a second plate of tourmaline with its axis parallel to the first, the light will pass through both; but that, if the axes be crossed, the

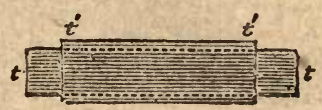

FIG. IO.

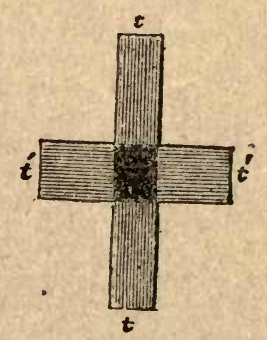

FIG. II.

light that passes through the one plate will be quenched by the other, a total interception of the light being the consequence. The image of a plate of tourmaline, $t t$ (Fig. IO), is now before you. I place parallel to it anot:er plate, $t^{\prime} t^{\prime}:$ the green of the crystal is a little deepened, nothing more. By means of an endless screw, I now turn one of the crystals gradually round; as long as the two plates are oblique to each other, a certain portion of light gets through; but, when they are at right angles to each other, the space common to both is a space of darkness, as shown in Fig. II.

Let us return to a single plate; and let me say that it is on the green light transmitted by the tourmaline that you are to fix your attention. We have now to illustrate the twosidedness of that green light. The light surrounding the green image being ordinary light, is reflect: d by a plane glass mirror in all directions; the green light, on the contrary, is not so reflectel. The image of the tourmaline is now horizontal ; reflected upwards, it is still green; reflected sideways, the image is reduced to blackness, because of the incompetency of the green l'ght to be reflected in this direction. Making the plate of tourmaline vertical and reflecting it as before, in the upper image the light is quenched; in the side image you have now the green. Picture the thing clearly. In the one case the mirror receives the impact ot the edges of the waves, and the green light is $\mathrm{q}$-enched. In the other case the sides of the waves strike the mirror, and $t$ e green light is reflected. To render the extinction complete, the light must be received upon the mirror at a special angle. What this angle is we shall learn presently.

The quality of two-sidedness conferred upon light by crystals may also be conferred upon it by ordinary reflection. Malus made this discovery in 1808 , while looking through Iceland spar at the light of the sun reflected from the windows of the Luxembourg palace in Paris. I receive upon a plate of windowglass the beam from our lamp; a great portion of the light reflected from the glass is polarized; the vibrations of this reflected beam are executed, for the most part, parallel to the surface of the glass, and, if the glass be held so that the beam shall make an angle of $58^{\circ}$ with the perpendicular to the glass, the whole of the reflected beam is polarized. It was at this angle that the image of the tourmaline was completely quenched in our former experiments. It is called the polarizing angle.

And now let us try to make substantially the experiment of Malus. I receive the beam from the lamp upon this plate of glass and reflect it through the spar. Instead of two images, you see but one. So that the light, when polarized, as it now is, can only get through the spar in one direction, and consequently produce but one image. Why is this? In the Iceland spar, as in the tourmaline, all the vibrations of the ordinary light 
are reduced to two plancs at right angles to each other; but, unlike the tourmaline, both beams are transmitted with cqual facility by the spar. The two beams, in short, emergent from the spar are polarized, their directions of vibration being at right angles to each other. When, therefore, the light was polarized by reflection, the direction of vibration in the spar which corresponded to the

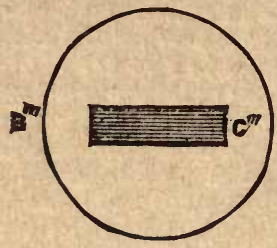

FIG. I2.

direction of vibration of the polarized beam transmitted it, and that direction only. But one image, therefore, was possible under the conditions.

And now you have it in your power to check many of my statements, and you will ubserve that such logic as connect our experiments is simply a transcript of the logic of Nature. On the screen before you are the

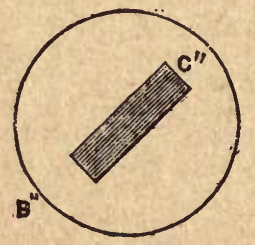

FIG. I3.

two disks of light produced by the double refraction of the spar. They are, as you know, two images of the aperture through which the light issues from the camera. Placing the tourmaline in front of the aperture, two images of the crystal will be obtained; but now let us reason out what is to be expected from this experiment. The light emergent from the tourmaline is polarized.

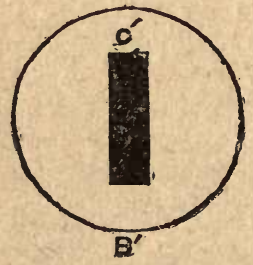

14.)

Let us rush our test still further. By means of an cndless screw, the crystal can he turned ninety degrees round. The black image, as I turn, becomes gradually brighter and the bright one gradually darker; at an angle of forty-five degrees both images ate equally bright (Fig. 13); while, when ninety degrees have been obtained, the axis of the crystal being then vertical, the brigh and

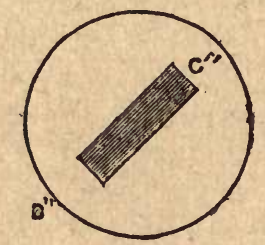

lack images have charged places. (Fig. Given two beams transmitted through Iceland spar, it is perfectly manifest that we have it in our power to determine instantly, by means of a plate of tourmaline, the directions in which the ether-particles vibrate in the two beams. I might place the doublerefracting sparin any position whatever. $A$

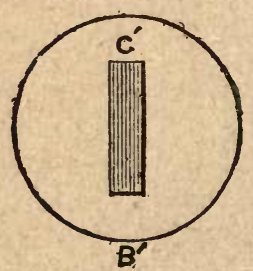

FiG. 14.

Placing the crystal with its axis horizontal, | minute's trial with the tourmaline would the vibrations of the transmitteu light will be horizontal. Now the spar, as already stated, has two perpendicular directions ot vibration, one of which, at the present moment, is vertical, the other horizontal. What are we to enable you to determine the position which yields a black and a bright image, and from these you would at once infer the directions of vibration.

Turther, the two beams from the spar 
being thus polarized, if they be suitably received upon a plate of glass at the polarizing angle, one of them will be reflected, the other not. This is the conclusion of reason from our previous knowledge; but you observe that reason is justified by experiment. (Figs. I5 and I6.)

I have said that the whole of the beam reflected from glass at the polarizing angle is polarized; a word must now be added regarding the larger portion of the light transmitted by the glass. The iransmitted beam contains a cuantity of polarized light equal to that of tl e reflected beam; but :his quantity is only a fraction of the whole transmitted light. By taking two plates of glass instead of one, we

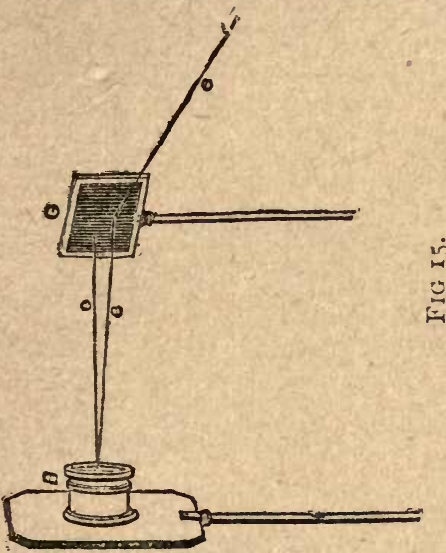

( $B$ is the birefracting spar, dividing the incident lizht into the two beams, $o$ and $e . \quad G$ is the mirror). Tne beam is here reflected laterally. When the reflection is uprvards, the other beam is reflected, as shown in Fig. 16.

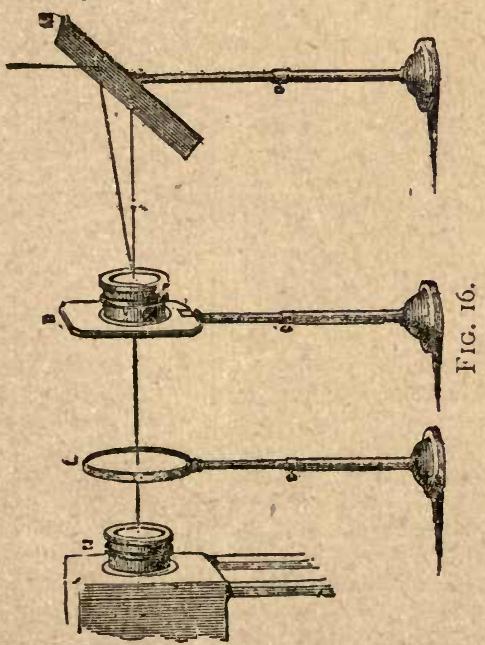

augment the quantity of the transmitted polarized light; and, by taking a bundle of pla:es, we so increase the quantity as to render the transmitted beam, for all practical purposes, perfectly polarized. Indeed, bundles of glass plates are often cmp'oyed as a means of furnishing polarized light.

One word more. IVhen the tourmalines are crossed, the space where they cross each other is black. But we have seen that the least obliquity on the part of the crystals permits light to get through both. Now suplose, when the two platcs are crossed, that we interpose a third plate of tourmaline between them, with its axis oblique to both. A portion of the light transmitted by the first plate will get through this intermediate cne. But, after it has got through, its plane of vibration is chansed: it is nolonger perpendicular to the axis of the crystal in front. Hence it will get through that crystal. Thus, by reasoning, we infer that the interposition of a third plate of tourmaline will in part abolish the darkness produced by the perpindicular crossing of the other two plates. I have not a third plate of tourmaline ; but the talc or mica which you employ in your stoves is a more convenient substance, which acts in the same way. Between the crossed tourmalines I introduce a film of this crystal. You see the edge of the film slowly descending, and as it descends between the tourmalines, light takes the place of darkness. The darkness, in fact, secmed scraped away as if it were something material. This effect has been called-and improperly called-depoiarization.

\section{LECTURE IV.}

Chromatic Phenomena produced by Crystals on Polarized Light: 'The Nicol Prisin : Polarizer and Analyzer: Action of thick and thin Plates of Selenite Colers dependen: on Thickness: Resolution of Polarized Beam into two others by the Selenite: Une of them more retarded than the other: Kecompounding of the two Systems of IVaves by the Analyzer: Interference thus rendered possible: Consequent Production of Culors: Action of Bodies Mechanicaliy strained or pressed: Action of Sunorous Vibrations : Action of Glass strained or pressed by Heat: Circular Polarization: Chromatic Phenomena produced by Quartz: The Magnetization of Light: Rings surrour:ding the Axes of Crystals : Biaxal and Uniaxal Crystals: Grasp of the Undulatory Theory.

We now stand upon the threshold of a new and splendid optical domain. We have to examine, this evening, the chromatic phenomena produced by the action ot crystals, and double-refracting bodies gene:ally, upon polarized light. For a long time investigators were compelled to empioy plates of touriualine for this purpose. and the progress they made with so defective a means of inquiry is astonishing. But these men had their hearts in their work. and were on this account enabled to extract great results from sniall instrumen. tal appliances. But we have better apparatus now. You have seen the two beams emergent from Iceland spar, and have proved them to be polarized. If we could abolish 
one of these beams, we might employ the other for experiments on polarized light.

These beams, as you know, are refracted differently, and from this we are able to infer that under some circumstances the one may be totally reflected, and the other not. An optician, named Nicol, cut a crystal of Iceland spar in two in a certain direction. He poilshed the severed urfaces, and reunited them by Canada balsam, the surface of union being so inclined to the beam traversing the spar that the ordinary ray, which is the most hir.lly refracted, was totally reflected by the balsam, while the extraordinary ray was permitted to pass on. The invention of the Nicol prism was a great step in practical optics, and quite recently such prisms have been constructed of a size which enables audiences like the present to witness the chromatic phenomena of polarized light to a degree altogether unattainable a short time ago. The two prisins here before you belong to my excellent friend, Mr. William Spottiswoode, and they were manufactured by $\mathrm{Mr}$. Ladd. I have with me another pair of very noble prisms, still larger than these, manufactured for me by Mr. Browning, who has gained so high and well-merited a reputation in the construction of spectroscopes.

These two Nicol prisms play the same part as the crystals of tourmaline. Placed with their directions of vibration parallel, the light passes through both. When these directions are crossed, the light is quenched. Introducing a film of mica between the prisms, the light is in part restored. But notice, when the film of mica is thin, you have sometimes not only light, but colored light. Our work for some time to come will be the examination of these colors. With this view. I will take a representative crystal, one easily dealt with; the crystal gypsum, or selenite, which is crystallized sulphate of lime. Between the crossed Nicols I place a thick plate of this crystal; like the mica, it restores the light, but it produce no color. With my penknife I take a thin splinter from this crystal and place it between the prism!: its image on the screen glows with the richest colors. Turning the prism in front, these colors gradually fade, disappear, but by continuing the rotation until the vibrating sections of the prisms are parallel, vivid colors again appear, but these colors are complementary to the former ones.

Some patches of the splinter appear of one color, some of another. These differences ar: due to the different thicknesses of the. film. If the thickness be uniform, the color is uniform. Here, for instance, is a stellar shape, every lozenge of the star leing a film of gipsum of uniform thickness. Each lozenge, you observe, shows a brilliant uniform color. It is easy, by shaping our films so as to represent flowers or other objects, to exhibit such objects in colors unattainable by art. Here, for example, is a specimen of heart's-ease, the colors of which you might safely defy the artist to reproduce. By turning the front Nicol ninety degrees round, we pass through a colorless phase to a series of colors complementary to the former cos. Here, for example, is a rose tree with red flowers and green leaves; turning the prism ninety degrees round, we obtain a green flower and red leaves. All these wonderful chromatic effects have definite mechanical causes in the motions of the ether. The principle of interference, duly applied and interpreted, explains them all.

By this time you have learned that the word "light" may be used in two different senses; it may mean the impression made upon consciousness, or it may mean the physical agent which makes the impression. It is with the agent that we have to occupy ourselves at present. That agent is the motion of a substance which fills all space, and surrounds the atoms and molecules of bodies. To this interstellar and interatomic medium definite mechanical properties are ascribed, and we deal with it as a body possessed of these $p$ operties. In meciranies we have the composition and resolution of forces, and of motions, extending to the composition and resolu:ion of vibrations. We treat the luminiferous ether on mechanical principles, and from the composition, resolution, and interference of its vibrations, we deduc: all the phenomena displayed by crystals in polarized light.

Let us take, as an example, the srystal of tourmaline, with which we are now so famil. iar. Let a vibration cross this erysta ablique to its axis ; we have seen by exf eriment tuat a portion of the light will pa:; throurb. How much, we determine in this way: Draw a straight line representing the intensity of the vibration before it reaches the tourmaline, and from the two ends of this line draw two perpendiculars to the axis of the crystal; the distance between the feet of these two perpendiculars will represent the intensity of the transmitted vibration.

Follow me now while I endeavor to make clear to you what occurs when a tilm of gypsum is placed between the Nicul prisms. liut, at the outset, let us esiablish still further the analogy between the action of the prisms and that of two plates of tourmaline. The plates are now crussed, and you see that by turning the film round, it muy be placed in a position where $\mathrm{i}^{\mathrm{r}}$ has no power to abolish the darkness. Why is this? The answer is that in the gypsum there are two directions, at right angles to each other, which the waves of light are constrained to follow. :ind that now one of these directions is paiallel to one of the axes of the tourmaline, and the other parallel to the other axis. When this is the case, the film exercises no sensible action upon the light. But now I turn the film so as to render its direction of vibration oblique to the axes; then you see it has the power, 
Semonstrate in ine last lecture, of restoring the light.

Let us now mount our Nicol prisms and cross them as we crossed the tourmalines. Introducing our film of gypsum between them, you notice that in one particular position the film has no power whatever over the field of view. But, when the film is turned a little way round, the light passes. We have now to understand the mechanism by which this is effected.

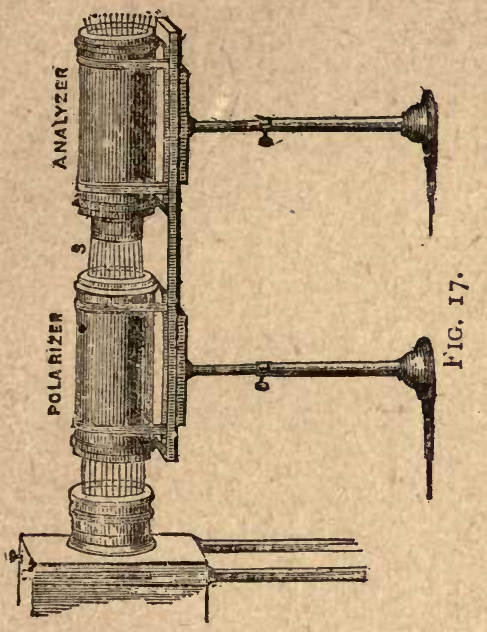

Firstly, then, we have this first prism which receives the light emergent from the electric tamp, and which is called the polarizer. Then we have the $p$ ate of grpsum, placed at $S$ (Fig. 17), and then the prism in front, which is called the analyzer. On its emergence from the first prism, the light is polarized; and in the particular case now before us, its vibrations are executed in an horizontal plane. The two directions of vibration of : he gypsum, placed at $\mathrm{S}$, are now oblique to the horizon. Draw a rectangular cross upon paper to represent the two directions of vibration within the gypsum. Draw an oblique line to represent the intensity of the vibration when it reaches the gvpsum. Let fall from the two ends of this line two perpendiculars on each of the arms of the cross; then the distances between the feet of these perpendiculars represent the intensities of two rectangular vibrations which are the equivalents of the first single vibration. Thus the polarized ray, when it enters the gypsum, is resolved into two others, vibrating at right angles to each other.

Now, in one of those directions of vibrition the ether is more sluggish than in the other; and, as a consequence, the waves that follow this direction are more retarded than the others. The waves of both systems, in fact, are shorlened when they enter the gypsum, but the one system is more shortened than the other. You can readily imagine that in this way the one system of waves may get half a wave-length, or indeed any number of half wave-lengths, in advance of the other. The possibility of interference here flashes upon the mind. A little consideration, however, renders it evident that, as long as the vibrations are executed at right angles to each other, they cannot quench each other, no matter what the retardation may be. This brings us at once to the part played by the analyzer. Its sole function is to recompound the two vibrations emergent from the gypsum. It reduces them to a single plane, where, if one of them be retarded by the proper amount, extinction can occur. But here, as in the case of thin films, the different lengths of the waves of light come into play. Red will require a greater thickness to produce the retardation necessary for extinction than blue; consequently, when the longer waves have been withdrawn by interference, the shorter ones remain and confer their colurs on the film of gypsum. Conversely, when the shorter waves have been withdrawn, the thickness is such that the longer waves remain. An elementary consideration suffices to show that, when the directions of vibration of prisms and gypsum enclose an angle of forty-five degrees, the colors are at their maximum brilliancy. When the film is I urned from this direction, the colors gradually face, until, at the point where the direc. tions are parallel, they disappear altogether.

A knowledge of these phenomena $\because$; best obtaired by means of a model of wood or pasteboard representing the plate of gypsum, its planes of vibration, and also those of the polarizer and analyzer. On these planes the waves may be drawn, showing the resolution of the first polarized ray into two others, and then the reduction of the two vibrations to a common plane. Following out 1igidly the inte:action of the two systems of waves, we are taught by such a model that $a^{1} l$ the phenomena of color, obtained when the planes of vibration of the two Nicols are parallel, are displaced by the complementary phenomena when the Nicols are perpendicular to each other.

In considering the next point, for the sake of simplicity, we will operate with monochromatic light-with red light, for example. Supposing that a certain thickness of the gypsum produces a retardation of half a wavelength, twice this thickness will produce a retardation of two half wave-lengths; three times this thickness a retardation of three half wave-lengths, and so on. Now, when the Nicols are parallel, the retardation of half a wave-length, cr of any odd number $s f$ half wave-leugths, produces extinction: at all thicknesses, on the other !and, which correspond to a retardation of an even number of lialf wave-lengths, the two beams support each other, when they are brought to a common plane by the analyzer. Supposing, then, 
that we take a plate of a wedge-form, which grows gradually thicker from edge to back, we ought to expect in red light a series of recurrent bands of light and darkness; the dark bands occurring at thicknesses which produce retardations of one, three, five, etc., half wave-lengths, while the light bands occur between the dark ones. Experiment proves the wedge-shaped crystal to show these bands; but they are far better shown by this circular film, which is so worked as to be thinnest at the centre, gradually increasing in thickness from the centre outwards. These splendid rings of light and darkness are thus produced.

When, instead of employing red light, we employ blue, the rings are also seen; but. as they occur at thinner portions of the film, they are smaller than the rings obtained with the red light. The consequence of employing zohite light may now be inferred: inasmuch as the red and the blue fall in different places, we have iris-colored rings produced by the white light.

Some of the c'romatic effects of irregular crystallization are beautiful in the extreme. Could I introduce between our Nicols a pane of glass covered by those frost-ferns which the cold weather renders now so frequent, rich colors would be the result. The beautiful effects of irregular crystallization on glass plates, now presented to you, illustrate what you might expect from the trosied windowpane. And not only do crystalline bodies act thus upon light, but almost all bodies that possess a definite structure do the same. As a general rule, organic bodies act in this way; for their architecture implies an arrangement of the ether which involves double refraction. A film of horn, or the section of a shell, for example, yields very beautiful colors in polarized light. In a tree, the ether certainly possesses different degrees of elasticity along and across the fibre; and, were wood transparent, this peculiarity of molecular structure would infallibly reveal itself by chromatic phenomena like those that you have seen. But net only do todies built permanently by Nature behave in this way, but it is possible, as shown by Brewster, to confer, by strain or by pressure, a temporary double-refracting structure upon non-crystalline bodies, such as common glass.

When I place this bar of wood across my knee and seek to break it, what is the mechanical condition of the bar? It bends, and its convex surface is strained longitudinally; its concave surface, that next my knee, is longitudinally pressed. Both in the strained portion and in the pressed portion the ether is thrown into a condition which would rend $r$ the wood, were it transparent, double-refracting. Let us repeat the experiment with a bar of glass. Between the crossed Nicols I introduce such a bar. By the dim residue of light lingering upon the screen, you see the image of the glass, but it has no effect upon the light. I simply bend the gla:s bar with my finger and thumb, keeping its length oblique to the directions of vibration in the Nicols. Instantly light flashes out upon the screen. The two sides of the bar are iliuminated, the edres most, for here the strain and pressure are greatest. In passing from strain to pressure, we cross a portion of the glass where neither is exerted. This is the so-called neutral axis of the bar of glass, and along it you see a dark band, indicating that the glass along this axis exercises no. ction upon the light. By employ. ing the force of a press, instead of the force of my finger and thumb, the brilliancy of the light is greatly augmented.

Again, I have here a square of glass which can be inserted into a press of another kind. Introducing the square between the prisms, its neutrality is declared; but it can hardly be held sufficiently loose.y to prevent its action from manifesting itself. Already, though the pressure is infinitesimal, you see spots of light at the points where the press is in contact with the glass. I now turn this screw. Instantly the image of the souare of glass flashes out upon the screen. You see luminous spaces separated from each other by dark bands. Every pair of adjacent luminous spaces is in opposite mechanical conditions. On one side of the dark band we have strain, on the other side pressure: while the dark band marks the neutral axis between both. I now tighten the vise, and you see color; tighten still more, and tha colors appear as rich as those presented by crystals. Releasing the vise, the colors suddenly vanish; tightening suddenly, they reappear. From the colors of a soap-bubble Newton was able to infer the thickness of the bubble, thus uniting by the bond of thought apparently incongruous things. From the colors here presented to you, the magnitude of the pressure employed might be inferred. Indeed, the late M. Wertheim, of Paris, invented an instrument for the determination of strains and pressures by the colors of polarized light, which exceeded in accuracy all other instruments of the kind.

You know that bodies are expanded by heat and contracted by cold. If the heat be applied with perfect uniformity, no local strains or pressures come into play; but, if one portion of a solid be heated and others not, the expansion of the heated portion introduces strains and pressures which reveal themselves under the scrutiny of polarized light. When a square of common windowglass is placed between the Nicols, you see its dim outline, but it exerts no action on the polarized light. Held for a moment over the flame of a spirit-lamp, on reintroducing it between the Nicols, light flashes out upnn the screen. Here, as in the case of mechanical action, you have spaces of strain divided by neutral axes from spaces of pressure.

I.et us apply the heat more symmetrically. This small square of glass is perforated at 
the centre, and into the orifice a bit of copper wire is intıoduced. Placing the square between the prisms, and heating the copper, the heat passes by conducticn along the wire to the glass, throug' 1 which it spreads from the certre outwards. You see a dim cross bounding four luminous quadrants growing up and becoming gradually black by comparison with the adjacent brightness. And as, in the case of pressure, we produced colors, so here als 3 , by the proper application of heat, gorgeous chromatic effects may be produced, and they may be rendered permanent by first heating the glass sufficiently, and then coolingit, so that the chilled mass shall remain in a state of strain and pressure. Two or three examples will illustrate this point. The colors, you observe, are quite as rich as those obtained in the case of crystals.

And now we have to push these considerations to a final illustration. Polarized light may be turned to account in various ways as an analyzer of molecular condition. A strip of glass six feet long, two inches wide, and a quarter of an inch thick, is held at the centre between my finger and thumb. I sweep over one of its halves a wet woolen rag; you hear an acute sound, due to the vibrations of the glass. What is the condition of the glass while the sound is heard? This: its two halves lengthen and shorten in guick succession. Its two ends, therefore, are in a state of quick vibration; but at the centre the pulses from the two ends alternately meet and retreat. Between their opposing actions, the glass at the centre is kept motionless; but, on the other hand, it is alternately strained and compressed. The state of the giass may be illustrated by a row of spots of light, as the propagation of a sonorous pulse was illustrated in a former

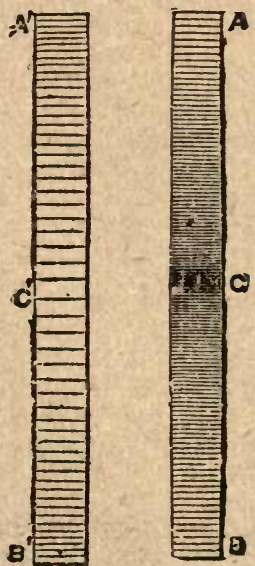

FIG. 18.

lecture. By a simple mechanical contrivance the spots are made to vibrate to and fro. The terminal dots have the largest amplitude of vibration, while those at the centre are alternately crowded together and torn asunder, the centre one not 1.2oving at all. The condition of the sounding strip of glass is here correct'y represented. In Fig. I8, $\boldsymbol{\Lambda}$ B represents the glass rectangle with its centre sondensed; while $\mathrm{A}^{\prime} \mathrm{B}^{\prime}$ represents the same rectangle with its centre rarefied.

If we introduce the glass $s s^{\prime}$ (Fig. I9) between the crossed Nicols, taking care to keep the strip oblique to the direction of vibration of the Nicols, anci sweep our wet rubber over the glass, this may $b=$ expected to occur : At every moment of compression the light will flash through ; at every moment of strain the light will also flash through; and these states of strain and pressure will follow each other so rapidiy that we may expect a permanent luminous impression to be made upon the eye. By pure reasoning, therefore, we reach the conclusion that the light will be revived whenever the glass is soundzd. That it is so, experiment testifies : at every sweep of the rubber, a fine luminous disk (o) flashes out upon the screen. The experiment may be varied in this way: Placing in fron of the polarizer a plate of unannealed glas;, you have those beautiful colored rings, interse ted by a black cross. Every sweep of the rubber not only abolishes the rings, but introduces complementary ones, the black cross being for the moment supplanted by a white one. This is a modification of an experiment which we owe to Biot. His apparatus, however, confined the observation of it to a single person at a time.

But we have to follow the ether still further. Suspended before you is a pendulum, which, when drawn aside and then liberated, oscillates to and fro. If when the pendulum is passing the middle point of its excursion, I impart a shock to it tending to drive it at right angles to its present course. what occurs? The two impulses compound themselves to a vibration oblique in direction to the former one, but the pendulum oscillates in a plane. But, if the rectangular hock be imjarted to the pendulum when it is at the limit of its swing, then the compounding of the two impulses causes the suspended ball to describe not a straight line, but an ellipse; and, if the shock be compstent of itself to produce a vibration of the same amplitude as the first one, the ellipse becomes a circle. But why do I dwell upon these things? Simply to make known to you the resemblance of these gross mechanical vibrations to the vibrations of light. I hold in my hand a plate of quartz cut from the crystal perpendicular to its axis. This crystal thus cut possesses the extraordinary power of twisting the plane of vibration of a polarized ray to an extent dependent on the thickness of the crystal. And the more refrangible the light the greater is the amount of twisting, so that, when white light is employed, its constituent colors are thus drawn 
asunder. Placing the quartz between the polatizer and the analyzer, you see this splendid color, and, turning the analyzer in front, from right to left, the other colors appear in succession. Specimens of quartz have been found which require the analyzer to be turned from left to right, to obtain the same succession of colors. Crystals of the first class are therefore called right-handed, and, of the second class, left handed crystais.

With profound sagacity, Fresne, to whose genius we mainly owe the expansion and final triumph of the undulatory theory of light, reproduced mentally the mechanism of these crystals, and showed their action to be due to the circumstance that, in them, the waves of ether so act upon each other as to produce the condition represented by our rotating pendulum. Instead of being plane polarized, the light in rock crystal is circularly polarized. Two such rays transmitted along the axis of the crystal, and rotating in although the mixture of blue and yellow pigments produces green, the mixture of biue and yellow lights produces white. Is enlarging our aperture, the two images pro. duced by the spar are caused to approach each other, and finally to overlap. The one is now a vivid yellow, the other a vivid blue, and you notice that where the colors are superposed we have a pure white. (See Fig. 20 , where $N$ is the nozzle of the lamp, $Q$ the quartz plate, $\mathrm{L}$ a lens, and $\mathrm{B}$ the birefracting spar. The two images overlap at $\mathrm{O}$, and produce white by their mixture.)

This brings us to a point of our inquiries which, though not capable of brilliant illustration, is nevertheless so likely to affect profoundly the future course of scientific thought that I am unwilling to pass it over without reference. I refer to the experiment which Faraday, its discoverer, called the magnetization of light. The arrangement for thi. celebrated experiment is now before you.

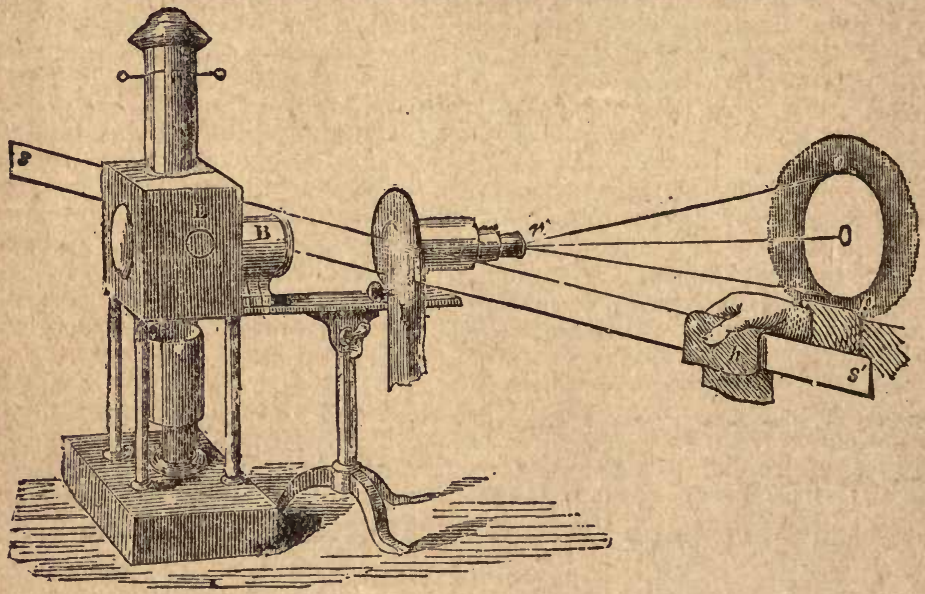

Fig. 19.

opposite directions, when brou $\cong$ hi to inter- We have first our electric lamp, then a Nicot ference by the analyzer, are demonstrably competent to produce the observed phenomena.

I now abandon the analyzer, and put in its place the piece of Iceland spar with which we have already illustrated double refraction. The two imagres of the carbon-points are now before you. Introducing a plate of quart $z$ between the polarizi.r and the spar, the two images glow with complementary colors. Employing the image of an aperture instead of that of the carbon-points, we have two complementary colored circles. As the analyzer is caused to rotate, the colors pass through various changes; but they are always complementary to each other. If the one be red, the other will be green; if the one be yellow, the other will be blue. Here prism, to polarize the beam emergent frotr. the lamp; then an electro-magnet, then a second Nicol prism, and finally our screen. At the present moment the prisms are crossed, and the screen is dark. I place from pole to pole of the electro-magnet a cylinder of a peculiar kind of glass, first made by Faraday, and called Faraday's heavy glass. Through this glass the bzam from the polarizer now passes, being intercepted by the Nicol in front. I now excite the magnet, and instantly light appears upon the screen. On examination, we find that, by the action of the magnet upon the ether contained within the heavy glass, the plane or vibration is caused to rotate, thus enabling the light to get through the analyzer.

The two classes into which quartz-crystals we have it in our power to demonstrate afresh $\mid$ are divided have been alreaciy mentione.? a statement made in a former lecture, that, I In my hand I hold a compound piate, on:- 
haif of it taken from a right-handed and the other from a left-handed crystal. Placing the plate in front of the polarizer, we turn one of the Nicols until the two halves of the plate show a common puce color. This yields an exceedingly sensitive means of rendering the action of a magzet upon light pisible. By turning either the polarizer or

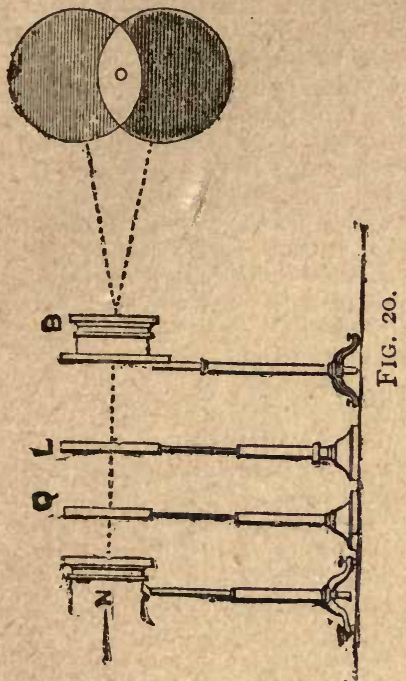

the analyzer through the smallest angle, tne uniformity of the color disappears, and the two halves of the quartz show different colors. The magnet also produces this effect. The puce-colored circle is now befcre you on the screen. (See Fig. 2I for the arrangement of the experiment. $\mathrm{N}$ is : he nozzle of the lamp, $H$ the first Nico!, $Q$ the biquartz plate, $L$ a lens, $\mathrm{M}$ the electro-magnet, and $\mathrm{P}$ the second Nicol.) Exciting the magnet, one half of the image becomes suddenly red, the other half green. Interrupting tire current, the two colors fade away, and the primitive puce is restored. The action, moreover, depends upon the polarity of the magnet, or, in other words, on the direction of the current which surrounds the magnet. Reversing the current, the red and green reappear, but they have changed places. The red was formerly to the right, and the green to the left ; the green is now to the right, and the red to the left. With the most exquisite ingenuity, Faraday analyzed all those actions a..d stated their laws. This experiment, however, long remained rather as a scientific curiosity than as a fruitful germ. That it would bear fruit of the highest importance, Faraday felt profoundly convinced, and recent researches are on the way to verify his conviction.

A few words more are necessary to complete our knowledge of the wonderful interaction between ponderable molecules and the ether interfused among them. Symmetry of molecular arrangement implies symmetry on the part of the ether; atomic dissymmetry, on the other hand, involves the dissymmetry of the ether, and, as a consequence, double refraction. In a certain class of crystals the structure is homogeneous, and such crystals produce no double refraction. In certain

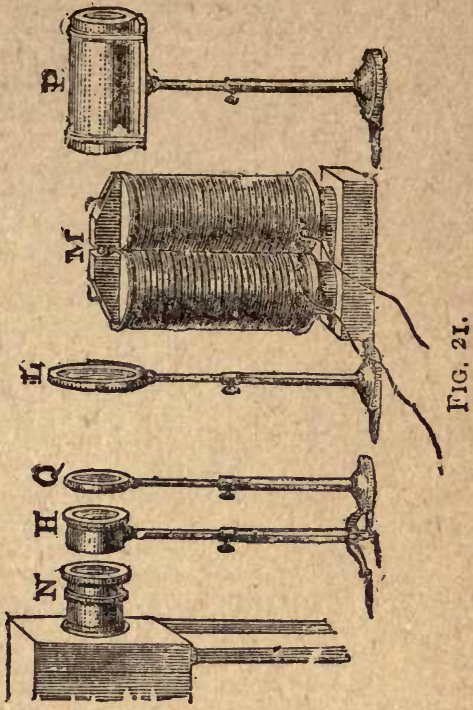

other crystals the mole dles are ranged symmetrically around ? ertain line, and not around others. A'sug the former, therefore, the ray is undiviced, while along all the others we have double refraction. Ice is a familiar example; it is built with perfect symmetry around the perpendiculars to the planes of freezing, and a ray sent through ice in this direction is not doubly refracted : whereas, in all other directions, it is. Iceland spar is another example of the same kind : its molecules are built symmetrically round the line uniting the two blunt angles of the rhomb. In this direction a ray suffers no double refraction, in all others it does. This direction of dorble refraction is called the optic axis of the crystal.

Hence, if a plate be cut from a crystal of Iceland spar perpendicular to the ax:s, a." rays sent across this plate in the dirction $c$ the axis will produce but cne image. $\mathrm{Bu}^{*}$ the moment we deviate from the parallelistm with the axis, double refraction sets in. If, therefore, $a$ beam that has been rendered conical by a converging lens be sent through the spar so that the central ray of the cone passes along the axis, this ray only will escape double refraction. Each of the others will be divided into an ordinary and extraor. dinary ray, the one moving more slowly through the crystal than the other; the one, therefore, retarded with reference to the other. Here, then, we have the conditions 
for interference, when the waves are reduce 1 by the analyzer to a common plane. $A$ highly beautiful and important source of chromatic phenomena is thus revealed. Placing the piate of spar between the crossed prisms, we have upon the screen a beautiful system of iris rings surrounding the end of the optic axis, the circular bands of color being intersected by a black cross. The arms nf this cross are parallel to the two directions of vibration in the polarizer and analyzer. It is easy to see that those rays whose planes of vibration within the spar coincide with the plane of vibration of either prism, cannot get through both. This complete interception produces the arms of the cross. With mono-chromatic light the rings would be simply bright and black-the bright rings occurring at those thicknesses of thic spar which cause the rays to conspire ; the black rings at those thicknesses which cause them to quench each other. Here, however, as elsewhere, the different lengths of the light-waves give rise to iris-colors when white light is employed.

Besides the regular crystals which produce double refraction in no direction, and the uniaxal crystals which produce it in all directions but one, Brewster discovercd that in a large class of crystals there are two directions in which double refraction does not take place. These are called biaxal crystals. When plates of these crystals, suitably cut, are placcd betwee ${ }_{2}^{\prime}$ the polarizer and analyzer, the axes are seen su -ounded, not by circles, but by curves of anc her order and of a per-

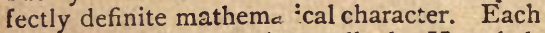
band, as proved experimentally by Herschel, forms a lemniscatu; bui the experimental proof was here, as in numberless other cases, preceded by the deduction which showed that. according to the undulatory theory, the bands must possess this special character.

$I$ have taken this somewhat wide range over polarization itselt and over the phenomena exhibited by crystals in polarized light, in order to give you some notion of the firmness and completeness of the theory which grasps them all. Starting from the single assumption of transverse undulations, we first of all determine the wave-lengths, and find all the phenomena of color dependent on this element. The wave-lengths may be determined in many independent ways, and, when the lengths so determined are compared together, the strictest agreement is found to exist between them. We follow the ether into the most complicated cases of interaction between it and ordinary matter, "the theory is equal to them all. It makes not a single new hypothesis ; but out of its original stock of principles it cduces the counterparts of all that observation shows. It accounts for, explains, simplifies the most entangled cases; corrects known laws and facts; predicts an 1 discloses unknown ones; becomes the guide of its forncr teacher Observation; and, enlightened by mechanical conceptions, acquires an insight which pierces through shape and color to force and cause. "*

But, while I have thus endeavored to illustrate before you the power of the undulatory theory as a solver of all the difficulties of optics, do I theréfore wish you to close your eyes to any evidence that may arise against it? By no means. You may urge, and justly urge, that a hundred years ago another theory was held by the most eminent men, and that, as the theory then held had to yield, the undulatory theory may have to yield also. This is perfectly logical; but let us understand the precise value of the $\arg 1$. ment. In similar language a person in the time of Newton, or cven in our time, might reason thus: "Hipparchus and I'tolemy, and numbers of great men after them, believed that the earth was the centre of the solar system. But this deep-set theoretic notion had to give way, and the theory of gravitation may, in its turn, rave to give way also." This is just as logical as the first argument. Wherein consists the strength of the theory of gravitation? Solely in its competence to account for all the phenomena of the solar system. Wherein consists the strength of the theory of undulation? Solely in its competence to disentangle and explain phetnomena a hundred-fold more complex than those of the solar system. Be as skeptical. if you like, regarding the undulatory theory; but if your skepticism be philosophical, it will wrap the theory of gravitation in the same or greater doubt. $\nmid$

\section{LECTURE V.}

Range of vision incommensurate with Range of Radiation: The Ultri-Violet Rays: Fluorescence: Rendering Invisible Rays visible: Vision not the only Sense appealed to by the Solar and Electric Beam : Heat of Beam: Combustion by 'l'otal Beam at the Foci of Mirrors and Lenses: Coinbustion through Ice-Lens: Ignition of Diamond: Search for the Kays here effective: Sir William Herschel's Discovery of Dark Solar Rays: Invisible Rays the Basis of the Visible: Detachment by a Ray-Filter of the Invisible Rays from the Visible: Combustion at Dark Foci: Conversion of Heat-Rays into Light-Rays : Calorescence : Part played in Nature by Dark Rays: Identity of Light and Radiant Heat: Invisible Images: Reflection, Refraction, Plane Polarization, Depolarization. Circular Polarization, Double Refraction, and Magnetization of Radiant Heat.

THE first question that we have to consider to-night is this: Is the eye, as an organ of vision, commensurate with the whole range of solar radiation-is it capable of receiving visual impressions from all the rays emitted by the sun? The answer is negative. If we allowed ourselves to accept for a

\section{* Whewell.}

+ The only essay known to me on t'se Undulatory Theory, from the pen of an American writer, is an excellent one by President Barnard, published in the Smithsonian Report for 1862 . 
moment that notion of gradual growth, amelioration, and ascension, implied by the term crolution, we might fairly conclude that there are stores of visua! impressions awaiting man far greater than those of which he is now in possession. For example, here beyond the extreme violet of the spectrum there is a vast efflux of rays which are totaily useless as regards our present powers of vision. But these ultra-violet waves, though incoinpetent to awaken the optic nerve, can so shake the molecules of certain compound substances as to effect their decomposition. The grandest example of the chemical action of light, with which my frierd Dr. Draper has so indissolubly associated his name, is that of the decomposition of carbonic acid in the leaves of plants. All photography is founded on such actions. There are substances on which the ultra-violet waves exert a special decomposing power; and, by permitting the invisible spectrum to fall upon surfaces prepared with such substances, we reveal both the existence and the extent of the ultraviolet spectrum.

This mode of exhibiting the action of the ultra-violet rays has been long known; indeed, Thomas Young photographed the ultraviolet rings of Newton. We have now to demonstrate their presence in another way. As a general rule, bodies transmit light or absorb it, but there is a third case in which the light falling upon the body is neither transmitted nor absorbed, but converted into light of another kind. Professor Stokes, the occupant of the Chair of Newton in the University of Cambridge, one of those original workers who, though not widely known beyond scientific circles, realiy constitute the core of science, has demonstrated this change of one kind of light into another, and has pushed his experiments so far as to render the invisible rays visible.

A long list of substances examined by Stokes when excited by the invisible ultraviolet waves, have been proved to emit light. You know the rate of vibration corresponding to the extreme violet of the spectrum; you are aware that, to produce the impression of this color, the retina is struck 789 millions of millions of times in a second. At this point, the retina ceases to be useful as an organ of vision, for, though struck by waves of more rapid recurr nce, they are incompetent to awaken the sensation of light. But, when such non-visual waves are caused to impinge upon the molecules of certain substanceson those of sulphate of quinine, for example -they compel those molecules, or their constituent atoms, to vibrate; and the peculiarity is, that the vibrations thus set up are of slower period than those of the exciting waves. By this lowering of tre rate of vibration through the intermediation of the sulphate of quinine, the invisible rays are renclered visible. Here we have our spectrum, and beyond the violet I place this prepared paper. The spectrum is immediately elongateu by the peneration of a new light beyond the extreme violet. President Morton has recently succeeded in discovering a substance of great sensibility which he has named Thallene, and he lias been good enough to favor me with some paper saturated with is solution of this substance. It causes a very siriking enlongation of the spectrum, the new light generated being of peculiar brilliancy. To this change of the rays from a higher to a lower refrangibility, Stokes has given the name of Fluorescence.

By means of a deeply-colored violet glass, we cut off almost the whole of the liglit of our electric beam ; but this glass is peculiarly transparent to the violet and ultra-violet rays. The violet beam now crosses a large jar filled with water. Into it I pour a solution of sulphate of quinine: opaque clouds, to all appearance, instantly tumble downwards. But these are not clouds : there is nothing precipitated here: the observed action is a action of molecule's, not of particles. The medium before jou is not a turbid medium, for, when you look through it at a luminious surface, it is perfectly clear. If we paint upon a piece of paper a flower or a bouquet with the sulphate of quinine, and expose it to the full beam, scarcely anything is seen. But on interposing the violet glass, the design instantly flashes forth in strong contrast with the deep surrounding violet. Here is such a design prepared for me by President Morton with his thallene: placed in the violet light it exhijits a peculiarly vivid and beautiful fluorescence. From the experiments of Dr. Bence Jones, it would seem that there is some substance in the human body resembling the sulphate of quinine, which causes all the tissues of the body to be more or less fluorescent. The crystalline lens of the eye exhibits the effect in a very striking manner. When I plunge my eye into this violet beam, I am conscious of a whitish-blue shimmer filling the space before me. This is caused by fluorescent light generated in the eye itself; looked at from with. out, the crystalline lens at the same time gleams vividly.

But the waves from our incandescent carbon-points appeal to another sanse than that of vision. They not only produce light as a sensation; they also produce heat. The magnified image of the carbon-points is now upons the screen, and with a suitable instrument the heating power of that instrument might be demonstrated. Here, however, the heat is spread over too large an area to be intense. By pushing out the lens and causing a movable screen to approach our lamp, the imige becomes smaller and smaller: the rays be. come more concentrated, until finally they are able to pierce black paper with a burning ring. Rendering the bean parallel, and receiving it upon a concave mirror, the rays are 
brought to a focus; and paper placed at the focus is caused to smoke and burn. This may be done by our common camera with its lens, and by a concave mirror of very moderate pow $r$ r.

We wi!l now adopt stronger measures with the radiation from the electric lamp. In this camera of blackened tin is placed a lamp, in all particulars similar to those already employed. But, instead of gathering up the rays from a carbon-point by a condensing lens placed in front of them, we gather them up by a co:scave mirror, silvered in front, and placed behind the carbons. By this mirror we can cause the rays to issue through the orifice in front, either parallel or convergent. They are now parallel, and therefore to a certain extent diffused. We place a convex lens in the path of the beam; the light is converged to a focus, and at that focus you $s=e$ that paper is not only pierced and a burning ring formed, but that it is instantly set ablaze. Many metals may be burned up in the same way. In our first lecture the combustibility of zinc was mentioned. Placing a strip of sheet-zinc at this focus, it is instantly ignited and burns with its characteristic purple flame. (In the annexed fizure $m m^{\prime}$ represents the concave mirror, $\mathrm{L}$ the

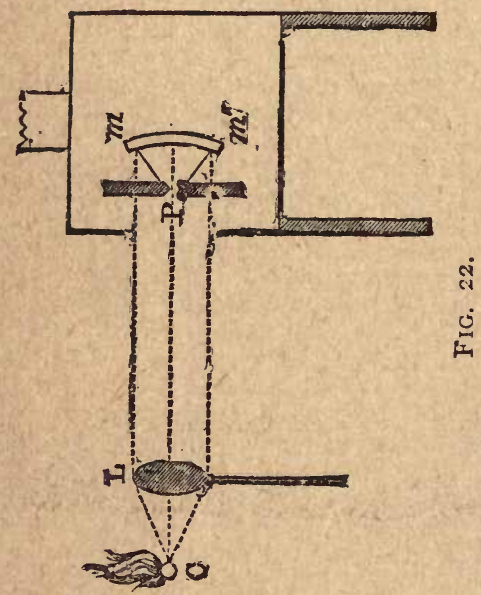

lens, at the focus $\mathrm{C}$ of which combustion is effected). Dr. Scoresby succeeded in exploding gunpowder by the sun's rays converged by large lenses of ice; the same effect may be produced with a small lens, and with a terrestrial source of heat. In an iron mould we have fashioned this leautiful lens of transparent ice. At the fucus of the lens I place a bit of black paper, with a little guncotton folded up within it. The paper ignites and the cotton explodes. Strange, is it not, that the beam should possess such heating power after having passed through so cold a substance?

In this experiment, you observe that, before the beam reaches the ice-lens, it has passed through a glass cell containing water. The beam is thus sifted of constituents, which, it permitted to fall upon the lens, would injure its surface, and blur the focus. And this leads me to say an anticipatory word regarding transparency. In our first lecture we entered fully into the production of colors by absorption, and we spoke repeatedly of the quenching of the rays of light. Did this mean that the light was altogether annihilated? By no means. It was simply so lowered in refrangibility as to escape the visual range. It was converted into heat. Our red ribbon in the green of the spectrum quenched the green, but if suitably examined its temcerature would have been found raised. Our green ribbon in the red of the spectrum quenched the red, but its temperature at the same time was augmented to a degree exactly equivalent to the light extinguished. Our black ribbon, when passed through the spectrum, was found competent to quench all its colors; but at every stage of its progress an amount of heat was generated in the ribbon exactly equivalent to the light lost. It is only when absorption takes place that heat is thus produced; and heat is always a result of ab_orption.

Examine this water, then, in front of the lamp, after the beam has passed a little time through it: it is sensibly warm, and, if permitted to remain there long enough, it may be made to boil. This is due to the absorption by the water of a portion of the electric beam. But a certain portion passes through unabsorbed, and does not at all contribute to the heating of the water. Now, ice is also transparent to the latter portion, and therefore is not melted by it ; hence, by employing this particular portion of the beam, we are able to keep our lens intact, and to produce by means of it a sharply-defined focus. Placed at that focus, black paper instantly burns, because the black paper absorbs the light which had passed through the ice-lens without absorption. In a subsequent lecture, we shall endeavor to penetrate further into the physical meaning of these and other similar actions. I may add to these illustrations of heating power, the ignition cf a diamond in oxygen, by the concentrated beam of the electric lamp. The diamond, surrounded by a hood of platinum to lessen the chilling due to convection, is exposed at the focus. It is rapidly raised to a white heat, and when removed from the focus continues to glow like a star.

Placed in the path of the beam issuing from our lamp is a cell with glass sides containing a solution of alum. All the light of the bean passes through this solution. The bean is received on a powerfully converging mirror silvered in front, and is brought to a focus by the mirror. You can see the conical beam of reflected light tracking itself through the dust of the room. I place at the focus a scrap of white paper: it glows there with 
dazzling biightness, but it is not even charred. On removing the alum-cell, however, the paper instantly inflames. There must, therefore, be something in this beam besides its light. The light is not absorbed by the white paper, and therefore does not burn the paper; but there is something over and above the light whic! is absorbed and which provokes combustion. What is this something?

In the year rSoo Sir IVilliam IHerschel passed a thermomcter through the various colors of the solar spectrum, an 1 marked the rise of temperature corresponding to each colo:. Ile found the heating effect to augment from the violet to the red; he did not, however, stop at the red. but pushed his thermometer into the dark space beyond it. Ilere he found the temperature actually higher than in any part of the visible spectrum. By this important observation, he proved that the sun emitted dark heat-rays which are entirely unfit for the purposes of vision. The subject was subsequently taken up by Seebeck, Melloni, Miiller, and others, and within the last few years it has been found capable of unexpected cxpansions and applications. A methoul has bcen devised whereby the solar or electric beam can be so filtered as to detach from it and preserve intact this invisible ultr --red emission, while the visible and ultraviolet emissions are wholly iatercepted. We are thus enabled to operate at will upon the purely ultra-red waves.

In the heating of so.id bodies to incandescence this non-visual emission is the necessary basis of the visual. A platinum wire is stretched in front of the table, and through it an electric current flows. It is warmed by the current, and may be felt to be warm by the hand; it also emits waves of heat, but no l ght. Augmenting the strength of the current, the wire becomes hotter; it finally glows with a sober red light. At this point Dr. Draper many years ago began an interesting investigation. He employed a voltaic current to heat his platinum, and he studied by means of a prism the successive introduction of the colors of the spectrum. His first colnr, as here, was red; then came orange, then yellow, then green, and lastly all the shades of blue. Thus as the temperature of the platinum was gradually augmented, the at:ms were caused to vibrate more rapidly, shorter waves wer 3 thus produced, until finally he obtained the waves corresponding to the entire spectrum. As each successive color was introduced, the colors preceding it became more vivid. Now, the vividness, or intensity of light, like that of sound, depends, not upon the length of the wave, but on the amplitude of the vioration. Hence, as the red grew more intense as the more refrangible colors were introduced, we are forced to conclude that, side by side with the introduction of the shorter waves, we had an augmentation of the amplitude of the ionger ones.
These remarks apply, not only to the visible emission exanined by Dr. Draper, but to the invisible emission which preceded the appearance of any light. In the emiss.on from the white-hot platinum wire now before you the very waves exist with which we started, only their intensity has been increased a thousand-fold by the augmentation of temperature necessary to the production of this white light. I oth effects are bound together: in an incandescent solid, or in a molten solid, you cannot have the shorter waves without this intensification of the longer ones. A sun is possible only on these conditions; hence Sir IVilllam Herschel's discovery of the invisible ultra-red solar emission.

The invisiblc heat, emitted both by dark bedies and by luminous ones, flies through space with the velocity of light, and is cauled radiant heat. Now, radiant heat may bs made a subtle and powerful exploter of molecular condition, and of late years it has given a new significance to the art of chemical combination. Take, for exanıle, the air we breathe. It is a mixture of oxygen and nitrogen; and with regard to radiant heat it behaves like a vacuum, being incom. petent to absorb it in any sensibl degree. But permit the same two gases to unite chemically; without any augmentation of the quantity of matter, without altering the gaseous condition, without interfering in any way with the transparency of the $g$ as, the act of chemical uni $n$ is accompanied by an enormous diminuvion of its diathermancv, or perviousness to radiant heat. The reseaiches which established this result also proved the clementary gases generally to be highly transparent to radiant heat. This, again, led to the proof of the diathermancy of elementary liquids, like bromine, an 1 of solutions of the elements sulphur, pliosphorus, and iodine. A spectrum is now before you, and you notice that this transparent bisulphide of carbon has no effect upon the colors. Dropping into the liquid a few flakes of iodine, you see the middle of the spectrum cut away. By augmenting the quantity of iodine, we invade the entire spectrum, and finally cut it off altogether. Now, the iodine which proves itself thus hostile to the light is perfectly transparent to the ultra-red emission with which we have now to deal. It, therefore, is to be our ray-filter.

Placing the alum-cell again in front of the electric lamp, we assure ourselves, as before, of the utter inability of the concentrated light to fire white paper. By introducing a cell containing the solution of iodine, the light is entirely cut off. On removing the alum-cell, the paper at the dark focus is int tantly set cn fire. Black paper is more absorbent than white for these ultra-red rays; and the consequence is, that with it the suddenness and vigor of the combustion are atgmented. Zinc is burnt up at the same place, 
while magnesium rib̧bon bursts into vivid combustion $\Lambda$ sheet of platinized platinum placed at the focus is heated to whiteness. looked at through a prism, the white-hot platinum yields all the colors of the spectrum. Before impinging upon the platinum, the waves were of too slow recurrence to awaken vision; by the atoms of the platinum, these long and sluggish waves are in part broken up into shorter ones, being thus brought within the visual range. At the other end of the spectrum, Stokes, by the interposition of suitable substances, lowered the refrangijility so as to render the non-visual rays visual, and to this change he gave the name of Fituorescence. Here, by the intervention of the platinum, the refrangibility is raised, so as to render the non-visual visial, and to this change we give the name of Calores. cence.

At the perfectly invisible focus where these effects are produced, the air may be as cold as ice. Air, as already stated, does not absorb the radiant heat, and is therefcre not warmed by it. Place at the focus the most sensitive air-thermometer : it is not affected by the heat. Nothing couid more forcibly illustrate the isolation, if I may use the term, of the luminiferous ether from the air. The wave-motion of the one is heaped up, without sensible effect, upon the other. I may add that, with suitable precautions, the eye may be placed in a focus competent to heat platinum to vivid redness, without experiencing any damage, or the slightest sensation either of light or heat.

These ultra-red rays play a most important part in Nature. I remove the iodine filter, and concentrate the total beam. A test-tube containing water is placed at the focus : it immediately begins to sputter, and in a minute or two it boils. What boils it? Placing the alum solution in front of the lamp, the boiling instantly ceases. Now, the alum is pervious to all the luminous rays; hence it cannot bethese rays that caused the boiling. I now introduce the iodine, and remove the alum; vigorous ebullition immediately recommences. So that we here fix upon the invisible ultra-red rays the heating of the water. We are enabled now to understand the momentous part played by these rays in $\mathrm{Na}$ ture. It is to them that we owe the warming and the consequent evaporation of the tropical ocean; it is to them, therefore, that we owe our rains and snows. They are absorbed close to the surface of the ocean, and warm the superficial water while the luminous rays plunge to great depths without producing any sensible effect. Further, here is a large flask containing a freezing mixture. Tre aqueous vapor of the air has been condensed and frozen on the flask, which is now covered with a white fur. Introducing the alum-cell, we place the coating of hoar-frost at the inrensely luminous focus ; not a spicula of the frost is melted. Introducing the iodine-cell, and removing the alum, a broad space of the frozen coating is instantly removed. Hence we infer that the ice which feeds the Rhone, the Rhine, and cthel rivers which have glaciers for tieir sources, is released from its imprisonment upon the mountains by the invisible ultra-red rays of the sun.

The growth of science is organic. The end of to-day becomes to-morrow the means to a remoter end. Every new discovery is immediately made the basis of other discoveries, or of new methods of investigation. $\Lambda$ bout fifty years ago, Eirsted, of Copenhagen, discovered the deflection of a magnetic needle by an electric current; and Thomas Seebeck, of Berlin, discovered that electric currents might be derived from heat. Soon afterwards these discoveries were turned to account by Nobili and Melloni in the construction of an apparatus which has vastly augmented our knowledge of radiant heat. The instrument is here. It is called a thermoelectric pile; and it consists of thin bars of bismuth and antimony soldered together in pairs at their ends, but separated from each other elswhere. From the ends of this "pile" wires pass to a coil of covered wire, within and above which are suspended two magnetic needles joined to a rigid system, and carefully defended from currents of air. The heat, then, acting on the pile, produces an electric current; the current, passing through the coil, deflects the needles, and the magnitude of the deflection may be made a measure of the heat. The upper needle moves over a graduated dial far too small to be seen. It is now, however, strongly illuminated. Above it is a lens which, if permitted, would form an image of the needle and dial upon the ceiling, where, however, it could not be conveniently seen. The beam is therefore received upon a looking-glass, placed at the proper angle, which throws the image upon the screen. In this way the motions of this small needle may be made visible to you all.

The delicacy of this instrument is such that in a room like this it is exceedingly difficult to work with it. My assistant stands several feet off. I turn the pile towards him: the heat from his face, even at this distance, produces a deflection of $90^{\circ}$. I turn the instrument towards a distant wall, which I judge to be a little below the average temperature of the room. The needle descends and passes to the other side of zero, declaring by this negative deflection that the pile feels the chill of the wall. Possessed of this instrument, of our ray-filter, and of our large Nicol prisms, we are in a condition to investigate a subject of great philosophical interest, and which long engaged the attention of some of our foremost scientific workers, Forbes being the first successful one-the substantial identity of light and radiant heat.

That they are identical in all respects cannot of course be the case, for if they ws re 
they would act in the same manner upon all instruments, the eye included. 'I he identity meant is such as subsists between one color and another, causing them to behave alike is regards reflection, refraction, double refraction, and polarization. As regards reflection, we may cmploy the looking glass used in our first lecture. Jlarking any point in the track of the reflected beam, and cutting off the light by the iodine, on placing the pile at the marked point, the needle immediately starts aside. This $i$ is true for every position of the mirror. So that both for light and heat the same law of reflection holds good; for both of them also the angular velocity of the reflected beam is twice that of the reflecting mirror. Receiving the beam on a concave mirror, it is gathered up into a cone of reflected ight; markin the apex of the cone, and cutting off the light, a moment's exposure of the pile at the marked point produces a violent deflection of the needle. (See Fig. 23 , where $m m$ is the mirror, $\mathrm{P}$ the pile, and I the opaque solution.)

This beam of light now enters a rightangled prism and is reflected at the hypothenuse, in a direction perpendicular to its former one. The reflection here is total. Cuting off the light, we prove the reflection of the heat to be total aiso. The formation of

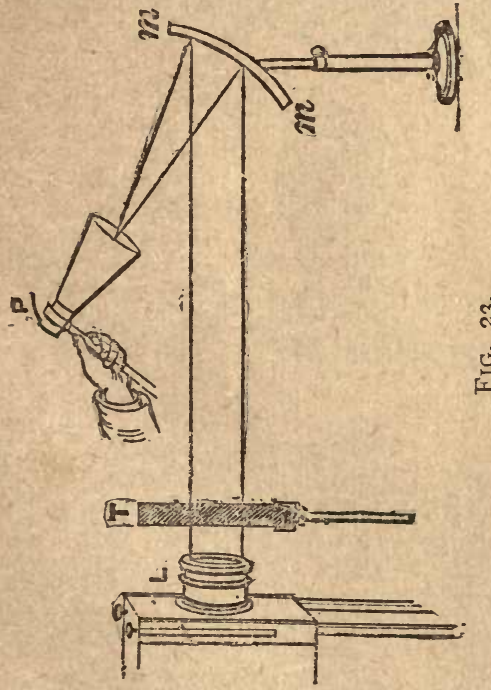

invisible images by lenses and mirrors may also be demonstrated. Concentrating the beam, and cuttin? off the light, a: the dark focus the carbon-points burn their images through a sheet of black paper. Placing a sheet of platinized platinum at the focus, when the concentration is strong an incandescent image of the points is immediately stamped upon the platinum.

And now for polarization and its attendant phenomena. Crossing our two Nicol prisms,
B, C, Fig. 24 , and placing ou pilc I) be. hind the analyzer, neither heat nor light reaches it; the needle remains undeflected. Introducing the iodine, the slightest turning of either prism causes the heat to pass, and to announce itself by the deflection of the needle. Like light, therefore, heat is polarized. Crossing the Nicols agcin, the heat is interccpted and
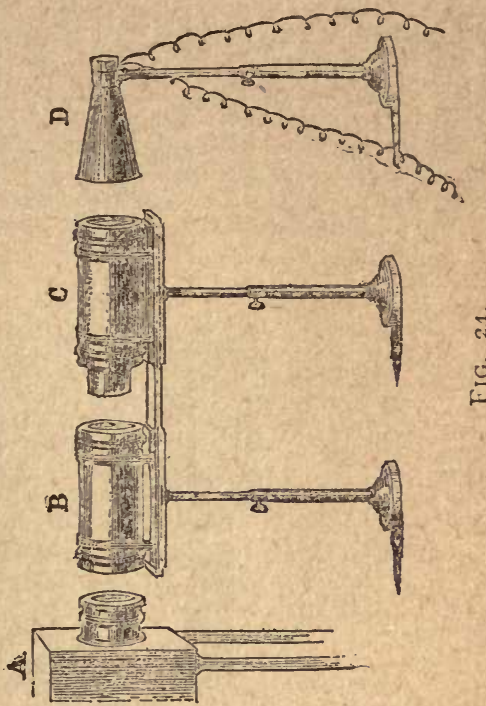

the reedle returns to zero. Plunging into the clark space between the prisms our plate of mica, the needle instantly starts off, showing that the mica acts upon the heat as it did: upon the light: we have in both cases the same resolution and recompounding of vibrations. Removing the mica, the needle falls to zero ; but, on introducing a plate of quartz between the prisms, the consequent deflection declares the circular polarization of the heat. For double refraction it is necessary that our images should not be too large and diluted: here are the two disks produced by the splitting of the beam in Iceland spar. Marking the positions of the disks. and cutting off the light, the pile finds in its places two heat-images. The needie row stands near $90^{\circ}$, and, on turning the spar, the deflection remains constant. Tran:ferring the pile to the other image, the deflection of $90^{\circ}$ is maintained; but on turning the spar the needle now falls to zero. The reason is manifest. Permitting the light to pass, we find the luminous disk at some distance from the pile. We are dealing, in fact, with the cxtraordinary bcam which rotates round the ordinary So that for i.eat as well as for light we have double refraction, and also an ordinary and extraordinary ray. (In the adjacent figure, which shows the experimental arrangement, $\mathrm{N}$ is the nozzle of 
the electric lamp, L a converging lens, $B$ the birefracting spar, and $\mathrm{P}$ the thermo-electric pile.)

If time permitted we might finish the series of demonstrations by magnetizing a ray of heat as we magnetizen a ray of light.

We have finally to determine the position and magnitude of the invisible radiation which produces these results. For this purpose we employ a particular form of the thermo-electric pile. Its face is a rectangle, which by movable side-pieces can be rendered as narrow as desirable. Throwing a concentrated spectrum upon a screen, by means of an endless screw, we move this. rectangular pile through the entire spectrum. Its surface is blackened so that it absorbs all the light incident upon it, converting it into a curve which exhibits the distribution of heat in our spectrum. It is represented in the adjacent figure. Beginning at the blue, the curve rises, at first very gradually; then, as it approaches the red more rapidly, the line $C D$ representing the strength of the extreme red radiation. Beyond the red it shoots upwards in a steep and massive peak to $B$, whence it falls, rapidly for a time, and afterwards gradual'y fading from the perception of the pile. 'This figure is the result of more than twelve careful series of measurements, for each of which the curve was constructed. On superposing all these curves, a satisfactory agreement was found to exist between them. So that it may safely be concluded that the areas of the dark and white spaces respectively represent the rela-

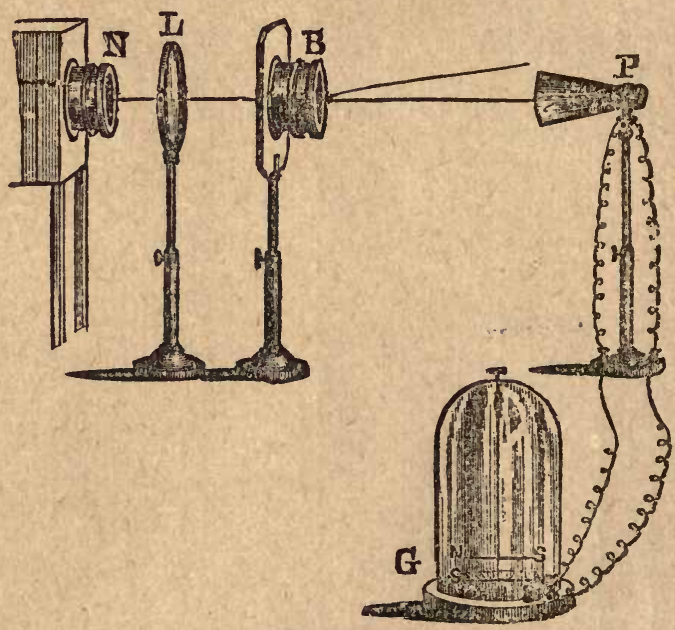

FIG. 25 .

heat, and thus enabling it to declare its power by the deflection of the magnetic needle.

When this instrument is brought to the violet end of the spectrum, the heat is found to be almost insensible. As the pile gradually moves from the violet towards the red, it encounters a gradually augmenting heat. The red itself possesses the highest heating power of all the colors of the spectrum. Fushing the pile into the dark space beyond the red, the heat rises suddenly in intensity, and, at some distance beyond the red, attains a maximum. From this point the heat falls somewhat more rapidly than it rose, and afterwards gradually fades away. Drawing. an horirontal line to represent the length of the spectrum, and erecting along it, at various points, perpendiculars proportional in length to the heat existing at those points, we obtain tive energies of the visible and invisible radiation. The one is 7.7 times the other.

But in verification, as already stated, consists the strength of science. Ditermining in the first place the total emission from the electric lamp; then by means of the iodine filter determining the ultra-red emission; the difference between both gives the luminous emission. In this way, it was found that the energy of the invisible emission is eight times that of the visible. No two methods could be more opposed to each other, and hardly any two results could better harmonize. I think, therefore, you may rely upon the accuracy of the distribution of heat here assigned to the prismatic spectrum of the electric light. There is nothing vague in the inode of investigation, nor doubtful in its conclusions. 


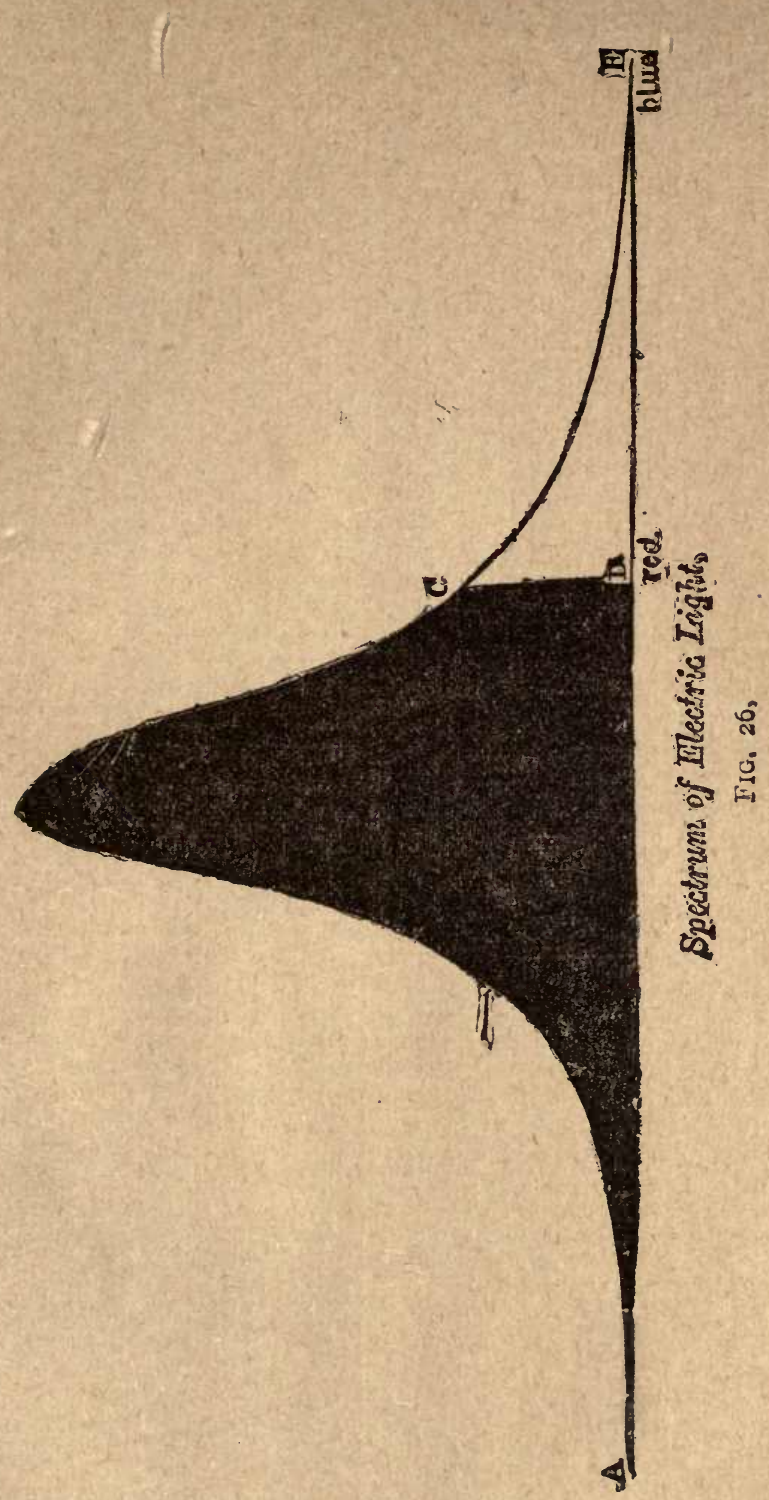

\section{LECTURE VI.}

Frizidiak of Spectrum Analysis: Solar Chemistry: Summary and Conclusions.

We have employed, as our source of light in these lectures, the ends of two rods of coke rendered incandescent by electricity. Coke is particularly suitable for this purpose, because it can bear intense heat without fus on or vaporization. It is also black, which helps the light; for, other circumstances being equal, as shown experimentally by Ba!- four Stewart, the blacker the body the brighter will be its light when incandescent. Still, refractory as carbon is, if we closely examine our voltaic arc, or stream of light between the carbon-points, we should find there incandescent carbon-vapor. We might also detach the light of this vapor from the more dazzling light of the solid points, and obtain its spectrum. This would be nat only les.s brilliant, but of a totally different character from the spectra that we have already seen. Instead of being an unbroken succession of colors from red to violet, the carbon-vapor 
would yield a few bands of color with spaces of darkness between them.

What is true of the carbon is true in a still more striking degree of the metals, the most refractory of which can be fused, boiled, and reduced to vapor by the electric current. From the incandescent vapor the light, as a general rule, flashes in groups of rays of definite degrees of refrangibility, spacez existing between group and group, which are unfilled by rays of any kind. But the contemplation of the facts will render this subject more intelligible than words can make it. Within the camera is now placed a cylinder of carbon hollowed out at the tr.p to receive a bit of metal; in the hollow is placed a frarment of the matal thallium, and now you see the are of incandescent thallium-rapor upon the screen. It is of a beautiful green color. What is the meaning of that green? IVc answer the question by subjecting the light to prismatic analysis. Here you have its spectrum, consisting of a single refracted band. Light of one degree of refrangibility, and that corresponding to green, is emitted by the thallium-vapor.

We will now remove the thallium and put a bit of silver in its place. The arc of silver is not to be distinguished from that of thallium; it is not only green, like the thalliumvapor, but the same shade cf green. Are they, then, alike? Prismatic analysis enables us to answer the question. It is perfectly impossible to confound the spectrum (f incandescent silver vapor with that of thallium. Here are two green bands instead of one. Adding to the silver in our camera a bit of thallium, we obtain the light of both metals, and you see that the green of the thallium lies midway between the two greens of the siiver. Hence this similarity of color.

But you cbserve another interesting fact. The thallium band is now far brighter than the silver bands ; indeed, the latter have wonderfully degencrated since the bit of thallium was put in. They are not at all so bright as they were at first, and for a reason worth knowing. It is the resistance offered to the passage of the electric current from carbon to carbon that calls forth the power of the current to produce heat. If the resistance were materially lessened, the heat wou!d be materially lessened; and, if all resistance were abolished, there would be no heat at all. Now, thallium is a much more fusible and vaporizable metal than silver; and its vapor facilitates the passage of the current to such a degree as to render it almost incompetent to vaporize the silver. But the thallium is gradually consumed; its vapor diininishes, the resistance rises, until finally you see the two silver bands as brilliant as they were at first. The three bands of the two metals are now of the same sensible brightness.

We have in these bands a perfectly unalterable characteristic of these two metals.
You never get other bands than these two green ones from the silver, never other than the single green band from the thallium, never oiher than the three green bands from the mixture of both metals. Every known metal has its bands, and in no known case are the bands of two different metals al!ke. Hence these spectra may be made a test for the presence or absence of any particular metal. If we pass from the metals to their alloys, we find no confusion. Copper gives us green bands, zinc gives us blue and red bands; brass, an alloy of copper and zinc, gives us the bands of both metals, perfectly unaltered in position or character.

But we are not confined to the metals ; the salts of these metais yield the bands of the metals. Chemical union is ruptured by a sufficiently high heat, the vapor of the metal is set free and yielcis its characteristic bands. The chiorides of the meta!s arc particularly suitable for experiments of this character. Common salt, for example, is a compound of chlor ne and sodium ; in the electric lamp, it yields the spectrum of the metal sodium. The chlorides of lithium and of strontium yield in like manner the bands of these metals. When, therefore, Bunsen and Kirchhoff, the celebrated founders of spectmem analysis, after having established by an exhaustive examination the spectra of all known substances, discovered a spectrum containing bands different from any known bands, they immediately inferred the existence of a new metal. They were operating at the time upon a residue obtained by evaporating one of the mineral waters of Germany. In that water they linew the new metal was concealed, but vast quantities of it had to be evaporated before a residue could be obtained sufficiently large to enable ordinary chemistry to grapple with the metal. But they hunted it down, and it now stands among chemical substances as the metal Rubidium. They subsequently discovered a second metal, whic: 1 they called Casium. Thus, having first placed spectrum analysis on a safe foundation, they demonstrated its capacity as an agent of discovery. Soon af:erwards Mr. Crookes, pursuing this same method, obtained the salts of the thallium which yielded that bright monoc-romatic green bard. The metal itself was first isolated by a French chemist.

All this relates to chemical discovery upon earth, where the materials are in our own hands. But Kirchhoff showed how spectrum analysis might be applied to the investigation of the sun and stars, and on tis way to this result he solved a problem which had been long an enigma to natural philosophers. $\Lambda$ spectrum is pure in which the colors do not overlap each other. We purify the spectrum by making our slit narrow and by augmenting the number of our prisms. When a ptare spectrum of the sun has been obtained in this way it is found to be furrowed by in- 
num rable dark lines. Folur of them were tirst seen by Dr. Wollaston, but they were afterwards multiplied and measured by Fraunhofer with sucin masterly skill that they are now universally known as Fraunhofer's lines. To give an explanation of

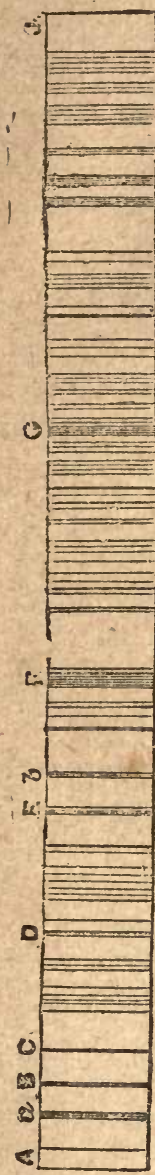

FIG. 27. these lines was, as I have said, a problem which long challenged the attention of philosophers. (The principal lines are lettered according to Fraunhofer in the annexed sketch of the solar spectrun. $A$, it may be stated stands near the extreme red, and $J$ near the extreme violet.)

Now, Firchhoff had made thoroughly clear to his mind the princ ples which linked together the emission of light and the absorption of light; he had proved their inseparability for cach particular kind of light and heat. He had proved, for every specific ray of the spectrum, the doctrine that the body emitting any ray absorbed with special energy a ray of the same refrangibility. Consider, then, the effect of knowledge, such as you now possess, upon a mind prepared like that of Kirchhoff. We have seen the incandescent vapors of metals emitting definite froups of rays : according to Kirchhoff's principle, those vapors, if crossed by solar light, cught to absorb : ays of the same refrangibility as those which they emit. He proved this to be the case; he was able, by the interposition of a vapor. to cut out of the solar spectrum the band corresponding in color to that vapor. Now. the sun possesses a photosphere, or vaporous envelope-doubtless mixed with violentlv agitated clouds-and Kirchhoff saw that the powerful rays coming from the solid, or the molten nucleus of the sun, must be iritercepted by this vapor. One dark band of Fraunhof $r$, for example, occurs in the yellow of the spectrum. Sodium vapor is demonstrably competent to produce that dark band; hence Kirchhoff inferred the existence of sodium-vapor in the atmosphere of , the sun. In the case of metals, which emit a large number of bands, the absolute coi c dence of every bright band of the metal, with a dark Fraunhofer line, raises to thc lighest degree of certa: nty the inference that the metal is present in the atmosphere of the sun. In this way solar chemistry was foundel on spectrum analysis.
But let me not skim so lightiy over this great subject. I have spoken of emission and absorption, and of the link that binds them. Let me endeavor to make plain to you, through the analogy of sound, their physical meaning. I draw a fiddle-bow across this tuning-fork, and it immediately fills the room with a musical sound; this may be regarded as the radiation or emission of sound from the fork. A few days ago, on sounding this fork, I noticed that, when its vibrations were quenched, the sound seemed to be continued, though more feebly: The sound appeared to come from under a distant table, where stood a number of tuning-forks of different sizes and rates of vibration. One of these, and one only, had been started by the fork, and it was one whose rate of ribration was the same as that of the fork which started it. This is an instance of the $a^{3}$ sorption of sound of one fork by another. Placing two forks near each other, sweeping the bow over one of them, and then quenching the agitated fork, the other continues to sound. Placing a cent-piece on each prong of one of the forks, we destroy its perfect synchronism with the oth $\mathrm{r}$, and then no communicarion of sound from the one to the other is possible.

1 will now do with lim ht what has been here done with sound. Placing a tin spoon containing sodium in a Bunsen's flame, we ottain this intensely yellow light, which corr.sponds in refrangibility with the yellow band of the spectrum. Like our tuning-fork, it emits waves at a special period. I will send the white light from our lamp through that flame, and prove before you that the yellow flame intercepts the yellow of the spectrum S S, Fig. 28; in other words, absorbs w $\approx$ ves of the same period as its own, thus producing, to all interts and purposes, $a$ da: $k$ Fraunhofer's band in the place of the yellow. (A Bunsen's flame contained within the chin:ney $C$ is placed in front of the lamp L. The tin spoon with its pellet of sodium is plunged into the flame. Vivid combustion soon set; in, and, when it does, the yellow of the spean trum, at $D$, is furrowed by a dark banc Withdrawing and introducing the sodium. flame in rapid succession, the sudden disay. pearance a' id reappearance of the strip of darkness arc observed).

Mentally, as well as physically, every age of the worid is the outgrowth and offspring of all preceding ages. Science proves itselt to be a genuin p product of Nature by growing accordiag to this law. We have no sclution of continuity here. Every great discovery has been duly prepared for in two ways: first, by other discoveries which form its prelude; and, secondly, through the sharpening, by exercise, of the intellectual instrument itself. Thus Ptolemy grew cai of Hipparchus, Copernicus out of both, Kepler out of all three, and Newton out of al! the four. Newton did not rise suddenly from 
the sea-level of the intellect to his amazing ejevation. At the time that he appeared, the table-!nd of knowledge was already high. He juts, it is true, above the table-land, as a massive peak; still he is supported by it, and a great part of his absolute height was the leight of humanity in his time. It is thus

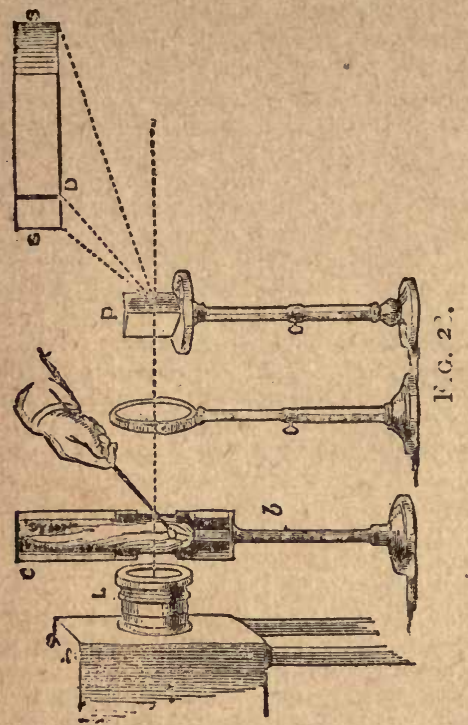

-'rn the discovi ies of Kirchhoff. Much had bet a previousi ; accomplished; this he mastered, and the: by the force of individual renius went biyond it. He replaced uncertainty by certaility, vagueness by definiteness, c mnfusion Ly crder; and I do not think that Newton has a sit, er claim to the discovelies that have made $\Lambda$ is name immortal than Kirch hoff has to the cre dit of gathering up the fragmentary knowledge of his time, of vastly extendin it, and of infusing into it the life of great principles. Splen ${ }^{*} i d$ results have since been obtained with whic $\zeta$ the names of Janssen, Huggins, I,ociy ;r, Respighi, Young, and others, are hnnora bly associated, jut, splendid as they are, they are but the sequel and application of the principles established in his Heidelberg labcratory by the celebrated German investigator.

\section{SUMMARY AND CONCLUSI $-N$}

My desire in these lectures has be an to show you, with as little breacin of continuity as possible, the past growth and piesent aspect of a department of scicace, in waich bave labored some of thi gre:test i itellects the world has ever seen. My friend Professor Henry, in introducing me at Washington, spoike of me as an apostle; but the onl, apostolate that I intended to fulfil was to place, in plain words, my subject before you, and to permit its own intrinsic attractions to act upon your minds. In the way of experiment, I have tried to give you the best which, under the circumstances, could be provided; but I have sought to confer on each experiment a distinct intellectual valıe, for experiments ought to be the representatives and expositors of thought $\rightarrow$ a language addressed to the eye as spoken words are to the ear. If association with its context, nothing is more impressive or instructive than a fit experiment; but, apart from its context, it rather suits the conjuror's purpose of surprise than that purpose of education which ought to be the ruling motive of the scientific man.

And now a brief summary of our work will not be out of place. Our present mastery over the laws and phenomena of light has its origin in the desire of man to knowo. IVe have seen the ancients busy with this problem, but, like a child who uses his arms ainlessly for want of the necessarv muscular exercise, so these early men speculated vaguc$\mathrm{ly}$ and confusedly regarding light, not having as yet the discipline needed to give clearnes; to their insight, and firmness to their grasp of principles. They assured themselves of the rectilineal propogation of light, and that the angle of incidence was equal to the angle of reflection. For more than a thousand years-I might say, indeed, for more than fitteen hundred years s: bsequentiy - the scientific intellect appears as if smitten with paralysis, the fact being that, during this time, the mental force, which might bave run in the direction of science, was diverted in:o other directions.

The course of investigation as regards light was resumed in I ioo by an Arabian philosopher named Alhazan. Then it was taken up in succession by Roger Bacon, Vitellio, and Kepler. 'These men, though failing to detect the principle which ruied the facts, kept the fire of investigation cons.antly burning. Then came the fundamental discovery of Snell, that corner-stone of optics, as I have already called it, and immediately afterward we have the application by Des. cartes of Snell's discovery to the expianation of the rainbow. Then came Newton's crowning experiments on the analysis and synthesis of white light, by which it was proved to be compounded of various kinds of light of different degrees of refrangibiiity.

In 1676 an impulse was given to optics by astronomy. In that year Olaf Roemer, a learned Dane, was engaged at the Observatory of Paris in observing the eclipses of Jupiter's moons. He converted them into so many signal-lamps, quenched when they plunged into the shadow of the planet, and relighted when they emerged from the shadow. They enabled him to prove that lig!t requires time to pass through space, and to assign to it the astounding velocity of Igo,1000 miles a second. Then came the Eiglish 
astronomer, Eradley, who noticed that the fixed stars did not really appear to be fixed, but describe in the heavens every year a little orbit resembling the earth's orbit. The result perplexed him, but Bradley had a mind open to suggestion, and capable of seeing, in the smallest fact, a picture of the largest. He was one day upon the Thames in a boat, and noticed that, as long as his course remained unchanged, the vane upon his mast-head showed the wind to be blowing constantly in the same direction, but that the wind appeared to vary with every change in the direction of his boat. "Here," as Whewell say-, "was the image of his case. The boat was the earth, moving in its orbit, and the wind was the light of a star."

We may ask in passi.ng, what, without the faculty which formed the "image," would Bradley's wind and vane have been to him? - $\Lambda$ wind and vane, and nothing more. You will immediately understand the meaning of Bracley's discovery. Imagine yourself in a motionless railway-train with a shower of rain descending vertically downward. The moment the train begins to move, the rain-drops begin to siant, and the quicker the train the greater is the obliquity. In a precisely similar manner the rays from a star vertically overhead are caused to slant by the motion of the earth through space. Knowing the speed of the train, and the obliquity of the falling rain, the velocity of the drops may be calculated; and knowing the speed of the earth in her orbit, and the obliquity of the rays due to this cause, we can calculate just as easily the velocity of light. Bradley did this, and the "aberration of light," as his discovery is called, enabled him to assign to it a velocity almost identical with that deduced by Roemer from a totally different method of observation. Subsequently Fizeau, employing not planetary or stellar distances, but simply the breadth of the city of Paris, determined the veloci $\mathrm{y}$ of light: while after him Foucault- a man of the rarest mechanical genius-solved the problems without quitting his private room.

Up to his demonstration of the composition of white light, Newton had been everywhere triumphant-triumpinant in the leavens, triumphant on the earth, and his subsequerit experimental work is for the most part of immortal value. But infallibility is not the gift of man, and, soon after his discovery of the nature of white light, Newton proved nimself luman. He supposed that refraction and disper:ion went hand in hand, and that you could not abolish the one without at the same time abolishing the other. Here Dol. land corrected him But Newton committed a graver error than this. Science, as I sought to make clear to you in our second lecture, is only in part a thing of the senses. The roots of phenomena are embediled in a reyion beyond the reach of the sen es, and less than the root of the matter will never: satisfy the scientific mind. We find, accordingly, in this career of optics, the greatest minds constantly yearning 10 pass from the phenomena to their causes-to explore them to their hidden roots. They thus entered the region of theory, and here Newton, though drawn from time to time towards the truth, was drawn still more strongly towards the error, and made it his substantial choice. His experiments are imperishable. but his theory has paised away. For a century it stood like a dam across the course of discovery; but, like all barri-rs that rest upon authority, and no. upon truth, the presiure from behind increased, and eventually swept the barricr away. This, as you know, was done mainly through the lubors of Thomas Young, and his iilustrious French fellowworker Fresnel.

In 1808 , Malus, loohing through Iceland spar at the sun reflected from the window of the Luxembourg Palace in l'aris, discovered the polarization of light by reflection. In I8II Arago discovered the splendid chromatic phenomena which we have had illustrated by plates of gypsum in polarized lignt ; he also discovered the rotation of the plane of polarization by quartz-crystals. In $181_{3}$ Seebeck discovered the polarization of ligint by tourmaline. That same year Brewsier discovered those magnificent band's of culor that surround the axes of biaxal crystals. In $18 \mathrm{I} 4$ Wollaston discovered the rings of Iceland spar. All these effects, which, without a theoretic clue, would leave the human mind in a hopeless jungle of phenomena without harmony or relation, were orga:ically connected by the theory of undulation. The theory was applied and verilied in all directions, Airy being especially cunspicuous for the severity and conclusiveness of his proofs. The most remarkable verification fell to the lot of the late Sir IVilliam Hamilton, of Dublin, a profound mathematician, who, taking up the theory where Fresnel bad left it, drrived at the conclusion that, at four special points at tive surface of the ether-wave in double-refracting crystals, the ray was divided not into two parts, but into an infinite number of parts ; forming at these points a continuous conical envelope instead of two images. No human eye had ever seen this envelope when Sir William Hamilton inferred its existence. Turning to nis fri nd Dr. Lloyd, he asked him to test experimentally the truth of his theoretic conclusion. Lloyd, taking a crystal of arragonite, and following with the most scrupulous exactness the indications of theory, cutting the crystal whe:e theory said it ought to be cut, observing it where theory said it ought to be observed, found the luminous envelope which had pre viously been a mere idea in the mind of the mathematician.

Nevertheless this great theory of undula. tion, like many another truth, which is the long-ru. has proved a blessi.ng $t$, humsnity. 
had to establish, by hot conflict, its right to existence. Great names were arrayed ayainst it. It had been enunciated by Hooke, it had been applied by Huyghens, it had been defended by Euler. But they made no impression. And, indeed, the theory in their hands was more an analogy than a demonstration. It first toois the form of a demonstrated verity in the hand of Thomas Young. He broug'it the waves of light to bear upon each otler, causing them to support each other, and to Extinguish each other at will. From their rnutual actions he determined their lengths, and applied his determinations in all directions. He showed $t$ at the standing dificulty of polarization might be embraced by the theory. After him came Fresnel, whose transcendent mathematical abilities enatled hin to give the theory a generality unattained bo Young. II grasped the theory in its entirety, followed the ether into its eddies and estuaries in the hearts of crystals of the most complicated structure, and into bodies subjected to strain and pressure. He showed that the facts discovered by Malus, Arago, Brewster, and Biot, were so many ganglia, so to speak, of his theoretic organism, deriv ing from it sustenance and explanation. With a mind 100 strong for the body with which it was associated, that body became a wreck long before it had become o!d, and Fresnel died, leaving, however, behind him a name immortal in the annals of science.

One word more I should like to say regarding Fresnel. There are things, ladies and genilemen, better even than science. There are matters of the character as well as matters of the intellect, and it is always a pleasure to those who wish to think weli oi human nature, when high intellect and upright character are combined. They were, I believe, combined in this young Frenchman. In thos a hot conflicts of the undulatory theory, he stood forth as a man of integrity, claiming no more than his right, and ready to concede their rights to others. He at once recognized and acknowledged the merits of Thomas Young. Indeed, it was he, and his fellowcountryman Arago, who first startled England into the consciousness of the injustice done io Young in the Edinburg/h Revnew. I should like to read you a brief extract from a letter written by Fresnel to Young in 324 , as it throws a pleasant light upon the character of the Frenc 1 philosopher. "For a long time," says Fresnel, "that sensibility, or that vanity, which people call love of glory, has been much blunted in me. I labor nuch less to catch the suffrages of the public than to obtain that inward approval which has always been the sweetest reward of my efforts. Without doubt, in moments of disgust and discouragement, I have often needed the spur of vanity to excite me to pursue my researches. But all the compliments I have received from Arago, De la Place, and Biot, never gave me so muct pleasure as the discovery of a theo- retic truth, or the confirmation of a calculation by experiment."

This, ladies and gentlemen, is the core of the whole matter as regards science. It must be cultivated for its own sake, for the pure love of truth, rather than for the applause or profit that it brings. And now my occupation in America is wellnigh $\mathrm{g}$ ne. Still I will bespeak your tolerance for a few concluding remarks in reference to the me! who have bequeathed to us the vast body of knowledge of which I have sought to give you some faint idea in these lectures. What was the motive that spurred them on? what the prize of their high calling for whic i they struggled so assiduously? What urged then to those battles and those victories over reticent Nature which have become the lieritage of the human race? It is never to be forgo:ten that not one of those great investigators, from Aristotie down to Stokes and Kirchhoff, had any practical end in view, according to the ordinary definition of the word "practical." They did not propose to themselves money as an end, and knowledge as a means of obtaining it. For the most part, they nobly reversed this process, made knowledge their end, and such money as they possessed the means of obtaining it.

IVe may see to-day the issues of their work in a thousand practical forms, and this may be thought sufficient to justify it, if not ennoble their efforts. But they did not work for such issues; their reward wa of a totally different kind. We love clothes, we love luxuries, we love fine equipages, we love money, and any man who can point to these as the result of $t$ is efforts in life justifies these efforts before all the world. In America and England more especially he is a "practical" man. But I would appeal confidently to this assembly whether such things exhaust the demands of human nature? 'The very presence here for six inclement nights of this audience, embodying so much oi the mental force and refinement of this great city, is an answer to my question I need not tell such an assembly that there are joys of the intellect as well as joys of the body, or that these pleasures of the spi-it constituted the reward of our great investigators. Led on by the whisperings of natural truth, through pain and self-denial, they often pursued their work. With the ruling passion strong in death, some of them, when no longer able to hoid a pen, dictated to their friends the result of their labors, and then rested from them forever.

Could we have seen these men at work without any knowledge of the conseq"ences of their work, what should we have thought of them? To many of their contemporaries it would have appeared simply ridiculous to sce men, whose name; are now stars in the firmanent of science, straining their attention to observe an effect of experiment almost too minute for detection. To the un. 
initiated, they might well appear as big children playing with not very amusing tors. It is so to this hour. Could you watch the true investigator-your Henry or your DraDer, for example-in his laboratory, nuless cnimated by his spirit, you could hardiy understand what keeps him there. Many of the objects which rivet his attention might appear to you utterly tivial; and, if you were -O step forward and ask him what is the use of his work, the chances are that you would confound him. He migit not be able to express the use of it in intelligible terms. He might not be able to assure you that it will put a dollar into the pocket of any luman being living or to come. That scientific discovery may put not only dollars into the poekets of individuals, but millions into the exchequers of nations, the history of science amply proves; but the hope of its doing so never was and never can be the motive power of the investigator.

I know that I run some risk in speaking thus before practical men. I know what De Tocqueville says of you. "The man of the North," he says, "lias not only experience, but knowledge. He, however, does not care for science as a pleasure, and only cmbraces t with avidity when it leads to useful applications." But what, I would ask, are the hopes of useful applications which have drawn you so many times to this place in s pite of snow-drifts and biting cold? What, I may ask, is the origin of that kindness which drew me from my work in London to address you here, and which, if I permitted it, would send me home a millionaire? Not because I had taught you to make a single cent by science, am I among you to-niglit, but because $I$ tried to the best of my ability io present science to the world is an intellectual good. Surely no two terms were ever so distorted and misapplied with refe.ence to man in his higher relations as these terms useful and practical. As if there were no nakedness of the mind to be clothed as well as naktdness of the body-no hunger and ihirst of the intellect to sitisfy. Let us expand the definitions of these terms until they embrace all the needs of man, his highest intellectual neetls inclusive. It is specially on this ground of its administering to the higher needs of intellect, it is mainly hecause I believe it to be wholesome as a source of knowledge, and as a means of discipline, that I arge the claims of science this evening upon your attention.

But. with reference to material needs and joys, surely pure science has also a word to say. People sometimes sp al as if steam had not been studied before James Watt, or clectricity before IVheatstone and Morse; whereas, in point of fact, Watt and Wheatstone and Morse, with all their practicality, were the mere outcome of antecedent forces, which acted without reference to practical ends. This also, I think, me its a moment's atten- tion. You are delighted, and with good reason, with your electric telegra phs, prcud of your stcam-engines and your factories, and charmeri with the productions of photo $r$ raphy. You see daily, with just elation, the creation of new forms of industry new powers of adding to the wealth and comfort of society. Industrial England is heaving with forces tending to this end, and the pulse of industry beats still stronger in the United States. And yet, when analyzed, what are industrial Anjerica and industrial England? If you can tolerate freedom of speech on my part, I will answer this question by an illustration. Strip a strong arm, and regard the knotted muscles when the hand is clenched and the arm bent. Is this exhibition of energy the work of the muscle alone? By no means. The muscle is the channel of an influence, without which it would be as powerless as a lump of plastic dough. It is the delicate unseen nerve that unlocks the power of the muscle. And, without those filaments of genius which have been shot like nerves through the body of society by the original discoverer, industrial America and industrial England would, I fear, be very much in the condition of that plastic dough.

At the present time there is a cry in England for technical education, and it is the expression of a true national want; but there is no cry for original investigation. Still without this, as surely as the stream dwindies when the spring dries, so surely will " technical education" lose all force of growth, all power of reproduction. Our great investigators have given us sufficient work for a time, but, if their spirit die out, we shali find ourselves eventually in the condition of those Chinese mentioned by De Tocqueville. who, having forgotten the scientific origin of what they did, were at length compeiled to copy without variation the inventions of an ancestry who, wiser than themselves, had drawn their inspiration direct from Nature.

To keep society as regards science in healthy play, three classes of workers are necessary : Firstly. the investigator of natural truth, whose vocation it is to pursue that truth, and exterd the field of discovery for the truth's own sake, and without reference to practical ends. Secondly, the teacher of natural truth, whose vocation it is to give public diffusion to the knowledge already won by the discoverer. Thirdly, the applier of natural truth, whose vocation it is to make scientific knowledge available for the needs. comforts, and luxuries of life. These three classes ought to coexist and interact. Now. the popular notion of science, both in this country and in England, often relates, not to science strictly so called, but to the applica. tions of science. Such applications, espccially on this continent, are so astoundingthey spread thenselves so largely and umbragcously before the public eye-as to shut 
out from view those workers who are engaged in the quieter anil profounder business of original investigation.

Take the electric telegraph as an example, which has been repeatedly forced upon my attention of late. I am not here to attenuate in the slightest degree the services of those who, in England and America, have given the telegraph a form so wonderfully fitted for public use. They earned a great reward, and assuredly they have received it. But I should be untrue to you and to myself if $I$ failed to tell you that, however high in particular respects their claims and qualities may be, practical men did not discover the electric telegraph. The discovery of the electric telegraph implies the discorery of electricity itself, and the development of its laws and phenomena. Such discoveries are not made by practical men, and they never will be made by them, because their minds are beset with ideas which, though of the highest value from one point of view, are not those which stimulate the original discoverer.

The ancients discovered the electricity of amber; and Gilbert, in the year 1600, extended the force to other bodies. Then foliowed other inquirers, your own Franklin among the number. But this form of electricity, though tried, did not come into use for telegraphic purposes. Then appeared the great Italian, Volto, who discovered the source of electricity, which bears his name, and applied the most profound i,sight and the most delicate experimental skill to its development. Then arose the man who added to the powers of his intellect all the graces of the human heart, Michael Faraday, the discoverer of the great domain of magnetoelectricity. CErsted discovered the deflection of the magnetic needle, and Arago and Sturgeo:1 the magnetization of iron by the electric current. The voltaic circuit finally found its theoretic Newton ir Ohm, while Henry, of Princeton, who had the sagacity to recogniize the merits of $\mathrm{Ohm}$ while they were still decried in his own country, was at this time in the van of experimental inquiry.

In the works of these men you have all the materials employed at this hour in all the forms of the electric telegraph. Nay, more ; Gauss, the celebrated astronomer, and IVeber, the celebrated natural philosopher, both professors in the University of Göttingen, wishing to establish a rapid mode of communication between the observatory and the physical cabinet of the university, did this by means of an electric telegraph. The force, in short, had been discovered, it: laws investigated and made sure, the most complete inastery of i's phenomena had been attained, nay, its applicability to teleg.aphic purposes demionstrated, by men whose sole reward for their labors was the nuble joy of discovery, and before your practical inen appeared at all upon the scene.

Are we to ignore all this? We do so at our peril. For I say again, that, behind all your practical applications, there is a region of intellectual action to which practical men have rarely contributed, but from which they draw all their supplies. Cut them off froni this region, and they become eventually helpless. In no case is the adage truer, "Other men 'abored, but ye are entered in o their labors," than in the case of the discoverer and the applier of natural truth. But now a word on the other sicle. While I say that practical men are not the men to make the necessary antecedent discoveries, the cases are rare in which the discoverer knows how to turn his labors to practical account. Different qualities of mind and different habits of thought are needed in the two cases; and, while I wish to give emphatic utterance to the claims of those whose claims, owing 10 the simple fact of their intellectual elevation. ar: often misunderstood, I am not here to exalt the one class of workers at the expense of the other. They are the necessary supplements of each other; but remember that one class is sure to be taken care of. All the material rewards of society are already within their reac. ; but it is at our peril that we neg. lect to provide opportunity for those studies and pursuits which have no such rewards, and from wiich, therefore, the rising genius of the country is incessantly tempted away.

Pasteur, one of the most eminent members of the Institute of France, in accounting for the disastrous overthrow of his country and the predominance of Germany in the late war, expresses himself thus: "Few persons comprehend the real origin of the marvels of industry and the wealth of nations. I need no further proof of this than the employment, more and more frequent in official language. and in writing of all sorts, of the erroneous exprcssion applied science. The abandon. ment of scientific c reers by men capable or pursuing them with distinction was recentlv complained of in the presence of a minister of the greatest talent. 'This statesman endeavored to show that we ought not to be surprised at this result, because in our day the reign of theoretic science yielded place to that of applied science. Nothing could be more erroneous than this opinion, nothing, I venture to say, more dangerous, even to practical life, than the consequences which might llow from these words. They have rested on my mind as a proof of the imperious necessity of reform in our superior edu. cation. There exists no category of the sciences to which the name of applied science could be given. We have science, and tine applications of science which are united together as the tree and its iruit."

And Cuvier, the great comparatise anatomist, writes thus upon the same theme. "These grand practical innovations are the mere applications of truths of a higner order. not sought with a practical intent, but which were pursued for their own sake, and solely 
through an ardor for knowledge. Those who applied them could not have discovered them; those who discovered them had no inciination to pursue them to a practica: end. Engaged in the high regions whither their thoughts had carried them, they hardly perceived these practical issues, though born of their own deeds. These rising workshops, these peopled colonies, those ships which furrow the seas-this abundance, this luxury, this tumult-all this comes from discoverers in science, and it all remains strange to them. At the point where science merges into practice, they abandon it; it concerns them no more."

When the Pilgrim Fathers landed at Plymouth Rock, and when Penn made his treaty with the Indians, the new-comers had to bui.d their houses, to chasten the earth into cultivation, and to take care of their souls. In such a community, science, in its more abstra:t forms, was not to be thought $\mathrm{cf}$. Ard, at the present hour, when your hardy Western pioneers stand face to face with stubborn Nature, piercing the mountains and subduing the forest and the prairie, the pursuit of science, for its own sake, is not to be expected. The first need of man is food and shelter; but a vast portion of this continent is already raised far beyond this need. The gentlemen of New York, Brooklyn, Boston, Philadelphia, Baltimore, and Washington, have already built their houses, and very beautiful they are; they have also secured their dinners, to the excellence of which I can also bear testimony. They have, in fact, reached that precise condition of wellbeing and independence when a culture, as figh as humanity has yet reached, may be justly demanded at their hands. They have reached that maturity, as possessors of wealch and leisure, when the investigator of natural truth, for the truth's own sake, ought to find among them promoters and protectors.

Among the many grave problems before them they have this to solve, whether a republic is able to foster the highest forms of genius. You are familiar with the writings of De Tocqueville, and silust be aware of the intense sympathy which he felt for your insti. tutions; and this sympathy is all the more valuable, from the philosophic candor with which he points out, not only your merits, but your defects and dangers. Now, if I come here to speak of science in America in a critical and captious spirit, an invisible radiation from my words and manner will erable you to find me out, and will guide your treatment of me to-night. But, if $\mathrm{I}$, in no unfriendly spirit-in a spirit, indeed, the reverse of unfriendly-venture to repeat before you what this great historian and analyst of democratic institutions said of America, I am persuaded that you will hear me out. He wrote some three-and-twenty years ago, and perhaps would not write the same to-day; but it will do nobody any harm to have his words repeated, and, if necessary, laid to heart. In a work publisned in I 550 , he says: "It must be confessed that, among the civilized peoples of our age, there are few in which the highest sciences have made sn little progress as in the United States." He declares his conviction that, had you been alone in the universe, you would speedily have discovered that you cannot long make progress in practical science, without cultivating theoretic science at the same time. But, according to De Tocqueville, you are not thus alone. He refuses to separate America from its ancestral home; and it is here, he contends, that you collect the treas. ures of the intellect, without taking the trouble to create them.

De Tocqueville evidently doubts the capacity of a democracy to foster genius as i: was fostered in the ancient aristocracies. "The future," he says, " wili prove whether the passion for profound knowledge, so rare and so fruitful, can be burn and developed so readily in democractic societıes as in aristocracies. As for me," he continues, "I can hardly believe it." He speaks of the unquiet feverishness of democratic communities, not in times of great excitement, for such times may give an extraordinary impetus to ideas, but in times of peace. There is then, he says, "a small and uncomfortable agaitation, a sort of incessant attrition of man against man, which troubles and dis. tracts the mind without imparting to it cither animation or elevation." It rests with you to prove whether these things are nece-sarily so - whether the highest scientific genius cannot find in the midst of you a tranquil home. I should be loath to gainsay so keen an observer and so profound a political writer, but, since my arrival in this country, I have been unable to see anything in the constitution of society to prevent a student with the roc: of the matter in him from bestowing the most steadfast devotion on purc science. If great: scientific results are not achieved in Ameri$\mathrm{ca}$, it is not to the small agitations of society that I slould be disposed to ascribe the defect, but to the fact that the men among you who possess the endownents necessary for scientific inquiry are laden with duties of ad. ministration or tuition so heavy as to be utterly incompatible with the continuous and tranquil meditation which original invest:gation demands. It may well be askewhether Henry would have been transforme. into an administrator, or whether Drarser would have forsaken science to write history, if the original investigator had been honored as he ought to be in this land? I hardly think they would. Still I do not think this

* Il faut reconnaitre, que parmis les peuples civilisés de nos jours, il en csi peu chez qui les hautes sciences aient fait moins de progrès qu'aux Etats. Unis, ou qui aient fourni moins de grands artisres, de poètes illustres, et de céièbres écrivains. ( $D \approx L$ Démocratie en Amérique, etc., tome ii., p. 36.) 
state of things likely to last. In America there is a willingness on the part of individuals to devote their fortunes, in the matter of education, to the service of the commonwealth. which is without a parallel elsewhere; and this willingness requires but wise direction to enable you effectually to wipe away the reproach of De Tocqueville.

Your most difficult problem will be not to build institutions, Lut to make men; not to form the body, but to find tne spiritual embers which shal! kindle within that body a living ssul. You have scientific genius among you; not sown broadcast, believe me, but still - cattered here and there. Take a'l innecessary impediments out of its way. Drawn by your kindness I have come here to give these lectures, and, now that my risit to America has become almost a thing of the past, I look back upon it as a memory withcut a stain. No lecturer was ever rewarded as I have been. From this vantage-ground howsyer, let me remind you that the work of the lecturer is not the highcst work; that in science, the lecturer is usually the distributor of intellectual wealth amassed by better men. It is not solely, or even chiefly, as lecturers, but as investigators, that your men of genius ought to be employed. Keep your sympathetic eyc upon the originator of knowledge. Give him the freedom necessary for his researches, not overloading him either with the duties of tu tion or of administration, not demanding from him so-called practical results -above all things, avoiding that question which ignorance so often addresses to genius, "What is the use of your work?" Let him make truth his object, however unpractical for the time being that truth may appear. If you cast your bread thus upon the waters, then be assured it will return to you, though it may be after many days.

\section{CONTENTS.}

HSCT. I.-INTRODUCTORY....... 2 II.-Origin of Physical Theories . . 8 III - Relation of Theories to Experience. 18 IV. Chromatic Phenomena produced by
V.-Range of Vision and Range of Radiation......... 34 VI.-Spectrum Analysis. . . . . . 4 I 




